\title{
The Role Of The Putative Receptor-Like Cytoplasmic Kinase CLR1 In Chitin Signalling
}

\author{
Dissertation \\ zur Erlangung des mathematisch-naturwissenschaftlichen Doktorgrades \\ "Doctor rerum naturalium" \\ der Georg-August-Universität Göttingen \\ im Promotionsprogramm Biologie \\ der Georg-August University School of Science (GAUSS)
}

vorgelegt von

Yvonne Ziegler

aus Wittlich

Göttingen, 2015 



\section{Betreuungsausschuss}

Prof. Dr. Volker Lipka

Zellbiologie der Pflanze,

Albrecht-von-Haller Institut für Pflanzenwissenschaften

PD Dr. Thomas Teichmann

Zellbiologie der Pflanze,

Albrecht-von-Haller Institut für Pflanzenwissenschaften

Prof. Dr. Christiane Gatz

Molekularbiologie und Physiologie der Pflanze,

Albrecht-von-Haller Institut für Pflanzenwissenschaften

\section{Mitglieder der Prüfungskommission}

Referent: Prof. Dr. Volker Lipka

Zellbiologie der Pflanze,

Albrecht-von-Haller Institut für Pflanzenwissenschaften

Korreferent: PD Dr. Thomas Teichmann

Zellbiologie der Pflanze,

Albrecht-von-Haller Institut für Pflanzenwissenschaften

\section{Weitere Mitglieder der Prüfungskommission:}

Prof. Dr. Christiane Gatz

Molekularbiologie und Physiologie der Pflanze, Albrecht-von-Haller Institut für Pflanzenwissenschaften Prof. Dr. Ivo Feußner

Biochemie der Pflanze, Albrecht-von-Haller Institut für Pflanzenwissenschaften Prof. Dr. Cynthia Gleason

Molekulare Pflanzenwissenschaften, Albrecht-von-Haller Institut für Pflanzenwissenschaften Prof. Dr. Andrea Polle

Forstbotanik und Baumphysiologie, Fakultät für Forstwissenschaften und Waldökologie

Tag der mündlichen Prüfung: 17.12.2015 



\section{Promovierenden-Erklärung der Georg-August-Universität Göttingen}

Die Gelegenheit zum vorliegenden Promotionsvorhaben ist mir nicht kommerziell vermittelt worden. Insbesondere habe ich keine Organisation eingeschaltet, die gegen Entgelt Betreuerinnen und Betreuer für die Anfertigung von Dissertationen sucht oder die mir obliegenden Pflichten hinsichtlich der Prüfungsleistungen für mich ganz oder teilweise erledigt.

Hilfe Dritter wurde bis jetzt und wird auch künftig nur in wissenschaftlich vertretbarem und prüfungsrechtlich zulässigem Ausmaß in Anspruch genommen. Insbesondere werden alle Teile der Dissertation selbst angefertigt; unzulässige fremde Hilfe habe ich dazu weder unentgeltlich noch entgeltlich entgegengenommen und werde dies auch zukünftig so halten.

Die Ordnung zur Sicherung der guten wissenschaftlichen Praxis an der Universität Göttingen wird von mir beachtet.

Eine entsprechende Promotion wurde an keiner anderen Hochschule im In- oder Ausland beantragt; die eingereichte Dissertation oder Teile von ihr wurden nicht für ein anderes Promotionsvorhaben verwendet.

Mir ist bekannt, dass unrichtige Angaben die Zulassung zur Promotion ausschließen bzw. später zum Verfahrensabbruch oder zur Rücknahme des erlangten Grades führen. 



\section{Abstract}

Plants detect potential pathogens by perception of conserved microbe-associated molecular patterns (MAMPs) through plasma membrane-localized receptors. Signalling initiated by these receptors is a key process of plant innate immunity. Typically, binding of MAMPs to the surface-exposed ectodomains of receptor components induces formation of homo- or heteromeric receptor complexes. These may consist of receptor-like kinases (RLKs), receptor-like proteins (RLPs) as well as receptor-like cytoplasmic kinases (RLCKs) which lack an extracellular ligand-binding domain.

This study focuses on a potential heteromeric signalling complex involving the Arabidopsis lysin motif (LysM)-RLK CERK1 (Chitin Elicitor Receptor Kinase1), which mediates chitininduced signalling and defence responses. In a preceding yeast two-hybrid screen the RLCK CERK1-INTERACTING LysM-RLK-LIKE RLCK1 (CLR1) was identified as a putative interactor of the CERK1 kinase domain. When taking a closer look at the amino acid sequence of CLR1, it becomes obvious that the sequence shares high homology with the kinase domains of Arabidopsis LysM-RLKs. Data obtained in this study suggest that the CLR1 sequence annotated by TAIR10 seems to be not correct and the protein likely starts 23 amino acids C-terminal of the annotated start, thus exposing a predicted N-myristoylation motif.

In vitro phosphorylation assays showed that the CERK1 kinase domain can directly phosphorylate CLR1 in vitro. This finding was supported by the fact that CLR1 fusion proteins stably expressed in Arabidopsis plants showed chitin-induced and CERK1-dependent phosphorylation. Thus, CLR1 represents a phosphorylation substrate of CERK1 in vitro and in vivo. This phosphorylation seemed to be independent of the $\mathrm{N}$-terminal myristoylation of CLR1. Microsomal fractionations and subcellular localization studies in transgenic plants suggested that the majority of the CLR1 protein is soluble, but a membrane-associated CLR1 subpopulation is present in plant cells. Three independent T-DNA insertion lines were isolated and characterized with regard to chitin signalling and immunity to fungal and bacterial pathogens. The clr1 T-DNA lines showed reduced chitin-induced ROS generation, MAPK activation and defence gene expression, suggesting that CLR1 plays a role in chitin signalling. The severity of the phenotype depended on the position of the T-DNA. clr1 plants were not impaired in resistance against fungal pathogens, but showed a subtly enhanced 
sensitivity to bacterial infection. Since the CLR1 promoter showed high activity in hydathodes, CLR1 could be involved in selectively restricting pathogen entry through these constitutively open vents. 


\section{Zusammenfassung}

Pflanzen erkennen potentielle Pathogene anhand von konservierten Mikroben-assoziierten molekularen Mustern (MAMPs) $^{1}$ welche sie über membranlokalisierte Rezeptoren wahrnehmen. Der durch diese Rezeptoren aktivierte Signalweg spielt eine wesentliche Rolle in der pflanzlichen angeborenen Immunität. Das Binden eines MAMPs an die oberflächenexponierten Ektodomänen der Rezeptoren führt typischerweise dazu, dass diese homo- oder heteromere Komplexe bilden. Diese Komplexe können aus rezeptorartigen Kinasen (RLKs), rezeptorartigen Proteinen (RLPS) sowie aus rezeptorartigen zytoplasmatischen Kinasen (RLCKs), welche keine extrazelluläre Domäne zur Ligandenbindung besitzen, bestehen.

Der Fokus dieser Arbeit liegt auf einem möglichen heteromeren Signalkomplex der unteranderem aus der lysinhaltigen-Motiv (LysM) RLK CERK1 besteht. CERK1 spielt eine Rolle in der durch Chitin induzierten Signaltransduktion und Abwehrantwort in Arabidopsis. In einer vorangegangenen Hefe-Zwei-Hybrid-Analyse wurde die RLCK CLR1 als möglicher Interaktor der CERK1 Kinasedomäne identifiziert. Vergleichende Sequenzanalysen zeigen, dass die Aminosäuresequenz von CLR1 eine hohe Homologie zu den Sequenzen der Kinasedomänen anderer Arabidopsis LysM-RLKs aufweist. Dies könnte möglicherweise für die Funktion des Proteins eine Rolle spielen. Die auf TAIR10 annotierte CLR1 Sequenz scheint falsch annotiert worden zu sein, da das eigentliche Protein laut Analysen in dieser Arbeit wahrscheinlich erst 23 Aminosäuren Richtung C-Terminus beginnt, wodurch dann ein mögliches N-Myristoylierungsmotiv exponiert wird.

In vitro wird CLR1 direkt von der CERK1 Kinasedomäne phosphoryliert. CLR1 Fusionsproteine wurden in stabil transgenen Arabidopsis-Pflanzen CERK1-abhängig durch Chitin phosphoryliert. Unabhängig von der möglichen N-terminalen Myristoylierung scheint CLR1 sowohl in vitro also auch in vivo ein Phosphorylierungssubstrat von CERK1 darzustellen. Mikrosomale Fraktionierungen und Analysen zur subzellulären Lokalisation in transgenen Pflanzen zeigten dass die Mehrheit der CLR1 Proteine löslich ist, wobei auch eine kleine Subpopulation von CLR1 membrangebunden in Pflanzenzellen vorliegt. Drei unabhängige T-DNA Insertionslinien wurden isoliert und im Hinblick auf die Weiterleitung Chitin-

\footnotetext{
${ }^{1}$ Für sämtliche Abkürzungen werden im Folgenden die gängigen englischen Abkürzungen verwendet (siehe hierfür auch: Seite VI, Abbreviations).
} 
induzierter Signale und Immunität gegen pilzliche und bakterielle Schädlinge getestet. Die clr1 T-DNA Linien wiesen eine verringerte ROS Produktion, MAPK Aktivierung und Expression von Abwehrgenen auf, was eine Rolle für CLR1 im Chitin-induzierten Signalweg bestätigt. Dabei hing die Ausprägung des Phänotyps von der Position der T-DNA ab. clr1 Pflanzen waren nicht in der Resistenz gegen pilzliche Schädlinge beeinträchtigt, wohingegen sie eine leicht erhöhte Anfälligkeit gegenüber bakterieller Infektionen zeigten. Da der CLR1 Promotor erhöhte Aktivität in Hydathoden zeigt, könnte CLR1 darin involviert sein selektiv das Eintreten von Pathogenen über diese konstitutiv geöffneten Öffnungen einzugrenzen. 
Abbreviations

\begin{tabular}{|c|c|c|c|}
\hline$::$ & fused to (associated with & et al. & Et alii; and others \\
\hline${ }^{\circ} \mathrm{C}$ & plasmid construction) & $\begin{array}{l}\text { ETI } \\
\mathrm{FtOH}\end{array}$ & $\begin{array}{l}\text { eftector-triggered immunity } \\
\text { ethanol }\end{array}$ \\
\hline$\mu$ & micro & ETS & effector-triggered \\
\hline A. thaliana & Arabidopsis thaliana & & susceptibility \\
\hline A. tumefaciens & Agrobacterium tumefaciens & Fig. & figure \\
\hline APS & ammonium persulfate & FLS2 & FLAGELLIN SENSING2 \\
\hline Asp/D & aspartate/ aspartic acid & FN & Fast neutron \\
\hline ATP & adenosine triphosphate & fwd & forward \\
\hline Avr & avirulence & $\mathrm{g}$ & gram \\
\hline B. cinerea & Botrytis cinerea & gDNA & genomic DNA \\
\hline \multirow[t]{3}{*}{ BAK1 } & BRASSINOSTEROID & GFP & green fluorescent protein \\
\hline & INSENSITIVE1-ASSOCIATED & Glu/E & glutamate/glutamic acid \\
\hline & RECEPTOR KINASE1 & GUS & $\beta$-glucuronidase \\
\hline BIK1 & BOTRYTIS-INDUCED KINASE1 & $\mathrm{h}$ & hour(s) \\
\hline bp & base pair(s) & $\mathrm{HCl}$ & hydrochloric acid \\
\hline$B R$ & brassinosteroid & $\mathrm{HR}$ & hypersensitive response \\
\hline \multirow[t]{2}{*}{ BRI1 } & BRASSINOSTEROID & HRP & horseradish peroxidase \\
\hline & INSENSITIVE1 & $K_{d}$ & dissociation constant \\
\hline C- & carboxy- & $\mathrm{kb}$ & kilobase(s) \\
\hline CBB & Coomassie Brilliant Blue & $\mathrm{kDa}$ & kilodalton(s) \\
\hline $\mathrm{CC}$ & coiled-coil & 1 & litre(s) \\
\hline $\operatorname{ccdB}$ & cytotoxic protein & LB & left border primer \\
\hline cDNA & complementary DNA & Leu/ L & leucine \\
\hline \multirow[t]{2}{*}{ CERK1 } & CHITIN ELICITOR RECEPTOR & $\log$ & decadic logarithm \\
\hline & KINASE1 & LP & left genomic primer \\
\hline CFP & cyan fluorescent protein & LPS & lipopolysaccharide \\
\hline cfu & colony forming unit & LRR & leucine-rich repeats \\
\hline \multirow[t]{2}{*}{ CLR1 } & CERK1-INTERACTING LYSM- & LysM & lysin motif \\
\hline & RLK-LIKE RLCK1 & $\mathrm{m}$ & milli/meter(s) \\
\hline \multirow[t]{2}{*}{ CLSM } & confocal laser scanning & $M$ & molar \\
\hline & microscopy & $\mathrm{mA}$ & milliampere \\
\hline $\mathrm{cm}$ & centimeter(s) & MAMP & microbe-associated \\
\hline Col-0 & Columbia & & molecular pattern \\
\hline $\mathrm{CSC}$ & crab shell chitin & MAPK/ MPK & mitogen activated protein \\
\hline CT & cycle threshold & & kinase \\
\hline$d$ & $\operatorname{day}(s)$ & Met & methionine \\
\hline \multirow[t]{2}{*}{ DAMP } & damage-associated & $\min$ & minute(s) \\
\hline & molecular pattern & MKK & MAPK kinase \\
\hline $\mathrm{ddH}_{2} \mathrm{O}$ & double deionised water & $\mathrm{ml}$ & millilitres \\
\hline DMSO & dimethylsulfoxide & $\mathrm{mM}$ & millimolar \\
\hline DNA & deoxyribonucleic acid & mRNA & messenger ribonucleic acid \\
\hline DNAse & deoxyribonuclease & MS & Murashige and Skoog \\
\hline dNTP & deoxynucleosidetriphosphate & & medium \\
\hline dpi & day(s) post infection & $\mathrm{N}-$ & amino- \\
\hline DTT & dithiothreitol & NASC & Nottingham Arabidopsis \\
\hline E. coli & Escherichia coli & & Stock Centre \\
\hline eCFP & $\begin{array}{l}\text { enhanced cyan fluorescent } \\
\text { protein }\end{array}$ & NB-LRR & $\begin{array}{l}\text { nucleotide binding-leucine- } \\
\text { rich repeat }\end{array}$ \\
\hline \multirow[t]{2}{*}{ EDS1 } & ENHANCED DISEASE & NBS & nucleotide binding site \\
\hline & SUSCEPTIBILITY 1 & ng & nanogram \\
\hline EDTA & $\begin{array}{l}\text { Ethylenediaminetetraacetic } \\
\text { acid }\end{array}$ & NLR & $\begin{array}{l}\text { nucleotide-binding domain } \\
\text { leucine-rich repeat }\end{array}$ \\
\hline EFR & EF-TU RECEPTOR & $\mathrm{nm}$ & nanometer \\
\hline \multirow[t]{2}{*}{ EF-Tu } & ELONGATION FACTOR & OD & optical density \\
\hline & THERMO UNSTABLE & PAD4 & PHYTOALEXIN DEFICIENT4 \\
\hline
\end{tabular}




\begin{tabular}{|c|c|c|c|}
\hline \multirow[t]{2}{*}{ PAGE } & polyacrylamide gel- & vir & virulence \\
\hline & electrophoresis & W & Watt \\
\hline \multirow[t]{2}{*}{ PAMP } & pathogen-associated & $w / v$ & weight per volume \\
\hline & molecular pattern & WT/wt & wild type \\
\hline PCD & programmed cell death & X-Gluc & 5-Bromo-4-chloro-3-indolyl- \\
\hline PCR & polymerase chain reaction & & $\beta$-D-glucuronide \\
\hline PDB & potato dextrose broth & $\mathrm{Y} 2 \mathrm{H}$ & yeast- 2 hybrid \\
\hline PGN & peptidoglycan & & \\
\hline $\mathrm{pH}$ & $\begin{array}{l}\text { negative log of the hydrogen } \\
\text { ion activity in a solution }\end{array}$ & & \\
\hline PR & pathogenesis related & & \\
\hline PRR & Pattern recognition receptor & & \\
\hline Pst & $\begin{array}{l}\text { Pseudomonas syringae pv. } \\
\text { tomato }\end{array}$ & & \\
\hline PTI & PAMP-triggered immunity & & \\
\hline PVDF & polyvinylidene fluoride & & \\
\hline qRT-PCR & $\begin{array}{l}\text { quantitative reverse } \\
\text { transcription polymerase } \\
\text { chain reaction }\end{array}$ & & \\
\hline $\mathrm{R}$ & resistance & & \\
\hline rev & reverse & & \\
\hline RLCK & $\begin{array}{l}\text { receptor-like cytoplasmic } \\
\text { kinase }\end{array}$ & & \\
\hline RLK & receptor-like kinase & & \\
\hline RLP & receptor-like protein & & \\
\hline RNA & ribonucleic acid & & \\
\hline RNAse & ribonuclease & & \\
\hline ROS & reactive oxygen species & & \\
\hline $\mathrm{RP}$ & right genomic primer & & \\
\hline $\mathrm{rpm}$ & rounds per minute & & \\
\hline RT & $\begin{array}{l}\text { room temperature/ reverse } \\
\text { transcription }\end{array}$ & & \\
\hline RT-PCR & $\begin{array}{l}\text { reverse transcription- } \\
\text { polymerase chain reaction }\end{array}$ & & \\
\hline s & second(s) & & \\
\hline SA & salicylic acid & & \\
\hline SAR & systemic acquired resistance & & \\
\hline SDS & sodium dodecyl sulphate & & \\
\hline Ser/ S & serine & & \\
\hline \multirow[t]{2}{*}{ SERK } & SOMATIC EMBRYOGENESIS & & \\
\hline & RECEPTOR KINASE & & \\
\hline T-DNA & transfer DNA & & \\
\hline TAE & tris-acetate-EDTA & & \\
\hline Taq & Thermus aquatcus & & \\
\hline TBS & tris buffered saline & & \\
\hline TEMED & $\begin{array}{l}\mathrm{N}, \mathrm{N}, \mathrm{N}^{\prime}, \mathrm{N}^{\prime}- \\
\text { tetramethylethane-1,2- } \\
\text { diamine }\end{array}$ & & \\
\hline TF & Transcription factor & & \\
\hline Thr/ T & threonine & & \\
\hline TIR & Toll interleukin-1 receptor & & \\
\hline Tris & $\begin{array}{l}\text { Tris-(hydroxymethyl)- } \\
\text { aminomethane }\end{array}$ & & \\
\hline TTSS & type III secretion system & & \\
\hline$U$ & unit & & \\
\hline UV & ultraviolet & & \\
\hline V & Volt & & \\
\hline$v / v$ & volume per volume & & \\
\hline
\end{tabular}




\section{Table of contents}

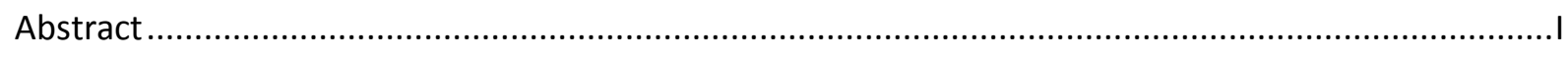

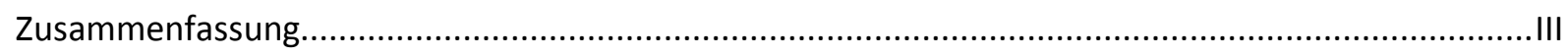

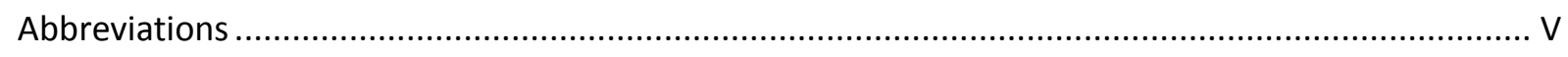

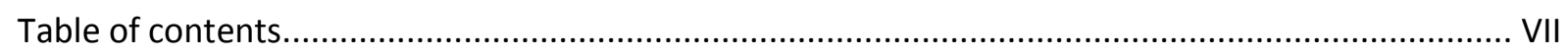

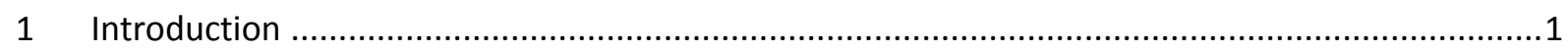

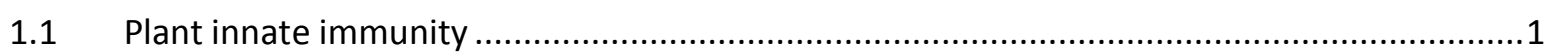

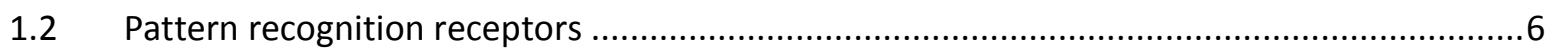

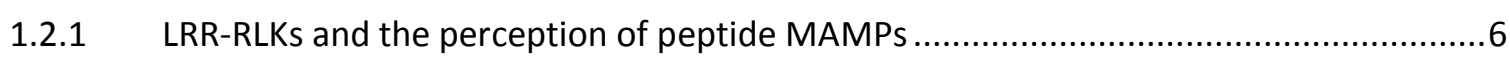

1.2.2 LysM-RLKs and the perception of carbohydrate MAMPs ......................................8

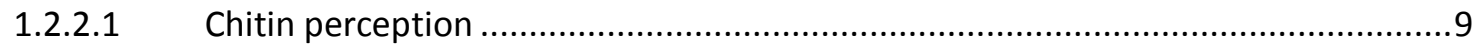

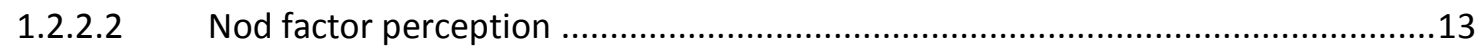

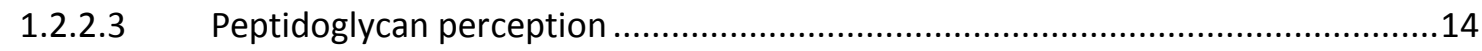

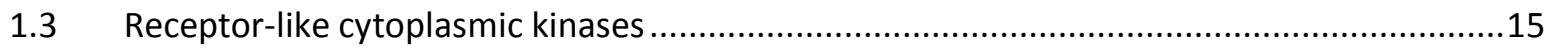

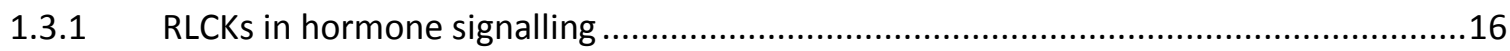

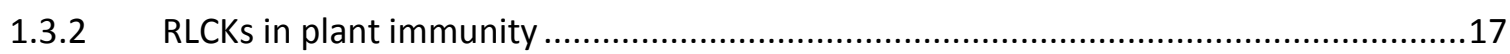

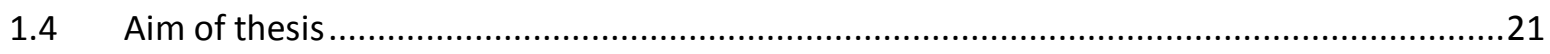

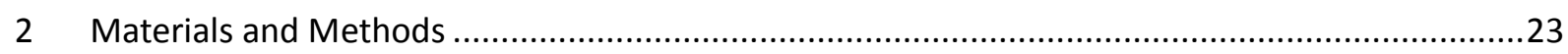

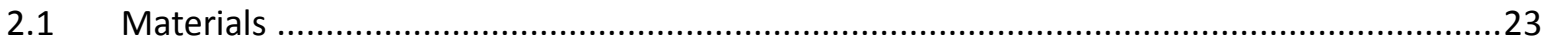

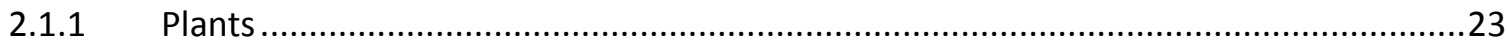

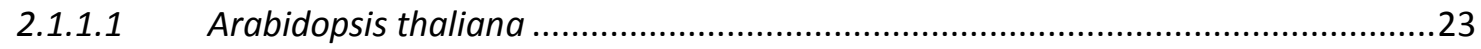

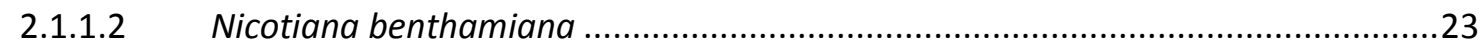

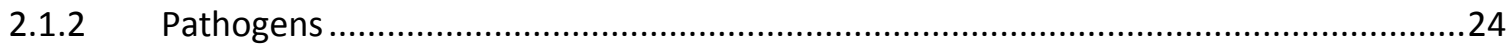

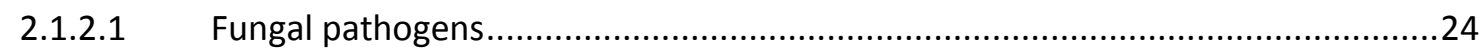

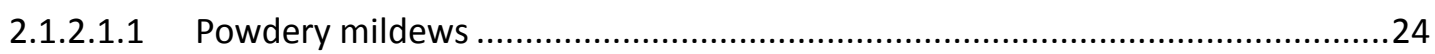

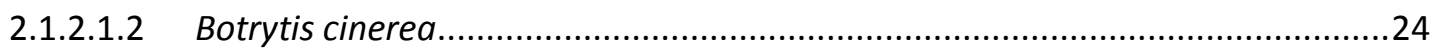

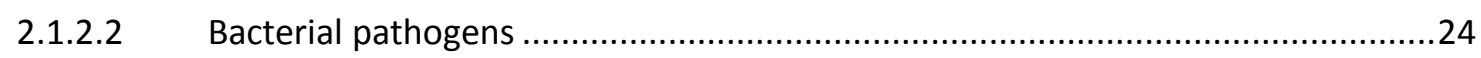

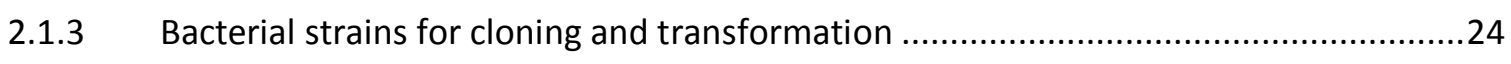

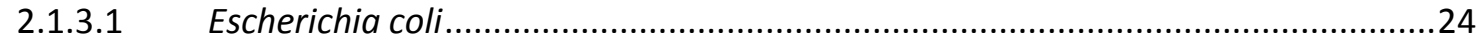

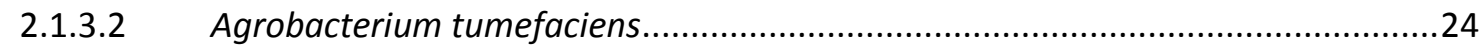

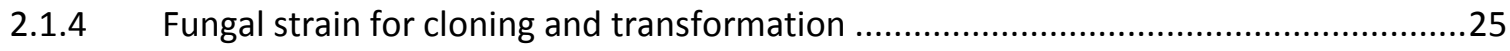

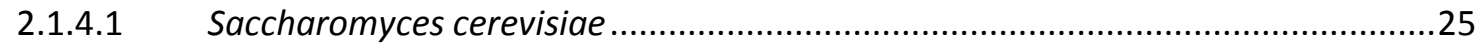

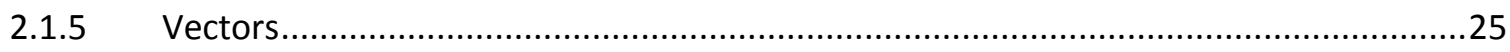

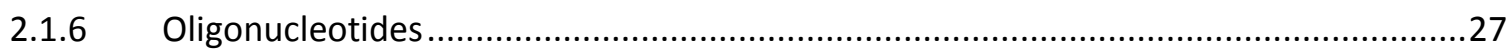




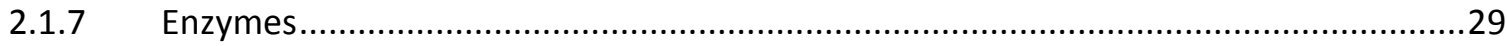

2.1.7.1 Restriction endonucleases ..............................................................29

2.1.7.2 Nucleic acid modifying enzymes ...........................................................29

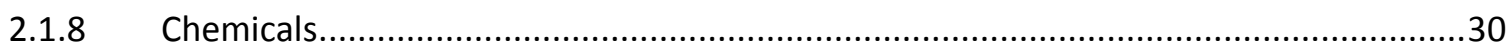

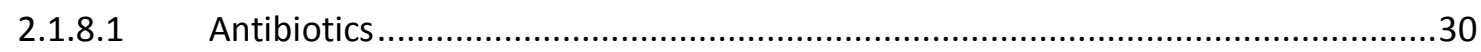

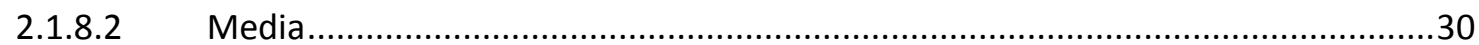

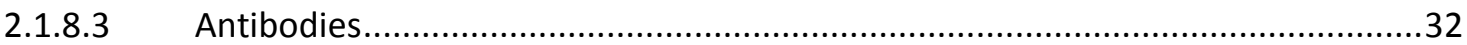

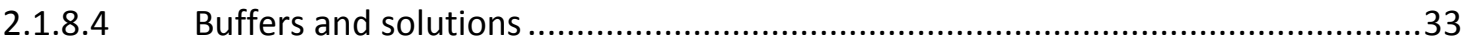

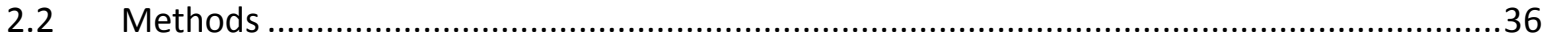

2.2.1 Methods for working with plants and plant material ........................................36

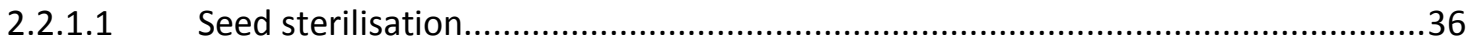

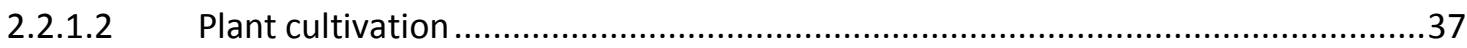

2.2.1.3 Stable transformation of Arabidopsis thaliana (floral dip)................................37

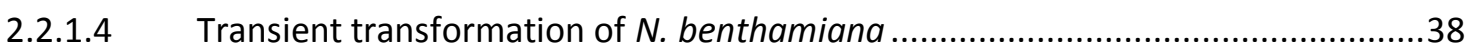

2.2.1.5 Selection of stably transformed Arabidopsis plants.........................................38

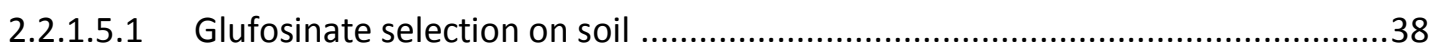

2.2.1.5.2 In vitro selection ........................................................................... 38

2.2.1.6 Confocal laser scanning microscopy (CLSM) .............................................39

2.2.1.7 Inoculation of Arabidopsis plants with powdery mildews .................................39

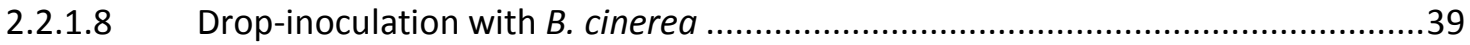

2.2.1.9 Pseudomonas syringae pv. tomato (Pst) vacuum-infiltration assay....................40

2.2.1.10 Vacuum-infiltration for MAMP treatment ..................................................40

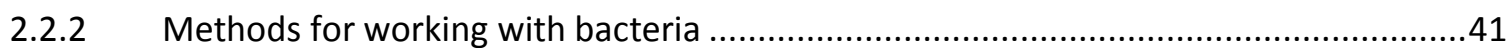

2.2.2.1 Cultivation of bacteria ....................................................................... 41

2.2.2.2 Preparation of chemically competent E.coli TOP10 cells ...................................41

2.2.2.3 Preparation of electro-competent $A$. tumefaciens cells .................................42

2.2.2.4 Transformation of chemically competent $E$. coli TOP10 cells .............................42

2.2.2.5 Transformation of electro-competent Agrobacterium tumefaciens cells ............42

2.2.2.6 Preparation of glycerol stocks..............................................................43

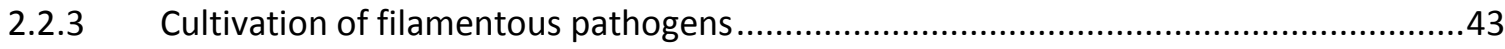

2.2.3.1 Powdery mildews............................................................................ 43

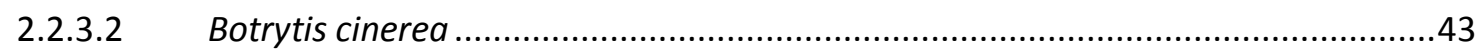

2.2.4 Molecular biological methods ......................................................................43

2.2.4.1 Extraction of genomic DNA from plants using the 'Quick-Prep' method .............43

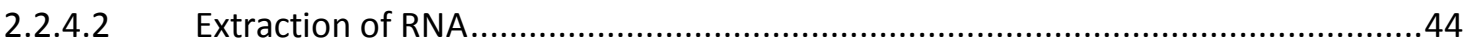




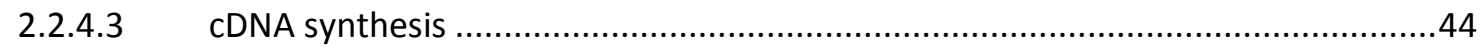

2.2.4.4 Preparation of plasmid DNA from E. coli .................................................44

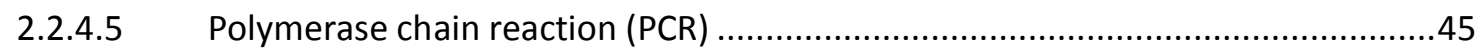

2.2.4.6 Quantitative reverse transcription PCR (qRT-PCR) ......................................46

2.2.4.7 Agarose gel electrophoresis.............................................................. 46

2.2.4.8 Isolation of DNA fragments from agarose gels ........................................47

2.2.4.9 Photometric measurement of DNA and RNA concentration .............................47

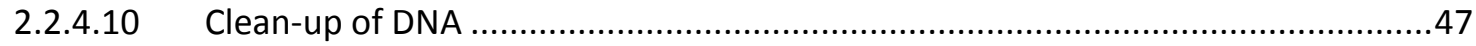

2.2.4.11 Sequencing of DNA and subsequent evaluation ......................................47

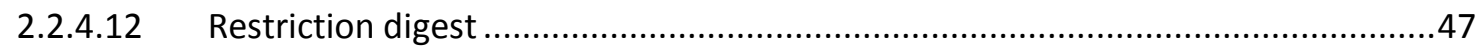

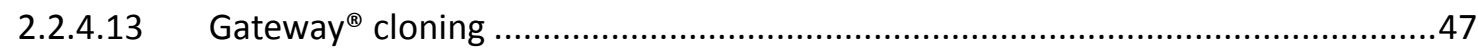

2.2.4.14 Preparation of chemically competent Saccharomyces cerevisiae cells ................48

2.2.4.15 Cloning of $p C L R 1:: C L R 1-G F P$ by homologous recombination in Saccharomyces

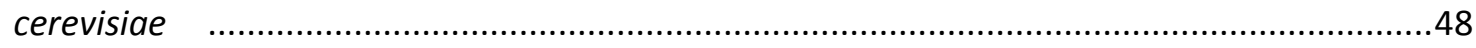

2.2.4.16 Ligation of DNA fragments and vectors ..................................................49

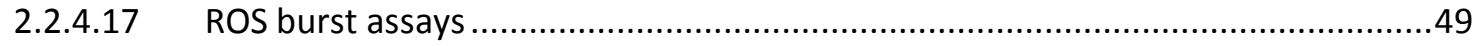

2.2.4.18 Histochemical staining with X-Gluc ..........................................................50

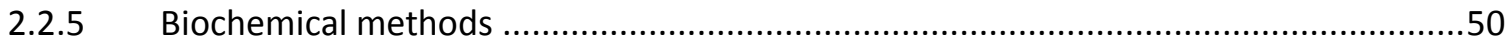

2.2.5.1 Total protein extraction from plants for Western blotting ..............................50

2.2.5.1.1 Protein extraction optimized for receptor-like kinases ................................50

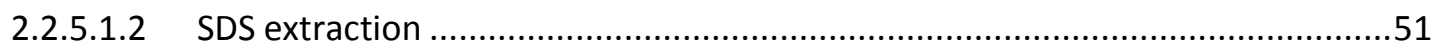

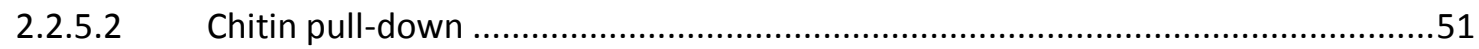

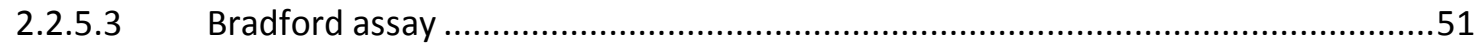

2.2.5.4 Lambda Protein Phosphatase ( $\lambda$ PPase) treatment......................................52

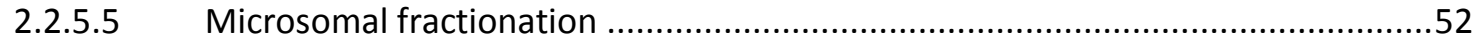

2.2.5.6 Denaturing SDS-polyacrylamide gel electrophoresis (SDS-PAGE) ....................53

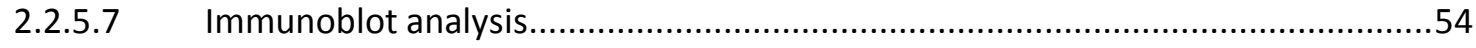

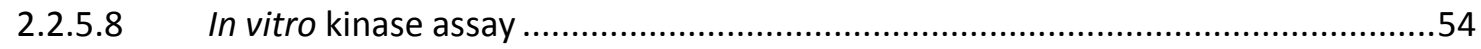

2.2.5.9 Coomassie staining of SDS-PAGE gels and membranes ..................................55

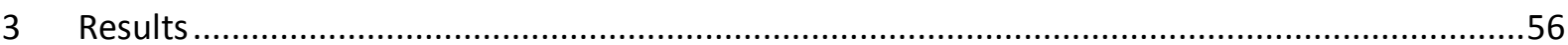

3.1 Identification and in silico analysis of CERK1-INTERACTING LysM-RLK-LIKE RLCK1 CLR1.....56

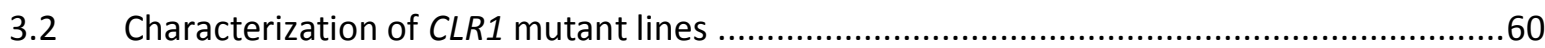

3.2.1 CLR1 T-DNA insertion mutant lines used in this study .....................................61

3.2.2 Chitin-induced phosphorylation of CERK1 and MAPKs in clr1 mutants ...................63

3.2.3 MAMP-induced generation of reactive oxygen species in CLR1 mutants .................64 
3.2.4 cIr1 T-DNA mutants show reduced expression of MAMP-induced genes after chitin polymer and chitin heptamer treatment

3.2.5 Identification of specifically chitin-induced genes and their analysis in clr1 mutants ..70

3.2.6 Involvement of CLR1 in immunity against biotrophic and necrotrophic fungal pathogens

3.2.7 Involvement of CLR1 in immunity towards virulent and avirulent Pseudomonas strains.

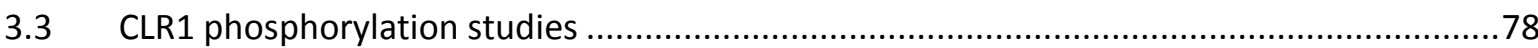

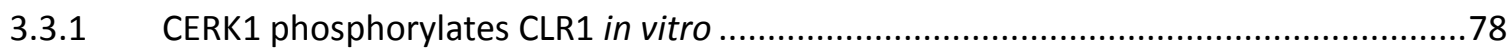

3.3.2 Chitin-induced and CERK1-dependent phosphorylation of CLR1 in planta ...................80

3.3.3 In planta phosphorylation of CLR1 is specifically induced by chitin ..............................82

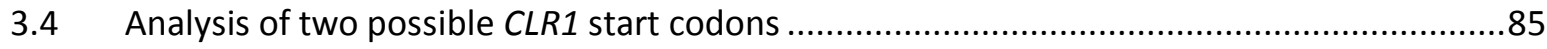

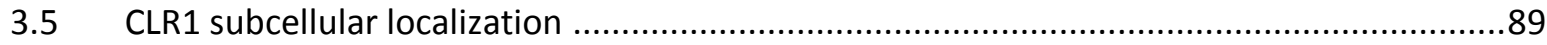

3.5.1 CLR1 is a soluble protein but membrane-associated pools exist in Arabidopsis cells ...89

3.5.2 Localization studies with CLR1 fusion proteins transiently expressed in $N$. benthamiana

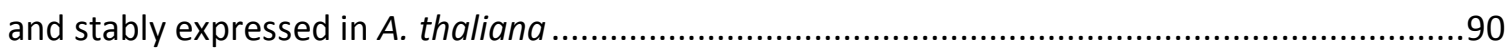

3.5.3 Expression of 6 -glucuronidase under the native CLR1 promoter reveals expression of

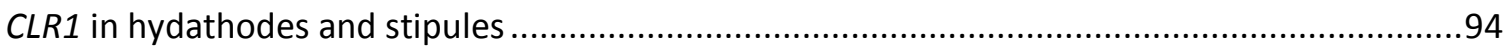

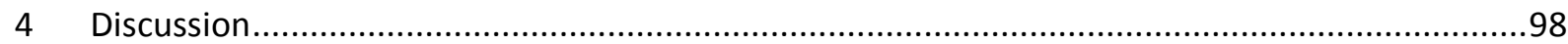

4.1 The putative inactive kinase CLR1 resembles the kinase domains of LysM-RLKs ...............98

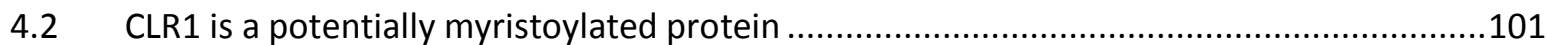

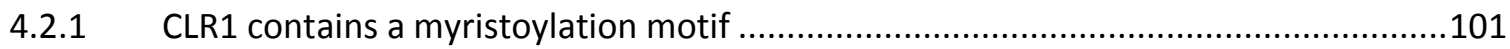

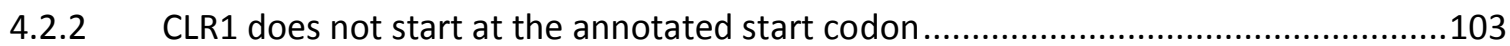

4.3 The kinase inactive CLR1 is a direct downstream phosphorylation target of CERK1 .........106

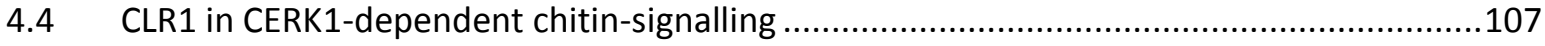

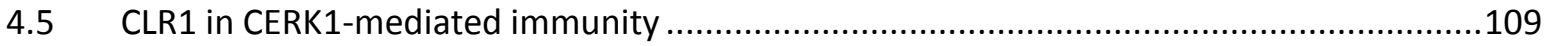

4.6 Possible roles of CLR1 in CERK1-dependent PTI or ETI .................................................111

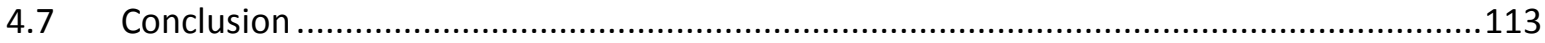

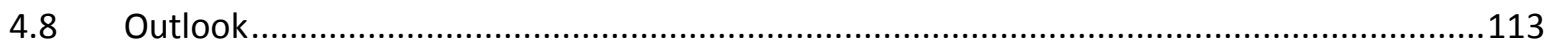

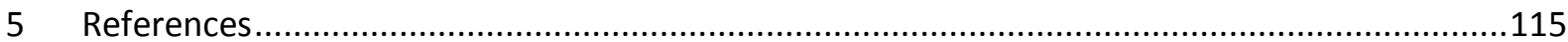

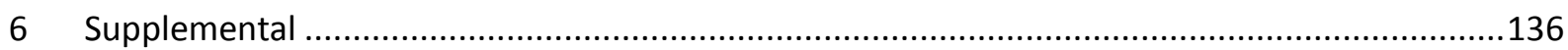

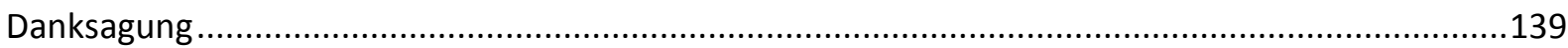





\section{Introduction}

Plants, similar to most multicellular organisms are constantly exposed to various biotic and abiotic stress factors (de Wit, 2007). Since, in contrast to most animals, plants are sessile and cannot evade attackers and unfavourable environmental conditions, they need to adapt to different stresses including climate, light and soil conditions, as well as pathogens and pests. Plants need to recognize potential pathogens in time and also initiate a robust immune response in order to defend themselves effectively (Dangl and Jones, 2001). In contrast to vertebrates, which possess an adaptive immune system, plants can only resort on an innate immune system consisting of two layers of defence responses (Jones and Dangl, 2006). The first layer involves the recognition of conserved 'non-self' pathogen- or microbe-associated molecular patterns (P-/MAMPs) or danger-associated-molecular patterns (DAMPs) by cell surface pattern recognition receptors (PRRs). This perception results in PAMP-triggered immunity (PTI), a basal defence response against a broad spectrum of pathogens. Together with preformed barriers on the plant surface these PRR-mediated defence responses protect plants from a wide variety of phytopathogens, leading to the so-called non-host resistance (Thordal-Christensen, 2003; Nürnberger and Lipka, 2005). Specialised pathogens have evolved mechanisms to overcome this first layer of plant defence by transfer of effector molecules also known as virulence (vir) factors into the host cells (Jones and Dangl, 2006). In an evolutionary arms race, plants have in turn responded with a second layer of defence, the effector-triggered immunity (ETI). ETI depends on the ability of plant resistance (R) molecules to recognize the presence of or modifications caused by effector proteins. $R$ protein activation effectively restricts further microbial growth (Jones and Dangl, 2006).

\subsection{Plant innate immunity}

Pathogens invading a plant, first encounter preformed constitutive barriers on the plant surface, such as a rigid cell wall, wax layers, secondary metabolites and anti-microbial enzymes to restrict pathogen proliferation (Heath, 2000; Muthamilarasan and Prasad, 2013). Should pathogens, however, be able to overcome the plants preformed barriers and breach the plant cell wall, they encounter the two-layered immune system of plants (Jones and Dangl, 2006). The plant immune system differs from that of vertebrates in one major aspect, which is the lack of an adaptive immunity. Plants do not possess mobile systemic cells or the 
ability of antigen presentation in order to create an immunological memory. They rather depend on cell-autonomous immunity, which upon the recognition of microbes and the onset of immune responses generates mobile signals that prime distant tissues for defence against further infection (Nürnberger et al., 2004; Jones and Dangl, 2006). The first layer of plant innate immunity depends on the recognition of microbial elicitors by specific cell surface pattern recognition receptors (PRRs; Figure 1).

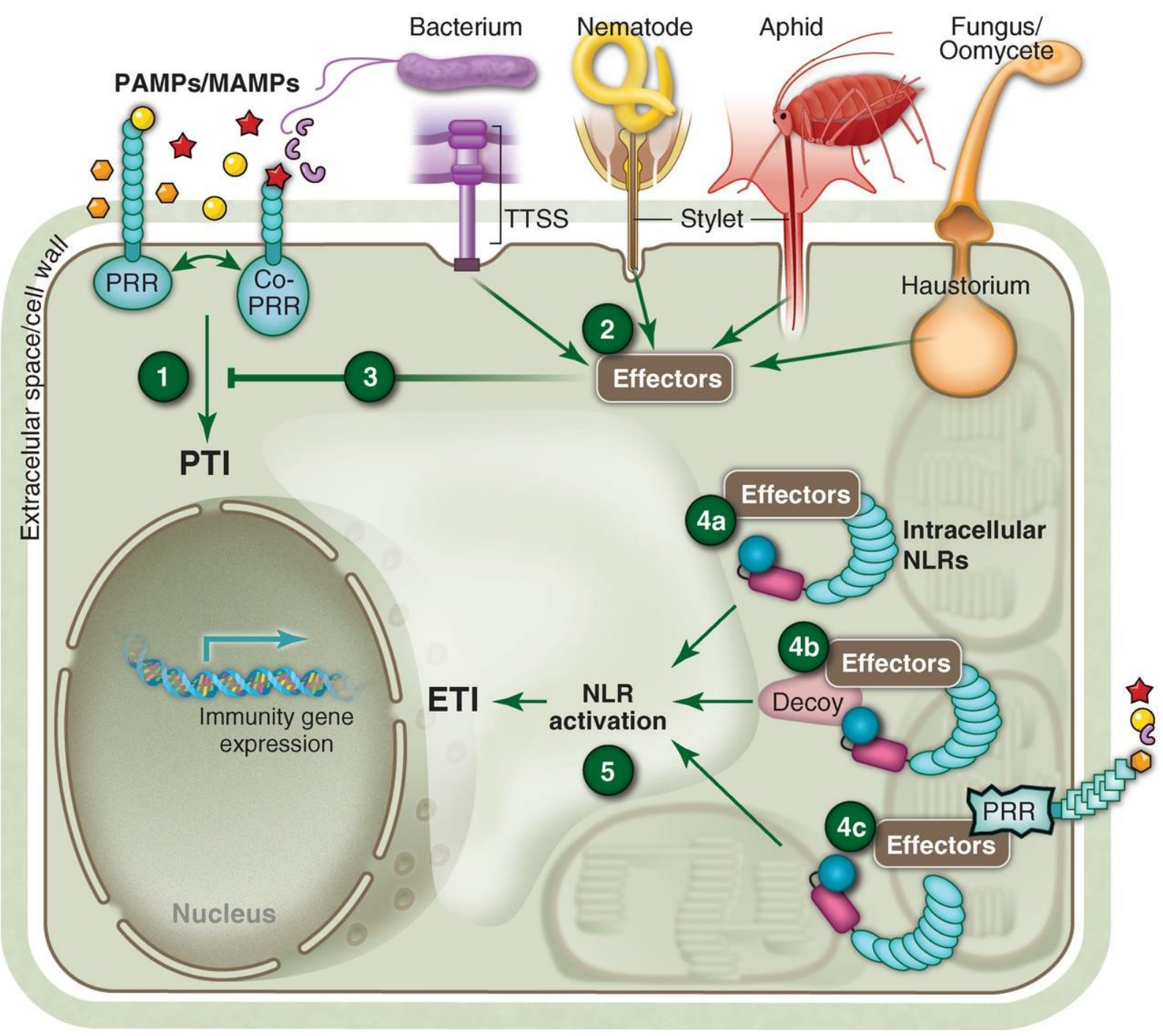

Figure 1. Model of the plant immune system. Pathogens expose pathogen-/ microbe-associated molecular patterns (P-/ MAMPs) into the extracellular space of plants, where they are recognized by cognate pattern recognition receptors (PRRs). This interaction leads to the initiation of PAMP-triggered immunity (PTI; 1). To overcome or suppress PTI, pathogens deliver effector proteins to the plant cell (2). In order to counteract PTI, effectors are addressed to distinct subcellular locations (3). To counteract effector-triggered susceptibility (ETS), plants have evolved intracellular nucleotide-binding domain leucine-rich repeat (NLR) proteins also known as resistance $(R)$ proteins. NLR proteins can recognize effector proteins in mainly three different ways: By directly interacting with the cognate effector (4a); by guarding a decoy protein which mimics an effector target with no other function in cellular processes (4b) and by sensing effector-triggered alterations made to host effector targets involved in immunity, like the cytosolic kinase domain of PRRs (4c). Activation of $R$ proteins (5) subsequently leads to an induction of defence responses resulting in effector-triggered immunity (ETI). Figure from Dangl et al., 2013. 
Microbial elicitors can be 'non-self' molecules such as pathogen- or microbe-associated molecular patterns (P-/MAMPs) as well as damage-associated molecular patterns (DAMPs), which are released from the plant host during pathogen attack (Figure 1; Chisholm et al., 2006; Boller and He, 2009; Boller and Felix, 2009). PAMPs/MAMPs are evolutionary conserved molecules which are characteristic for a whole class of microbes (Boller, 1995; Felix et al., 1999). Since not only pathogenic microorganisms exhibit these conserved structures, the term MAMP is more appropriate (Boller and Felix, 2009) and will be used in the following work. To date, a great variety of MAMPs have been identified. Some of the best studied MAMP-PRR interactions are those of the bacterial flagellin and the PRR FLAGELLIN SENSING2 (FLS2, Gómez-Gómez and Boller, 2000), elongation factor thermo unstable (EF-Tu) and its cognate EF-TU RECEPTOR (EFR, Zipfel et al., 2006), as well as the fungal and oomycete chitin and the CHITIN RECEPTOR KINASE1 (CERK1, Miya et al., 2007). Upon recognition of MAMPs, PRRs trigger a number of signalling events and defence responses leading to PAMP-triggered immunity (PTI; Figure 1 (1)).

Cellular processes involved in PTI are the generation of reactive oxygen species (ROS) and alterations of ion fluxes at the plasma membrane (PM), the activation of downstream mitogen-activated protein kinase (MAPK) signalling cascades, as well as the induction of defence-related genes (Boller and Felix, 2009). Usually PTI together with the preformed constitutive barriers is sufficient to protect most plant species from colonization and devastation by most non-adapted microbial pathogens, a mechanism termed non-host resistance (Thordal-Christensen, 2003). However, pathogens have evolved so-called effector molecules to evade recognition by PRRs and to suppress PTI-triggered defence responses. This leads to effector-triggered susceptibility (ETS; Figure 1 (2-3)) in the host (Jones and Dangl, 2006). Adapted pathogens can secrete these effectors into the apoplastic space or directly into the cytoplasm of host plants. For example, gram-negative bacteria use their type III secretion system (TTSS) to directly deliver effector molecules into the host cells (Figure 1 (2)). The TTSS, a specialized structure used by bacteria, is encoded by hrp (hypersensitive response and pathogenicity) as well as hrc (hrp conserved) genes (Alfano and Collmer, 1997; Lindgren, 1997; Badel et al., 2003; Jin et al., 2003). Pseudomonas strains deficient in hrp or hrc genes as for example the Pseudomonas syringae pathovar tomato (Pst) DC3000 hrcC mutant strain which lack a functional TTSS are unable to deliver effectors into the host cytoplasm. These Pseudomonas strains still trigger PTI but are not able to 
counteract the activated defence responses, thus their proliferation on the host plant is strongly impaired (Peñaloza-Vázquez et al., 2000; Navarro et al., 2008). Instead of delivering effector molecules directly into the host through a TTSS, obligate biotrophic fungal and oomycete pathogens use specialized structures called haustoria (Figure 1 (2); O'Connell and Panstruga, 2006). During infection biotrophic fungi penetrate the host cell wall by forming an infection peg and invaginating the host plasma membrane to form the haustorium, which then serves to take up nutrients and deliver effectors. It has been shown that one group of effectors is secreted into the host apoplast, whereas as another group of effectors is present in the host cytoplasm (de Wit et al., 2009). So far, the exact mechanisms how fungal effectors enter the host cytoplasm have not yet been clarified. Effectors that have already been secreted into the apoplast need to overcome the plant cell wall, as well as the plasma membrane in order to enter the host cytoplasm. Haustorium-derived effector proteins, however, need to pass the pathogens PM and cell wall, the extrahaustorial matrix and the extrahaustorial membrane to reach the host cytoplasm (Panstruga and Dodds, 2009). Oomycete effector proteins with an N-terminal secretion signal followed by a host-targeting domain were suggested to be subject to exocytosis for secretion. Thereby, they could use a mechanism similar to the eukaryotic type II secretory pathway before exploiting host endocytosis for translocation into the cytoplasm (Whisson et al., 2007; Dou et al., 2008; Kale and Tyler, 2011). However, also effector proteins without a predicted translocation signal where shown to cross the plasma membrane (Kale and Tyler, 2011). So far, the question how effector molecules pass the host plasma membrane has not been solved fully and different hypothesises are under discussion. Once effector proteins are in the apoplast or translocated into the host cytoplasm or even the host nucleus, they target host proteins involved in plant immunity. Hence, host proteins like proteases (Song et al., 2009), glucanases (Rose et al., 2002), PRRs (Gimenez-lbanez et al., 2009a), RLCKs (Wang et al., 2015), MAPKs (Zhang et al., 2007) and proteins associated with the transcriptional machinery (Schornack et al., 2010) as well as the ubiquitination machinery (Park et al., 2012) are just some examples for effector targets (Kale and Tyler, 2011).

As a consequence of ETS plants have evolved a second layer of defence involving intracellular resistance $(R)$ proteins, which sense the presence of specific effector molecules. $R$ proteins are typically nucleotide-binding domain leucine-rich repeat (NLR or NB-LRR) proteins closely related to the NUCLEOTIDE-BINDING OLIGOMERIZATION DOMAIN 
(NOD)-like immune receptors in animals (Ausubel, 2005). Apart from the central nucleotide binding site (NB) and the leucine-rich repeats (LRRs) at the C-terminus, these proteins contain a variable $\mathrm{N}$-terminus either consisting of coiled-coil (CC) domains or Toll interleukin-1 receptor (TIR) domains (Dangl and Jones, 2001; Gay and Gangloff, 2007).

So far three different $\mathrm{R}$ protein-mediated effector detection mechanisms are known. In the first one the $\mathrm{R}$ protein directly associates with and recognizes a specific pathogen effector (Jia et al., 2000; Dodds et al., 2006). In the second model the R protein guards a decoy protein which mimics an actual effector target with no further function (Mackey et al., 2003; Dodds and Rathjen, 2010). The $\mathrm{R}$ protein then senses alterations of the decoy protein exerted through the effector. Similar to this is the third mechanism, where the R protein associates with a putative effector target involved in plant innate immunity and senses effector-mediated alterations on the host protein (Mucyn et al., 2006; Gimenez-Ibanez et al., 2009a). Upon recognition by a host $\mathrm{R}$ protein, the effector molecule is termed an Avirulence (Avr) protein.

Recognition of effector molecules and the subsequent activation of $\mathrm{R}$ proteins lead to effector-triggered immunity (ETI) in the host plant (Figure 1 (5)). ETI culminates in a strong defence response, including processes already know from PTI as for example the generation of ROS, activation of MAPK signalling cascades and induction of defence gene expression. Often, ETI is associated with the initiation of local programmed cell death at the infection site, also known as hypersensitive response (HR, Chisholm et al., 2006). Since biotrophic pathogens depend on living host tissue to colonize and proliferate, the HR is an effective immune response against this class of pathogens. Necrotrophic pathogens which kill their host in order to feed on the dead tissue, however, benefit from the programmed cell death during HR (Govrin and Levine, 2000).

ETI and the accompanying HR lead to a long-lasting broad spectrum resistance in the infected but also in distant tissues called systemic acquired resistance (SAR). This increased resistance is associated with the expression of PATHOGENESIS-RELATED (PR) genes and the accumulation of salicylic acid (SA) (Cao et al., 1994; Bowling et al., 1994; Durrant and Dong, 2004). 


\subsection{Pattern recognition receptors}

The plasma membrane-localized PRRs can be subcategorized into two classes, the receptorlike kinases (RLKS) and the receptor-like proteins (RLPS). Both, RLKs and RLPs have an extracellular ligand-binding domain (also known as ectodomain) and a plasma membranespanning transmembrane domain. RLKs possess an additional cytoplasmic kinase domain which is important for intracellular downstream signal transduction. In contrast, RLPs contain only a short cytoplasmic tail (Monaghan and Zipfel, 2012). The ectodomain of PRRs may contain different functional motifs, which reflect the type of ligand they bind. PRRs with a variable number of leucine-rich repeats (LRRs) in their ectodomain have been shown to be involved in recognizing protein or peptide MAMPs (Monaghan and Zipfel, 2012). However, PRRs with an ectodomain composed of lysin motif (LysM) domains are important for the perception of $\mathrm{N}$-acetylglucosamine-containing oligosaccharide MAMPs, including fungal chitin (Zhang et al., 2007). Although a great number of RLKs have been identified in Arabidopsis to date, the ligands are known only for a small number of RLKs and RLPs. Though the mentioned PRRs differ in structure and also in the MAMP specificity, they all seem to depend on dimerization for proper immune signalling. Both, homo- and heterodimerization have been described in plants (Macho and Zipfel, 2014).

In the following section the most prominent examples will be described in more detail.

\subsubsection{LRR-RLKs and the perception of peptide MAMPs}

The LRR-RLK FLAGELLIN-SENSING2 (FLS2) constitutes the Arabidopsis flagellin receptor. FLS2 directly binds the bacterial flagellin, or to be more precise its conserved N-terminal 22-amino acid epitope flg22 via its 28 LRRs in the ectodomain (Gómez-Gómez and Boller, 2000; Chinchilla et al., 2006). FLS2 orthologs are found in a great number of higher plants indicating that the perception of bacterial flagellin is an evolutionary old mechanism (Boller and Felix, 2009). Arabidopsis fls2 mutant plants as well as Nicotiana benthamiana plants silenced for NbFLS2 are more susceptible to both, adapted and non-adapted bacterial pathogens (Zipfel et al., 2004; Li et al., 2005; Hann and Rathjen, 2007). Likewise, mutations in the flg22 sequence can render bacteria more pathogenic since mutant flg22-variants partially or completely failed to elicit plant immune responses (Felix et al., 1999; Pfund et al., 
2004; Sun et al., 2006). The Arabidopsis elongation factor Tu receptor (EFR) belongs to the same class of LRR-RLKs as FLS2, the LRR XII family (Shiu and Bleecker, 2003). With its ectodomain consisting of 21 LRRs EFR recognizes and binds to the elongation factor Tu (EF-Tu) and its conserved epitope elf18 (Zipfel et al., 2006). The presence of EFR orthologs and subsequently also the perception of elf18 is restricted to Brassicaceae (Kunze et al., 2004). efr knockout mutants show an enhanced susceptibility to Agrobacterium tumefaciens transformation as well as to Pseudomonas syringae pv. tomato infection (Zipfel et al., 2006; Zipfel, 2009). A LRR-RLK which shares high homology to EFR is the rice XA21 (Boller and Felix, 2009). Similar to EFR, XA21 possesses an ectodomain with 21 LRRs which were shown to bind the Xanthomonas oryzae pv. oryzae type I-secreted protein Ax21 and its minimal active peptide $A x Y^{S} 22$. Ax21 was suggested to be involved in quorum sensing, a mechanism conserved among bacteria and therefore constitutes a typical MAMP (Han et al., 2011). XA21 was shown to confer resistance against $X$. oryzae (Song et al., 1995). Two LRR-RLKs involved in perception of the DAMP peptides AtPep1 and its homologs are PEP1 RECEPTOR1 (PEPR1) and PEPR2 (Yamaguchi et al., 2006; Yamaguchi et al., 2010; Krol et al., 2010). The different AtPep peptides were shown to be involved in the induction of defence responses as for example in $\mathrm{Ca}^{2+}$ signalling (Huffaker et al., 2006; Qi et al., 2010). Studies in Arabidopsis and maize suggest a possible role for the AtPep/PEPR system in enhancing resistance against pathogen infection but also in signalling upon herbivore attack and wounding (Huffaker and Ryan, 2007; Huffaker et al., 2011; Boller and Flury, 2012).

One LRR-RLK which is involved in complex formation and subsequent signalling of the described PRRs is the BRI1-ASSOCIATED RECEPTOR KINASE1 (BAK1). A lot of research has been conducted on the heterocomplex formation of the co-receptor BAK1 (Mazzotta and Kemmerling, 2011). BAK1, also known as SOMATIC EMBRYOGENESIS RECEPTOR KINASE3 (SERK3), is a LRR-RLK and belongs to the LRR II family (Shiu and Bleecker, 2003). Initially, BAK1 was identified as positive regulator of brassinosteroid (BR) signalling due to its liganddependent interaction and transphosphorylation with the BR receptor BRASSINOSTEROID INSENSITIVE1 (BRI1, (Nam and Li, 2002; Li et al., 2002; Wang, 2008; Sun et al., 2013). bak1 mutants only show a subtle phenotype in BR-signalling because of functional redundancy with two other members of the SERK family of receptor-like kinases, SERK1 and SERK4/BAK1LIKE1 (BKK1; Karlova et al., 2006; He et al., 2007). Independent from its function in BRI1mediated BR signalling, BAK1 is also involved in plant innate immunity by forming 
heteromeric complexes with FLS2 and EFR, respectively (Kemmerling et al., 2007; Chinchilla, 2007; Heese et al., 2007; Schulze et al., 2010; Roux et al., 2011). Similar to its function in BRsignalling, BAK1 is not important for binding of flg22 and elf18 to FLS2 and EFR, respectively, but rapidly dimerizes with the two receptor-like kinases upon MAMP perception (Chinchilla, 2007; Roux et al., 2011). This heterodimerization between the different LRR-RLKs leads to mutual transphosphorylation on the intracellular domains (Schulze et al., 2010). bak1 mutant plants are not fully impaired in FLS2- and EFR-mediated defence responses, they rather show quantitative alterations in the immune signalling pathways (Chinchilla, 2007; Roux et al., 2011). Studies in yeast and Arabidopsis indicated an association of BAK1 with PEPR1 and PEPR2, suggesting that BAK1 is also involved in DAMP signalling (Postel et al., 2010; Schulze et al., 2010). BAK1 has also been shown to be involved in immune responses elicited by other bacterial and oomycete MAMPs including lipopolysaccharides (LPSs), peptidoglycans (PGNs), and the elicitin INF1 (Heese et al., 2007; Shan et al., 2008). Upon infection with the fungal pathogen Botrytis cinerea, bak1 mutants develop spreading necrosis indicating an enhanced susceptibility to necrotrophic pathogens (Kemmerling et al., 2007). Interestingly, bak1 bkk1 mutants exhibit seedling-lethality due to constitutive active defence responses accompanied by spontaneous cell death (He et al., 2007). The bak1-5 mutant allele is impaired in flg22- and elf18-triggered immune responses but does not show the pleiotropic defects in BR-signalling and cell-death formation of knockout mutants (Roux et al., 2011; Schwessinger et al., 2011). Analysis of a bak1-5 bkk1 double mutant showed that both, BAK1 and BKK1 contribute to FLS2-, EFR- and Pep1-dependent immune signalling. The reduced MAMP signalling in bak1-5 bkk1 led to reduced resistance against pathogens, for example the hemibiotrophic Pseudomonas syringae and the biotroph oomycete Hyaloperonospora arabidopsidis (Roux et al., 2011). BAK1 seems to be an important regulator in plant immunity due to its ligand-dependent complex formation with various PRRs (He et al., 2007).

\subsubsection{LysM-RLKs and the perception of carbohydrate MAMPs}

The carbohydrate-binding lysin motif (LysM) was initially identified in enzymes of bacteria, which were shown to be involved in degrading bacterial and fungal cell walls composed of peptidoglycan (PGN) and chitin, respectively (Bateman and Bycroft, 2000; Buist et al., 2008). 
Moreover, also eukaryotic proteins like LysM-RLKs or a fungal effector were shown to contain LysM domains involved in binding fungal chitin oligosaccharides, structurally chitinrelated Nod factors and bacterial PGNs (Bolton et al., 2008; Buist et al., 2008; Jonge and Thomma, 2009).

\subsubsection{Chitin perception}

Chitin constitutes a major component of the fungal cell well and therefore represents a wellconserved MAMP recognized by PRRs of several plant species (Boller and Felix, 2009). Chitin is a polymer consisting of $\beta$-1,4-linked $N$-acetylglucosamine (GICNAC) monomers (Muzzarelli, 1977).

The first chitin receptor, CHITIN ELICITR BINDING PROTEIN (CEBiP), was identified in rice (Oryza sativa) due to its chitin-binding affinity (Kaku et al., 2006). CEBiP contains an extracellular domain with three LysMs and a C-terminal transmembrane domain, but lacks an intracellular part (Hayafune et al., 2014). Therefore CEBiP is assigned to belong to the class of RLPs. Due to the lack of an intracellular kinase domain which is vital for proper signal transduction, CEBiP seems to form a complex with the RLK OsCERK1 (Shimizu et al., 2010). Silencing of OSCERK1 led to disruption of chitin-induced immune responses in rice (Kouzai et al., 2014; Ao et al., 2014). Hayafune and colleagues (2014) suggested that two CEBiP molecules bind to one $(\mathrm{GlcNAc})_{8}$ chain from opposite sides in a sandwich-type manner (Figure 2 (a)). In order to form a stable dimer, at least five internal GIcNAc moieties are necessary, since the two CEBiP molecules bind four monomers each, sharing three of them. Studies with a modified oligosaccharide which instead of having four alternated $\mathrm{N}$-acetyl groups only had the $\mathrm{N}$-acetyl groups pointing to one side (GICN $\beta 1,4 \mathrm{GICNAc})_{4}$, showed that although it was able to bind to CEBiP it did not induce receptor dimerization and immune signalling. Additionally, pre-treatment with $(\mathrm{GICN} \beta 1,4 \mathrm{GICNAC})_{4}$ blocked the receptor for further (GIcNAc) 8 binding and dimerization (Hayafune et al., 2014). The LysM-RLK OsCERK1 was shown to have no chitin-binding activity, underlining its function in solely transmitting the CEBiP-perceived signal into the intracellular part of the plant cell (Shimizu et al., 2010; Shinya et al., 2012). 


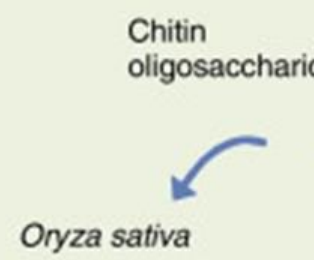

(a)

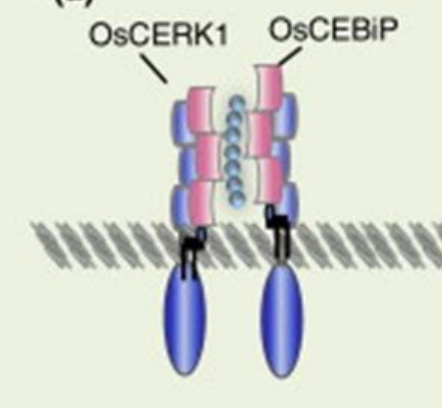

(b) AICERK1
Arabidopsis thaliana

(c)
AICERK1 AtLYK5
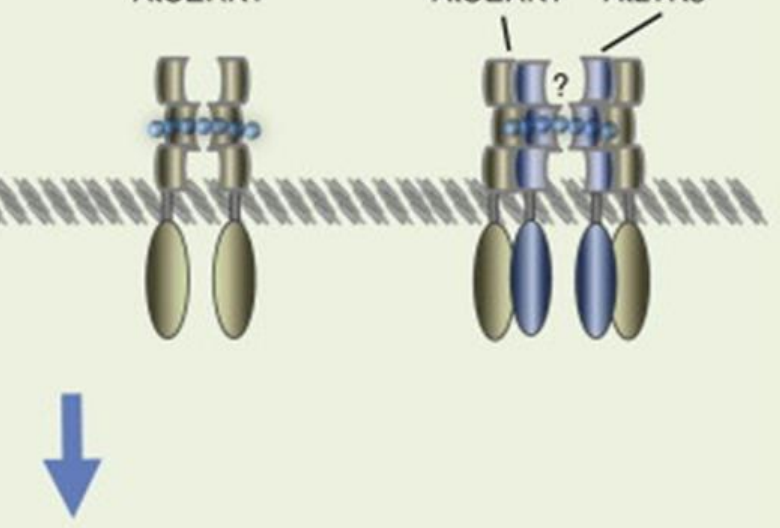

Defense

Figure 2. Model for chitin-induced receptor complex formation in rice (Oryza sativa) and Arabidopsis. a) In rice two OsCEBiP molecules bind a chitin oligosaccharide in a sandwich-type manner via their central LysMs, leading to homodimerization. Ligand-dependent homodimerization of OsCEBiP leads to association of OsCERK1 in order to transmit and activate downstream signalling. b) and c): Two models for chitin perception in Arabidopsis. b) AtCERK1 homodimerizes upon chitin perception. The direct binding of AtCERK1 to a chitin oligosaccharide is mediated via its central LysM. Homodimerization of AtCERK1 leads to activation of chitin-induced defence responses. c) In this model AtLYK5 represents the major chitin receptor. Upon chitin perception AtLYK5 heterodimerizes with AtCERK1 molecules. This dimerization is important to transduce the signal from the kinase inactive AtLYK5 via kinase active AtCERK1 to downstream defencesignalling components. However, detailed chitin-binding mechanism and complex formation have not been resolved, yet. Figure from Shinya et al., 2015.

Two additional LysM proteins, Oryza sativa LysM-CONTAINING PROTEIN4 (OsLYP4) and OsLYP6, were suggested to be involved in chitin signalling due to their chitin-binding ability (Liu et al., 2012). These probably glycosylphosphatidylinositol (GPI)-anchored plasma membrane proteins were shown to associate with CEBiP under non-elicited conditions. Upon chitin perception OsLYP4 and OsLYP6 were shown to form complexes with OsCERK1, similar to the previously described OsCERK1-CEBiP complex (Ao et al., 2014; Hayafune et al., 2014). Transgenic rice plants silenced for OSLYP4 or OSLYP6 were impaired in chitin-induced defence signalling, including ROS production, defence gene expression and callose deposition (Liu et al., 2012). To date, the exact complex formation and signalling mechanism upon chitin perception in rice has not been solved. 
A similar mechanism involving heterocomplex formation between RLKs and RLPs was shown for the Arabidopsis LRR-RLP CLAVATA2 (CLV2) involved in shoot meristem and organ development. CLV2 forms a heteromeric signalling complex with the RLK CLV1 to initiate proper developmental signalling (Clark et al., 1993; Jeong et al., 1999).

The OsCERK1 ortholog in Arabidopsis, CHITIN ELICITOR KINASE1 (CERK1)/LYK1/LysM-RLK1, was identified as the primary receptor for the fungal MAMP chitin (Miya et al., 2007). It is one of five LYK proteins encoded by the Arabidopsis genome (Zhang et al., 2007). CERK1 directly binds chitin and its derivatives via its three LysMs on the extracellular domain and is directly involved in transmitting the perceived signal into intracellular parts of the cell (Figure 2 (b); (Petutschnig et al., 2010; lizasa et al., 2010; T Liu et al., 2012). Analysis of the crystal structure of CERK1 in complex with a chitin pentamer revealed a chitin binding site in the second of the three LysMs (Liu et al., 2012). Upon chitin perception, the extracellular domains of two CERK1 molecules rapidly homodimerize leading to transphosphorylation on their intracellular domains (Liu et al., 2012). Phosphorylation of CERK1 induces a band shift of the CERK1 protein which can be visualized via immunoblot (Petutschnig et al., 2010). Besides chitin, CERK1 was also shown to recognize several chitin derivatives with varying lengths of the $\beta$-1,4-linked $N$-acetylglucosamine (GlcNAc) chains (Petutschnig et al., 2010). It was shown that the degree of polymerization of the chitin molecules is important for CERK1 dimerization. Petutschnig and colleagues (2010) showed that besides chitin and chitosan, CERK1 also bound chitin oligomers with a polymerization degree (pd) of 5 and higher. In contrast, chitin mono- and dimers did not induce CERK1 mobility shift at all. Chitin tri- and tetramers as well as chitosan only induced a weak shift compared to polymeric chitin. However, chitin oligomers with a pd $\geq 5$ induced a mobility shift comparable to that observed upon treatment with polymeric chitin and also activated subsequent immune responses like ROS production and MAPKs (Petutschnig et al., 2010). Interestingly, Liu and colleagues (2012) reported that upon binding of chitin pentamers no conformational change indicative for dimerization could be observed on the CERK1 ectodomain. Additionally, they proposed that neither chitin tetramers nor pentamers induced CERK1 ectodomain dimerization as it was observed for the octamer. These results contradict the observed induction of immune responses with chitin pentamers by Petutschnig et al., 2010. The mentioned discrepancies are probably due to the different experimental setups and differences in in vitro or in vivo performed assays. 
Upon CERK1 phosphorylation downstream intracellular immune responses are initiated including the induction of early immune responses like the generation of ROS and activation of MAPK cascades (Wan et al., 2004; Miya et al., 2007; Petutschnig et al., 2010). The signalling cascade leads to up-regulation of MAMP-induced genes, including transcription factors (TFs) which contain a WRKY DNA-binding domain, such as WRKY 22/29/33/53 (Wan et al., 2004; Libault et al., 2007). cerk1-2, a T-DNA knockout mutant lacking a functional CERK1 protein, was shown to be completely insensitive to chitin (Miya et al., 2007). Hence, the mutant plants were more susceptible to fungal pathogens (Wan et al., 2004; Miya et al., 2007). Additionally, cerk1 mutants showed enhanced susceptibility to strains of the bacterial pathogen Pseudomonas syringae (Gimenez-Ibanez et al., 2009b).

Interestingly Arabidopsis also possesses an ortholog to the rice RLP CEBiP. The LysMCONTAINING RECEPTOR-LIKE PROTEIN2 (LYM2) was identified due to its high affinity to chitin in pull-down assays (Petutschnig et al., 2010; Shinya et al., 2012). Despite the shown chitin-binding capacity, no function in canonical chitin perception or CERK1-mediated chitin signalling could be assigned to LYM2 (Wan et al., 2008; Shinya et al., 2012; Narusaka et al., 2013; Faulkner et al., 2013). Instead, LYM2 was shown to mediate molecular fluxes through plasmodesmata in a chitin-dependent manner (Faulkner et al., 2013). This CERK1independent function of LYM2 was reported to be an important mechanism in defence against necrotrophic fungal pathogens (Faulkner et al., 2013; Narusaka et al., 2013).

So far, CERK1 was proposed to be the major chitin receptor in Arabidopsis responsible for perception and signalling of chitin and its derivatives (Petutschnig et al., 2010; Liu et al., 2012). As shown earlier, PRR complex formation is an important mechanism in MAMP perception and signalling. The reported complex formation of OsCERK1 in rice suggested that Arabidopsis CERK1 might do so as well. The fact that CERK1 shows quite a low affinity to chitooctaose supports the idea (Liu et al., 2012; Cao et al., 2014). Recently, two Arabidopsis LysM-RLKs, LYK4 and LYK5, were shown to be involved in chitin signalling (Wan et al., 2012; Cao et al., 2014). LYK4 was shown to play a minor role in chitin signalling, since lyk4 mutants were only slightly impaired in the induction of chitin-responsive genes, ROS generation, calcium influx and resistance against bacterial and fungal pathogens (Wan et al., 2012). For LYK5 contradictory findings were published. Initially, the lyk5-1 mutant in the Landsberg (Ler) background was suggested to show no alteration in chitin-induced immunity based on 
the expression of WRKY53 (Wan et al., 2008; Wan et al., 2012). These findings were revoked, due to the fact that in additional assay lyk5-1 mutants showed a reduced CERK1 band shift, reduced expression of WRKY33 and reduced activation of MAPKs upon chitin treatment. Moreover, the Ler background of lyk5-1 could be critical, since Ler wild type plants already showed a reduced ROS production compared to Col-0 upon chitin treatment (Cao et al., 2014). To circumvent variations due to the Ler background, Cao and colleagues (2014) characterized lyk5-2 in the Col-0 background and showed that lyk5-2 mutant plants were significantly impaired in chitin-induced defence responses, however not to the same extent as cerk1 knockout mutants. lyk4 lyk5 double mutants showed a phenotype which resembled the complete blocking of chitin-induced responses seen in the cerk1-2 mutant, indicating a redundancy of LYK4 and LYK5 in chitin signalling (Cao et al., 2014). LYK5 constitutes an inactive kinase which forms homodimers in the absence of chitin and is suggested to be necessary for CERK1 homodimerization and phosphorylation (Figure 2 (c)). Interestingly, LYK5 association with CERK1 upon chitin perception seemed to be stronger than CERK1 homodimerization (Cao et al., 2014). Recent findings indicated that the LYK5 kinase domain is phosphorylated by CERK1 (Erwig et al., in preparation). The chitin-binding affinity measured for LYK5 $\left(K_{d}=1.72 \mu \mathrm{M}\right)$, was 200-fold higher than that of CERK1 $\left(K_{d}=455 \mu M\right)$ (Cao et al., 2014). Intriguingly, the value for CERK1 chitooctaose binding affinity differs from the value $\left(K_{d}=45 \mu M\right)$ measured by Liu and colleagues (2012). Hence, whether one of the two RLKs functions as the primary chitin receptor due to stronger chitin-binding affinity is not yet proven and the exact structure of the receptor complex around CERK1 involved in chitin signalling has not yet been fully solved.

\subsubsection{Nod factor perception}

The perception of MAMPs via LysM domains plays a role in symbiosis of legumes with specialized rhizobial microbes (Antolín-Llovera et al., 2014). Nod factors (NFs) represent modified chitin oligosaccharides, so-called lipochitooligosaccharides, which are produced by the bacteria and are necessary for infection and nodule formation of the host (Radutoiu et al., 2003; Nakagawa et al., 2011; Rey et al., 2013; de Mita et al., 2014). The exact structure of NFs can vary in the acyl chain attached to the non-reducing terminal glucosamine residue depending on the bacterial species (Oldroyd and Downie, 2008). In the interaction between 
Lotus japonicus and NF-secreting rhizobia two LysM-RLKs, namely NOD FACTOR RECEPTOR1 (NFR1) and NFR5 play an important role (Madsen et al., 2011). NFR1 and NFR5 are both involved in Nod factor-perception. $n f r 1$ and $n f r 5$ mutant plants exhibit similar mutant phenotypes, including impaired Nod factor responses as for example nodule primordia formation. However, only NFR1 possesses an active kinase domain and is thus thought to be required for initiation of downstream Nod factor-signalling (Radutoiu et al., 2003; Madsen et al., 2011; Broghammer et al., 2012). In Medicago truncatula two orthologs of NFR1/5 are responsible for NF perception, LysM-RLK3 (LYK3) and NOD FACTOR PERCEPTION (NFP) (Arrighi et al., 2006; Smit et al., 2007; Rey et al., 2013). While $n f p$ mutants are impaired in rhizobial symbiosis including the NF perception, root hair deformation and initial NF responses (Amor et al., 2003; Mulder et al., 2006), lyk3 mutants are impaired in rhizobialinfection including the formation of infection threads and nodules (Limpens et al., 2003; Riely et al., 2004). Interestingly, the lyk3 phenotype resembles the phenotype observed upon infection of wild type M. truncatula with a mutant Sinorhizobium meliloti $(\mathrm{Sm})$ nodF nodL strain. NFs secreted by this Sm mutant miss an acetate substitution at the non-reducing terminal glucosamine residue and have a C18:1 chain in place of the C16:2 acyl chain (Ardourel et al., 1994). Whereas single mutations of nodF and nodL have only minor effects on nodulation, the double mutant leads to an impairment of the bacteria to initiate the formation of functional infection threads (Ardourel et al., 1994; Limpens et al., 2003). Taken these results together, LYK3 is suggested to function as entry receptor in $M$. truncatula with high stringency to NF structure and recognition (Limpens et al., 2003; Riely et al., 2004).

\subsubsection{Peptidoglycan perception}

Peptidoglycan (PGN) is composed of alternating GICNAc and $\mathrm{N}$-acetylmuramic acid residues and is thus structurally related to chitin. PGN is also a well-conserved MAMP due to its function as structural component in cell walls of Gram-positive and Gram-negative bacteria (Gust et al., 2007). As already mentioned, LysMs are not only involved in the binding and perception of chitin and Nod factors, but they were also shown to be important for perception of peptidoglycan in plants (Willmann et al., 2011).

Recently, two Arabidopsis LysM-RLPs, LysM-CONTAINING RECEPTOR-LIKE PROTEIN1 and -3 (LYM1 and LYM3) were shown to bind PGN and to be required for PGN perception together 
with CERK1 (Willmann et al., 2011). In this tripartite PGN signalling complex proposed by Willmann and colleagues (2011), LYM1 and LYM3 were shown to be important for binding of the ligand, whereas CERK1 showed no direct binding to PGN. Willmann et al., (2011) showed that cerk1 mutants were more susceptible to bacterial infection probably due to the observed PGN-insensitivity. In contrast to that are the findings by Gimenez-lbanez et al., (2009b) which show enhanced susceptibility to bacterial infection independent of PGN, since perception of PGN is not blocked in cerk1 mutants in their studies. Although the exact PGN perception and signalling mechanisms have not yet been clarified, a model has been proposed where LYM1 and LYM3 bind PGN and then form a complex with CERK1 for downstream signal transduction (Willmann et al., 2011).

The rice LySM-RLK OSCERK1 was also suggested to play a role in PGN perception and immunity in rice together with the two LysM-RLPs OsLYP4 and OsLYP6 (Liu et al., 2012; Miyata et al., 2014). Plants silenced for OSCERK1 were impaired in PGN-induced defence responses indicating a dual role for OsCERK1 in chitin and PGN signalling (Kouzai et al., 2014).

\subsection{Receptor-like cytoplasmic kinases}

Members of a subfamily of RLKs, the receptor-like cytoplasmic kinases (RLCKs) have emerged as essential proteins to transmit signals from PRRs to further downstream components (Lin et al., 2013). RLCKs represent about one quarter of all RLKs and can be divided into 12 subfamilies (I-XII; Shiu et al., 2004). RLCKs differ from RLKs through the lack of an extracellular domain required for elicitor perception and a missing transmembrane domain. However, sequence analyses indicated that RLCKs exist which have additional domains to the cytoplasmic Ser/Thr kinase domain which might be important for interaction with other proteins (Shiu and Bleecker, 2001). These domains resemble structures already known from the ectodomains of RLKs, as for example LRRs, LysMs, and lectin domains (Shiu et al., 2004; Vij et al., 2008). RLCKs which lack any additional domains and/ or signal sequences for membrane localization may localize to the plasma membrane through association with membrane proteins or due to lipid modifications (Veronese et al., 2006; Tang et al., 2008). $\mathrm{N}$-myristoylation is a co- or post-translational protein modification where a myristic acid residue is irreversibly linked to an $\mathrm{N}$-terminal glycine residue which has been exposed due to 
previous co-translational removal of the $\mathrm{N}$-terminal methionine (Johnson et al., 1994). It has also been shown that myristoylation can proceed post-translationally. In this case the mature protein is enzymatically cleaved and an internal glycine is then exposed to the $\mathrm{N}$ myristoyltransferase (Zha, 2000). N-myristoylation plays a role in translocating and anchoring proteins to membranes within cells (Johnson et al., 1994). Interestingly, it was shown to be important for proper function and localization of several RLCKs, including BIK1, PBS1-LIKE1 (PBL1), and CAST AWAY (Burr et al., 2011; Lin et al., 2013; Ranf et al., 2014).

\subsubsection{RLCKs in hormone signalling}

The RLCK BR-SIGNALING KINASE1 (BSK1) constitutes a substrate of the BR receptor BRI1 and acts as a positive regulator in BR-induced responses (Tang et al., 2008). Under non-elicited conditions, BRI1 is inactive and the expression of BR-responsive genes is repressed due to inactivation of the corresponding transcription factors by the GSK3-like kinase BR INSENSITIVE2 (BIN2, (Wang et al., 2002; Li and Nam, 2002; Yin et al., 2002; He, 2002; Vert and Chory, 2006; Gampala et al., 2007). BSK1 contains an N-terminal myristoylation motif which could mediate plasma membrane localization and subsequently be involved in proper function of the protein (Tang et al., 2008). Together with BSK1, which belongs to the RLCK family XII (Shiu et al., 2004), an additional RLCK of the subfamily VII, CONSTITUTIVE DIFFERENTIAL GROWTH1 (CDG1), was identified to function in parallel in downstream BRI1signalling (Muto et al., 2004; Kim et al., 2011). The two RLCKs are phosphorylated by BRI1 and also transphosphorylate BRI1 vice versa. Upon activation, BSK1 and CDG1 dissociate from BRI1 in order to associate with the phosphatase BRI1 SUPPRESSOR1 (BSU1) (Tang et al., 2008; Kim et al., 2009, 2011). Enhanced BR perception leads to increased dephosphorylation of BIN2 by BSU1 (Kim et al., 2009). Dephosphorylated inactive BIN2 no longer phosphorylates the TFS BZR1 and BZR2/BES1 which are further dephosphorylated by the PROTEIN PHOSPHATASE2A (PP2A) and subsequently translocate into the nucleus to regulate expression of BR-sensitive genes (Sun et al., 2010; Tang, 2011). Kim et al. (2011) reported that either of the two RLCKs, CDG1 or BSK1, is enough to mediate BR-signalling from BRI1 to BSU. BSK1 and CDG1 were both found to be plasma membrane-associated, probably due to $\mathrm{N}$-myristoylation and palmitoylation, respectively (Tang et al., 2008; Kim et al., 2011). bsk1 and $c d g 1$ mutant plants showed only subtle phenotypes indicating alterations in BR- 
signalling (Kim et al., 2011; Shi et al., 2013a). This could be explained by the fact that both proteins have homologs in Arabidopsis which show a redundant function in BR-signalling (Tang et al., 2008; Kim et al., 2011). Additionally to its role in BR-signalling BSK1 was found to also play a role in FLS2-mediated immunity (see below; Shi et al., 2013a).

\subsubsection{RLCKs in plant immunity}

BSK1 seems to have a dual function in BR-signalling as well as in PTI mediated by FLS2 (Shi et al., 2013b). bsk1-1 was identified in an suppressor screen for enhanced disease resistance 2 (edr2), involved in increased resistance against powdery mildews and connected induced cell death (Shi et al., 2013a). Additionally, bsk1 mutants also showed enhanced susceptibility to virulent and avirulent bacterial and oomycete pathogens. BSK1 was found to play a role in SA accumulation and in FLS2-mediated ROS production triggered by flg22. Elf18-triggered ROS burst was not affected in bsk1 mutants. BSK1 associates with FLS2 already under non-elicited conditions (Shi et al., 2013a). The bsk1 mutant phenotype suggests that similar to BIK1 (see below), BSK1 probably interacts with additional RLKs and therefore is involved in several different defence response pathways (Shi et al., 2013a). Taken together the RLCK BSK1 is not only a major component in BR-signalling but also takes up an important role in PTI.

The RLCK subfamily VII protein BOTRYTIS-INDUCED KINASE1 (BIK1) was initially identified due to its involvement in resistance against necrotrophic fungal pathogens as well as a negative regulatory role in resistance towards a virulent Pst strain (Veronese et al., 2006). On the molecular level, BIK1 was shown to associate with the previously described FLS2/BAK1 and EFR/BAK1 complexes (1.2.1) and is rapidly phosphorylated upon flg22 and elf18 treatment suggesting a role in early flagellin and EF-Tu signalling (Lu et al., 2010). BIK1 is associated with FLS2 under unstimulated conditions forming a constitutive complex (Zhang et al., 2010). Upon flg22 perception FLS2 is activated and heterodimerizes with BAK1. Activated FLS2 and BAK1 phosphorylate the FLS2-associated RLCK BIK1, which also transphosphorylates the two LRR-RLKs FLS2 and BAK1 (Lu et al., 2010). BIK1 then dissociates from the FLS2/BAK1 complex to positively regulate PTI signalling. BIK1 is not only important for FSL2-dependent immune signalling, but was also shown to associate with the RLKs EFR, CERK1 and PEPR1 (Lu et al., 2010; Zhang et al., 2010). Recent studies showed that BIK1 directly phosphorylates the NADPH oxidase AtRBOHD (Arabidopsis thaliana RESPIRATORY 
BURST OXIDASE HOMOLOG,D), the main component involved in production of apoplastic ROS in PTI upon flg22 perception (Nühse et al., 2007; Kadota et al., 2014). Phosphorylation of AtRBOHD and the associated ROS burst were shown to be important for initiation of further downstream immune responses (Kadota et al., 2014).

Besides BIK1 also other closely related members of the RLCK subfamily VII were identified to be involved in PTI (Zhang et al., 2010). PBS1 (AVRPPHB SUSCEPTIBLE1) and several related PBL (PBS1-like) proteins were found to contribute to flg22-, elf18-, chitin- and Pep1-induced immune responses (Lu et al., 2010; Zhang et al., 2010). BIK1, PBS1 and several members of the PBL family are targeted and cleaved by the Pseudomonas syringae effector AvrPphB in order to overcome PTI (Zhang et al., 2010). The proteolytic cleavage of PBS1 seems to be recognized by its guard R-protein RPS5 which subsequently leads to ETI (Shao et al., 2003). Similar to BIK1, PBS1 and two PBLs associate with the inactive FLS2 and dissociate upon flg22-induced phosphorylation of FLS2 regulating downstream flg22-induced ROS production (Zhang et al., 2010). Whereas, ROS burst mediated by PEPR1 and PEPR2 seems to depend only on BIK1 and PBL1 (Liu et al., 2013). Although BIK1, PBS1 and PBL proteins are closely related, selectively only BIK1 and PBL1 were shown to be involved in regulating calcium influx during MAMP and DAMP associated PTI. Moreover, the RLCKs regulate overlapping but also distinct downstream calcium responses. Only pbl1 mutants showed arrested root growth in flg22-induced root growth assays (Ranf et al., 2014). Additionally, the CALCIUMDEPENDET PROTEIN KINASE28 (CPK28) which constitutes a negative regulator of PTI was shown to associate with and phosphorylate BIK1. CPK28 is suggested to reciprocal regulate BIK1 turnover. Presumably, the constitutive turnover of BIK1 is important for maintaining cellular immune homeostasis indicating that BIK1 could have a rate-limiting function in PTI signalling (Monaghan et al., 2014).

BIK1 has already been shown to constitute a target of the Xanthomonas campestris pv. campestris (Xcc) effector AvrAC/XopAC, which inhibits BIK1 function through uridylylation and thereby interferes with BIK1-mediated PTI signalling in mesophyll cells (Feng et al., 2012). AvrAC seems to be specifically recognized in vascular tissues leading to ETI (Xu et al., 2008). Interestingly, also other BIK1-related RLCKs were suggested to interact with AvrAC. Recent findings suggest that the BIK1 paralog PBL2 functions as AvrAC decoy. Similar to BIK1, PBL2 is uridylylated by AvrAC which leads to the initiation of ETI in vascular tissues (Guy et 
al., 2013; Wang et al., 2015). However, PBL2 is not involved in AvrAC-mediated virulence required for PTI. Uridylylated PBL2 associates with the NLR protein HOPZ-ACTIVATED RESISTANCE1 (ZAR1) and the RLCK family XII pseudokinase RESISTANCE RELATED KINASE1 (RKS1), which activates ETI (Wang et al., 2015). This also supports the findings described before for redundant and selective functions of BIK1 and related RLCKs (Zhang et al., 2010; Lu et al., 2010; Ranf et al., 2014).

So far, mainly RLCKs involved in signalling mediated by LRR-RLKs involved in the perception of peptide elicitors were identified. Two examples for RLCKs have been reported to be involved in chitin and PGN signalling in rice (Yamaguchi et al., 2013; Ao et al., 2014). OsRLCK185, target of the Xanthomonas oryzae effector Xoo1488, was shown to directly interact with OSCERK1 at the plasma membrane and to constitute a phosphorylation substrate of the same. The RLCK subfamily VII protein (Shiu et al., 2004) OsRLCK185 forms a heterodimer with OsCERK1 under non-elicited conditions. Upon chitin perception OsCEBiP, the major chitin receptor in rice, associates with OSCERK1 which gets activated and subsequently phosphorylates OsRLCK185 leading to dissociation of the RLCK probably in order to activate downstream immune responses (Yamaguchi et al., 2013). Phosphorylation of OSRLCK185 by OSCERK1 was shown to be suppressed by Xoo1488 inhibiting MAPK activation. Mutants silenced for OsRLCK185 were impaired for chitin- and PGN-induced immune responses like MAPK activation and defence-gene expression (Yamaguchi et al., 2013). OsRLCK185 seems to be involved in downstream chitin- and PGN-induced immunity mediated by OsCERK1.

An additional member of the RLCK subfamily VII, OsRLCK176, was identified due to its in vivo interaction with OsCERK1 (Shiu et al., 2004; Ao et al., 2014). Similar to OsRLCK185 and OSCERK1, the association between OsRLCK176 and OsCERK1 was also reduced upon chitin and PGN treatment. OsRLCK176-silenced rice plants were impaired in chitin- and PGNinduced ROS production, MAPK activation and defence gene expression (Ao et al., 2014). These findings suggest that OsRLCK176 functions a positive regulator in OsCERK1-mediated chitin-and PGN-induced immunity together with OsRLCK185.

Recently, the RLCK PBL27 involved in CERK1-mediated chitin signalling was identified due to its homology to the rice OsRLCK185 (Shinya et al., 2014). PBL27 belongs to the RLCK VII subfamily, similar to BIK1, PBS1 and PBL RLCKs mentioned above (Shiu et al., 2004). 
Resembling the situation in rice, PBL27 was shown to interact with CERK1 at the plasma membrane. pb/27 mutant plants were impaired in chitin-triggered callose deposition, MITOGEN-ACTIVATED PROTEIN KINASE3 (MPK3) and MPK6 activation and expression of defence-related genes. Interestingly, the chitin-induced generation of ROS was not influenced in these mutant plants. pb/27 mutants were specifically impaired in chitininduced immune responses, since flagellin signalling was not affected in these mutants. Furthermore, PBL27 was specifically phosphorylated by CERK1 but not by BAK1 or FLS2 in vitro (Shinya et al., 2014). The pbl27 mutant plants exhibited a decreased resistance against the fungal pathogen Alternaria brassicicola. Additionally, pb/27 plants were also impaired in resistance against the bacterial pathogen Pst DC3000 hrcC suggesting that PBL27 plays a role in signal transduction of a bacterial MAMPs (Shinya et al., 2014).

Taken together, these studies demonstrate that different RLCKs act in specific MAMPinduced signalling pathways, although some RLCKs also exhibit overlapping functions. Interestingly, RLCKs often constitute targets of effector proteins, emphasizing their important role in plant innate immunity. 


\subsection{Aim of thesis}

The formation of receptor complexes has been shown to be a common mechanism in plant innate immunity (1.2 and 1.3). These signalling complexes typically consist of an RLK or RLP that mediates ligand binding and associates with an RLK-type co-receptor. At least one of the receptor components needs to contain an enzymatically active kinase domain for phosphorylation and activation of the receptor complex and subsequent transduction of the perceived signal to downstream components. Activated receptor complexes then transmit the signal to RLCKs which target further downstream components involved in immune signalling and defence. RLCKs have been shown to be involved in immune signalling pathways mediated by different PRRs (Lin et al., 2013). While a considerable number of studies have been conducted on RLCKs that act downstream of receptor complexes involved in peptide MAMP perception, the RLCKs in chitin signalling are less well characterized.

Recently, the RLCK OsRLCK185 was shown to act downstream of the chitin receptor in rice (Yamaguchi et al., 2013) and its homolog PBL27 performs a similar role in Arabidopsis (Shinya et al., 2014). However, the exact mechanisms of chitin receptor formation and immune signalling have not yet been clarified and many questions still remain open.

To add more information to a putative CERK1 receptor complex and potential signalling partners of CERK1, a yeast two-hybrid screen was initiated in context of this study. In this screen the RLCK CLR1 was identified as a putative interactor of the CERK1 kinase domain. The main aim of this project was to characterize CLR1 and study its role in chitin signalling. First, clr1 T-DNA insertion mutants were isolated and analysed for their contribution in CERK1-mediated chitin signalling. Therefore, chitin-induced phosphorylation of CERK1 as well as ROS production, the activation of MAPKs and the induction of MAMP-induced genes were analysed in these lines. Furthermore, a possible involvement of CLR1 in CERK1dependent resistance against fungal and bacterial pathogens should be investigated.

Since CERK1 is an active kinase, one of the aims was to investigate if the interaction between CERK1 and CLR1 leads to phosphorylation of CLR1. To do so, epitope-tagged versions of CLR1 and the kinase domain of CERK1 were expressed in E. coli, purified and used in in vitro phosphorylation assays. To investigate the phosphorylation of CLR1 by CERK1 in planta, transgenic plants expressing tagged versions of CLR1 should be generated and further used 
for biochemical analysis of CLR1 in the wild type and cerk1-2 knockout background in presence and absence of chitin and other MAMPs.

For cell biological studies, CLR1 fusion proteins with different fluorescent tags were generated and CLR1 subcellular localization could be investigated after transient expression in $N$. benthamiana as well as in stably transformed Arabidopsis plants.

According to the TAIR10 prediction the CLR1 protein harbours an N-myristoylation motif that is not at the $\mathrm{N}$-terminus. Therefore, it was tested if the predicted start codon represents the real start of the protein. This could be achieved by fusing the two possible versions of the coding sequence to the Ubiquitin10 promoter and comparing the resulting proteins to the CLR1 protein expressed from the native promoter. To enable comparison of the CLR1 protein variants with regard to size, subcellular localisation and biochemical properties, the coding sequences were fused to fluorescence tags. 


\section{Materials and Methods}

The following chapter describes organisms, chemicals and materials, as well as methods used in this work.

\subsection{Materials}

\subsubsection{Plants}

\subsubsection{Arabidopsis thaliana}

The Arabidopsis (L.) Heynh. ecotype Columbia-0 (Col-0) was used as wild type plant line (J. Dangl, University of North Carolina, USA). Novel T-DNA insertion lines from the SALK collection (Alonso et al., 2003) were obtained from the Nottingham Arabidopsis Stock Center (NASC). T-DNA insertion lines from the GABI collection were ordered from GABI-KAT (Kleinboelting et al., 2012). For published mutants used in this work, the references are given in Table 1.

Table 1. Mutant Arabidopsis lines used in this study.

\begin{tabular}{|c|c|c|c|c|}
\hline \multirow[t]{2}{*}{ Genotype } & AGI locus & Accession & T-DNA/mutagen & Reference/ Source \\
\hline & \multicolumn{4}{|l|}{ identifier } \\
\hline cerk1-2 & At3g21630 & Col-0 & GABI_096F09 & Miya et al., 2007 \\
\hline clr1-1 & At3g57120 & Col-0 & SALK_102100 & NASC \\
\hline clr1-3 & At3g57120 & Col-0 & GABI_267B04 & GABI-KAT \\
\hline clr1-4 & At3g57120 & Col-0 & GABI_416D04 & GABI-KAT \\
\hline edr1 & At1g08720 & Col-0 & $\gamma$-irradiation & Frye and Innes, 1998 \\
\hline eds1-2 & At3g48090 & Col-0 & fast neutron & Bartsch et al., 2006 \\
\hline mpk3 DG & At3g45640 & Col-0 & fast neutron & Miles et al., 2005 \\
\hline \multirow{4}{*}{$\begin{array}{l}\text { pbl27-1 } \\
\text { pen2 pad4 sag101 }\end{array}$} & At5g18610 & Col-0 & GABI_001C07 & GABI-KAT \\
\hline & At2g44490/ & Col-0 & EMS/ & Lipka et al., 2005 \\
\hline & At3g52430/ & & transposon & \\
\hline & At5g14930 & & & \\
\hline pen2-2 & At2g44490 & Col-0 & GK-134C04 & Lipka et al., 2005 \\
\hline snc1 & At4g16890 & Col-0 & EMS & Li et al., 2001 \\
\hline
\end{tabular}

\subsubsection{Nicotiana benthamiana}

$N$. benthamiana seeds originally obtained from T. Romeis (Biochemistry of Plants, Institute of Biology, Freie Universität Berlin) were used for propagation of plants used for transient expression mediated by Agrobacterium tumefaciens. 


\subsubsection{Pathogens}

\subsubsection{Fungal pathogens}

\subsection{Powdery mildews}

The adapted and the non-adapted filamentous powdery mildews Golovinomyces orontii and Erysiphe pisi, respectively, were used for inoculation experiments of Arabidopsis plants. Both pathogens were originally obtained from the Max-Planck-Institute for Plant Breeding Research, Cologne, Germany).

\subsection{Botrytis cinerea}

The B. cinerea strain B05.10 (A. Sharon, Tel Aviv University, Israel) was used for inoculation experiments of Arabidopsis plants.

\subsubsection{Bacterial pathogens}

Different isolates of the Pseudomonas syringae pv. tomato (Pst) strain DC3000 were used for infections of Arabidopsis plants.

Table 2. Pseudomonas strains and their respective antibiotic resistance used in this study.

\begin{tabular}{|c|c|c|}
\hline Pseudomonas strain & Antibiotic resistance & References \\
\hline Pst DC3000 (-) & Kan, Rif & Buell et al., 2003 \\
\hline Pst DC3000 (hrcC) & Kan & Deng et al., 1998 \\
\hline 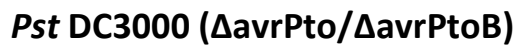 & Kan, Rif & Lin and Martin, 2005 \\
\hline
\end{tabular}

Kan: Kanamycin; Rif: Rifampicin

\subsubsection{Bacterial strains for cloning and transformation}

\subsubsection{Escherichia coli}

Chemically competent $E$. coli TOP10 cells (F- mcrA $\Delta$ (mrr-hsdRMS-mcrBC) Ф80lacZ $\Delta$ M15 $\Delta$ lacX74 deoR recA1 araD139 $\Delta$ (ara-leu)7697 galU galK rpsL (StrR) endA1 nupG) were used for cloning and amplification of plasmids (Invitrogen ${ }^{\mathrm{TM}}$, Life Technologies $\mathrm{GmbH}$, Darmstadt, Germany).

\subsubsection{Agrobacterium tumefaciens}

The A. tumefaciens strain GV3101 (Koncz and Schell, 1986) was used for transient expression in $N$. benthamiana leaves and stable transformation of $A$. thaliana plants. One of the strains used in this study possesses the helper plasmid PMP90RK, which confers resistance to 
kanamycin (Koncz and Schell, 1986). The other strain used in this work contains the helper plasmid pSoup, which confers resistance to tetracycline (Hellens et al., 2000). The bacterial genome itself additionally contains resistances against gentamycin and rifampicin.

\subsubsection{Fungal strain for cloning and transformation}

\subsubsection{Saccharomyces cerevisiae}

S. cerevisiae cells of the S288C-derived haploid BY4741 strain (MATa his3 $\triangle 1$ leu2 $\Delta 0$ met15 $\Delta 0$ ura3 $\triangle 0$; Brachmann et al., 1998) were used for heterologous recombination of DNA fragments used for cloning.

\subsubsection{Vectors}

The following table contains vectors used or generated during this work, as well as their description and antibiotic resistance. Cloning was performed according to the manufacturer's instructions using the Gateway ${ }^{\circledR}$ System (Invitrogen ${ }^{\mathrm{TM}}$, Life Technologies GmbH, Darmstadt, Germany).

Table 3. Vectors used in this study.

\begin{tabular}{|c|c|c|c|}
\hline Nomenclature & Description & Resistance & Reference/ source \\
\hline pENTR $^{\text {TM }} /$ D-TOPO $^{\circledR}$ & $\begin{array}{l}\text { Entry vector of the Gateway }{ }^{\circledR} \\
\text { System for TOPO }{ }^{\circledR} \text { Cloning of blunt- } \\
\text { end PCR products. }\end{array}$ & Kan & Invitrogen $^{\mathrm{TM}}$ \\
\hline $\begin{array}{l}\text { pGWB643; no } \\
\text { promoter, C-eCFP }\end{array}$ & $\begin{array}{l}\text { Binary } \text { Gateway }^{\circledR} \text { destination } \\
\text { vector for expression of fusion } \\
\text { proteins with a C-terminal eCFP-tag } \\
\text { under control of the endogenous } \\
\text { promoter. }\end{array}$ & $\begin{array}{l}\text { Bacterial } \\
\text { selection: Spc } \\
\text { Plant marker: } \\
\text { Basta }^{\circledR}\end{array}$ & $\begin{array}{l}\text { Nakamura et al., } \\
2010\end{array}$ \\
\hline pUBC-GFP & $\begin{array}{l}\text { Binary Gateway }{ }^{\circledast} \text { destination } \\
\text { vector for expression of fusion } \\
\text { proteins with a C-terminal GFP-tag } \\
\text { under control of the Ubiquitin10 } \\
\text { promoter. }\end{array}$ & $\begin{array}{l}\text { Bacterial } \\
\text { selection: Spc } \\
\text { Plant marker: } \\
\text { Basta }^{\circledR}\end{array}$ & Grefen et al., 2010 \\
\hline $\begin{array}{l}\text { pGWB604; no } \\
\text { promoter, C-sGFP }\end{array}$ & $\begin{array}{l}\text { Binary Gateway }{ }^{\circledast} \text { destination } \\
\text { vector for expression of fusion } \\
\text { proteins with a C-terminal sGFP-tag } \\
\text { under control of the endogenous } \\
\text { promoter. }\end{array}$ & $\begin{array}{l}\text { Bacterial } \\
\text { selection: Spc } \\
\text { Plant marker: } \\
\text { Basta }^{\circledR}\end{array}$ & $\begin{array}{l}\text { Nakamura et al., } \\
2010\end{array}$ \\
\hline $\begin{array}{l}\text { pGWB643- } \\
\text { pCLR1::CLR1-eCFP }\end{array}$ & $\begin{array}{l}\text { Binary Gateway }{ }^{\circledR} \text { vector for } \\
\text { expression of the CLR1 gDNA with } \\
\text { a C-terminal eCFP-tag under } \\
\text { control of } p C L R 1 \text {. }\end{array}$ & $\begin{array}{l}\text { Bacterial } \\
\text { selection: Spc } \\
\text { Plant marker: } \\
\text { Basta }^{\circledR}\end{array}$ & This work \\
\hline
\end{tabular}




\begin{tabular}{|c|c|c|c|}
\hline $\begin{array}{l}\text { pUBC-GFP- } \\
\text { pUBQ10::CLR1-M }{ }^{-} \\
\text {GFP }\end{array}$ & $\begin{array}{l}\text { Binary Gateway }{ }^{\circledast} \text { vector for } \\
\text { expression of the CLR1-M } M_{1} \text { gDNA } \\
\text { with a C-terminal GFP-tag under } \\
\text { the Ubiquitin10 promoter. }\end{array}$ & $\begin{array}{l}\text { Bacterial } \\
\text { selection: } \\
\text { Plant marker: } \\
\text { Basta }^{\circledR}\end{array}$ & This work \\
\hline $\begin{array}{l}\text { pUBC-GFP- } \\
\text { pUBQ10::CLR1-M } \\
\text { GFP }\end{array}$ & $\begin{array}{l}\text { Binary Gateway }{ }^{\circledast} \text { vector for } \\
\text { expression of the CLR1-M } \\
\text { with a C-terminal GFP-tag under } \\
\text { the Ubiquitin10 promoter. }\end{array}$ & $\begin{array}{l}\text { Bacterial } \\
\text { selection: } \\
\text { Plant marker: } \\
\text { Basta }^{\circledR}\end{array}$ & This work \\
\hline $\begin{array}{l}\text { pGWB604- } \\
\text { pCLR1::CLR1-sGFP }\end{array}$ & $\begin{array}{l}\text { Binary Gateway }{ }^{\circledR} \text { vector for } \\
\text { expression of the CLR1 gDNA with } \\
\text { a C-terminal SGFP-tag under } \\
\text { control of } p C L R 1 \text {. }\end{array}$ & $\begin{array}{ll}\text { Bacterial } & \\
\text { selection: } & \text { Spc } \\
\text { Plant } \quad \text { marker: } \\
\text { Basta }^{\circledR}\end{array}$ & This work \\
\hline $\begin{array}{l}\text { pGreenll-0229- } \\
\text { pCLR1::CLR1-GFP }\end{array}$ & $\begin{array}{l}\text { Vector for expression of the CLR1 } \\
\text { gDNA with a C-terminal GFP-tag } \\
\text { under the endogenous promoter. } \\
\text { Generated by homologous } \\
\text { recombination of the N-terminal } \\
\text { part of pCLR1::CLR1-sGFP and the } \\
\text { C-terminal part of pUBQ10::CLR1- } \\
\mathrm{M}_{1} \text {-GFP. }\end{array}$ & $\begin{array}{l}\text { Bacterial } \\
\text { selection: Spc } \\
\text { Plant marker: } \\
\text { Basta }^{\circledR}\end{array}$ & This work \\
\hline $\begin{array}{l}\text { pGWB633; no } \\
\text { promoter, no tag }\end{array}$ & $\begin{array}{l}\text { Binary Gateway }{ }^{\circledast} \text { destination } \\
\text { vector for expression of uidA, the } \\
\text { gene encoding for } \beta \text {-glucuronidase } \\
\text { (GUS), under control of the } \\
\text { promoter if interest. }\end{array}$ & $\begin{array}{l}\text { Bacterial } \\
\text { selection: Spc } \\
\text { Plant marker: } \\
\text { Basta }^{\circledR}\end{array}$ & $\begin{array}{l}\text { Nakamura et al., } \\
2010\end{array}$ \\
\hline $\begin{array}{l}\text { pGWB633- } \\
\text { pCLR1::GUS }\end{array}$ & $\begin{array}{l}\text { Binary Gateway }{ }^{\circledR} \text { vector for } \\
\text { expression of uidA, the gene } \\
\text { encoding for } \beta \text {-glucuronidase } \\
\text { (GUS), under control of the } 1000 \\
\text { bp-long putative CLR1 promoter. }\end{array}$ & $\begin{array}{l}\text { Bacterial } \\
\text { selection: Spc } \\
\text { Plant marker: } \\
\text { Basta }^{\circledR}\end{array}$ & This work \\
\hline pHG22_pGH215 & $\begin{array}{l}\text { Vector expressing free GFP under } \\
\text { the maize Ubiquitin1 promoter. }\end{array}$ & Hyg & $\begin{array}{lr}\text { H. } & \text { Ghareeb } \\
\text { (University } & \text { of } \\
\text { Göttingen) } & \\
\end{array}$ \\
\hline
\end{tabular}

Spec: Spectinomycin; Kan: Kanamycin; Hyg: Hygromycin; Basta ${ }^{\circledR}$ : Glufosinate ammonium/

Phosphinothricin (PPT) 


\subsubsection{Oligonucleotides}

Primers used in this work where synthesized by Invitrogen ${ }^{\mathrm{TM}}$. The lyophilised oligonucleotides were dissolved in ultrapure $\mathrm{H}_{2} \mathrm{O}$ to a concentration of $100 \mu \mathrm{M}$. These stocks were further diluted to ready-to-use $10 \mu \mathrm{M}$ aliquots. The oligonucleotides were stored at -20 ${ }^{\circ} \mathrm{C}$.

Table 4. List of oligonucleotides used in this work. Start codons are highlighted in red. The CACC sequences for PENTR $^{\mathrm{TM}} / \mathrm{D}$-TOPO ${ }^{\circledR}$ cloning are marked in blue.

\begin{tabular}{|c|c|c|c|}
\hline \multirow{2}{*}{\multicolumn{3}{|c|}{$\begin{array}{l}\text { Nomenclature Sequence } 5^{\prime} \rightarrow 3^{\prime} \\
\text { Primers for genotyping and expression analyses }\end{array}$}} & \multirow[t]{2}{*}{ Description } \\
\hline & & & \\
\hline UU41 & & CCCATTTGGACGTGAATGTAGACAC & $\begin{array}{l}\text { Left border primer for GABI-KAT T-DNA } \\
\text { lines }\end{array}$ \\
\hline EP64 & & ATTTTGCCGATTTCGGAAC & Left border primer for SALK T-DNA lines \\
\hline YZ01 & $\mathrm{RP}$ & TAAAACCGTCATAAAGCGGTG & $\begin{array}{l}\text { Genotyping of SALK_102100 (clr1-1, } \\
\text { At3g57120) }\end{array}$ \\
\hline YZ02 & LP & CGATCTCTAAGCTCATCCGTG & $\begin{array}{l}\text { For genotyping SALK_102100 (clr1-1, } \\
\text { At3g57120) and GABI_416D04 (c/r1-4, } \\
\text { At3g57120) }\end{array}$ \\
\hline EP128 & $\mathrm{RP}$ & GCCGTCTGATGTCTGATCTTC & $\begin{array}{l}\text { For genotyping GABI_416D04 (clr1-4, } \\
\text { At3g57120) and semi-quantitative RT- } \\
\text { PCR on At3g57120 }\end{array}$ \\
\hline YZ35 & LP & CACCATGGGAGTCAATGCTTCAG & $\begin{array}{l}\text { For genotyping GABI_267B04 (clr1-3, } \\
\text { At3g57120) and semi-quantitative RT- } \\
\text { PCR on At3g57120 }\end{array}$ \\
\hline YZ36 & $\mathrm{RP}$ & TCTGGGAGCGAAAGAGACG & $\begin{array}{l}\text { For genotyping GABI_267B04 (clr1-3, } \\
\text { At3g57120) and semi-quantitative RT- } \\
\text { PCR on At3g57120 }\end{array}$ \\
\hline YZ127 & LP & TCATGCAGATACTCCAGTCCC & $\begin{array}{l}\text { For genotyping GABI_001C07 (pb/27-1; } \\
\text { At5g18610) }\end{array}$ \\
\hline YZ128 & $\mathrm{RP}$ & GATCTGATGTGTTTTGGGAGG & $\begin{array}{l}\text { For genotyping GABI_001C07 ( } p b / 27-1 ; \\
\text { At5g18610) }\end{array}$ \\
\hline YZ156 & & ATCGGATGTTTACGCTTTCG & Semi-quantitative RT-PCR on At3g57120 \\
\hline EP127 & & CGATCTCTAAGCTCATCCGTG & Semi-quantitative RT-PCR on At3g57120 \\
\hline Act fwd & & TGCGACAATGGAACTGGAATG & Semi-quantitative RT-PCR on Actin1 \\
\hline Act rev & & GGATAGCATGTGGAAGTGCATAC & Semi-quantitative RT-PCR on Actin1 \\
\hline \multicolumn{4}{|c|}{ Primers for cloning } \\
\hline YZ33 & & CACCGGTGTCACACTGCTTGTAGTTG & $\begin{array}{l}\text { Fwd. primer for amplification of } \\
\text { gAt3g57120 (CLR1) with } 1000 \text { bp } \\
\text { promoter sequence from Col-0 for } \\
\text { cloning into pENTR }{ }^{\text {TM }} \text { / D-TOPO }{ }^{\circledR}\end{array}$ \\
\hline YZ34 & & CACCATGTCTGATCTTCTAGG & $\begin{array}{l}\text { Fwd. primer for amplification of } \\
\text { gAt3g57120 (CLR1-M } 1 \text { ) from Col-0 for }\end{array}$ \\
\hline
\end{tabular}




\begin{tabular}{|c|c|c|}
\hline & & cloning into $\mathrm{pENTR}{ }^{\mathrm{TM}} / \mathrm{D}-\mathrm{TOPO}^{\circledR}$ \\
\hline YZ35 & CACCATGGGAGTCAATGCTTCAG & $\begin{array}{l}\text { Fwd. primer for amplification of } \\
\text { gAt3g57120 }\left(C L R 1-M_{2}\right) \text { from Col-0 for } \\
\text { cloning into } \text { pENTR }^{T M} / \text { D-TOPO }{ }^{\circledR}\end{array}$ \\
\hline YZ36 & TCTGGGAGCGAAAGAGACG & $\begin{array}{l}\text { Rev. primer for amplification of } \\
\text { gAt3g57120 without stop codon for } \\
\text { cloning into } \mathrm{pENTR}{ }^{\mathrm{TM}} / \mathrm{D}^{\mathrm{TOPO}}{ }^{\circledR}\end{array}$ \\
\hline YZ109 & CAGACGGCGAAGAGAGGCTGAG & $\begin{array}{l}\text { Rev. primer for amplification of } \\
\text { At3g57120 promoter sequence for } \\
\text { cloning into } \text { EENTR }^{\mathrm{TM}} / \text { D-TOPO }^{\circledR}\end{array}$ \\
\hline YZ122 & TTGATGTGATTGTGAACTAGGTTTTC & $\begin{array}{l}\text { Rev. primer for amplification of } p U B Q 10 \\
\text { and N-terminal } C L R 1 \text { fragment }\end{array}$ \\
\hline YZ123 & $\begin{array}{l}\text { GATCGAAAACCTAGTTCACAATCACATCAA } \\
\text { GAGCTCGGCGGTGATCGTGACGGAGCCAG }\end{array}$ & $\begin{array}{l}\text { Fwd. primer to amplify C-terminal CLR1 } \\
\text { fragment and GFP tag; adding overhang } \\
\text { to } \mathrm{YZ122} \text { sequence }\end{array}$ \\
\hline YZ124 & $\begin{array}{l}\text { GCGGATAACAATTTCACACAGGAAACAGCC } \\
\text { CCGGGTTATAACTTGTACAGCTCGTCCATGC } \\
\text { CGAGAGTG }\end{array}$ & $\begin{array}{l}\text { Rev. primer to amplify C-terminal CLR1 } \\
\text { fragment and GFP tag; adding Smal } \\
\text { restriction site and pRS426 overhang }\end{array}$ \\
\hline YZ125 & $\begin{array}{l}\text { GTAACGCCAGGGTTTCCCAGTCACGACGG } \\
\text { GTACCGGTGTCACACTGCTTGTAGTTGTAAT } \\
\text { TTTTAATG }\end{array}$ & $\begin{array}{l}\text { Fwd. primer to amplify } p C L R 1 \text { and } \mathrm{N}- \\
\text { terminal } C L R 1 \text { fragment; adding } p R S 426 \\
\text { overhang and } K p n / \text { restriction site }\end{array}$ \\
\hline \multicolumn{3}{|c|}{ Primers used for colony PCR or sequencing } \\
\hline Lac25 & CAGTCACGACGTTGTAAAACGACGG & $\begin{array}{l}\text { pENTR }^{\mathrm{TM}} / \mathrm{D}-\mathrm{TOPO}^{\circledR} \text { sequencing and } \\
\text { colony PCR }\end{array}$ \\
\hline Lac26 & CAGTCACGACGTTGTAAAACGACGG & $\begin{array}{l}\text { pENTR }{ }^{\mathrm{TM}} / \mathrm{D}-\mathrm{TOPO}^{\circledR} \text { sequencing and } \\
\text { colony PCR }\end{array}$ \\
\hline MW6 & GTAAAACGACGGCCAG & $\begin{array}{l}\text { pENTR }{ }^{\mathrm{TM}} / \mathrm{D}-\mathrm{TOPO}^{\circledR} \text { sequencing and } \\
\text { colony PCR }\end{array}$ \\
\hline MK5 & CGATTTTCTGGGTTTGATCG & Sequencing and colony PCR on $p U B Q 10$ \\
\hline UL205 & TGATTATTGACCCACACTTTGC & Sequencing and colony PCR on GUS \\
\hline JE4 & $\begin{array}{l}\text { GGAATTCCCGGGGAGACGATCTCCGTCAAC } \\
\text { GAGCAAC }\end{array}$ & Sequencing $C L R 1$ fusion constructs \\
\hline EP156 & AGCTTGCCGTAGGTGGCATC & Sequencing and colony PCR on GFP \\
\hline EP164 & GACTGGTGATTTTTGCGGACTC & Sequencing and colony PCR on $t 35 S$ \\
\hline 35SGC248 & GACGCACAATCCCACTATCCTTCG & Sequencing and colony PCR on $p 35 S$ \\
\hline YZ01 & TAAAACCGTCATAAAGCGGTG & Colony PCR and sequencing of CLR1 \\
\hline YZO3 & TGCTTTCTCATCCGTTTATCG & Colony PCR and sequencing of CLR1 \\
\hline YZ04 & CGATCTCTAAGCTCATCCGTG & Colony PCR and sequencing of CLR1 \\
\hline YZ35 & CACCATGGGAGTCAATGCTTCAG & For sequencing $C L R 1$ \\
\hline YZ36 & TCTGGGAGCGAAAGAGACG & For sequencing $C L R 1$ \\
\hline YZ56 & GGGATCGCAGTGGTGAGTAAC & For sequencing $C L R 1$ \\
\hline YZ59 & TAGGCCGGAGATGGGAAGAG & CLR1 sequencing \\
\hline YZ109 & CAGACGGCGAAGAGAGGCTGAG & $p C L R 1$ sequencing \\
\hline
\end{tabular}




\begin{tabular}{|c|c|c|c|}
\hline \multicolumn{4}{|c|}{ Primers used for qRT-PCR } \\
\hline YZ149 & ACACCGCATCAAGAAACCGA & \multirow{2}{*}{ qRT-PCR on At3g43250 } & \\
\hline YZ150 & TACCACATGTGTTGCAGCGA & & \\
\hline YZ153 & AGGTCACCTCCACAAATTCG & \multirow{2}{*}{ qRT-PCR on At3g57120 } & \\
\hline YZ154 & TTGACTTGGTCGCGATCGTG & & \\
\hline YZ155 & GGCGTTGCAATTTAAGAGGG & \multirow{2}{*}{ qRT-PCR on At3g57120 } & \\
\hline YZ02 & CGATCTCTAAGCTCATCCGTG & & \\
\hline YZ156 & ATCGGATGTTTACGCTTTCG & \multirow{2}{*}{ qRT-PCR on At3g57120 } & \\
\hline YZ157 & TCCGCTCGAAATCTCCTGTG & & \\
\hline YZ158 & CCGGGTTGTTGGATCCGTTA & \multirow{2}{*}{ qRT-PCR on At4g16820 } & \\
\hline YZ159 & TTCCGGGTCTGAGTGAAACG & & \\
\hline JE73 & GGTCACAACAATCCGGAAGA & \multirow{2}{*}{ qRT-PCR on WRKY33 } & \multirow{6}{*}{ 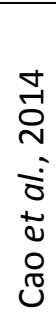 } \\
\hline JE74 & GGAGAGACAAGAGAAGGAGAGA & & \\
\hline JE77 & AGCCAAATTTCCAAGAGGAT & \multirow{2}{*}{ qRT-PCR on WRKY3O } & \\
\hline JE78 & GCAGCTTGAGAGCAAGAATG & & \\
\hline JE79 & TCACCGAGCGTACAACTTATTCC & \multirow{2}{*}{ qRT-PCR on WRKY53 } & \\
\hline JE80 & CGTTTATCGATGCCGGAGATT & & \\
\hline EP223 & GGTTTTCCCCAGTGTTGTTG & \multirow{2}{*}{ qRT-PCR on Actin8 } & \\
\hline EP224 & CTCCATGTCATCCCAGTTGC & & \\
\hline
\end{tabular}

LP: left primer, RP: right primer

\subsubsection{Enzymes}

\subsubsection{Restriction endonucleases}

Restriction endonucleases were obtained either from New England BioLabs (Frankfurt/Main, Germany) or Thermo Scientific ${ }^{\mathrm{TM}}$ (Life Technologies $\mathrm{GmbH}$, Darmstadt, Germany) and used according to the manufacturer's manual.

\subsubsection{Nucleic acid modifying enzymes}

Genotyping and colony PCRs were performed using homemade Taq DNA polymerase. PCR products for further use in cloning were either amplified with iProof ${ }^{\mathrm{TM}}$ High-Fidelity DNA Polymerase (BioRad, München, Germany) or the Phusion ${ }^{\circledR}$ High-Fidelity DNA Polymerase (Finnzymes, Espoo, Finland). The LR recombination reaction using the Gateway ${ }^{\circledR}$ system was performed with the Gateway ${ }^{\circledR}$ LR Clonase $^{\mathrm{TM}}$ enzyme mix (Invitrogen ${ }^{\mathrm{TM}}$, Life Technologies $\mathrm{GmbH}$, Darmstadt, Germany). 


\subsubsection{Chemicals}

Chemicals used in this work were obtained from Sigma-Aldrich (München, Germany), Roth (Karlsruhe, Germany), Merck (Darmstadt, Germany), BioRad (München, Germany), AppliChem (Darmstadt, Germany), Duchefa (Haarlem, Netherlands), VWR (Lutterworth, UK), Serva (Heidelberg, Germany) or Invitrogen ${ }^{\mathrm{TM}}$.

\subsubsection{Antibiotics}

Ampicillin (Amp) $100 \mathrm{mg} / \mathrm{ml}$ in $\mathrm{dd}_{2} \mathrm{O}$

Chloramphenicol (Cam) $34 \mathrm{mg} / \mathrm{ml}$ in ethanol

Carbenicillin (Carb) $50 \mathrm{mg} / \mathrm{ml}$ in $\mathrm{dd}_{2} \mathrm{O}$

Gentamycin (Gent) $15 \mathrm{mg} / \mathrm{ml}$ in $\mathrm{dd}_{2} \mathrm{O}$

Kanamycin (Kan) $50 \mathrm{mg} / \mathrm{ml}$ in dd $\mathrm{H}_{2} \mathrm{O}$

Rifampicin (Rif) $50 \mathrm{mg} / \mathrm{ml}$ in methanol

Spectinomycin (Spc) $100 \mathrm{mg} / \mathrm{ml}$ in $\mathrm{ddH}_{2} \mathrm{O}$

Tetracyclin (Tet) in $5 \mathrm{mg} / \mathrm{ml}$ in ethanol

Phosphinothricin (PPT) $25 \mathrm{mg} / \mathrm{ml}$ in $\mathrm{ddH}_{2} \mathrm{O}$

Aqueous stock solutions were sterile filtrated using filters with a pore size of $0.2 \mu \mathrm{m}$. The stock solutions were stored at $-20^{\circ} \mathrm{C}$ and used in $1: 1000$ dilutions.

\subsubsection{Media}

All media were prepared with deionized water and autoclaved for $20 \mathrm{~min}$ at $121^{\circ} \mathrm{C}$. If not used immediately after autoclaving, the solidified media were liquefied for a few minutes in the microwave. Before adding any additives, the hot media were cooled down to a moderate temperature of about $60^{\circ} \mathrm{C}$. 
Table 5. Media used for cultivation of the different organisms included in this study.

\begin{tabular}{|c|c|}
\hline Medium & Composition \\
\hline \multirow[t]{5}{*}{ Luria-Bertani (LB) medium } & Tryptone \\
\hline & Yeast extract \\
\hline & $5.0 \mathrm{~g} / \mathrm{l}$ \\
\hline & Adjust to $\mathrm{pH} 7.0$ \\
\hline & $\begin{array}{l}\text { For LB agar } 1.5 \%(\mathrm{w} / \mathrm{v}) \text { agar was added to the broth } \\
\text { before autoclaving. }\end{array}$ \\
\hline \multirow[t]{5}{*}{ Double yeast, tryptone (DYT) medium } & Tryptone \\
\hline & Yeast extract \\
\hline & $\mathrm{NaCl} 5 \mathrm{~g} / \mathrm{l}$ \\
\hline & Adjust to $\mathrm{pH} 7.0$. \\
\hline & $\begin{array}{l}\text { For DYT agar } 1.5 \%(\mathrm{w} / \mathrm{v}) \text { agar was added to the broth } \\
\text { before autoclaving. }\end{array}$ \\
\hline \multirow[t]{4}{*}{$1 / 2$ Murashige and Skoog (MS) medium } & MS powder \\
\hline & Sucrose \\
\hline & Adjust to $\mathrm{pH} 5.7(\mathrm{KOH})$. \\
\hline & $\begin{array}{l}\text { For } 1 / 2 \mathrm{MS} \text { agar } 4.5 \mathrm{~g} / \mathrm{l} \text { plant agar were added before } \\
\text { autoclaving. After autoclaving } 100 \mu \mathrm{g} / \mathrm{ml} \text { ampicillin were } \\
\text { added. }\end{array}$ \\
\hline \multirow[t]{5}{*}{ NYG medium } & Peptone \\
\hline & Yeast extract \\
\hline & Glycerol \\
\hline & Adjust to $\mathrm{pH} 7.0$. \\
\hline & $\begin{array}{l}\text { For NYG agar plates } 1.5 \%(\mathrm{w} / \mathrm{v}) \text { agar was added before } \\
\text { autoclaving. }\end{array}$ \\
\hline \multirow[t]{2}{*}{ Potato Dextrose Broth (PDB) } & PDB powder \\
\hline & For PDA $1.5 \%(w / v)$ agar was added before autoclaving. \\
\hline \multirow[t]{4}{*}{ YPD } & Yeast extract \\
\hline & Peptone \\
\hline & Dextrose/glucose \\
\hline & $\begin{array}{l}\text { For YPD agar plates } 1.5 \%(\mathrm{w} / \mathrm{v}) \text { agar was added before } \\
\text { autoclaving. }\end{array}$ \\
\hline \multirow{6}{*}{$\begin{array}{l}\text { Synthetic complete (SC) medium (- Ura } \\
+ \text { Glu) }\end{array}$} & Yeast nitrogen base (YNB) \\
\hline & w/o amino acids \\
\hline & Drop-out base (- Ura) \\
\hline & $40.0 \mathrm{~g} / \mathrm{l}(2 \mathrm{x})$ \\
\hline & $40.0 \mathrm{~g} / \mathrm{l}(2 \mathrm{x})$ \\
\hline & $\begin{array}{l}\text { Prepare glucose solution separate from the remaining } \\
\text { components. Solutions were prepared in } 2 x \\
\text { concentrations because they were mixed after } \\
\text { autoclaving before pouring the plates. }\end{array}$ \\
\hline
\end{tabular}




\subsubsection{Antibodies}

Table 6. List of primary antibodies and the respective secondary antibodies used in this work.

\begin{tabular}{|c|c|c|c|c|c|}
\hline $\begin{array}{l}\text { Primary } \\
\text { Antibody/ } \\
\text { dilution }\end{array}$ & Source & $\begin{array}{l}\text { Reference/ } \\
\text { provider }\end{array}$ & $\begin{array}{l}\text { Secondary } \\
\text { Antibody/ } \\
\text { dilution }\end{array}$ & Source & $\begin{array}{l}\text { Reference/ } \\
\text { provider }\end{array}$ \\
\hline $\begin{array}{l}\alpha G F P / \\
1: 3000\end{array}$ & $\begin{array}{l}\text { Rat, } \\
\text { monoclonal }\end{array}$ & $\begin{array}{l}\text { ChromoTek } \\
\text { GmbH, Planegg- } \\
\text { Martinsried, } \\
\text { Germany }\end{array}$ & $\begin{array}{l}\alpha-\text { rat, AP- } \\
\text { conjugate/ } \\
1: 5000\end{array}$ & $\begin{array}{l}\text { Rabbit, } \\
\text { polyclonal }\end{array}$ & $\begin{array}{l}\text { Sigma-Aldrich } \\
\text { Chemie GmbH, } \\
\text { Taufkirchen, } \\
\text { Germany }\end{array}$ \\
\hline $\begin{array}{l}\text { aCERK1/ } \\
1: 3000\end{array}$ & $\begin{array}{l}\text { Rabbit, } \\
\text { polyclonal }\end{array}$ & $\begin{array}{l}\text { Eurogentec } \\
\text { Deutschland } \\
\text { GmbH, Köln, } \\
\text { Germany }\end{array}$ & $\begin{array}{l}\alpha-\text { rabbit, AP- } \\
\text { conjugate/ } \\
1: 5000\end{array}$ & $\begin{array}{l}\text { Goat, } \\
\text { polyclonal }\end{array}$ & Sigma-Aldrich \\
\hline $\begin{array}{l}\text { apMAPKs } \\
\text { (Phospho- } \\
\text { p44/42 } \\
\text { MAPK)/ } \\
1: 2000\end{array}$ & $\begin{array}{l}\text { Rabbit, } \\
\text { polyclonal }\end{array}$ & $\begin{array}{l}\text { Cell Signaling } \\
\text { Technology, } \\
\text { Danvers, MA, USA }\end{array}$ & $\begin{array}{l}\alpha \text {-rabbit, HRP- } \\
\text { conjugate/ } \\
1: 5000\end{array}$ & $\begin{array}{l}\text { Goat, } \\
\text { polyclonal }\end{array}$ & $\begin{array}{l}\text { Cell Signaling } \\
\text { Technology, } \\
\text { Danvers, MA, } \\
\text { USA }\end{array}$ \\
\hline $\begin{array}{l}\alpha \text { PEPC/ } \\
1: 7500\end{array}$ & $\begin{array}{l}\text { Rabbit, } \\
\text { polyclonal }\end{array}$ & $\begin{array}{l}\text { Rockland } \\
\text { Immunochemicals } \\
\text { Inc., Limerick, PA, } \\
\text { USA }\end{array}$ & $\begin{array}{l}\alpha \text {-rabbit, AP- } \\
\text { conjugate/ } \\
\text { 1:5000 }\end{array}$ & $\begin{array}{l}\text { Goat, } \\
\text { polyclonal }\end{array}$ & Sigma-Aldrich \\
\hline $\begin{array}{l}\text { QBAK1/ } \\
1: 3000\end{array}$ & $\begin{array}{l}\text { Rabbit, } \\
\text { polyclonal }\end{array}$ & $\begin{array}{l}\text { Agrisera } A B, \\
\text { Vännäs, Sweden }\end{array}$ & $\begin{array}{l}\alpha \text {-rabbit, AP- } \\
\text { conjugate/ } \\
1: 5000\end{array}$ & $\begin{array}{l}\text { Goat, } \\
\text { polyclonal }\end{array}$ & Sigma-Aldrich \\
\hline $\begin{array}{l}\alpha G S T / \\
1: 5000\end{array}$ & Mouse & $\begin{array}{l}\text { Sigma-Aldrich } \\
\text { Chemie GmbH, } \\
\text { Taufkirchen, } \\
\text { Germany }\end{array}$ & $\begin{array}{l}\alpha \text {-mouse, AP- } \\
\text { conjugate/ } \\
1: 5000\end{array}$ & $\begin{array}{l}\text { Goat, } \\
\text { polyclonal }\end{array}$ & Sigma-Aldrich \\
\hline $\begin{array}{l}\alpha H \text { His/ } \\
1: 2000\end{array}$ & Mouse & $\begin{array}{l}\text { GeneTex } \\
\text { International } \\
\text { Corporation } \\
\text { (Global), Hsinchu } \\
\text { City, Taiwan, } \\
\text { R.O.C. }\end{array}$ & $\begin{array}{l}\alpha \text {-mouse, AP- } \\
\text { conjugate/ } \\
1: 5000\end{array}$ & $\begin{array}{l}\text { Goat, } \\
\text { polyclonal }\end{array}$ & Sigma-Aldrich \\
\hline
\end{tabular}




\subsubsection{Buffers and solutions}

Buffers and solutions used in this work were sterilized by autoclaving for $20 \mathrm{~min}$ at $121^{\circ} \mathrm{C}$. All buffers and solutions were prepared with ultrapure water. Solutions which were not autoclaved were sterile filtered using filters with a pore size of $0.2 \mu \mathrm{m}$.

Table 7. List of buffers and solutions used in this work.

\begin{tabular}{|c|c|c|}
\hline \multirow{2}{*}{$\begin{array}{l}\text { Buffer/solution } \\
\text { Bacterial infection }\end{array}$} & \multicolumn{2}{|l|}{ Composition } \\
\hline & & \\
\hline \multirow[t]{2}{*}{ Agrobacterium infiltration medium } & $\mathrm{MgCl}_{2}$ & $10 \mathrm{mM}$ \\
\hline & Acetosyringone & $150 \mu \mathrm{M}$ \\
\hline \multirow[t]{2}{*}{ Pseudomonas infiltration medium } & $\mathrm{MgCl}_{2}$ & $5 \mathrm{mM}$ \\
\hline & Silwet L-77 & $0.002 \%$ \\
\hline \multicolumn{3}{|l|}{ GUS staining } \\
\hline \multirow[t]{7}{*}{ Washing solution (1 ml) } & $\begin{array}{l}\text { Na-phosphate buffer, pH } 7.2 \\
{[100 \mathrm{mM}]}\end{array}$ & $500 \mu \mathrm{l}$ \\
\hline & EDTA [500 mM] & $20 \mu \mathrm{l}$ \\
\hline & Ferricyanide $[50 \mathrm{mM}]$ & $10 \mu \mathrm{l}$ \\
\hline & Ferrocyanide [50 mM] & $10 \mu \mathrm{l}$ \\
\hline & Triton X-100 [10\%] & $20 \mu \mathrm{l}$ \\
\hline & $\mathrm{ddH}_{2} \mathrm{O}$ & $440 \mu \mathrm{l}$ \\
\hline & Prepare freshly and keep on $\mathrm{i}$ & ore use \\
\hline \multirow[t]{7}{*}{ Staining solution (1ml) } & $\begin{array}{l}\text { Na-phosphate buffer, pH } 7.2 \\
{[100 \mathrm{mM}]}\end{array}$ & $500 \mu \mathrm{l}$ \\
\hline & EDTA [500 mM] & $20 \mu \mathrm{l}$ \\
\hline & Ferricyanide $[50 \mathrm{mM}]$ & $10 \mu \mathrm{l}$ \\
\hline & Ferrocyanide [50 mM] & $10 \mu \mathrm{l}$ \\
\hline & Triton X-100 [10 \%] & $20 \mu \mathrm{l}$ \\
\hline & $\mathrm{dd} \mathrm{H}_{2} \mathrm{O}$ & $420 \mu \mathrm{l}$ \\
\hline & $\begin{array}{l}\text { Add } 1 \mathrm{mg} \mathrm{X} \text {-Gluc dissolved ir } \\
\text { on ice). Prepare freshly and } \mathrm{k}\end{array}$ & $\begin{array}{l}\text { DMSO (Do not put } \\
\text { ice before use. }\end{array}$ \\
\hline \multicolumn{3}{|l|}{ Kinase buffer (10x) } \\
\hline & Tris, $\mathrm{pH} 7.5$ & $200 \mathrm{mM}$ \\
\hline & Glycerol & $10 \%$ \\
\hline & $\mathrm{MgCl}_{2}$ & $100 \mathrm{mM}$ \\
\hline & $\mathrm{MnCl}_{2}$ & $100 \mathrm{mM}$ \\
\hline & DTT & $100 \mathrm{mM}$ \\
\hline & ATP & $500 \mu \mathrm{M}$ \\
\hline \multicolumn{3}{|l|}{ PCR and agarose gel electrophoresis } \\
\hline \multirow{5}{*}{$\begin{array}{l}\text { Homemade Taq DNA polymerase PCR } \\
\text { reaction buffer }(10 \mathrm{x})\end{array}$} & Tris & $100 \mathrm{mM}$ \\
\hline & $\mathrm{KCl}$ & $500 \mathrm{mM}$ \\
\hline & $\mathrm{MgCl}_{2}$ & $15 \mathrm{mM}$ \\
\hline & Triton $\mathrm{X}-100$ & $1 \%$ \\
\hline & Adjust to $\mathrm{pH} 9.0$ and autoclav & \\
\hline \multirow[t]{3}{*}{ TAE (50x) } & Tris & $242 \mathrm{~g} / \mathrm{l}$ \\
\hline & Glacial acetic acid & $57.1 \mathrm{ml} / \mathrm{l}$ \\
\hline & EDTA [0.5 M; pH 8.0] & $100 \mathrm{ml} / \mathrm{l}$ \\
\hline \multirow[t]{2}{*}{ TE buffer $(1 \mathrm{x})$} & Tris- $\mathrm{HCl}, \mathrm{pH} 8.0$ & $2 \mathrm{M}$ \\
\hline & EDTA & $1 \mathrm{mM}$ \\
\hline
\end{tabular}




\begin{tabular}{|c|c|c|}
\hline DNA loading dye $(6 x)$ & Sucrose & $4 \mathrm{~g}$ \\
\hline & EDTA [0.5 M] & $2 \mathrm{ml}$ \\
\hline & Bromophenol blue & $25 \mathrm{mg}$ \\
\hline & Add $\mathrm{ddH}_{2} \mathrm{O}$ to $10 \mathrm{ml}$. & \\
\hline DNA loading dye, yellow (6x) & Orange $\mathrm{G}$ & $0.25 \%$ \\
\hline & Xylene cyanol & $0.25 \%$ \\
\hline & Glycerol & $30 \%$ \\
\hline & Fill up with dd $\mathrm{H}_{2} \mathrm{O}$. & \\
\hline Plasmid preparation (homem & & \\
\hline Buffer P1 & Tris- $\mathrm{HCl}, \mathrm{pH} 8.0$ & $50 \mathrm{mM}$ \\
\hline & EDTA, pH 8.0 & $10 \mathrm{mM}$ \\
\hline & RNase A (DNase free) & $100 \mu \mathrm{g} / \mathrm{ml}$ \\
\hline & Store at $4^{\circ} \mathrm{C}$ after add & \\
\hline Buffer P2 & $\mathrm{NaOH}$ & $200 \mathrm{mM}$ \\
\hline & SDS & $1 \%$ \\
\hline Buffer P3 & KAc & $3 \mathrm{M}$ \\
\hline & Acetic acid & $2 \mathrm{M}$ \\
\hline Preparation of competent $E$. & & \\
\hline Transformation buffer & PIPES & $10 \mathrm{mM}$ \\
\hline & $\mathrm{CaCl}_{2}$ & $15 \mathrm{mM}$ \\
\hline & $\mathrm{KCl}$ & $250 \mathrm{mM}$ \\
\hline & $\mathrm{MnCl}_{2}$ & $55 \mathrm{mM}$ \\
\hline
\end{tabular}

Dissolve all components except for $\mathrm{MnCl}_{2}$ and adjust to $\mathrm{pH}$ 6.7. Then add $\mathrm{MnCl} 2$ and sterilize by filtration. Store at $4{ }^{\circ} \mathrm{C}$.

\begin{tabular}{|c|c|c|}
\hline \multicolumn{3}{|c|}{ Genomic DNA extraction from plants for PCR } \\
\hline \multirow[t]{4}{*}{ Extraction buffer } & Tris-HCl, $\mathrm{pH} 7.5$ & $0.2 \mathrm{M}$ \\
\hline & $\mathrm{NaCl}$ & $1.25 \mathrm{M}$ \\
\hline & EDTA & $0.025 \mathrm{M}$ \\
\hline & SDS & $0.5 \%$ \\
\hline \multicolumn{3}{|l|}{ ROS burst assay } \\
\hline \multirow[t]{3}{*}{ L-012 solution } & Tris-HCl, pH 9.5 & $10 \mathrm{mM}$ \\
\hline & Horseradish peroxidase (HRP) & $10 \mu \mathrm{g} / \mathrm{ml}$ \\
\hline & L-012 & $100 \mu \mathrm{M}$ \\
\hline \multicolumn{3}{|c|}{ Protein extraction, SDS PAGE and Western blot } \\
\hline \multirow[t]{10}{*}{ CERK1 extraction buffer } & Sucrose & $250 \mathrm{mM}$ \\
\hline & HEPES-KOH, pH 7.5 & $100 \mathrm{mM}$ \\
\hline & Glycerol & $5 \%(v / v)$ \\
\hline & $\mathrm{Na}_{4} \mathrm{P}_{2} \mathrm{O}_{7}$ & $50 \mathrm{mM}$ \\
\hline & $\mathrm{Na}_{2} \mathrm{MoO}_{4}$ & $1 \mathrm{mM}$ \\
\hline & $\mathrm{NaF}$ & $25 \mathrm{mM}$ \\
\hline & EDTA & $10 \mathrm{mM}$ \\
\hline & DTT & $1 \mathrm{mM}$ \\
\hline & Triton $\mathrm{X}-100$ & $0.5 \%(v / v)$ \\
\hline & Before use add PIC (1:100). & \\
\hline \multirow[t]{3}{*}{ Coomassie staining solution } & Methanol & $45 \%$ \\
\hline & Acetic Acid & $10 \%$ \\
\hline & Coomassie R 250 & $0.05 \%$ \\
\hline
\end{tabular}


Destaining solution for polyacrylamide gels

for PVDF membranes

Laemmli (SDS) sample buffer (2x)

SDS loading buffer (loading dye, 4x)

SDS running buffer (10x)

Stacking gel buffer

Resolving gel buffer (8\%)

Resolving gel buffer (10\%)

Resolving gel buffer (12\%)

TBS-T (20x)

Transfer buffer (20x)

Alkaline phosphatase (AP) buffer
Methanol

Glacial acetic acid

Add $\mathrm{H}_{2} \mathrm{O}$

Methanol

Glacial acetic acid

Add $\mathrm{H}_{2} \mathrm{O}$.

Tris-HCl, pH 6.8

SDS

Glycerol

Bromophenol blue

DTT

Tris- $\mathrm{HCl}, \mathrm{pH} 6.8$

DTT

SDS

Glycerol

Bromophenol blue

Tris base

Glycine

SDS

$1 \mathrm{M}$ Tris, $\mathrm{pH} 6.8$

$10 \%$ SDS

$\mathrm{H}_{2} \mathrm{O}$

$1 \mathrm{M}$ Tris, $\mathrm{pH} 8.8$

$10 \%$ SDS

$\mathrm{H}_{2} \mathrm{O}$

$1 \mathrm{M}$ Tris, pH8.8

$10 \%$ SDS

$\mathrm{H}_{2} \mathrm{O}$

$1 \mathrm{M}$ Tris, $\mathrm{pH} 8.8$

$10 \%$ SDS

$\mathrm{H}_{2} \mathrm{O}$

$\mathrm{NaCl}$

Tris- $\mathrm{HCl}, \mathrm{pH} 8.0$

Tween-20

Tris-base

Boric acid

Adjust to $\mathrm{pH}$ 8.3.

Tris, pH 9.5

$\mathrm{NaCl}$

$\mathrm{MgCl}_{2}$
$100 \mathrm{mM}$

$100 \mathrm{mM}$

$25 \%(v / v)$

$7 \%(v / v)$

$45 \%(v / v)$

$10 \%(\mathrm{v} / \mathrm{v})$

$0.125 \mathrm{M}$

$4 \%(\mathrm{w} / \mathrm{v})$

$20 \%(\mathrm{v} / \mathrm{v})$

$0.02 \%(w / v)$

$0.2 \mathrm{M}$

$200 \mathrm{mM}$

$400 \mathrm{mM}$

$8 \%$

$40 \%$

$0.1 \%$

$30.28 \mathrm{~g} / \mathrm{l}$

$144.13 \mathrm{~g} / \mathrm{l}$

$10 \mathrm{~g} / \mathrm{l}$

$38.58 \mathrm{ml}$

$3.06 \mathrm{ml}$

208.24

$130.9 \mathrm{ml}$

$3.46 \mathrm{ml}$

$115.64 \mathrm{ml}$

$143.6 \mathrm{ml}$

$3.79 \mathrm{ml}$

$102.53 \mathrm{ml}$

$160.2 \mathrm{ml}$

$4.24 \mathrm{ml}$

$85.39 \mathrm{ml}$

$3 \mathrm{M}$

$200 \mathrm{mM}$

$1 \%$

$1 \mathrm{M}$

$1 \mathrm{M}$

$50 \mathrm{mM}$ 


\begin{tabular}{|c|c|c|}
\hline \multirow[t]{5}{*}{ Mild washing buffer for pull-downs } & Sucrose & $250 \mathrm{mM}$ \\
\hline & HEPES-KOH, pH 7.5 & $100 \mathrm{mM}$ \\
\hline & Glycerol & $5 \%(v / v)$ \\
\hline & Triton $X-100$ & $0.5 \%(v / v)$ \\
\hline & Before use add PIC (1:100). & \\
\hline \multirow[t]{7}{*}{$\begin{array}{l}\text { Protease inhibitor cocktail (PIC, } 200 \mathrm{ml} \text {, } \\
\text { 100x) }\end{array}$} & $\begin{array}{l}\text { 4-(2-aminoethyl)benzenesulfonyl } \\
\text { fluoride hydrochloride (AEBSF) }\end{array}$ & $1 \mathrm{~g}$ \\
\hline & Bestatin hydrochloride & $5 \mathrm{mg}$ \\
\hline & Pepstatin A & $10 \mathrm{mg}$ \\
\hline & Leupeptin hemisulfate & $100 \mathrm{mg}$ \\
\hline & $\begin{array}{l}\text { E-64 (trans-epoxysuccinyl-L- } \\
\text { leucylamido-(4- } \\
\text { guanidino)butane) }\end{array}$ & $10 \mathrm{mg}$ \\
\hline & $\begin{array}{l}\text { Phenanthroline }(1,10- \\
\text { phenanthroline monohydrate })\end{array}$ & $10 \mathrm{~g}$ \\
\hline & $\begin{array}{l}\text { All components were solved se, } \\
\text { amount of DMSO, before being } \\
\text { with DMSO to a total volume of } 20 \\
\text { tubes and store at }-20^{\circ} \mathrm{C} \text {. }\end{array}$ & $\begin{array}{l}\text { parately in a small } \\
\text { combined and filled } \\
0 \mathrm{ml} \text {. Aliquot in } 2 \mathrm{ml}\end{array}$ \\
\hline \multicolumn{3}{|c|}{ Preparation of competent yeast cells and their transformation } \\
\hline \multirow[t]{5}{*}{ Li-PEG buffer } & Lithium acetate & $100 \mathrm{mM}$ \\
\hline & Tris- $\mathrm{HCl}, \mathrm{pH} 8.0$ & $10 \mathrm{mM}$ \\
\hline & EDTA, pH 8.0 & $1 \mathrm{mM}$ \\
\hline & PEG4000 & $50 \%(w / v)$ \\
\hline & Autoclave before use. & \\
\hline \multirow[t]{5}{*}{ SORB buffer } & Lithium acetate & $100 \mathrm{mM}$ \\
\hline & Tris- $\mathrm{HCl}, \mathrm{pH} 8.0$ & $10 \mathrm{mM}$ \\
\hline & EDTA, pH 8.0 & $1 \mathrm{mM}$ \\
\hline & Sorbitol & $1 \mathrm{M}$ \\
\hline & Autoclave before use. & \\
\hline
\end{tabular}

\subsection{Methods}

\subsubsection{Methods for working with plants and plant material}

\subsubsection{Seed sterilisation}

Seeds to be sown on soil were frozen to kill off potential pests (in particular thrips eggs). For this, seeds were packed doubly in airtight plastic bags, incubated at $-20{ }^{\circ} \mathrm{C}$ for at least $48 \mathrm{~h}$ and then allowed to warm up to room temperature while still in the bags.

For in vitro propagation seeds were surface sterilized by washing twice with $70 \%$ ethanol (EtOH) in a sterile hood. For this an appropriate amount of seeds was poured in a $1.5 \mathrm{ml}$ reaction tube and incubated in $1 \mathrm{ml} 70 \% \mathrm{EtOH}$ for $5 \mathrm{~min}$. To ensure equal washing of the seeds, the tube was inverted several times. Then the seeds were allowed to sink to the bottom and the $\mathrm{EtOH}$ was removed before repeating the washing step. Next, the $70 \% \mathrm{EtOH}$ was exchanged by $100 \% \mathrm{EtOH}$ and the seeds incubated in it for 2 min. A Whatman ${ }^{\circledR}$ filter paper was placed into a petri dish lid and the seeds together with the $100 \% \mathrm{EtOH}$ were 
poured onto the filter paper. The EtOH was allowed to evaporate before seeds were used further.

\subsubsection{Plant cultivation}

Surface-sterilized Arabidopsis seeds were sown onto damp soil (Frühstorfer Erde, Type T25, Str1, Archut), which was steamed before use to eliminate potential contaminations. Plant pots were covered with a plastic lid to increase humidity and transferred into a climate chamber (Johnson Controls, Milwaukee, WI, USA) set to short-day growth conditions ( $8 \mathrm{~h}$ light [ 150 $\mu$ Einstein $\mathrm{m}^{-2} \mathrm{~s}^{-1}$ ], $22{ }^{\circ} \mathrm{C}, 65 \%$ relative humidity). After germination the plastic lids were removed. About 4-week-old plants were then used for subsequent assays.

To induce flowering and for seed production plants were transferred into climate chambers with long-day conditions ( $16 \mathrm{~h}$ light $\left[\sim 200 \mu\right.$ Einstein $\mathrm{m}^{-2} \mathrm{~s}^{-1}$ ], $22^{\circ} \mathrm{C}, 65 \%$ relative humidity). For harvesting seeds, shoots with still green siliques were put in paper bags and left to ripen.

Arabidopsis plants used in qRT-PCRs were grown in vitro in 24-well plates. For this, the wells were filled with $2 \mathrm{ml} 1 / 2 \mathrm{MS}$ liquid medium before adding 3-5 surface sterilized Arabidopsis seeds using a sterile toothpick. The seeds were allowed to germinate and grow for $13 \mathrm{~d}$ in a Percival ${ }^{\circledR}$ plant growth chamber (CLF Plant Climatics, Wertingen, Germany) before replacing the medium with $1.5 \mathrm{ml}$ new $1 / 2 \mathrm{MS}$ medium. After another day in the growth chamber (on day 14 of the experiment), the seedlings were treated with polymeric chitin, chitin oligomers or medium as control. For this, $0.5 \mathrm{ml} 1 / 2 \mathrm{MS}$ medium with $4 \mathrm{x}$ the final concentration of the respective substance were added to the wells.

$N$. benthamiana seeds were also frozen at $-20{ }^{\circ} \mathrm{C}$ for at least $48 \mathrm{~h}$ before being sown into soil. The plant pots were directly transferred to long-day conditions for germination and further growth. About 5-week-old plants were used for transient expression studies.

All plants grown on soil were watered with tap water every 2-3 days.

\subsubsection{Stable transformation of Arabidopsis thaliana (floral dip)}

Flowering Arabidopsis plants were transformed via the Agrobacterium-mediated floral dip method (Clough and Bent, 1998). A single colony of $A$. tumefaciens cells transformed with the construct of interest (2.2.2.5) was used to inoculate a $25 \mathrm{ml}$ pre-culture in DYT mixed with the appropriate antibiotics. The pre-culture was incubated in a shaker overnight at 28 ${ }^{\circ} \mathrm{C}$ and $180 \mathrm{rpm}$. The complete pre-culture was used to inoculate the main culture containing $250 \mathrm{ml}$ DYT with antibiotics which was also incubated at $28^{\circ} \mathrm{C}$ and $180 \mathrm{rpm}$ overnight. Next, cells were spun down at $1200 \mathrm{~g}$ for $20 \mathrm{~min}$ at room temperature. After discarding the supernatant, the pellet was resuspended in $250 \mathrm{ml} 5 \%$ sucrose solution. To decrease surface tension, $0.05 \mu \mathrm{l}$ Silwet-77 were added to the cell suspension before dipping flowers for $2 \mathrm{x}$ $15 \mathrm{~s}$ into the suspension. After dipping into the solution, flowers were tapped onto paper 
towels to wipe of any excess liquid. Plant pots with the dipped flowers were placed back onto the tray and covered with a plastic lid overnight to increase humidity. Plants were kept in the dark until the plastic lid was removed and the trays placed into a climate chamber with long-day conditions for seed set.

\subsubsection{Transient transformation of $\boldsymbol{N}$. benthamiana}

For Agrobacterium-mediated transformation of $N$. benthamiana a $5 \mathrm{ml}$ pre-culture in DYT with the appropriate antibiotics was inoculated with a single $A$. tumefaciens colony carrying the plasmid of interest. The pre culture was incubated in a shaker at $28^{\circ} \mathrm{C}$ overnight at 180 rpm. Cells were then pelleted for $10 \mathrm{~min}$ and $1200 \mathrm{~g}$ at room temperature. The pellet was resuspended in $1 \mathrm{ml}$ infiltration buffer and the concentration of the bacterial solution measured. The bacterial solution was then adjusted to $\mathrm{OD}_{600}=0.4$ with infiltration buffer and further incubated at room temperature until used. Several hours before infiltrating, 4-weekold $N$. benthamiana plants were placed on the bench and covered with a plastic lid after watering to increase relative humidity. Whole leaves were infiltrated with a $1 \mathrm{ml}$ syringe and marked with coloured tape at the petioles. Three days after infiltration samples for protein extracts were harvested or leaves were analysed by confocal laser scanning microscopy.

\subsubsection{Selection of stably transformed Arabidopsis plants}

\subsection{Glufosinate selection on soil}

For selection with the herbicide Basta ${ }^{\circledR}(200 \mathrm{~g} / \mathrm{l}$ glufosinate/ phosphinothricin ammonium solution, Bayer CropScience AG, Monheim, Germany) $T_{1}$ seeds were sown densely onto damp soil and allowed to germinate covered with a plastic lid. After germination, the plastic lid was removed and the seedlings grown for another week. Seedlings were then thoroughly sprayed with a 1:1000 diluted Basta ${ }^{\circledR}$ solution. The spraying was repeated three times in two day intervals. Resistant and therefore successfully transformed seedlings which survived the Basta ${ }^{\circledR}$ treatment were picked and transplanted into fresh single pots onto soil. Seedlings were then grown as described in 2.2.1.2 before being used for further analyses.

\subsection{In vitro selection}

For segregation analyses of transgenic Arabidopsis $T_{2} / T_{3}$ plants, sterilized seeds were spread onto $1 / 2$ MS agar plates containing $25 \mu \mathrm{g} / \mathrm{ml}$ phosphinothricin (PPT) as a selection marker. Seedlings were grown under short-day conditions until resistant seedlings clearly differed from non-resistant seedlings. Resistant plants were picked and transferred onto soil for further propagation (see 2.2.1.2). 


\subsubsection{Confocal laser scanning microscopy (CLSM)}

To analyse stable transgenic Arabidopsis plants or transiently transformed $N$. benthamiana leaves expressing fluorescence protein-tagged fusion proteins, a SP5 DM6000 CS confocal laser scanning microscope (Leica, Wetzlar, Germany) and the appropriate software (LAS AF Leica Application Suite, Version 2.7.2) were used. Small and preferably even leaf discs were cut out and placed onto an object slide wetted with water, before the cover glass was placed on top. Analyses were performed with the appropriate lasers and emission filters. GFP was excited at $488 \mathrm{~nm}$ and the fluorescence emissions detected between 500 and $540 \mathrm{~nm}$. The autofluorescence of chlorophyll was captured between 720 and $760 \mathrm{~nm}$.

\subsubsection{Inoculation of Arabidopsis plants with powdery mildews}

For infection with Erysiphe pisi, 4-week-old Arabidopsis plants were placed in a box, the socalled inoculation tower, and evenly inoculated with spore material from above. For this, infected pea plants were shaken above the Arabidopsis plants to transfer the spore material.

For the infection with Golovinomyces orontii 4-week-old Arabidopsis plants were also placed in an inoculation tower covered with a nylon mesh. The spore material was harvested from host plants using a paint brush which was then evenly swept across the mesh to inoculate the Arabidopsis plants beneath.

For macroscopic analyses plants were photographed after the indicated amount of days.

\subsubsection{Drop-inoculation with $B$. cinerea}

B. cinerea spores were harvested from an overgrown PDA plate by washing small pieces of the agar in a $50 \mathrm{ml}$ falcon tube with $1 / 4$ PDB medium by vortexing. The spore suspension was filtered through a miracloth tissue to get rid of contaminations by agar residues and fungal mycelium. Spore concentrations were determined by counting in a Neubauer counting chamber. The spore solution was adjusted to a working concentration of $5 \times 10^{4}$ spores $/ \mathrm{ml}$ with $1 / 4$ PDB. Spores were either directly used for inoculation or after adding $20 \%$ glycerol frozen in liquid nitrogen for longer storage at $-80^{\circ} \mathrm{C}$.

The final spore suspension was incubated at room temperature for $2 \mathrm{~h}$ to allow germination of the spores. 4-week-old Arabidopsis plants were inoculated with $6 \mu \mathrm{l}$ droplets of the $B$. cinerea spore solution. The droplet should not be placed on the middle vein. Up to three leaves per plant were inoculated. The petioles of the inoculated leaves were marked with a pen. Trays with inoculated plants were watered and then covered with a plastic lid. To increase relative humidity the trays were sealed with adhesive tape and the plants were incubated in a growth chamber under short-day conditions. After three days, the inoculated leaves were harvested and the lesion diameters measured using a calliper rule. 


\subsubsection{Pseudomonas syringae pv. tomato (Pst) vacuum-infiltration assay}

Seeds of Arabidopsis plants used for Pst infiltration were sown onto pots with piled up soil covered with a fine mesh. The mesh prevents the bacterial suspension from contamination through soil during infiltration. The plants were grown for four weeks under short-day conditions and the number reduced to five plants per pot. One of the Pst strains described above (2.1.2.2) was grown on a NYG plate for at least two days and used to inoculate a $50 \mathrm{ml}$ NYG liquid culture supplemented with the appropriate antibiotics for selection. After incubation overnight at $28^{\circ} \mathrm{C}$ and $180 \mathrm{rpm}, 3 \mathrm{ml}$ of this culture were used to inoculate a new $50 \mathrm{ml}$ culture. The new bacterial culture was incubated as described for approximately $3 \mathrm{~h}$. The cells were then harvested by centrifugation at $1200 \mathrm{~g}$ for $10 \mathrm{~min}$ and room-temperature. The supernatant was discarded and the cells resuspended in $50 \mathrm{ml} 5 \mathrm{mM} \mathrm{MgCl}$. Prior to vacuum-infiltration, the bacterial solution was diluted to a concentration of $1 \times 10^{5}$ colony forming units (cfu)/ $\mathrm{ml}$. Per two plant pots about $1 \mathrm{I}$ of bacterial solution is needed for infiltration. For infiltration, two plant pots were put upside down into a plastic desiccator, which was then filled up with the bacterial suspension until most of the leaves were submerged. The vacuum was then applied for 1:15 min and maintained for 1:30 min before being released very slowly. The pots were then removed from the desiccator and the leaves gently swayed in a tub filled with tap water. Non-infiltrated leaves were then removed immediately.

Day zero $\left(d_{0}\right)$ samples were prepared by harvesting four leaf discs from four different plants from one pot using a cork borer (diameter $0.55 \mathrm{~cm}$, with a total area of $1 \mathrm{~cm}^{2}$ ). The leaf discs were transferred into a $1.5 \mathrm{ml}$ reaction tube. $50 \mu \mathrm{l} 10 \mathrm{mM} \mathrm{MgCl}_{2}$ were added and the leaf discs disrupted using a plastic pistil. The leaf suspensions were then diluted 1:10 by adding $450 \mu \mathrm{l} 10 \mathrm{mM} \mathrm{MgCl}$. $50 \mu \mathrm{l}$ of each sample were plated on NYG agar plates with the respective antibiotics for selection. $d_{0}$ samples were harvested in duplicates.

The infiltrated plants were well watered and further grown in a Percival ${ }^{\circledR}$ growth cabinet (CLF Plant Climatics, Wertingen, Germany) under short-day conditions. Day three samples $\left(d_{3}\right)$ were prepared in a similar way as the $d_{0}$ samples, only that three replicates of four leaf discs from four independent plants were harvested and further processed. Instead of preparing a 1:10 dilution, a dilution series ranging from $10^{-1}$ to $10^{-7}$ was pipetted in a 96-well microtiter plate. $5 \mu$ of each dilution were pipetted on NYG agar plates supplemented with the appropriate antibiotics for selection. When the plates appeared no longer wet, they were incubated for two days at $28^{\circ} \mathrm{C}$ before counting the cfu.

\subsubsection{Vacuum-infiltration for MAMP treatment}

Depending on the following experiments, an appropriate amount of leaves from approximately six-week-old plants was harvested of each genotype of interest. For standard chitin treatment, 10 leaves (approximately $3 \mathrm{~cm}$ long) per genotype were harvested and divided into two $15 \mathrm{ml}$ tubes. The tubes were then filled with tap water until leaves were fully covered. To one of the two $15 \mathrm{ml}$ tubes polymeric chitin (stock concentration: 10 
$\mathrm{mg} / \mathrm{ml}$ ) was added to a final concentration of $100 \mu \mathrm{g} / \mathrm{ml}$. The second tube served as a control with only water being infiltrated. The tubes were then placed in a plastic desiccator and vacuum-infiltrated for about $5 \mathrm{~min}$. After releasing the vacuum, the leaves were incubated in the solution for another $15 \mathrm{~min}$. The leaves were then blotted dry using a paper towel and either wrapped in aluminium foil or transferred into a new tube before being frozen in liquid nitrogen. The leaf samples were either directly used for protein extraction or stored at $-80^{\circ} \mathrm{C}$.

\subsubsection{Methods for working with bacteria}

\subsubsection{Cultivation of bacteria}

E.coli TOP10 cells used for plasmid amplification were either grown in liquid LB medium with the appropriate antibiotics for selection or on the respective solid LB agar plates. The bacteria were incubated at $37{ }^{\circ} \mathrm{C}$ overnight and liquid cultures additionally shaken at 200 rpm.

A. tumefaciens GV3101 (pMP90RK or pSoup) cells used for transformation of plants were cultivated in liquid DYT medium supplied with the respective antibiotics for selection (2.1.3.2) or on the corresponding DYT agar plates. Bacteria were grown for $2-3$ days at $28{ }^{\circ} \mathrm{C}$ and liquid cultures were additionally shaken at $180 \mathrm{rpm}$.

Pseudomonas strains were grown on NYG agar supplemented with the appropriate antibiotics for selection. Plates were incubated for two days at $28^{\circ} \mathrm{C}$ and then sealed with Parafilm ${ }^{\circledR}$ and stored at $4{ }^{\circ} \mathrm{C}$. The strains were subcultured on plates every two weeks.

\subsubsection{Preparation of chemically competent E.coli TOP10 cells}

$25 \mathrm{ml}$ of LB supplemented with the appropriate antibiotics were inoculated with a single colony of $E$. coli TOP10 cells grown on plate. The culture was incubated overnight at $37{ }^{\circ} \mathrm{C}$ and $200 \mathrm{rpm}$. A new $300 \mathrm{ml}$ LB culture was then inoculated to an $\mathrm{OD}_{600}$ of 0.2 using inoculum from the overnight culture. The culture was incubated at room temperature under constant shaking until it reached an $\mathrm{OD}_{600}$ of 0.6 . The culture was then chilled on ice for $10 \mathrm{~min}$ before being centrifuged at $4^{\circ} \mathrm{C}$ and $2500 \mathrm{~g}$ for $10 \mathrm{~min}$. The supernatant was discarded and the pellet resuspended in $80 \mathrm{ml}$ ice cold transformation buffer. The bacterial solution was kept on ice for $10 \mathrm{~min}$ again, before centrifuging as described before and resuspending the pellet in $20 \mathrm{ml}$ ice cold transformation buffer. DMSO was added to a final concentration of $7 \%$ and the cells kept on ice for another $10 \mathrm{~min}$. The bacterial solution was divided into $100 \mu \mathrm{l}$ aliquots in new $1.5 \mathrm{ml}$ reaction tubes and frozen in liquid nitrogen for storage at $-80^{\circ} \mathrm{C}$. 


\subsubsection{Preparation of electro-competent $A$. tumefaciens cells}

A $2 \mathrm{ml}$ LB overnight culture supplemented the appropriate antibiotics was inoculated with an A. tumefaciens colony from a fresh plate. The cells were incubated at $28{ }^{\circ} \mathrm{C}$ and $180 \mathrm{rpm}$ overnight. $0.5 \mathrm{ml}$ of the culture were used to inoculate a fresh $50 \mathrm{ml}$ culture and the cells were grown at $28^{\circ} \mathrm{C}$ and $180 \mathrm{rpm}$ overnight. A $300 \mathrm{ml} \mathrm{LB}$ culture containing the appropriate antibiotics was inoculated to an $\mathrm{OD}_{600}$ of 0.3 and the cells were grown at $28{ }^{\circ} \mathrm{C}$ and $180 \mathrm{rpm}$ to an $\mathrm{OD}_{600}$ of 1- 1.5. The cultures were then chilled on ice for $15 \mathrm{~min}$ before being spun down at $4^{\circ} \mathrm{C}$ and $5000 \mathrm{~g}$ for $20 \mathrm{~min}$. The supernatant was removed and the pellet resuspended in $30 \mathrm{ml}$ ice cold $1 \mathrm{mM}$ HEPES, $\mathrm{pH}$ 7.0. The samples were centrifuged as described before and this washing step repeated twice. After removal of the supernatant the pellet was resuspended in $30 \mathrm{ml}$ ice cold $10 \%$ glycerol and centrifuged as before. The supernatant was removed and the pellet resuspended in $2 \mathrm{ml}$ ice cold $10 \%$ glycerol. The bacterial solution was the aliquoted in $45 \mu \mathrm{l}$ aliquots into sterile $1.5 \mathrm{ml}$ reaction tubes and frozen in liquid nitrogen before being stored at $-80^{\circ} \mathrm{C}$.

\subsubsection{Transformation of chemically competent $E$. coli TOP10 cells}

E.coli cells were transformed with plasmid DNA using the heat shock method. The complete reaction volumes of Gateway ${ }^{\circledR}$ cloning approaches were added to the $E$. coli cells, whereas only 1-50 ng of plasmid DNA was added to the cells for re-transformations. To start off, $100 \mu \mathrm{l}$ of competent $E$. coli cells were thawed on ice before adding $1 \mu \mathrm{l}(0.25 \mu \mathrm{l}$ for retransformations) of the plasmid DNA. After another 20 min on ice, the mixture was heat shocked in a heating block at $42{ }^{\circ} \mathrm{C}$ for $45 \mathrm{~s}$. The cells were immediately put back on ice and kept there for another $5 \mathrm{~min}$, before adding $750 \mu$ of liquid LB medium. The sample was incubated at $37^{\circ} \mathrm{C}$ for $1 \mathrm{~h}$ and $220 \mathrm{rpm}$. Then the cells were pelleted for $5 \mathrm{~min}$ at $6000 \mathrm{rpm}$ and room temperature. Most of the supernatant was discarded and the cell pellet resuspended in the residual liquid in the tube. The bacterial solution was then plated onto LB agar plates supplemented with the appropriate antibiotics for selection. The plates were incubated at $37^{\circ}$ overnight for the bacteria to grow.

\subsubsection{Transformation of electro-competent Agrobacterium tumefaciens cells}

$40 \mu \mathrm{l}$ of competent $A$. tumefaciens cells were used for transformation with plasmid DNA by electroporation. First, the cells were thawed on ice and $0.3 \mu$ l plasmid DNA were added. The mixture was then transferred into a precooled electroporation cuvette with $0.1 \mathrm{~cm}$ gap width. The cuvette was pulsed in a Micro Pulser ${ }^{\mathrm{TM}}$ (BioRad, München, Germany) electroporation apparatus which was set to $25 \mu \mathrm{F}, 2.5 \mathrm{kV}$ and $400 \Omega .750 \mu \mathrm{l}$ ice cold liquid DYT were then added to the transformed cells and the bacterial solution was transferred into a $2 \mathrm{ml}$ centrifugation tube. The sample was incubated at $28{ }^{\circ} \mathrm{C}$ and $180 \mathrm{rpm}$ for $2-3 \mathrm{~h}$. Then $50 \mu \mathrm{l}$ of the mixture were plated onto a DYT agar plate with the appropriate antibiotics and the plate incubated at $28^{\circ} \mathrm{C}$ for $2-3$ days. 


\subsubsection{Preparation of glycerol stocks}

For longer storage glycerol stocks of bacterial strains were prepared. $800 \mu \mathrm{l}$ of a bacterial liquid culture were mixed with $200 \mu \mathrm{l}$ sterile $86 \%$ glycerol. The aliquots were frozen in liquid nitrogen and stored at $-80^{\circ} \mathrm{C}$.

\subsubsection{Cultivation of filamentous pathogens}

\subsubsection{Powdery mildews}

Erysiphe pisi was propagated on its host plant pea 'Kleine Rheinländerin' (Pisum sativum) under $8 \mathrm{~h}$ light, $22^{\circ} \mathrm{C}$ and $80 \%$ relative humidity.

Golovinomyces orontii was propagated in parallel on two Arabidopsis genotypes, namely Col0 and eds1-2. Fungal material grown on Col-0 plants was used for re-inoculation of Col-0 and eds1-2 to maintain the fungal culture. eds1-2 plants which are more susceptible to G. orontii and form more spores were used for inoculation of experimental plants.

\subsubsection{Botrytis cinerea}

B. cinerea was propagated on PDA plates at room temperature in the dark. When the fungus started to sporulate (after circa 10 days) it was transferred onto a fresh PDA plate. For this a small agar cube was cut out from the overgrown plate and placed onto the centre of the new agar plate. The older and overgrown agar plate was sealed with Parafilm ${ }^{\circledR}$ and stored at $4{ }^{\circ} \mathrm{C}$ for up to 4 weeks. For longer conservation the spores were washed off from the overgrown plate with $1 / 4$ PDB, adjusted to a concentration of $5 \times 10^{4}$ spores/ $\mathrm{ml}$ and supplemented with $20 \%$ glycerol before being frozen in liquid nitrogen and stored at $-80^{\circ} \mathrm{C}$.

\subsubsection{Molecular biological methods}

\subsubsection{Extraction of genomic DNA from plants using the 'Quick-Prep' method}

One small Arabidopsis leaf was harvested and transferred into a $1.5 \mathrm{ml}$ reaction tube. $300 \mu \mathrm{l}$ extraction buffer were added to the leaf and the leaf was disrupted using a plastic micro pistil. The mixture was left to incubate for $1 \mathrm{~min}$ at room temperature before being centrifuged at maximum speed for $5 \mathrm{~min}$. The supernatant was transferred into a new $1.5 \mathrm{ml}$ tube with $300 \mu \mathrm{l}$ isopropanol. After mixing by pipetting up and down the solution was incubated for $5 \mathrm{~min}$ at room temperature. The sample was centrifuged at $14000 \mathrm{rpm}$ for 5 min before the supernatant was removed. The pellet was air-dried and later resuspended in $50 \mu$ ultrapure water. $1 \mu$ l of the sample was used as template in PCRs. 


\subsubsection{Extraction of RNA}

Arabidopsis RNA was prepared using the innuPREP Plant RNA kit (Analytikjena, Jena, Germany). The extraction was performed according to the manufacturer's instructions. About $100 \mathrm{mg}$ powdered plant material or 3-5 seedlings that were disrupted using a Tissuelyser LT (Qiagen, Hilden, Germany) were used as starting material for the extraction. The plant material used in this study was resuspended in the lysis buffer RL. For quality control, the total RNA was analysed via agarose gel electrophoresis (2.2.4.7). For this $3 \mu \mathrm{l}$ of RNA were mixed with $7 \mu \mathrm{l}$ water and $2 \mu \mathrm{l} 6 \mathrm{x}$ loading dye. The samples were then loaded onto a $1 \%$ agarose gel and separated electrophoretically.

The exact RNA concentration was then measured using the TECAN Infinite ${ }^{\circledR} 200$ PRO NanoQuant plate reader (2.2.4.9).

\subsubsection{3 cDNA synthesis}

cDNA was synthesized from 1-4 $\mu \mathrm{g}$ of total RNA prepared as described in 2.2.4.2 using the RevertAid $^{\mathrm{TM}} \mathrm{H}$ Minus Reverse Transcriptase (Fermentas) according to the manufacturer's instructions. The RNA and $1 \mu$ of oligo(dT) $)_{18}$ primer $(100 \mu \mathrm{M})$ were pipetted into a PCR tube which was filled up with RNase-free water to a total volume of $12.5 \mu$ l. The PCR tube was kept on ice. Then, $4 \mu \mathrm{l} 5 \mathrm{x}$ reverse transcriptase (RT) reaction buffer, $0.5 \mu \mathrm{l}(20 \mathrm{u})$ RiboLock $^{\mathrm{TM}}$ RNase inhibitor (Fermentas), $2 \mu \mathrm{l}$ dNTP mix (10 mM each) and $1 \mu \mathrm{l}(200 \mathrm{u})$ RevertAid $^{\mathrm{TM}} \mathrm{H}$ Minus RT were added to make a final volume of $20 \mu \mathrm{l}$. The mixture was mixed gently and centrifuged briefly. The synthesis was performed at $42{ }^{\circ} \mathrm{C}$ for $60 \mathrm{~min}$ before being terminated at $70{ }^{\circ} \mathrm{C}$ for $10 \mathrm{~min}$. The produced cDNA was either directly used for further experiments or stored at $-20^{\circ} \mathrm{C}$.

\subsubsection{Preparation of plasmid DNA from E. coli}

Plasmid DNA was extracted using a homemade small scale plasmid preparation protocol. All steps of this protocol were carried out at room temperature.

A 3-ml overnight culture was inoculated with the bacteria strain containing the plasmid of interest and incubated at $37{ }^{\circ} \mathrm{C}$ and $220 \mathrm{rpm}$ overnight.

$1.5 \mathrm{ml}$ of the overnight culture was poured into a new $1.5 \mathrm{ml}$ reaction tube and spun down at maximum speed for $1 \mathrm{~min}$. The supernatant was removed and the pellet was resuspended in buffer $200 \mu \mathrm{l} \mathrm{P1}$ until no clumps were visible. Then, $200 \mu \mathrm{l}$ buffer P2 were added and the solutions were mixed by inverting the tube 5-6 times gently but thoroughly. The reaction was incubated for 3-5 min and then stopped by adding $200 \mu \mathrm{l}$ buffer P3. The content of the tube was mixed immediately by inverting the tube 5-6 times. The mixture was then spun down at maximum speed for 5-10 $\mathrm{min} .500 \mu \mathrm{l}$ of the clear supernatant were transferred into a new $1.5 \mathrm{ml}$ reaction tube without disturbing the white precipitate. $1 \mathrm{ml}$ of $96 \%$ EtOH was added and the tubes were inverted 5-6 times for mixing. The tubes were centrifuged at 
maximum speed for $5 \mathrm{~min}$ and the supernatant was removed. The pellet was washed by adding $1 \mathrm{ml}$ of $70 \% \mathrm{EtOH}$ and centrifuging at maximum speed for $1 \mathrm{~min}$. The supernatant was discarded and the centrifugation step repeated. The residual $\mathrm{EtOH}$ was removed and the pellet air-dried. Finally, the dried pellet was resuspended in $50 \mu \mathrm{ddd}_{2} \mathrm{O}$ and stored at $-20^{\circ} \mathrm{C}$.

\subsubsection{Polymerase chain reaction (PCR)}

Standard PCRs for plant genotyping and colony PCRs using the homemade Taq DNA polymerase were performed according to the following program:

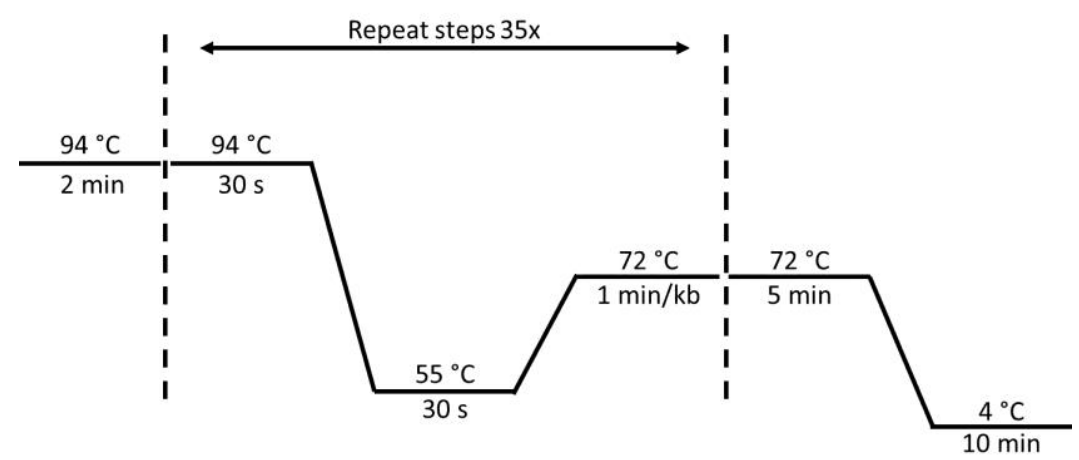

The PCR program was adjusted to the manufacturer's instructions when using a different polymerase. Also the annealing temperature was adjusted depending on the primers used for amplification.

Standard reactions were prepared in a $20 \mu$ l volume:

10x Taq buffer

dNTP mix (10 $\mu$ M each)

Primer $1(10 \mathrm{mM})$

Primer $2(10 \mathrm{mM})$

Taq DNA polymerase

Water
$2 \mu \mathrm{l}$

$0.5 \mu \mathrm{l}$

$1 \mu \mathrm{l}$

$1 \mu \mathrm{l}$

$0.5 \mu \mathrm{l}$

$15 \mu \mathrm{l}$

To test for presence of a T-DNA, a T-DNA left border (LB) primer (UU41 for plants from the GABI-KAT collection and EP64 for SALK lines) and an appropriate flanking primer (RP) were used. To detect the wild type allele, a second reaction was performed using primers which flank the T-DNA insertion (LP and RP).

For amplification of products used for cloning, the iProof ${ }^{\mathrm{TM}}$ High-Fidelity DNA Polymerase (BioRad, Munich, Germany) or the Phusion ${ }^{\circledR}$ High-Fidelity DNA Polymerase (Finnzymes, Espoo, Finland) were used according to the manufacturer's instructions. The amplified PCR products were then loaded onto agarose gels and separated electrophoretically to analyse the resulting bands. 


\subsubsection{Quantitative reverse transcription PCR (qRT-PCR)}

For qRT-PCR, the amplification and simultaneous quantification was performed using the CFX96 Touch $^{\text {TM }}$ Real-Time PCR Detection System equipped with the CFX Manager ${ }^{\mathrm{TM}}$ Software $^{2}$ (BioRad, Hercules, CA, USA) and matching qRT-PCR-96-well plates (BioRad). One reaction

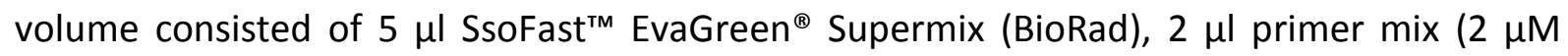
each) and $3 \mu \mathrm{l} \mathrm{cDNA}$. The following PCR program was used: Denaturation at $95{ }^{\circ} \mathrm{C}$ for $30 \mathrm{~s}$ followed by 45 cycles of $95^{\circ} \mathrm{C}$ for $5 \mathrm{~s}$ and $55^{\circ} \mathrm{C}$ for $10 \mathrm{~s}$. The melting curve was measured and analysed during a temperature increase from $60{ }^{\circ} \mathrm{C}$ to $95^{\circ} \mathrm{C}$ in $0.5^{\circ} \mathrm{C}$ and 5 s steps.

To test primer efficiency and determine the optimum cDNA concentration, a calibration curve was analysed for each experiment and primer combination. For this, $3 \mu \mathrm{l}$ of each sample within an experiment were pooled and a 1:3 dilution series of the pooled CDNA was pipetted in a PCR 8-tube strip resulting in 8 dilution steps.

Primer efficiency $(E)$ was inferred from the calibration curve $\left(E=10^{\wedge}(-1 /\right.$ slope of calibration curve). Primers were used only if the calibration curve was linear over several dilution steps and efficiency was close to 2 (perfect doubling of DNA in each cycle). Optimum template concentration (in the middle of the linear range) was chosen based on the calibration curve. Four technical replicates were measured for each sample. For each of the 4 replicates $\mathrm{E}^{\wedge} \mathrm{Cq}$ was calculated and the mean was determined. The relative gene expression (gene of interest/ reference gene) was then calculated as (mean [reference gene])/ (mean [target gene]). Each experiment was performed three times. The results from individual experiments were normalized by division by the mean of the respective experiment. The mean of the normalized values \pm standard deviation were calculated.

\subsubsection{Agarose gel electrophoresis}

DNA fragments were separated according to their size via agarose gel electrophoresis. DNA samples were mixed with 6x DNA loading dye prior to loading onto an agarose gel with appropriate percentage of agarose (ranging from 0.8-3\%). The smaller in size the expected fragment is, the higher the percentage of the gel. The respective amount of agarose was melted in 1x TAE buffer using a microwave. After the agarose was completely dissolved and cooled down to about $60^{\circ} \mathrm{C}$, one drop of ethidium bromide solution $(10 \mathrm{mg} / \mathrm{ml})$ was added to $50 \mathrm{ml}$ gel. The gel was then cast and after solidifying, placed in 1X TAE buffer in a Sub-Cell GT apparatus (BioRad) for electrophoretic separation. The DNA samples were loaded into the prepared pockets. The GeneRuler ${ }^{\mathrm{TM}}$ (Thermo Scientific ${ }^{\mathrm{TM}}$ ) was applied as a size standard. The electrophoresis was performed at 90-120 V for $25 \mathrm{~min}-1 \mathrm{~h} 25 \mathrm{~min}$, depending on the size and percentage of the gel. The gel was exposed to UV light (312 nm) to visualize DNA bands and a picture was taken using a gel documentation and analysis system (VWR, Lutterworth, UK). 


\subsubsection{Isolation of DNA fragments from agarose gels}

DNA fragments which were separated by agarose gel electrophoresis and required for further cloning were cut out of the gel under UV-light $(365 \mathrm{~nm})$ for visualization using a scalpel and stored in a $1.5 \mathrm{ml}$ reaction tube. The DNA was then extracted from the agarose using the QIAquick ${ }^{\circledR}$ gel extraction kit (Qiagen, Hilden, Germany) according to the manufacturer's instructions.

\subsubsection{Photometric measurement of DNA and RNA concentration}

The TECAN Infinite ${ }^{\circledR} 200$ PRO NanoQuant plate reader (Tecan Group Ltd, Männedorf, Switzerland) was used for determination of DNA and RNA concentrations as well as for checking the purity of the nucleic acids. For this, $1 \mu \mathrm{l}$ of the sample was pipetted onto the NanoQuant Plate ${ }^{\mathrm{TM}}$ and the absorption was measured at $260 \mathrm{~nm}$ and $280 \mathrm{~nm}$. The ratio between the absorbance of $260 \mathrm{~nm}$ and $280 \mathrm{~nm}$ indicates the purity of the sample. The optimal ratio $\left(O D_{260} / 280\right)$ for DNA is $~ 1.8$ and for RNA $~ 2.0$.

\subsubsection{Clean-up of DNA}

To purify DNA samples after restriction digestion or PCR amplification, the QIAquick ${ }^{\circledR}$ gel extraction kit (Qiagen, Hilden, Germany) was used according to the respective manual.

\subsubsection{Sequencing of DNA and subsequent evaluation}

DNA sequencing was performed through Seqlab (Göttingen, Germany) using the Barcode Economy Run Service. Sequencing reactions were prepared considering the Seqlab sample requirements. The results were then analysed using the bioinformatics software Geneious version 7.1.5 (Kearse et al., 2012).

\subsubsection{Restriction digest}

To obtain specific ends for ligation or to check plasmids during cloning and after transformation, restriction endonucleases from Thermo Fisher Scientific ${ }^{\mathrm{TM}}$ or New England Biolabs were used to process DNA fragments according to the manufacturer's instructions.

\subsubsection{Gateway ${ }^{\circledR}$ cloning}

The pENTR ${ }^{\mathrm{TM}}$ Directional TOPO ${ }^{\circledR}$ cloning kit $\left(\right.$ Invitrogen $^{\mathrm{TM}}$ ) was used for directional cloning of blunt-end PCR products into the Gateway ${ }^{\circledR}$ entry vector PENTR $^{\mathrm{TM}} / \mathrm{D}-\mathrm{TOPO}^{\circledR}$. The TOPO ${ }^{\circledR}$ cloning reaction was performed according to the manufacturer's instructions, but only using $1 / 4$ of the recommended reaction volume. The complete reaction was transformed into chemically competent E. coli TOP10 cells. The Gateway ${ }^{\circledR}$ LR Clonase ${ }^{\circledR}$ enzyme kit 
(Invitrogen ${ }^{\mathrm{TM}}$ ) was used in the next step to perform the LR reaction. This enables a sequence-specific recombination of the DNA fragment of interest from the entry vector into a Gateway ${ }^{\circledR}$ destination/ expression vector. The LR reaction was performed in a total reaction volume of $2.8 \mu \mathrm{l}$, containing $0.3 \mu \mathrm{l}$ entry vector, $0.6 \mu \mathrm{l}$ destination vector, $0.5 \mu \mathrm{l} 5 \mathrm{x}$ LR Clonase ${ }^{\circledR}$ buffer, $0.9 \mu \mathrm{l}$ TE buffer and $0.5 \mu \mathrm{l}$ LR Clonase ${ }^{\circledR}$. The reaction mixture was incubated for $1 \mathrm{~h}$ at $25{ }^{\circ} \mathrm{C}$ before being terminated by adding $0.5 \mu \mathrm{l}$ Proteinase $\mathrm{K}$ and subsequent incubation at $37{ }^{\circ} \mathrm{C}$ for $10 \mathrm{~min}$. The whole reaction was then used for transformation of chemically competet $E$. coli TOP10 cells (2.2.2.4). Subsequently, positive transformants were determined by colony PCR (2.2.4.5).

\subsubsection{Preparation of chemically competent Saccharomyces cerevisiae cells}

A $5 \mathrm{ml}$ YPD overnight culture of the Saccharomyces cerevisiae S288C-dervied BY4741 strain (Brachmann et al., 1998) was used to inoculate a new $20 \mathrm{ml}$ YPD culture with an $\mathrm{OD}_{600}$ of 0.1 . The new culture was grown for $6 \mathrm{~h}$ at $30{ }^{\circ} \mathrm{C}$ and $200 \mathrm{rpm}$ before being spun down at 2000 rpm for $3 \mathrm{~min}$. The cell pellet was washed with 0.5 volumes of sterile water, followed by a wash step with $0.1 \mathrm{vol}$ of sterile SORB buffer. Cells were then resuspended in $180 \mu \mathrm{l}$ SORB buffer and $20 \mu \mathrm{l}$ single-stranded (ss) carrier-DNA (salmon sperm DNA, $2 \mathrm{mg} / \mathrm{ml}$ ). The mixture was then aliquoted in $50 \mu \mathrm{l}$ aliquots, which were either frozen at $-80^{\circ} \mathrm{C}$ or directly used for transformation.

\subsubsection{Cloning of $p C L R 1:$ CLR1-GFP by homologous recombination in Saccharomyces cerevisiae}

Due to usage of different Gateway ${ }^{\circledR}$ systems, the expression vector pGWB604- $p$ CLR1::CLR1-sGFP had a different vector backbone than pUBC-GFP-pUBQ10::CLR1-M 1 -GFP and pUBC-GFP-pUBQ10::CLR1-M - GFP. Therefore the fusion constructs had different linker sequences between the gene of interest and the C-terminal tag. By homologous recombination of the 5' part of pGWB604-pCLR1::CLR1-sGFP (including the promoter and the CDS for the N-terminal part of CLR1) and the $3^{\prime}$ part of pUBC-GFP-pUBQ10::CLR1-M 1 -GFP (including the CDS for the C-terminal part of CLR1 and the C-terminal GFP-tag), the pGreenII-0229- $p C L R 1:: C L R 1-G F P$ vector was generated to make the fusion protein comparable to those expressed from pUBC-GFP-pUBQ10::CLR1-M 1 -GFP and pUBC-GFP-pUBQ10::CLR1-M2-GFP concerning the molecular mass.

For this, the N-terminal fragment (1) was amplified from pGWB604- $p C L R 1:$ :CLR1-sGFP with primers adding a $5^{\prime}$ overhang matching the plasmid pRS426 followed by a Kpnl restriction site. The 3' fragment from pUBC-GFP-pUBQ10::CLR1-M 1 -GFP (2) was amplified with primers adding a $5^{\prime}$ overhang overlapping in sequence with the fragment (1) and a Smal restriction site followed by a pRS426 overhang. The correct sizes of the PCR products were checked via agarose gel electrophoresis and the products then purified as described in 2.2.4.10. Fragment (1) and (2) were then used to transform chemically competent $S$. cerevisiae 
BY4741 cells. $3 \mu$ l of pRS426 plasmid DNA, 500 ng of fragments (1) and (2), $300 \mu$ Li-PEG buffer and $20 \mu \mathrm{l}$ DMSO were mixed and added to $50 \mu$ l of yeast cells in a $1.5 \mathrm{ml}$ reaction tube. The sample was incubated for $30 \mathrm{~min}$ on a wheel at $18 \mathrm{rpm}$ and room temperature, before heat shocking the cells at $42{ }^{\circ} \mathrm{C}$ for $15 \mathrm{~min}$. The cells were then spun down for $3 \mathrm{~min}$ at $2000 \mathrm{rpm}$ and the supernatant was discarded. The pellet was resuspended in the residual liquid in the tube and the cell suspension was plated onto an SC medium agar plate (- Ura + Gluc). Cells were allowed to grow for $2 \mathrm{~d}$ at $28^{\circ} \mathrm{C}$.

An appropriate amount of cells was harvested by scraping some smear of the overgrown

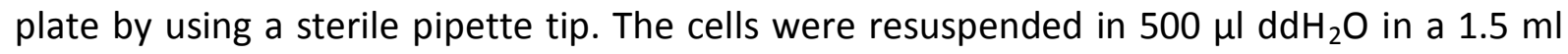
reaction tube. The solution was spun down at $2000 \mathrm{rpm}$ for $2 \mathrm{~min}$ and the supernatant was discarded. The plasmid was then extracted using the GeneJET Plasmid Miniprep Kit (Thermo Scientific ${ }^{\mathrm{TM}}$ ) according to the manufacturer's instructions. About $50 \mathrm{ng}$ of the extracted plasmid was the used for transformation of chemically competent E.coli TOP10 cells as described in 2.2.2.4. The transformed cells were plated on LB agar plates supplemented with ampicillin and incubated at $37^{\circ} \mathrm{C}$ overnight. After checking the grown colonies for insertion of the plasmid by colony PCR, overnight cultures for plasmid preps were inoculated and the plasmids extracted the next day (see 2.2.4.4). The plasmids were checked in restriction digests using $\mathrm{Kpnl}$ and Smal and positive bands were extracted from the agarose gel (see 2.2.4.8). The products were then used for ligation with Kpnl- and Smal- digested pGreenll0229 (kindly provided by J. Erwig).

\subsubsection{Ligation of DNA fragments and vectors}

The ligation was performed using the T4 DNA ligase (Fermentas ${ }^{\mathrm{TM}}$ ) according to the manufacturer's instructions. $20-200$ ng linearized vector were mixed with the DNA insert at a ratio of 1:1 to 1:5. $2 \mu \mathrm{l} 10 \mathrm{x}$ reaction buffer, $2 \mu \mathrm{l} 50 \%$ PEG 4000 solution, $1 \mu \mathrm{l}(5 \mathrm{u})$ T4 DNA ligase were added and the reaction was filled up with water to a total volume of $20 \mu \mathrm{l}$. PEG 4000 solution was added only for blunt-end ligations. The ligation reaction was then incubated for $1.5 \mathrm{~h}$ at room temperature. $5 \mu \mathrm{l}$ of the reaction volume were then used for transformation of chemically competent $E$. coli TOP10 cells.

After checking for correctly ligated plasmids by colony PCR and sequencing, plasmids were transformed into electro-competent pMP90RK A. tumefaciens

\subsubsection{ROS burst assays}

This chemiluminescent-based assay was performed in 96-well microtiter plates. For the standard setup used in this work, one microtiter plate was needed per treatment (chitin or control). The wells were filled with $100 \mu \mathrm{l}$ tap water each. For analysing the production of reactive oxygen species (ROS) upon MAMP treatment 12 leaves per genotype were harvested. 2 leaf discs were cut out from each leaf and transferred into the same well on the 
different microtiter plates, ending up with 2 times 12 wells in a row per genotype. The plates were wrapped in a plastic bag and incubated overnight.

The next day, the L-012 solution was prepared. For each well, $100 \mu \mathrm{L}$ L-012 solution were needed, but some extra solution was prepared to allow pipetting with multichannel pipettes. The water in the microtiter plates was removed and replaced either by $100 \mu \mathrm{L}$ L-012 solution (control) or L-012 solution containing $100 \mu \mathrm{g} / \mathrm{ml}$ chitin. The L-012 solution was added to the wells just before the measurement. The chemiluminescence was measured every minute over a period of 35 min using a TECAN infinite ${ }^{\circledR}$ M200 plate reader (Tecan Group Ltd., Männedorf, Switzerland). The data were evaluated using Excel.

\subsubsection{Histochemical staining with X-Gluc}

The plant tissue of interest from stable transgenic Arabidopsis plants expressing the GUS reporter gene was harvested and distributed into water-containing $2 \mathrm{ml}$ reaction tubes. The water was then exchanged to ice-cold acetone and the samples incubated for $20 \mathrm{~min}$ to destain. The acetone was then replaced by the washing solution and the samples were incubated for $10 \mathrm{~min}$. Then the washing solution was removed and the staining solution was added. The samples were vacuum-infiltrated in a plastic desiccator for $1 \mathrm{~min}$ and afterwards kept in the dark at $37{ }^{\circ} \mathrm{C}$ overnight. The staining solution was replaced with $100 \%$ ethanol and the samples were incubated at $37{ }^{\circ} \mathrm{C}$ for further destaining of the tissue. The samples were then analysed and documented using a stereo microscope (Leica, Wetzlar, Germany).

\subsubsection{Biochemical methods}

\subsubsection{Total protein extraction from plants for Western blotting}

\subsection{Protein extraction optimized for receptor-like kinases}

$50-100 \mathrm{mg}$ frozen plant material was ground in $300 \mu \mathrm{l}$ CERK1 extraction buffer and a small spatula of quartz sand using a glass drill until the mixture was smooth. Residual plant extract was rinsed of the drill using $700 \mu \mathrm{l}$ extraction buffer. The samples were then centrifuged at $12000 \mathrm{rpm}$ and $4{ }^{\circ} \mathrm{C}$ for $10 \mathrm{~min}$. The supernatants were transferred into new reaction tubes and kept on ice. The protein concentrations were determined via the Bradford assay (2.2.5.3). Then, the samples were adjusted to the same protein concentration and volume using CERK1 extraction buffer.

From each sample an equal volume of $60-120 \mu \mathrm{l}$ was transferred to a new $1.5 \mathrm{ml}$ reaction tube and mixed with $4 x$ SDS loading dye to serve as total extract (TE) for Western blots. Samples were stored at $-20{ }^{\circ} \mathrm{C}$. The residual extract was either stored at $-20{ }^{\circ} \mathrm{C}$ or used in pull-down experiments. 


\subsection{SDS extraction}

For preparation of total protein extracts 15 leaf discs per sample were cut out with a cork borer (diameter $0.5 \mathrm{~cm}$ ) and transferred into a $2 \mathrm{ml}$ reaction tube together with two metal beads (diameter $0.4 \mathrm{~cm}$ ) before being frozen in liquid nitrogen. Samples were either stored at $-80{ }^{\circ} \mathrm{C}$ or directly ground to a fine powder by disrupting the plant material using a Tissuelyser LT (Qiagen, Hilden, Germany) for 3x $2 \mathrm{~min}$ at 50 Hertz. Between the three repetitions of $2 \mathrm{~min}$ the samples were cooled in liquid nitrogen to prevent thawing. After grinding, the samples are transferred back onto ice and $150 \mu \mathrm{l} 2 \mathrm{x}$ SDS (Laemmli) sample buffer were added. The tubes were flicked to dispense the buffer. The tubes were vortexed twice while thawing. The samples were then boiled at $95{ }^{\circ} \mathrm{C}$ for $5 \mathrm{~min}$ before being centrifuged for $25 \mathrm{~min}$ at $4{ }^{\circ} \mathrm{C}$ and $13000 \mathrm{rpm}$. The supernatants were transferred into new 1.5 reaction vials and stored at $-20^{\circ} \mathrm{C}$.

\subsubsection{Chitin pull-down}

First, chitin magnetic beads (NEB, Frankfurt/Main, Germany) were washed with ultrapure water at least two times and then the volume was adjusted to the volume of the original suspension. $20 \mu \mathrm{l}$ beads were added to each tube of protein extract. The samples were then incubated in a cold room on a wheel at about $18 \mathrm{rpm}$ for $45 \mathrm{~min}$. The samples were transferred on ice and the magnetic beads were pelleted using a magnetic rack. The supernatants were discarded and the beads washed $1 \mathrm{ml}$ cold TBST-T. This was repeated once before performing a washing step with cold deionized water. After removing the water, the magnet was removed and $20 \mu \mathrm{l}$ of $1.5 x$ SDS sample buffer were added. The samples were spun down for a few seconds in a table top centrifuge to mix all the beads with the SDS buffer. The samples were stored at $-20^{\circ} \mathrm{C}$. Before use, samples were boiled at $95{ }^{\circ} \mathrm{C}$ for 5 $\min$.

\subsubsection{Bradford assay}

Protein concentrations were determined by using a method based on Bradford, 1976. A calibration curve using a bovine serum albumin (BSA) standard was measured. For this, the following volumes of $1 \mathrm{mg} / \mathrm{ml}$ BSA were pipetted into a cuvette each: $0 \mu \mathrm{l}, 3 \mu \mathrm{l}, 5 \mu \mathrm{l}, 10 \mu \mathrm{l}$ and $15 \mu \mathrm{l}$. For the samples to be measured an appropriate volume of protein extract was pipetted into cuvettes (typically $3 \mu \mathrm{l}$ ). The samples were pipetted in duplicate to later calculate the mean. Then $1 \mathrm{ml}$ of Bradford solution (Roti ${ }^{\circledR}$-Quant, Roth, diluted 1:5 with water) was added to each cuvette, which were then carefully vortexed to mix the solution. After $10 \mathrm{~min}$ of incubation at room temperature the absorption at $595 \mathrm{~nm}$ was measured using a WPA Biowave II photometer (Biochrom, Berlin, Germany) for each sample. The absorption values of the BSA standards were plotted against the protein concentration to obtain a calibration curve. 
Based on the calibration curve, the protein amount $(\mu \mathrm{g} / \mu \mathrm{l})$ was calculated in the measured samples and subsequently, the mean protein concentration of the duplicate samples was calculated.

\subsubsection{Lambda Protein Phosphatase ( $\lambda$ PPase) treatment}

Total protein extracts were prepared as described before (2.2.5.1.1). Protein extracts from chitin-treated and control plants were divided into three aliquots, respectively. The protein of interest was pulled down using appropriate magnetic beads (in this work $20 \mu \mathrm{l} \mathrm{GFP-}$ binding protein magnetic beads (GFP-Trap ${ }^{\circledR} \_$M, ChromoTek, Planegg-Martinsried, Germany) were used). The samples mixed with the magnetic beads were incubated in a cold room for 1:15 $\mathrm{h}$ on a wheel at $18 \mathrm{rpm}$. After the incubation time, the samples were washed similar as described in 2.2.5.2. However, instead of being washed with TBS-T and water, the samples were washed twice with $1 \mathrm{ml}$ mild washing buffer. After removal of the buffer from the last wash step, $5 \mu \mathrm{l}$ 10x $\lambda$ PPase buffer (NEB, New England Biolabs, Ipswich, MA, USA) and $5 \mu \mathrm{l}$ $\mathrm{MnCl}_{2}$ (NEB) were added to each aliquot. $6 \mu \mathrm{l}$ of $\lambda$ PPase were added to one of the aliquots and all aliquots were supplemented with water to a total volume of $50 \mu \mathrm{l}$. One aliquot without $\lambda$ PPase was directly mixed with $17 \mu \mathrm{l} 4 \mathrm{x}$ SDS sample buffer and frozen at $-20^{\circ} \mathrm{C}$ (dir). The residual two samples were then incubated for $1 \mathrm{~h}$ at $30^{\circ} \mathrm{C}$ either with $\lambda$ PPase $(\boldsymbol{\lambda})$ or mock-treated in parallel without $\lambda$ PPase $(\mathbf{m})$. After the incubation the samples were mixed with $4 \times$ SDS sample buffer and stored at $-20^{\circ} \mathrm{C}$.

\subsubsection{Microsomal fractionation}

For microsomal fractionations about $100 \mathrm{mg}$ ground plant material were transferred into a $1.5 \mathrm{ml}$ reaction tube. The plant powder was further ground in $800 \mu \mathrm{l}$ CERK1 extraction buffer without Triton X-100 using a glass drill. The samples were spun down at $1000 \mathrm{rpm}$ and $4{ }^{\circ} \mathrm{C}$ for $5 \mathrm{~min} .120 \mu \mathrm{l}$ of the supernatant were transferred into a new $1.5 \mathrm{ml}$ reaction tube and mixed with $40 \mu \mathrm{l} 4 \mathrm{x}$ SDS sample buffer to serve as total extract (TE). The residual supernatant was transferred into a $1.5 \mathrm{ml}$ ultracentrifuge tube. The pellet was mixed with $150 \mu \mathrm{l} 1.5 x$ SDS sample buffer $\rightarrow$ pellet 1 sample (P1). The supernatant in the ultracentrifuge tube was ultracentrifuged at $29000 \mathrm{rpm}$ and $4{ }^{\circ} \mathrm{C}$ for $30 \mathrm{~min} .120 \mu \mathrm{l}$ of the supernatant were transferred into a new $1.5 \mathrm{ml}$ reaction tube and mixed with $40 \mu \mathrm{l} 4 \mathrm{x}$ SDS sample buffer $\rightarrow$ supernatant sample (S). The residual supernatant was removed and immediately frozen in liquid nitrogen and stored at $-80{ }^{\circ} \mathrm{C}$ for later experiments. $800 \mu$ l CERK1 extraction buffer without Triton X-100 were added in $200 \mu \mathrm{l}$ steps to the pellet, which was resuspended using a plastic micro pistil. The dissolved pellet was centrifuged at $29000 \mathrm{rpm}$ and $4{ }^{\circ} \mathrm{C}$ for $30 \mathrm{~min}$. Again, $120 \mu$ of the supernatant were transferred to a new $1.5 \mathrm{ml}$ reaction tube and mixed with $40 \mu \mathrm{l} 4 \mathrm{x}$ SDS sample buffer $\rightarrow$ wash 1 (W1). This time, the microsomal pellet was dissolved in $800 \mu \mathrm{l}$ CERK1 extraction buffer (with Triton X-100) with a micro pistil. $90 \mu \mathrm{l}$ of the dissolved pellet were transferred into a new $1.5 \mathrm{ml}$ reaction tube and mixed with $30 \mu \mathrm{l}$ $4 x$ SDS sample buffer $\rightarrow$ microsomal pellet (MP). The residual microsomal extract was frozen 
in liquid nitrogen and stored at $-80^{\circ} \mathrm{C}$. The samples mixed with SDS buffer were stored at $-20^{\circ} \mathrm{C}$.

\subsubsection{Denaturing SDS-polyacrylamide gel electrophoresis (SDS-PAGE)}

For separation of proteins according to their molecular mass the Mini-PROREAN ${ }^{\circledR} 3$ system (BioRad) was used. First, resolving gels with the appropriate percentage (see below) were prepared and poured between two glass plates with a spacing of $1.5 \mathrm{~mm}$ set in a gel stand. Immediately, the gel solution was completely overlaid with isopropanol. After the gels had polymerized, the isopropanol was poured off and any residual isopropanol was removed by wiping with a piece of Whatman ${ }^{\circledR}$ paper. Next, the stacking gel was prepared and poured onto the resolving gels and a comb was inserted on top to form the sample pockets. After polymerization of the stacking gel, the gels between the glass plates were either directly used or wrapped in damp paper towels and stored in plastic bags in the fridge.

Table 8. Composition of resolving and stacking gels used in this study.

\begin{tabular}{|c|c|c|}
\hline \multirow[t]{4}{*}{ Resolving gel $(8 \%, 10 \mathrm{ml})$} & $8 \%$ resolving gel buffer & $7.2 \mathrm{ml}$ \\
\hline & $\begin{array}{l}30 \% \text { acrylamide/ Bis solution, } \\
29: 1\end{array}$ & $2.7 \mathrm{ml}$ \\
\hline & $10 \%$ APS & $0.1 \mathrm{ml}$ \\
\hline & TEMED & $0.006 \mathrm{ml}$ \\
\hline \multirow[t]{4}{*}{ Resolving gel $(10 \%, 10 \mathrm{ml})$} & $10 \%$ resolving gel buffer & $6.6 \mathrm{ml}$ \\
\hline & $\begin{array}{l}30 \% \text { acrylamide/ Bis solution, } \\
29: 1\end{array}$ & $3.3 \mathrm{ml}$ \\
\hline & $10 \%$ APS & $0.1 \mathrm{ml}$ \\
\hline & TEMED & $0.004 \mathrm{ml}$ \\
\hline \multirow[t]{4}{*}{ Resolving gel $(12 \%, 10 \mathrm{ml})$} & $10 \%$ resolving gel buffer & $5.9 \mathrm{ml}$ \\
\hline & $\begin{array}{l}30 \% \text { acrylamide/ Bis solution, } \\
29: 1\end{array}$ & $4.0 \mathrm{ml}$ \\
\hline & $10 \%$ APS & $0.1 \mathrm{ml}$ \\
\hline & TEMED & $0.004 \mathrm{ml}$ \\
\hline \multirow[t]{4}{*}{ Stacking gel $(10 \mathrm{ml})$} & Stacking gel buffer & $8.16 \mathrm{ml}$ \\
\hline & $\begin{array}{l}30 \% \text { acrylamide/ Bis solution, } \\
29: 1\end{array}$ & $1.66 \mathrm{ml}$ \\
\hline & $10 \%$ APS & $0.05 \mathrm{ml}$ \\
\hline & TEMED & $0.005 \mathrm{ml}$ \\
\hline
\end{tabular}

Gels for direct use were placed in the gel apparatus and put in the running tank before filling the tank with 1x SDS running buffer. Samples which had not yet been boiled were boiled before loading on to the gels. Next, the combs were carefully removed from the gels and the samples were then loaded into the gel pockets. The volume loaded depended on the protein 
concentration of the samples and size of the pocket. As size standard the PageRuler ${ }^{\mathrm{TM}}$ Prestained Protein Ladder (Fermentas ${ }^{\mathrm{TM}}$ ) was used. The SDS-PAGE was run at $30 \mathrm{~mA}$ per gel until an appropriate separation of the proteins was achieved. After disassembling the gel apparatus, the gels were then either directly stained with Coomassie Brilliant Blue (CBB) (2.2.5.9) or used further for immunoblot analysis (2.2.5.7).

\subsubsection{Immunoblot analysis}

After SDS-PAGE the gels were released from the glass plates and the stacking gel was cut off. To transfer the separated proteins from the gel onto a polyvinylidene difluoride (PVDF) membrane with a pore size of $0.45 \mu \mathrm{m}$, the gel and the membrane were assembled in the transfer cassette according to the manufacturer's instruction (BioRad) and placed in a blotting tank filled with $1 \mathrm{x}$ transfer buffer. The transfer was performed at $100 \mathrm{~V}$ for $2 \mathrm{~h}$. After disassembly of the blotting cassette, the membranes were blocked with $1 \times$ TBS-T containing $3 \%$ milk powder for $1 \mathrm{~h}$ at room temperature. Next, the blocking solution was poured off and the membranes were incubated with the primary antibody in $1 \mathrm{x}$ TBS-T $+3 \%$ milk powder overnight at $4{ }^{\circ} \mathrm{C}$ under slow constant shaking. The primary antibody solution was removed and the membranes briefly rinsed with $1 \times$ TBS-T $+3 \%$ milk powder before being washed $6 \times$ for 15 min with $1 \times$ TBS-T $+3 \%$ milk powder on a rotary shaker. After discarding the TBS-T $+3 \%$ milk powder from the last washing step, the secondary antibody diluted in $1 \times$ TBS-T with $3 \%$ milk powder was added. The membranes were then incubated for $2 \mathrm{~h}$ at room temperature under slow constant shaking. After removing the antibody solution, the membranes were again washed $6 \times$ with $1 \times$ TBS-T (without milk powder) as described before. The TBS-T was then replaced by AP buffer, in which the membranes were incubated for 10 min under constant shaking. The membranes were then incubated in Immun-Star ${ }^{\mathrm{TM}}$ substrate for $5 \mathrm{~min}$ before they were placed in a plastic bag and transferred into a exposure cassette. The luminescence was then detected by exposing the membranes to an X-ray film. To visualize protein amounts, membranes were stained with $C B B$ afterwards (2.2.5.9).

To enhance the detected signal and reduce the background in aGFP Western blots, the SuperSignal $^{\mathrm{TM}}$ Western Blot Enhancer (Thermo Scientific ${ }^{\mathrm{TM}}$, Life Technologies $\mathrm{GmbH}$, Darmstadt, Germany) was used according to the manufacturer's instructions.

\subsubsection{In vitro kinase assay}

His- and GST-tagged fusion proteins used in this assay were obtained from Jan Erwig (Erwig, 2012). Proteins were heterologously expressed in E. coli. GST-tagged fusion proteins were purified via glutathione magnetic beads (Pierce ${ }^{\mathrm{TM}}$, Thermo Fisher; Erwig, 2012) and Histagged fusion proteins were purified by binding to His Mag Sepharose Ni magnetic beads (GE Healthcare, Freiburg, Germany) according to the manufacturer's purification protocol for high capacity. 
For the in vitro phosphorylation assay different combinations of the fusion proteins were incubated together as indicated in Figure 15. To each reaction, $2 \mu \mathrm{l} 10 \mathrm{x}$ kinase buffer and $148 \mathrm{kBq}\left[\gamma^{32}-\mathrm{P}\right]-\mathrm{ATP}$ were added and the reaction was filled up to $20 \mu \mathrm{l}$ with water. During pipetting, reactions were kept on ice. The reactions were then incubated for $30 \mathrm{~min}$ at room temperature before being stopped by adding $4 \times$ SDS loading dye and boiling at $95{ }^{\circ} \mathrm{C}$ for 2 min. The proteins were then separated by SDS-PAGE (2.2.5.6) and the gels were stained with Coomassie Brilliant Blue (2.2.5.9). After destaining, the gels were placed on a Whatman ${ }^{\circledR}$ paper covered with a cling film and dried at $80{ }^{\circ} \mathrm{C}$ for $\sim 2 \mathrm{~h}$ using a vacuum gel dryer. Then they were exposed to AGFA CRONEX 5 X-ray films (Agfa HealthCare, Mortsel, Belgium) overnight.

For visualization of protein amounts, Western blots were performed with kinase reactions performed in parallel which lacked the $\left[\gamma^{32}-\mathrm{P}\right]-\mathrm{ATP}$. The membranes were probed with $\alpha \mathrm{His}$ and $\alpha$ GST antibodies simultaneously.

\subsubsection{Coomassie staining of SDS-PAGE gels and membranes}

For visualization of proteins, polyacrylamide gels and PVDF membranes were stained with Coomassie Brilliant Blue. For this the gels/ membranes were placed in a plastic box and covered with Coomassie staining solution. Membranes were incubated for 2 min and gels for $30 \mathrm{~min}$ at room temperature while shaking. Then the staining solution was removed and the gels/ membranes rinsed with water. Background staining was removed by incubation in destaining solution until only protein bands were stained. The staining solution was removed and the membranes/gels rinsed twice with water. 


\section{Results}

The results chapter of this work is divided into three parts. The first chapter describes the identification of the receptor-like cytoplasmic kinase (RLCK) CERK1-INTERACTING LySM-RLKLIKE RLCK1 (CLR1), in silico analyses and sequence comparisons with Arabidopsis LysM receptor-like kinases. In the second part three independent homozygous CLR1 T-DNA mutant alleles were isolated and analysed regarding their genetic requirement for CERK1dependent chitin signalling. The CLR1 alleles were tested for chitin-induced defence responses and the involvement of CLR1 in immunity against fungal and bacterial pathogens was assessed. The third chapter describes the generation of CLR1 fusion proteins for analysis in biochemical assays and localization studies using confocal laser scanning microscopy (CLSM).

\subsection{Identification and in silico analysis of CERK1-INTERACTING LysM-RLK-LIKE RLCK1 CLR1}

Despite the crucial role of Arabidopsis CERK1 in chitin perception and signalling, only little is known about its complex partners and possible downstream targets. A yeast two-hybrid screen with the CERK1 intracellular domain was initiated and performed by Hybrigenics (Paris, France) in order to identify putative intracellular interactors and components of the signalling cascade downstream of CERK1. The intracellular domain of CERK1 (amino acids 254-617) was used as a bait to screen a prey cDNA library from 1-week-old Arabidopsis seedlings. From the total clones obtained in the yeast two-hybrid assay, the single clone which contained a prey fragment of $1167 \mathrm{bp}$, corresponding to amino acids 83-456 of an uncharacterized protein kinase superfamily protein encoded by At3g57120 was further analysed (Figure 3). According to The Arabidopsis Information Resource (TAIR) genome annotation (Lamesch et al., 2012), At3g57120 is a single exon gene with a coding region of $1371 \mathrm{bp}$. 
$5^{\prime}$ UTR

AGCTTAAAAGACCTCTATATAAATATGTATCTGTCAAACACAAAAGTTACATGTATAGAGAGAAAACAAAAGAAGAGTAGACTTCCCATCATCCTCCGCTATAATGCGC At3g57120

CACTCTCCGCGTTATCTATAATACGCTAGTATTCCGTGCCCGCTATAATGCGCAAGTCTCCGTCTCAGCCTCTCTTCGCCGTCTGATGTCTGATCTTCTAGGTCACCTCCA

CAAATTCGAACAAGAATTTGTCTTTATGTGCAAAACCAAAATGGGAGTCAATGCTTCAGAGCCAAAACGAACACGATCGCGACCAAGTCAATCGCAGGGGAGGCA TCCGTCGACGAGACGATCTCCGTCAACGAGCAACACCGGCACAACAACAACCACGACGACATCGAATTCTAACAAAACTGGTGCCTCCTCTTCCTCCTCCGGTGCG GCTTCTTCCTCAGTCGCTAGTCGAACATCTCTCGCTAGTCTCCGAGAATCCTTACCGGAAAATCCTCACATATACAACGTCTCCGAGATTCGTGCCGCTACCAACAATT TCCTCGCTAATCGCTTATCTTCCTCTTCCTCTAAAGCCTCCTGGCGTTGCAATTTAAGAGGGAAAGAAGTCGTTGTGTTTCAGAGAAAGTTTAGGCGAAGGATCGAC ACGGATGAGCTTAGAGATCGTCTTTCAGATATTTGCCGGAGCCACCACGGAAGCATCATTAATCTACTCGGCGCTTCTGTTTCCGGCGGTGGAAGAGTAGGAGGAG GAGGAGGAGGAGGAGGTGATCACATCTACTTGGTCTACGAATACGTCAACGGAGCATCTCTAGCTGATTGCTTGAGAAACCCTAAGAACCCTAAATTTACAGTTCTA TCGAATTGGACTTCACGGATTCAAATTGCAACAGATCTAGCTCATGGACTCGATTACATCCACAACAAAACCGGATTAAAGATCGAAAACCTAGTTCACAATCACATC AAGAGCTCGGCGGTGATCGTGACGGAGCCAGATTTCAACGCTAAGATCTGTCACTTCGGAACTGCGCAGCTTTGCGGCGAAACAGATGAAATGTCACTGGAGAG AGACGAATCGAGAAATTCAAGGCGATCTGATAGCAGAGCGATCAGATTCGAAGGAGTTAGAGGTTACATGTCGCCGGAATTTCAAAATTTGGGAATCGCTACTCAG AAATCGGATGTTTACGCTTTCGGAGTTATGATGTTGGAGCTTCTCTCAGGCGAGGAGCCGTTGAAGTACAGGTATGATAAAGCCACAGGAGATTTCGAGCGGACGT CGGTGATTGAAACGGCGAGAGCGGCGATCGAAGATGGAGATGGTGATAGAGATGGAAGACTGAGGAGGTGGATGGATCGGAGATTGGAGGATTCGTTTCCTGT GACGGTGGTGGAGAAGTTAACGAGGCTAGCGTTGGATTGTGTTCAGGATGATCCAGTGAATAGGCCGGAGATGGGAAGAGTCGCCGGAAAAATATCACAACTGT $3^{\prime}$ UTR ATTTAGAATCGGAAAAATGGTCGGCGAATATGAAACGGCCAACGGATATCACCGTCTCTTTCGCTCCCAGATGAGGGAATCTTCTTATTCCTTTTTTCAAAAGATGT

Figure 3. Genomic sequence of At3g57120 obtained from TAIR10 with the At3g57120 prey fragment retrieved from a single clone in a yeast two-hybrid screen with the CERK1 intracellular domain. The 1371 bp coding sequence of the single exon gene At3g57120 is shown in black with the putative start codon marked in red and the stop codon shown in bold black. The 5' and 3' untranslated regions are indicated in orange. The sequence of the $1167 \mathrm{bp}$ long prey fragment obtained in the yeast two-hybrid assay is underlined in green.

Analysis with the NCBI Conserved Domain Database online tool (NCBI CDD, http://www.ncbi.nlm.nih.gov/Structure/cdd/wrpsb.cgi; Marchler-Bauer et al., 2015) identified the At3g57120 protein as a serine/threonine protein kinase (calculated Expect (E) value of 4.65e-21). Analysis with the Basic Local Alignment Search Tool (BLAST, blastp NCBI, http://blast.ncbi.nIm.nih.gov/Blast.cgi; Altschul et al., 1997) using the At3g57120 amino acid sequence as query against the Arabidopsis proteome database revealed that the identified protein shares high homology to Arabidopsis LysM-RLKs (data not shown). Among the first four hits with the highest alignment scores are three described LysM-RLKs, as well as a yet uncharacterized putative receptor-like protein. LYK3 (At1g51940) showed the highest match to the At3g57120 sequence with a E value of 5e-45, followed by LYK1/ CERK1 and LYK5 with E values of $3 e-31$ and $4 e-30$, respectively. 


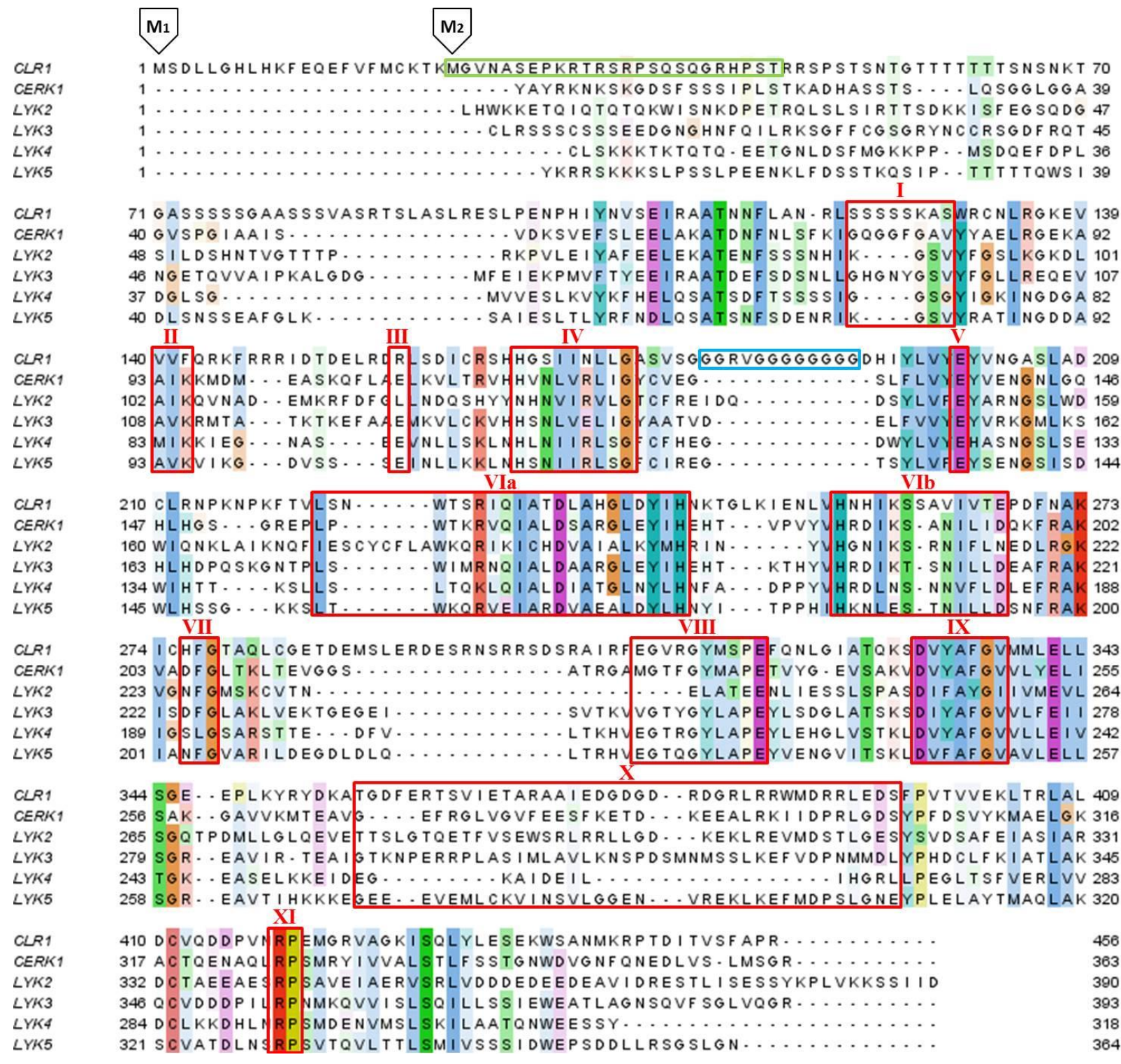

Figure 4. Amino acid sequence alignment of CLR1 (At3g57120) with the intracellular domains of the five Arabidopsis lysin motif-containing receptor-like kinases (LysM-RLKs). The kinase subdomains I-XI are shown as red boxes. The myristoylation motif of CLR1 was predicted with Podell and Gribskov, 2004 (http://plantsp.genomics.purdue.edu/myrist.html) and is indicated by a green box. Framed with a blue box is the putative glycine-rich nuclear localization motif (Cokol et al., 2000). The alignment was generated in Geneious 7.1.7 using the ClustalW algorithm (Kearse et al., 2012). Colouring was performed in Jalview 2.8.2 using the Clustalx settings with a conservation threshold of 30 (Waterhouse et al., 2009).

In particular, the amino acids in the kinase subdomains (I-XI) show a high level of conservation comparing the sequence of At3g57120 to that of the other LysM-RLKs (Figure 4). Interestingly, also an amino acid stretch $\mathrm{N}$-terminal of the kinase subdomain I shares high homology among the depicted proteins (Figure 4). Protein kinases contain ten subdomains (Hanks and Hunter, 1995). Subdomains I-V are required for ATP-binding and subsequently for the activity of the corresponding kinase. Important conserved features involved in ATP binding are the GxGxxG-motif (P-loop) in subdomain I, a conserved lysine (K) 
in subdomain II and a nearly invariant glutamate (E) residue in subdomain III (Hanks and Hunter, 1995). All these motifs/residues are absent in the amino acid sequence of At3g57120, suggesting that it constitutes an inactive kinase. CLR1 also lacks conserved amino acids in subdomain VIb (catalytic loop), subdomain VII (magnesium binding loop) and subdomain VIII. The activation loop which spans subdomains VII and VIII and is involved in switching the kinase activity on and off (Taylor and Radzio-Andzelm, 1994) contains an insertion of several amino acids in At3g57120. Taken together, these variations in the kinase domain make it very unlikely for the At3g57120 protein to have enzymatic activity.

No transmembrane domain or extracellular domain was predicted for the protein encoded by At3g57120, making it a member of the class of receptor-like cytoplasmic kinases (RLCKs). Phylogenetic analyses assigned At3g57120 specifically to the RLCK subfamily XII (Shiu and Bleecker, 2003). Due to the lack of an extracellular domain and sequence homology to the kinase domain of LysM-RLKs we named the protein encoded by At3g57120 CERK1INTERACTING LySM-RLK-LIKE RLCK1 (CLR1).

In the TAIR10 genome annotation (Lamesch et al., 2012) CLR1 is predicted to be a protein of 456 amino acids. However, analysis with a plant specific myristoylation prediction tool (PlantsP; Podell and Gribskov, 2004) revealed a putative internal N-myristoylation motif that lies 23 amino acids C-terminal of the annotated $\mathrm{N}$-terminus (Figure 4, green box). Typically, $\mathrm{N}$-myristoylation is a co-translational protein modification where the $\mathrm{N}$-terminal methionine is removed from the growing peptide and an N-myristoyltransferase (NMT) attaches a myristic acid residue to the now N-terminal glycine at position two (Johnson et al., 1994; Thompson and Okuyama, 2000). However, it is also known that myristoylation can occur post-translationally. Here, a mature protein is enzymatically cleaved to expose a previously internal glycine residue (Zha, 2000; Martin et al., 2011). This raises the question whether the start codon annotated for CLR1 in TAIR10 is correct or the protein in fact starts at the methionine associated with the $\mathrm{N}$-myristoylation motif. The methionine encoded by the originally predicted start codon is named $M_{1}$ and the methionine at position 23 is named $M_{2}$ for the remainder of this work (Figure 4). If CLR1 starts at $M_{1}$, CLR1 is either not myristoylated or is subject to post-translational cleavage behind $M_{2}$ in order to expose the internal glycine residue for $\mathrm{N}$-myristoylation to take place. In the alternative scenario the open reading frame of CLR1 is misannotated and the actual start of the protein is $M_{2}$. 
Besides the putative $\mathrm{N}$-terminal myristoylation motif CLR1 harbours a glycine-rich segment inserted between the kinase subdomains IV and V (Figure 4). This stretch of amino acids might constitute an uncommon nuclear localization signal (NLS) with potential DNA-binding ability (Cokol et al., 2000). Glycine-rich sequences near the C-terminus have been reported to mediate nuclear import in some proteins, including the human heterogeneous NUCLEAR RIBONUCLEOPROTEIN (hnRNP) A1, which is involved in alternative pre-and mRNA splicing as well as in regulating telomere length (Siomi and Dreyfuss, 1995; Cokol et al., 2000). In Arabidopsis a hnRNP homolog, RNP1, and a glycine-rich (RNA-binding) protein, AtGRP7 were reported to have a glycine-rich sequence shown to be important for nuclear import of the two proteins which is similar to that present in hnRNP A1 (Ziemienowicz et al., 2003). For AtGRP7 a role in alternative (pre-mRNA) splicing was demonstrated, regulating a feedback loop which negatively controls the circadian rhythm (Heintzen et al., 1994; Heintzen et al., 1997).

Based on BLAST analysis (NCBI blastp, http://blast.ncbi.nlm.nih.gov/Blast.cgi; Altschul et al., 1997, the CLR1 protein is encoded by a single copy gene in Arabidopsis. However, related proteins can be found in other plant species (data not shown). The majority of these proteins are not yet characterized but predicted to be LysM domain receptor-like kinases of a similar length to the CLR1 sequence. Since, like CLR1, they probably only resemble the kinase domain of LysM proteins, these predicted proteins could represent orthologues of CLR1.

\subsection{Characterization of CLR1 mutant lines}

In order to analyse the involvement of CLR1 in MAMP signalling and immunity, homozygous CLR1 T-DNA knockout mutant alleles were isolated and tested for chitin-induced signalling and defence responses. Furthermore, the CLR1 T-DNA insertion mutants were used to investigate the role of CLR1 in immunity towards pathogens, including biotrophic powdery mildews, a necrotrophic fungus and different bacterial pathogens. 


\subsubsection{CLR1 T-DNA insertion mutant lines used in this study}

All T-DNA insertion mutants used in this work were obtained from the Nottingham Arabidopsis Stock Centre (NASC). Three independent alleles of CLR1, namely clr1-1 (SALK_102100), clr1-3 (GK-267B04) and clr1-4 (GK-416D04) were characterized in this work. The schematic gene structure of the single exon gene CLR1 and the position of T-DNA insertions in the characterized lines are depicted in Figure $5 \mathrm{~A}$.

A

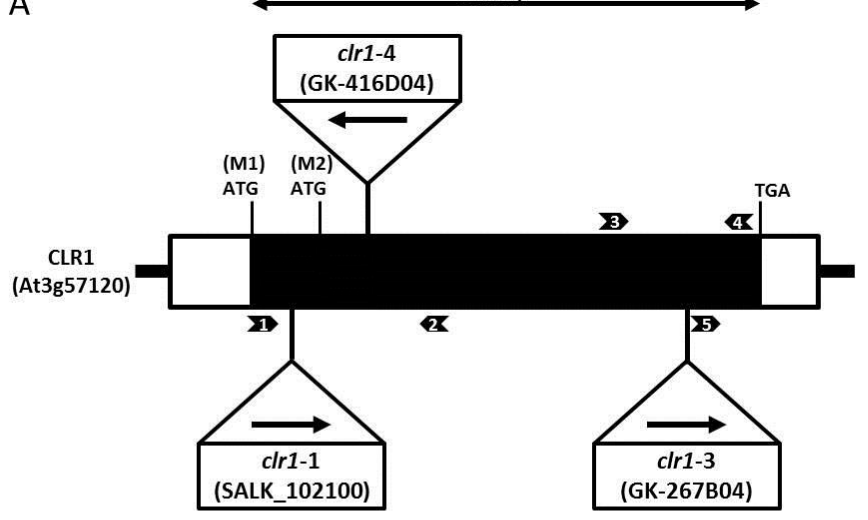

C

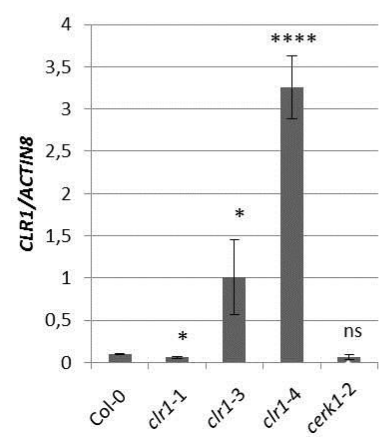

D

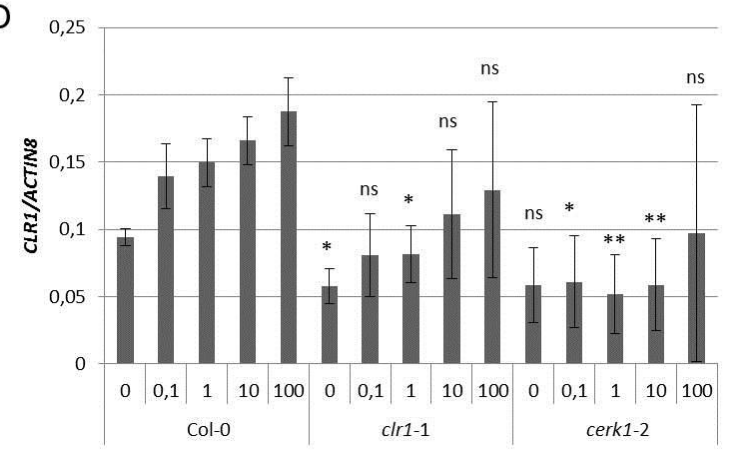

Figure 5. Position of T-DNA insertions in CLR1 and transcript analysis in clr1 mutants. (A) Schematic depiction of the CLR1 gene structure. CLR1 consists of only one $1371 \mathrm{bp}$ exon. The transcribed region of CLR1 is indicated as black box. Start and stop codons are labelled with ATG and TGA, respectively. White boxes represent the ' 5' and 3' untranslated region of the mRNA. The T-DNA insertions are shown as triangles and arrows indicate the orientation of the left T-DNA border. Primers used for genotyping and RT-PCR are indicated as arrow heads. (B) Semi-quantitative RT-PCR in leaves confirms transcript disruption in clr1 mutants. PCR reactions were performed using the flanking primers indicated in A. Expression of Actin1 was analysed to demonstrate equal cDNA concentrations. Col-0 cDNA as well as gDNA were used as wild type and genomic controls, respectively. The no template control (NTC) was used to rule out contamination or primer dimer formation in the reactions. (C) qRT-PCR analysis of transcripts downstream of clr1 T-DNA insertions reveals a moderate knockdown in clr1-1, and enhanced transcript levels in clr1-3 and clr1-4. Primers 4 and 5, as indicated in A, were used for the analysis in two-week-old in vitro grown seedlings. Col-0 and cerk1-2 were included as positive and negative control, respectively. Actin8 served as reference gene. The bars represent the mean \pm STDEV of three biological replicates consisting of four technical repetitions. Asterisks indicate statistical significance of the mutants compared to Col-0 (**** $=p \leq 0.0001, * * *=p \leq$ $0.001, * *=p \leq 0.01, *=p \leq 0.05, n s=p>0.05)$. P-values were calculated using the unpaired student's t-test. D) qRT-PCR shows that CLR1 is moderately chitin inducible. Two-week-old in vitro grown seedlings of the indicated lines were treated with the chitin concentrations indicated, ranging from $0 \mu \mathrm{g} / \mathrm{ml}$ to $100 \mu \mathrm{g} / \mathrm{ml}, \mathrm{for}$ $30 \mathrm{~min}$. The samples were further processed and analysed as described in (C). 
The clr1-1 T-DNA insertion is located between the two possible start codons $\left(M_{1}\right.$ and $M_{2}$, compare chapter 3.1) and thus may not have an effect if CLR1 translation starts at $M_{2}$. In contrast, clr1-3 and clr1-4 insertions are downstream of the second possible start codon, likely disrupting both possible variants of the CLR1 protein. Homozygous mutant plants were identified via PCR-based genotyping and the positions of the T-DNAs were verified by sequencing. Subsequently, homozygous plants were analysed for disruption of the fulllength transcript by semi-quantitative reverse transcriptase PCR (RT-PCR) with CDNA-specific primers flanking the T-DNA insertions (Figure $5 \mathrm{~B}$ ).

Transcript analysis was performed in leaves and two different primer combinations were used. The first combination (P1+P2) spans the two T-DNA insertions in the 5 ' region of the gene (c/r1-1 and clr1-4) while the second combination (P3+P4) flanks the T-DNA insertion clr1-3 in the 3 ' region (Figure 5 A). PCR with flanking primers shows that the clr1-1, clr1-3, as well as clr1-4 T-DNA insertions disrupt the full-length CLR1 transcript (Figure 5 B). PCR with the non-flanking primer pair revealed the presence of upstream transcripts in c/r1-3 and downstream transcripts in clr1-1 and clr1-4. Expression of the 3' transcript appeared to be enhanced in clr1-4 compared to the Col-0 wild type. To address this question further, quantitative reverse transcriptase PCR (qRT-PCR) was performed in seedlings using primers P4 and P5 to amplify the transcripts $3^{\prime}$ of all CLR1 T-DNA insertions (Figure $5 \mathrm{C}$ ). Indeed, clr1-4 as well as clr1-3 showed significantly enhanced transcript levels $3^{\prime}$ of the T-DNA insertions. These transcripts are likely derived by strong promoters present in the T-DNAs. Compared to Col-0, clr1-1 showed a moderate reduction in expression of the CLR1 transcript, suggesting that it might have a mild knockdown effect on CLR1 even if the translation starts at $M_{2}$. In order to investigate if CLR1 expression itself is chitin responsive, seedlings were treated with different concentrations of polymeric chitin (Figure $5 \mathrm{D}$ ) and CLR1 transcripts were analysed by real-time PCR with primers P4 and P5. In Col-0, CLR1 expression was slightly induced by chitin in a dose-dependent manner. The same effect could be observed in clr1-1 (albeit at somewhat lower levels), but not in the CERK1 knockout mutant cerk1-2 (Miya et al., 2007). 


\subsubsection{Chitin-induced phosphorylation of CERK1 and MAPKs in clr1 mutants}

To assess the involvement of CLR1 in CERK1-mediated chitin signalling, CLR1 T-DNA lines were tested for chitin induced CERK1 phosphorylation. CERK1 phosphorylation is a very early chitin response and can be visualized as a distinctive band shift of the CERK1 full-length protein in SDS-PAGE (Petutschnig et al., 2010). The band shift was analysed in clr1-1, clr1-3 and clr1-4. Col-0 and cerk1-2 served as controls, as well as pb/27-1, a mutant of a RLCK reported to function downstream of CERK1 (Shinya et al., 2014). Leaves of four-week-old Arabidopsis plants were either vacuum-infiltrated with $\mathrm{H}_{2} \mathrm{O}$ or polymeric chitin to induce CERK1 phosphorylation and the consequent CERK1 mobility shift. Total protein extracts were prepared and used in a Western blot which was developed with a CERK1 specific antibody (Petutschnig et al., 2010; Figure 6). CERK1 has a predicted molecular mass of 67.3 kDa and migrates at around $70 \mathrm{kDa}$ in SDS-PAGE. Col-0 showed a clear signal and chitin-induced band shift for CERK1. As expected, the knockout mutant cerk1-2 did not contain any CERK1 protein. A band shift indicating phosphorylation of CERK1 was detected in all clr1 T-DNA lines to a comparable degree as in Col-0. Also in pb/27-1 CERK1 phosphorylation seemed similar to the wild type Col-0.

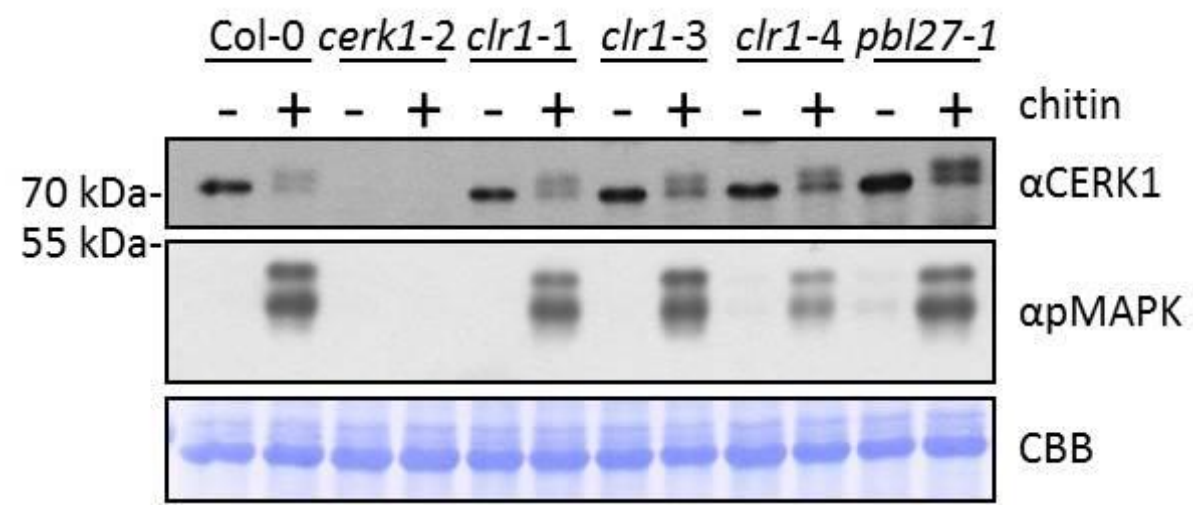

Figure 6. Immunoblot analyses of cIr1 T-DNA insertion mutants show chitin-induced phosphorylation of CERK1, MPK3 and MPK6. Total protein extracts from leaf tissue of four-week-old Arabidopsis plants after vacuum-infiltration with $\mathrm{H}_{2} \mathrm{O}(-)$ or $100 \mu \mathrm{g} / \mathrm{ml}$ polymeric chitin (+) were loaded. Samples were separated on $10 \%$ SDS-PAGE. Membranes were either probed with aCERK1 or apMAPK antibodies. Equal loading was monitored by staining the membrane with Coomassie Brilliant Blue (CBB). CERK1 has a molecular weight of $67.3 \mathrm{kDa}$. Phosphorylated MPK3 and MPK6 appear at a molecular weight of $43 \mathrm{kDa}$ and $46 \mathrm{kDa}$, respectively. The experiment was repeated three times with similar results.

One downstream event in chitin signalling after phosphorylation of the chitin receptor CERK1 is the activation of mitogen-activated protein kinase (MAPK) cascades (Miya et al., 2007). Activation, and hence phosphorylation of two MAPKs, MITOGEN-ACTIVATED PROTEIN 
KINASE3 and -6 (MPK3 and MPK6), can be readily visualized in immunoblot analyses using an antibody (aMAPK) which specifically recognizes their phosphorylated form (Shinya et al., 2014). MPK3 and MPK6 are important positive regulators of plant disease resistance due to their involvement in multiple defence signalling pathways (Han et al., 2010, 2010; Galletti et al., 2011; Mao et al., 2011). To analyse the role of CLR1 in chitin-induced activation of MAPK signalling cascades, phosphorylation of MPK3 and MPK6 upon chitin treatment was investigated in the clr1 mutants, with Col-0, cerk1-2 and pb/27-1 as controls.

To do so, the protein extracts used for CERK1 band shift analysis (see above) were used in a Western blot probed with the antibody specific for phosphorylated MAPKs (Phospho-p44/42 MAPKs/ apMAPK; Figure 6). The two bands detected with apMAPK correspond to the MAPKs MPK3 (43 kDa) and MPK6 (46 kDa) (Zhao et al., 2014). In all tested clr1 T-DNA lines MPK3 and - 6 were activated upon chitin treatment similarly to Col-0, except for clr1-4 where a reduced degree of MAPK activation could be seen. The Coomassie Brillant Blue (CBB) stained membrane indicates equal loading of the samples, suggesting that the weaker signal for phosphorylated MPK3 and MPK6 in clr1-4 was due to reduced signal transduction. pb/27-1 knockout lines were reported to show reduced chitin-induced MAPK phosphorylation (Shinya et al., 2014) but surprisingly, MAPK activation was similar to the wild type in this study.

\subsubsection{MAMP-induced generation of reactive oxygen species in CLR1 mutants}

Activation of PRRs results in rapid production of reactive oxygen species (ROS) by NADPH oxidases at the cell surface, which is a commonly analysed early MAMP-induced defence response (Torres et al., 2006). The ability of the different clr1 T-DNA mutant lines to generate ROS upon treatment with the fungal elicitor chitin was investigated in a luminolbased assay with L-012 (Figure 7). 

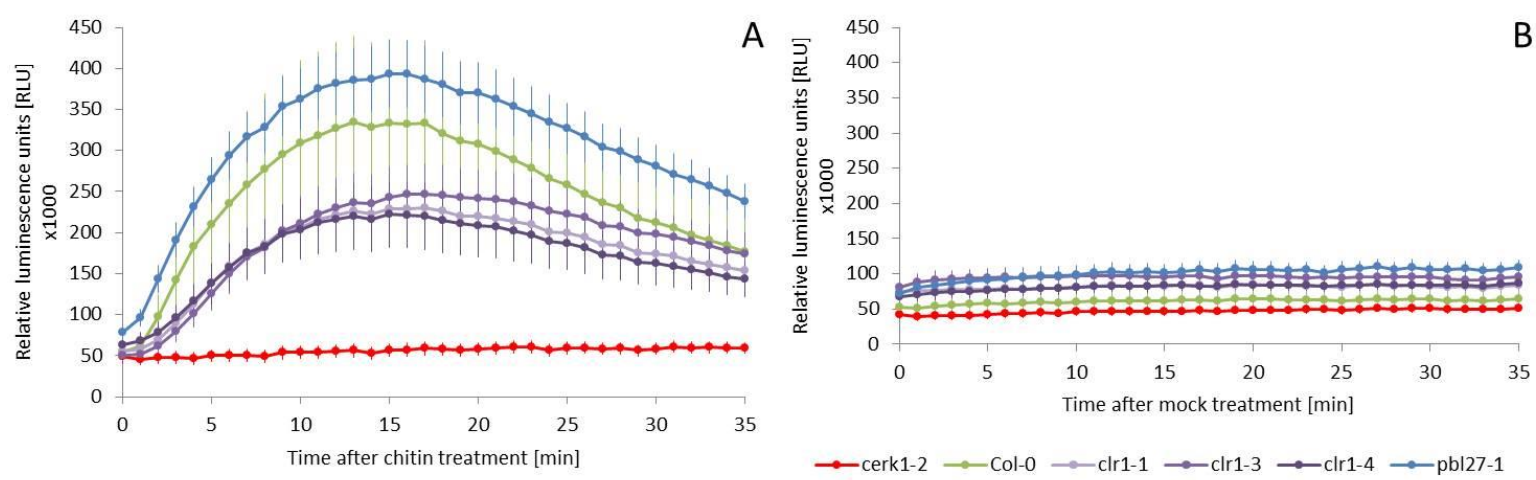

Figure 7. cIr1 mutants show reduced ROS-generation upon chitin treatment. Leaf discs of five-week-old Arabidopsis plants were either treated with $100 \mu \mathrm{g} / \mathrm{ml}$ polymeric chitin (A) or mock treated with buffer (B). Relative luminescence units (RLU) were measured for $\mathbf{3 5} \mathrm{min}$ after the respective treatment. The data are shown as mean of 12 leaf discs per genotype \pm SE. The experiment was repeated three times with similar results.

In addition to the three clr1 alleles, wild type Col-0, cerk1-2 and pb/27-1 were included as controls. Although PBL27 is involved in regulating chitin-induced defence responses the generation of ROS is not impaired in pb/27 mutants (Shinya et al., 2014). As described previously (Miya et al., 2007; Petutschnig et al., 2010) chitin did not induce a ROS burst in cerk1-2 (Figure 7 A). All three clr1 mutants showed reduced chitin-induced ROS generation compared to Col-0 in the three independent experiments, suggesting that CLR1 is required for full activation of ROS generating enzymes (Figure 7 A; Suppl. Figure 1). In pb/27-1 the ROS burst was not decreased in comparison to Col-0, which is in agreement with previous reports (Shinya et al., 2014). pb/27-1 even appeared to have a slightly higher chitin-induced ROS production, but more sensitive methods would be required to investigate the significance of this. None of the tested lines showed induction of ROS burst without elicitor treatment in the mock-treated assay (Figure $7 \mathrm{~B}$ ).

\subsection{4 cIr1 T-DNA mutants show reduced expression of MAMP-induced genes after chitin polymer and chitin heptamer treatment}

After the very early MAMP-triggered signalling events such as receptor phosphorylation, ROS burst and MAPK activation, defence-related genes are induced. Among many others, the expression of several genes from the WRKY-transcription factor family was shown to be upregulated upon treatment with chitin and other MAMPs (Wan et al., 2004; 2008). To test whether lack of functional CLR1 leads to alterations in chitin-induced expression of defence 
genes, qRT-PCR was performed. For this, the expression of WRKY30, WRKY33 and WRKY53, was monitored in response to different polymeric chitin concentrations in the clr1 mutants, Col-0 and cerk1-2. In all of the tested lines, apart from cerk1-2, a clear dose-dependent induction in expression of the three WRKYS was visible (Figure 8). The expression of WRKY3O and WRKY53 in the clr1-3 and clr1-4 mutants was significantly lower than in Col-0 at all tested chitin concentrations (Figure $8 \mathrm{~A}$ and C). clr1-1 showed an intermediate phenotype between Col-0 and the other two clr1 mutant alleles. The expression of WRKY33 was reduced in clr1-3 and clr1-4 only at lower chitin concentrations (Figure 8 B). The obtained results lead to the assumption that CLR1 contributes to chitin-induced expression of defence-related genes and that different genes might be affected to different degrees. 

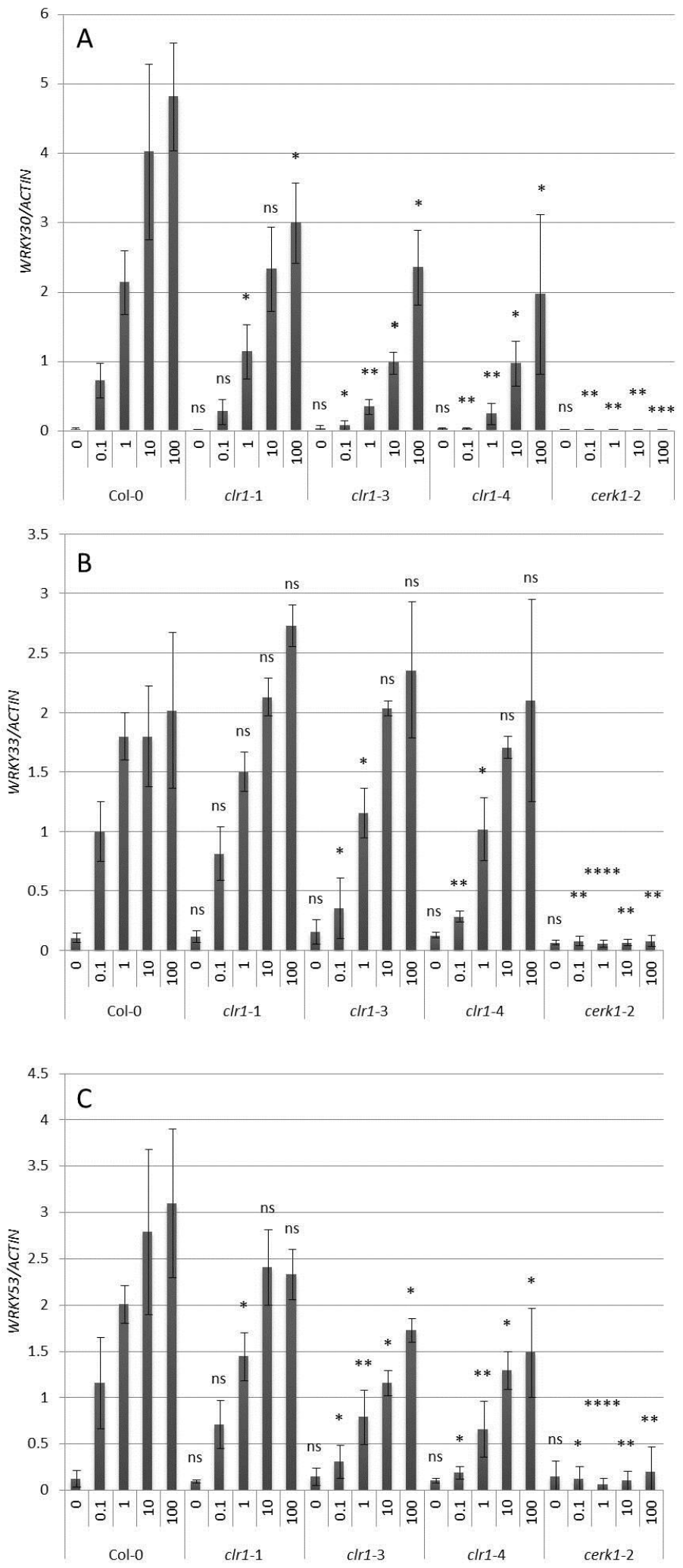

Figure 8. Chitin-induced expression of WRKY30, WRKY33 and WRKY53 is reduced in the clr1 mutants. Twoweek-old in vitro grown seedlings of the depicted clr1 Arabidopsis mutants were treated with the chitin concentrations indicated, ranging from $0 \mu \mathrm{g} / \mathrm{ml}$ to $100 \mu \mathrm{g} / \mathrm{ml}$, for $30 \mathrm{~min}$. Col-0 and cerk1-2 were included as positive and negative control, respectively. qRT-PCR of the following genes was performed: (A) WRKY30, (B) WRKY33, (C) WRKY53. ACTIN8 served as a reference gene. The bars represent the mean \pm STDEV of three biological replicates consisting of 4 technical repetitions each. Asterisks indicate statistical significance of the mutants compared to Col-0 ( $* * * *=p \leq 0.0001, * * *=p \leq 0.001, * *=p \leq 0.01, *=p \leq 0.05, n s=p>0.05)$. P. values were calculated using the unpaired student's t-test. 
Besides polymeric chitin, also fully acetylated chitin oligomers are able to induce CERK1mediated immune responses in Arabidopsis (Miya et al., 2007; Wan et al., 2008; Petutschnig et al., 2010; Liu et al., 2012). Chitin oligomers with a polymerization degree $\geq 5$ are efficiently able to induce CERK1-dependent immune responses as for example CERK1 band shift, ROS burst and MAPK activation (Petutschnig et al., 2010).

To analyse whether chitin oligomers have the same effect on WRKY gene expression as observed for seedlings treated with polymeric chitin (Figure 8), the previous experiments were repeated with chitin heptamer (7mer; Figure 9). Similar to the results obtained after treatment with polymeric chitin, the 7 mer treatment resulted in a significant induction of WRKY3O, WRKY33 and WRKY53 expression compared to mock treatment in all tested genotypes apart from cerk1-2. Also, the 7mer-induced expression of the WRKYS was significantly reduced in clr1-3 and clr1-4 compared to Col-0 (Figure 9). The reduction of WRKY expression levels in clr1-1 however was not significant. 

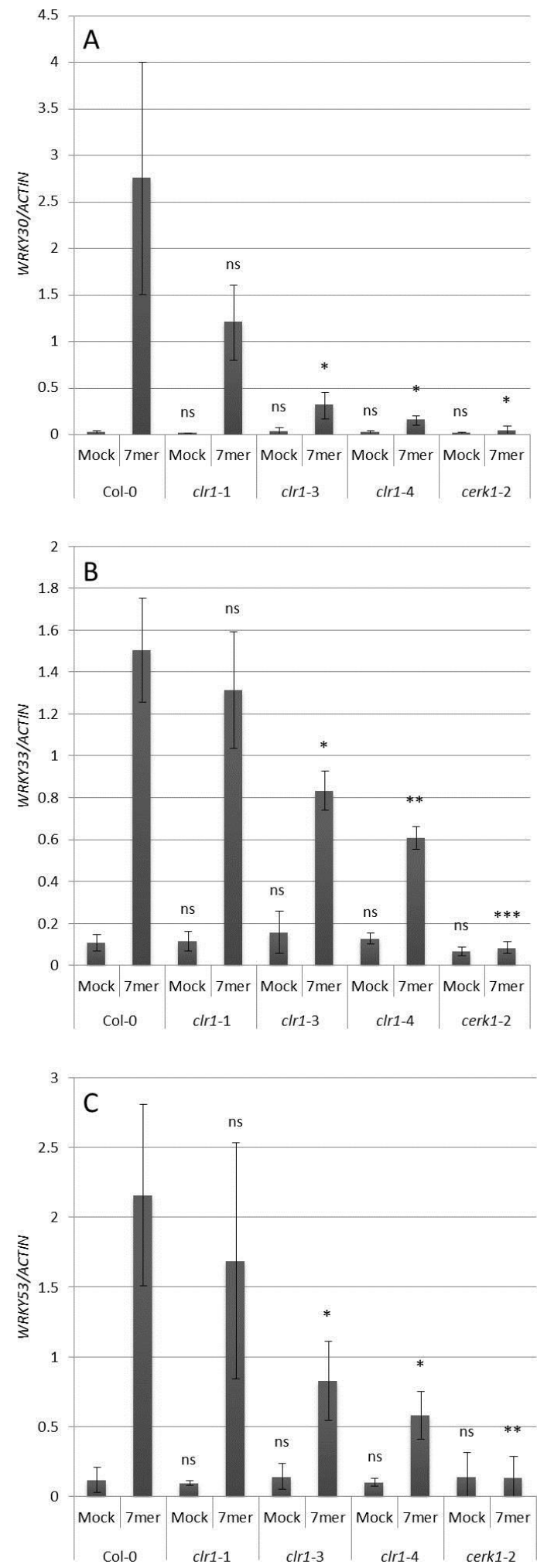

Figure 9. Expression levels of WRKY30, WRKY33 and WRKY53 are significantly reduced in clr1-3 and clr1-4 mutants after treatment with chitin heptamer ( $7 \mathrm{mer}$ ). Two-week-old in vitro grown Arabidopsis seedlings of the indicated clr1 mutants were treated with $1 \mu \mathrm{M} 7 \mathrm{mer}$ for $30 \mathrm{~min}$. Col-0 and cerk1-2 were included as positive and negative control, respectively. qRT-PCR of the following genes was performed: (A) WRKY3O, (B) WRKY33, (C) WRKY53. ACTIN8 served as a reference gene. The bars represent the mean \pm STDEV of three biological replicates consisting of 4 technical repetitions. Asterisks indicate statistical significance of the mutants compared to Col-0 (**** $=p \leq 0.0001, * * *=p \leq 0.001, * *=p \leq 0.01, *=p \leq 0.05$, ns $=p>0.05)$. P. values were calculated using the unpaired student's t-test. 


\subsubsection{Identification of specifically chitin-induced genes and their analysis in clr1 mutants}

The reduction of chitin-induced expression of WRKY30, WRKY33 and WRKY53 in clr1 mutants was relatively moderate. Also, the three WRKY genes appeared to be reduced to different degrees, indicating that CLR1 might affect some MAMP-responsive genes more than others. In an attempt to identify genes whose expression might be more strongly dependent on CLR1, chitin-specific marker genes were investigated. Since the majority of chitin-responsive genes are not only induced by chitin, but also after elicitation with other MAMPs publicly available microarray data were analysed in order to identify exclusively chitin-induced genes. Only studies using the Affymetrix ATH1 gene chip and Arabidopsis seedlings were included to ensure comparability of the data and are listed in Table 9. The gene expression data from these studies were compared and 27 genes were found to be induced after both chitin octamer (8mer) and crab shell chitin (CSC) treatment but not after treatment with flg22 or elf18/elf26 (Suppl. Table 1).

Table 9. List of studies used for selection of specifically chitin-induced genes. Microarrays were performed with plant material from Arabidopsis seedlings using the full-genome Affymetrix Gene Chip ${ }^{\circledR}$ (ATH1).

\begin{tabular}{ll}
\hline Publication & Treatment \\
\hline \hline Ramonell et al., 2005 & $1 \mu \mathrm{M}$ chitooctamer or $100 \mu \mathrm{g} / \mathrm{ml}$ crab shell chitin mixture; 30 min \\
Mészáros et al., 2006 & $1 \mu \mathrm{M}$ flg22; $30 \mathrm{~min}$ \\
Navarro et al., 2004 & $10 \mu \mathrm{M}$ flg22; $30 \mathrm{~min}$ \\
Tintor et al., 2013 & $1 \mu \mathrm{M}$ elf18; $2 \mathrm{~h}$ \\
Zipfel et al., 2004 & $10 \mu \mathrm{M}$ flg22, 30 min \\
Zipfel et al., 2006 & $1 \mu \mathrm{M}$ elf26, 30 min \\
\hline
\end{tabular}

From the 27 genes specifically upregulated after chitin treatment (Suppl. Table 1), two genes with high fold induction compared to mock treatment were selected as putative marker genes for further analysis by qRT-PCR in this work. The first gene is At4g16820, coding for DAD1-LIKE LIPASE 1 (DALL1, Ruduś et al., 2014), which showed a 37-fold induction after 8mer treatment and 42-fold induction after CSC treatment. At3g43250, a gene of yet unknown function, was the second gene selected for further analysis. It showed a 23-fold induction after 8 mer treatment and a 30 -fold induction after CSC treatment compared to the mock-treated controls (Ramonell et al., 2005). 
As described above, clr1 mutant seedlings were treated with different concentrations of polymeric chitin and Col-0 and cerk1-2 served as controls. qRT-PCR confirmed the chitin responsiveness of the two putative chitin-specific novel marker genes. In Col-0, the expression of both genes increased with the concentration of polymeric chitin. In cerk1-2, this induction did not occur (Figure 10).
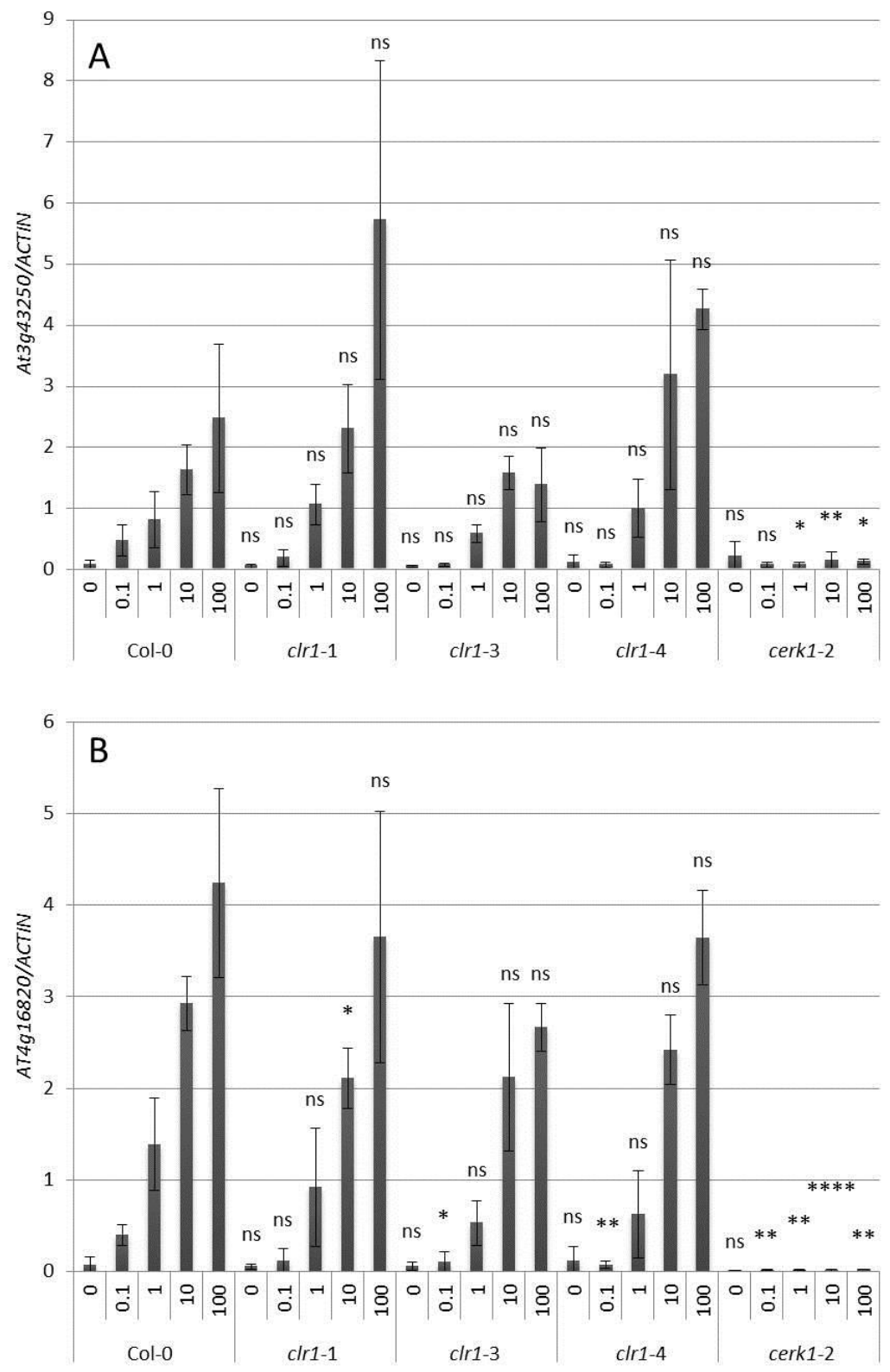

Figure 10. Expression levels of putatively chitin-specific marker genes (At3g43250, At4g16820) was not clearly reduced in clr1 mutants after chitin treatment. Two-week-old in vitro grown seedlings of the indicated $c / r 1$ mutants were treated with the chitin concentrations indicated, ranging from $0 \mu \mathrm{g} / \mathrm{ml}$ to 100 $\mu / \mathrm{ml}$, for $30 \mathrm{~min}$. Col-0 and cerk1-2 were included as positive and negative control, respectively. Quantitative RT-PCR of the following genes was performed: (A) At3g43250, (B) At4g16820. ACTIN8 served as a reference gene. The bars represent the mean \pm STDEV of three biological replicates consisting of 4 technical repetitions. Asterisks indicate statistical significance of the mutants compared to Col-0 (**** $=p \leq 0.0001$, $* * *=\mathrm{p} \leq 0.001, * *=\mathrm{p} \leq 0.01, *=\mathrm{p} \leq 0.05, \mathrm{~ns}=\mathrm{p}>0.05)$. P-values were calculated using the unpaired student's t-test. 
For At3g43250 no significant difference regarding the expression levels could be observed for the clr1 mutants compared to Col-0 (Figure 10 A). For At4g16820, chitin-induced expression levels appeared to be reduced in clr1-3 and clr1-4 at low chitin concentrations, but not at higher ones. The expression of the two potential specifically chitin-induced genes At3g43250 and At4g16820 was also assessed upon treatment with chitin heptamer (Suppl.

Figure 2). The overall induction was low and variability between experiments was high. Consequently, the obtained results were not informative.

The high variation between the biological replicates of At3g43250 and At4g16820 could be due to their low expression levels. Because of this technical limitation and the fact that no clear difference between Col-0 and clr1 mutants was observed, the response of these genes to other MAMPs was not investigated further.

\subsubsection{Involvement of CLR1 in immunity against biotrophic and necrotrophic fungal pathogens}

Early MAMP-triggered defence responses such as the generation of ROS, activation of MAPK signalling cascades and expression of defence genes result in immunity towards nonadapted plant pathogens. Since CLR1 was found to interact with CERK1 (see chapter 3.1) and showed reduced chitin-induced gene expression, we hypothesized that it might be involved in MAMP-triggered immunity against fungi and possibly also other pathogens. To test this hypothesis, several pathogen assays were conducted in this work.

First infection assays with the pea powdery mildew Erysiphe pisi were performed. This pathogen is not adapted to Arabidopsis and cannot grow to macroscopically visible levels on wild type Col-0. However, Arabidopsis mutants with impaired non-host resistance have been described that allow growth of this pathogen (Lipka et al., 2005). PENETRATION2 (PEN2) encodes a glycosyl hydrolase, that is important for pre-invasion resistance (Lipka et al., 2005). The pen 2 mutant allows higher penetration rates of non-adapted powdery mildews, which leads to increased cell death formation (Lipka et al., 2005). PHYTOALEXINEDEFICIENT4 (PAD4) and SENESCENCE-ASSOCIATED GENE101 (SAG101) are two structurally related lipase-like proteins. Both are involved in post-invasion resistance and TIR-NB-LRR Rprotein-mediated immune responses (Feys et al., 2005). In the triple mutant 
pen2 pad4 sag101 both pre- and post-invasion non-host resistance are impaired, thus this mutant is susceptible to $E$. pisi.

As expected, no growth of E.pisi could be seen on Col-0 macroscopically 11 days after inoculation, but was clearly visible on pen2 pad4 sag101. The pen2 single mutant showed slight chlorosis, which is in agreement with enhanced cell death. For the clr1-1 and clr1-3 mutants, no fungal growth could be detected macroscopically (Figure 11). Also, no cell death lesions could be observed, which suggests normal penetration rates and resistance.

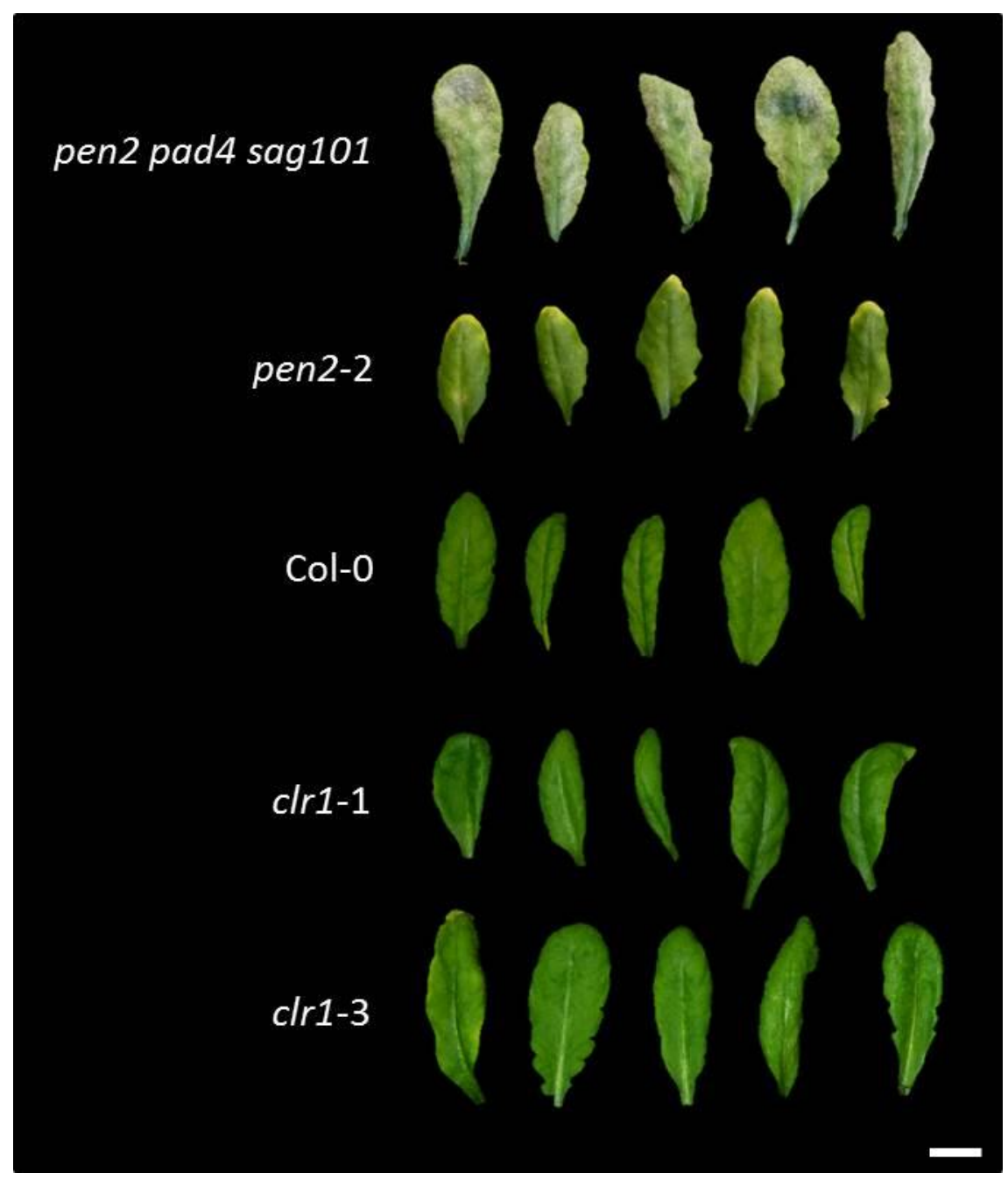

Figure 11. The macroscopic Erysiphe pisi infection phenotype of clr1 mutants resembles the wild type. Fourweek-old plants of the indicated Arabidopsis mutants were inoculated with the non-adapted powdery mildew E. pisi. pen2-2 and pen2 pad4 sag101 serve as controls impaired in pre-invasion and nonhost resistance, respectively. Pictures were taken $11 \mathrm{dpi}$. The size standard corresponds to a length of $1 \mathrm{~cm}$. 
Next, the interaction of clr1 mutants with the adapted powdery mildew Golovinomyces orontii was tested (Figure 12). Besides the wild type Col-0 and the highly susceptible triple mutant pen2 pad4 sag101, a mutant of ENHANCED DISEASE RESISTANCE1 (edr1) was included as a more resistant control. The protein kinase EDR1 negatively regulates disease resistance and its loss leads to enhanced resistance to different fungal and bacterial pathogens (Frye and Innes, 1998). In the G. orontii infection experiment, the enhanced susceptibility of pen2 pad4 sag101 could be clearly observed as dense growth of fungal mycelium on the leaf surface (Figure 12). After inoculation with the powdery mildew $G$. orontii edr1 plants start to develop chlorotic lesions on the leaves and fungal growth was strongly reduced compared to wild type (Figure 12). The clr1 mutants showed no obvious differences compared to the wild type Col-0 seven days post-inoculation (Figure 12), suggesting normal levels of susceptibility to $G$. orontii.

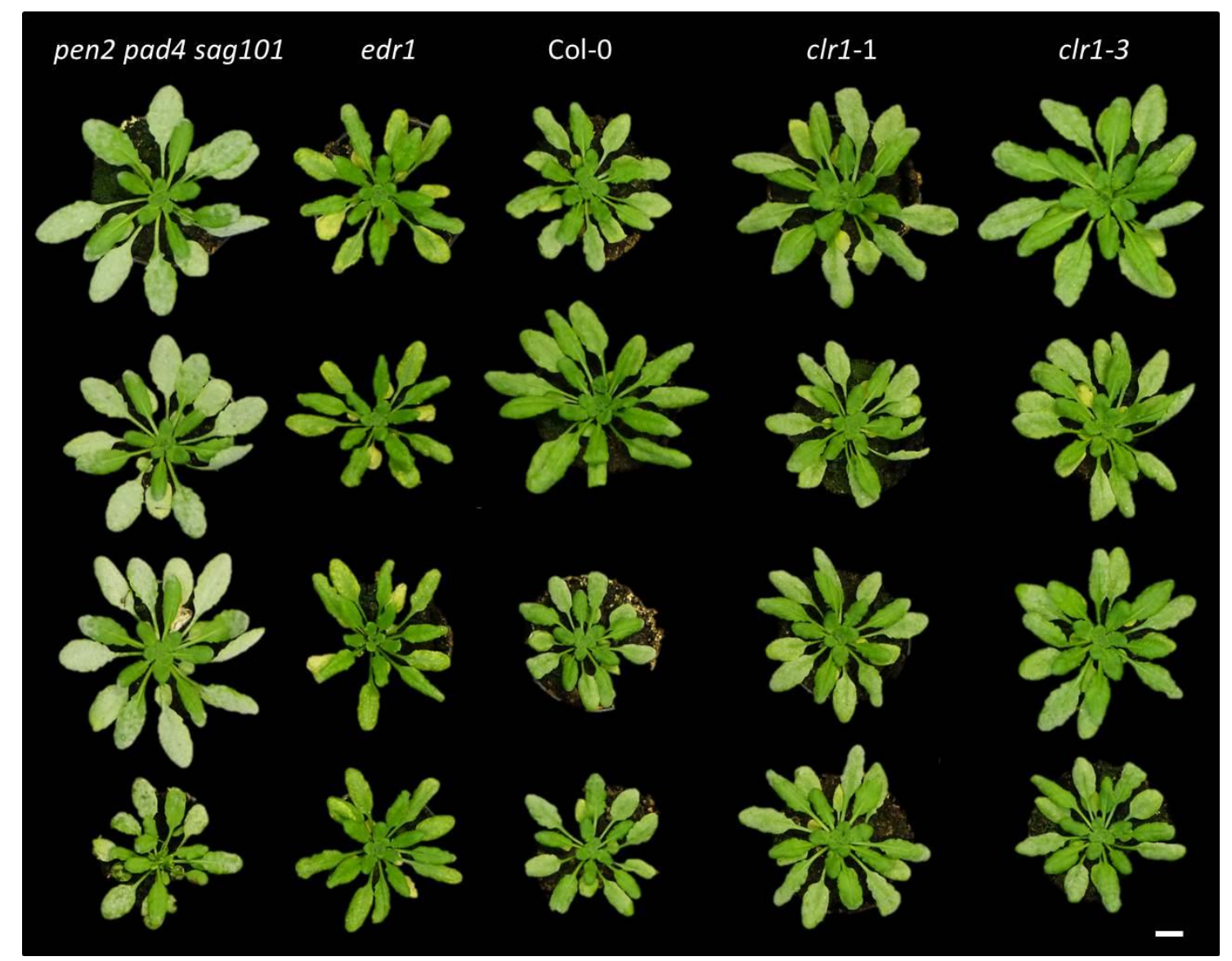

Figure 12. clr1 mutants show wild type-like resistance to Golovinomyces orontii. Four-week-old wild type and mutant Arabidopsis plants were inoculated with G. orontii and pictures were taken 7 dpi. pen 2 pad4 sag101 serves as susceptible control, whereas edr1 represents as more resistant control, compared to the wild type Col-0. The standard corresponds to a length of $1 \mathrm{~cm}$. 
Miya et al., (2007) and Wan et al., (2008) showed enhanced susceptibility of the cerk1-2 T-DNA mutant line against the incompatible fungal pathogen Alternaria brassicicola implying a role for CERK1 in defence against necrotrophic fungi. Thus, the necrotrophic fungal pathogen Botrytis cinerea was used to assess the involvement of CLR1 in defence responses against necrotrophic fungi. In this assay, lesion size correlates with the level of susceptibility. Besides Col-0 as wild type control, mpk3 as a more susceptible mutant was included in this assay (Han et al., 2010, 2010; Galletti et al., 2011; Mao et al., 2011). Upon B. cinerea infection, mpk3 showed bigger lesions than the wild type (Figure 13). cerk1-2 and the clr1 mutant lines tested showed no significant differences compared to Col-0.

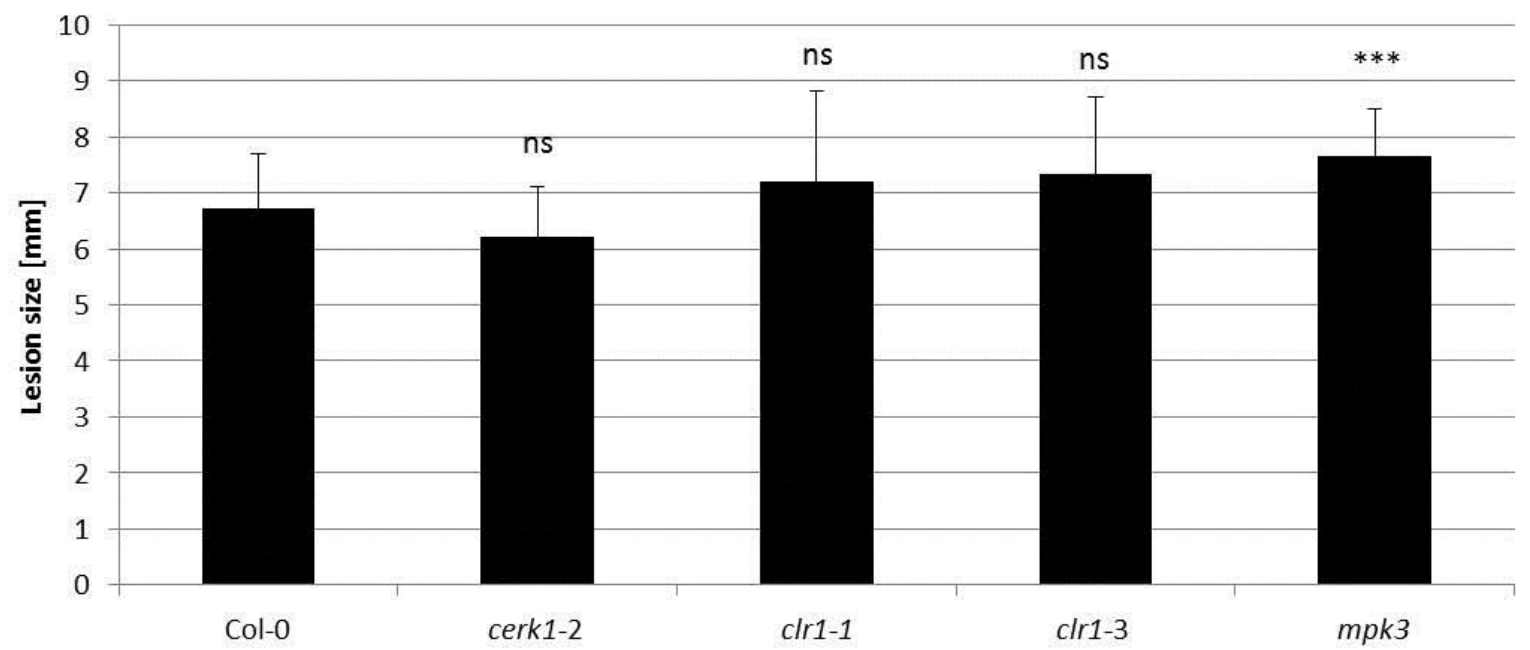

Figure 13. clr1 mutants are not significantly altered in resistance towards the fungal pathogen Botrytis cinerea. Four-week old Arabidopsis wild type and mutant plants were drop-inoculated with $B$. cinerea droplets containing $5 \times 10^{4}$ spores $/ \mathrm{ml}$. Per leaf a $6 \mu \mathrm{l}$ droplet was applied beside the mid leaf vein. Lesion diameters were measured macroscopically $3 \mathrm{dpi}$ with a calliper rule. Depicted are the mean \pm STDEV of 24 inoculation sites (one site per leaf, three leaves per plant). Statistically significant differences of the mutants compared to Col- 0 are indicated by asterisks. $* * *=p \leq 0.001$, $n s=p>0.05$. P-values were calculated using unpaired student's t-test (GraphPad Software QuickCalcs (http://www.graphpad.com/quickcalcs/ttest1/). The experiment was repeated twice with similar results.

\subsubsection{Involvement of CLR1 in immunity towards virulent and avirulent Pseudomonas strains}

Since CLR1 seems not to be involved in defence against the fungal pathogens analysed, the contribution of CLR1 in immunity towards virulent and avirulent Pseudomonas syringae pv. tomato strains was addressed. Previous experiments showed that CERK1 plays a role in restricting bacterial proliferation in Arabidopsis (Gimenez-lbanez et al., 2009b). Thus the 
cerk1-2 mutant was included as a susceptible control. Further mutants used in addition to Col-0 wild type were eds1 (enhanced disease susceptibility1) as more susceptible and snc1 (suppressor of npr1-1, constitutive1) as more resistant control, respectively. EDS1 has been shown to be involved in defence against virulent and avirulent bacterial pathogens (Feys et al., 2005). snc1 was previously demonstrated to be more resistant to the virulent strains Pseudomonas syringae pv. maculicola ES4326 and Pseudomonas syringae pv. tomato DC3000 (Li et al., 2001; van Hulten et al., 2006). Three different Pseudomonas syringae pv tomato (Pst) strains were used in this work: The virulent Pst DC3000 (-), the weakly virulent Pst DC3000 ( $\triangle$ avrPto/DavrPtoB) and the non-pathogenic Pst DC3000 (hrcC). Pst DC3000 ( $\triangle$ avrPto/DavrPtoB) lacks two secreted effectors that suppress MAMP perception and one of them (AvrPtoB) has been shown to mediate degradation of CERK1 (M de Torres et al., 2006; Xiang et al., 2008; Göhre et al., 2008; Gimenez-Ibanez et al., 2009a). The type III secretion system (TTSS) mutant Pseudomonas strain Pst DC3000 ( $\mathrm{hrcC}$ ) is secretion-defective and thus only very weakly or rather non-pathogenic (Laluk et al., 2011). None of the tested clr1 T-DNA mutants showed significant alterations in resistance against the virulent Pst DC3000 (-) rendering a role of CLR1 in defence against Pst DC3000 (-) unlikely (Figure 14 A). As expected, the snc1 mutant showed significantly enhanced resistance to Pst DC3000 (-), while eds1 was moderately more susceptible. In experiments with Pst DC3000 ( $\triangle$ avrPto/DavrPtoB) clr1-3 and cerk1-2 showed significantly more bacterial growth 3dpi compared to Col-0 (Figure $14 \mathrm{~B}$ ). Although susceptibility was not significantly enhanced, elevated numbers of colony forming units could be observed as a trend for all the other clr1 alleles as well (Figure 14 B). Pst DC3000 ( $\mathrm{hrcC}$ ) showed very little growth on all tested Arabidopsis lines (Figure $14 \mathrm{C}$ ). No significant differences between Col-0 and any of the mutants could be seen, presumably due to the very low virulence of the strain under our experimental conditions. 

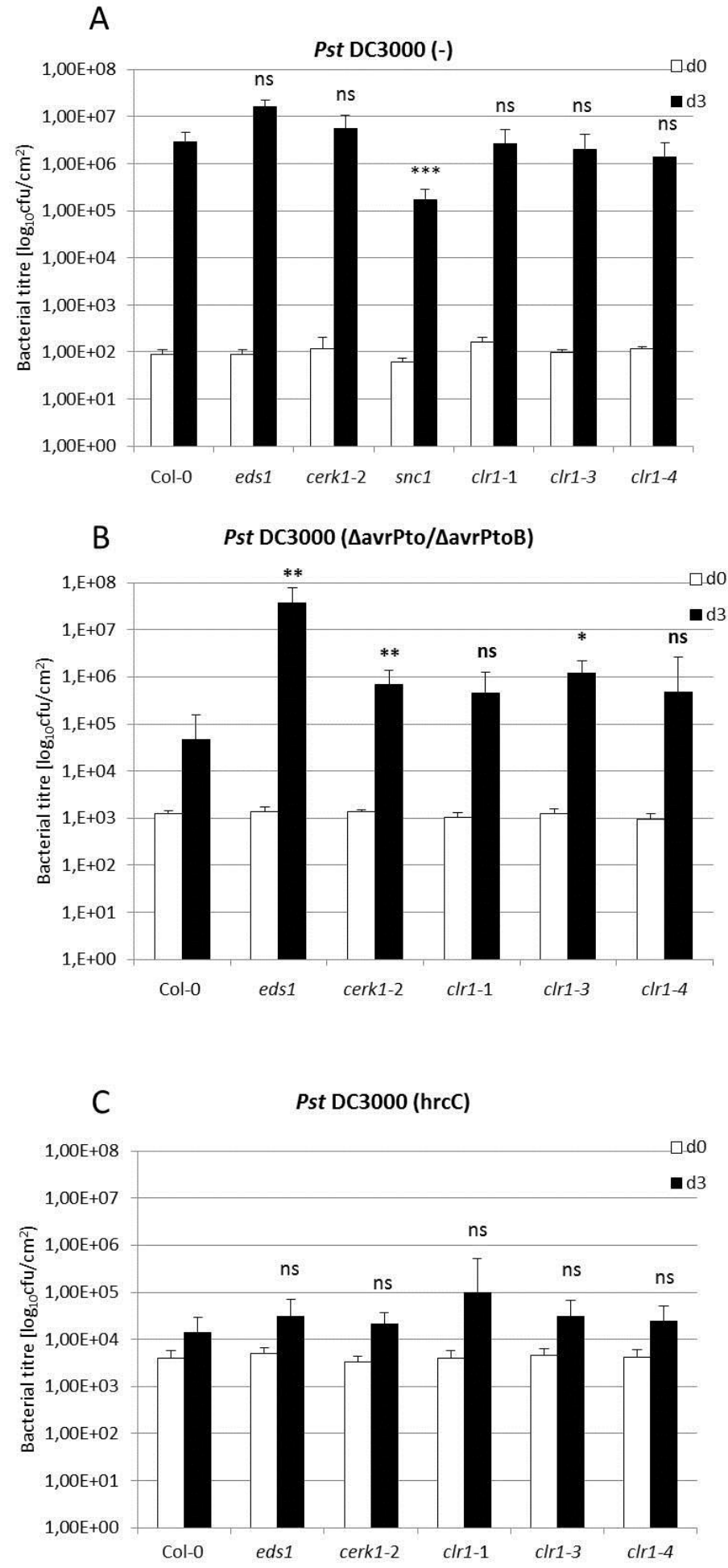

Figure 14. clr1 mutants show wild type-like resistance to Pst DC3000 (-) but are more susceptible to Pst DC3000 ( $\triangle$ avrPto/PtoB). Leaves of four-week-old Arabidopsis plants were vacuum-infiltrated with a bacterial suspension of (A) Pst DC3000 (-) (B) Pst DC3000 (DavrPto/PtoB) or (C) Pst DC3000 (hrcC) at a density of $1 \times 10^{5}$ $\mathrm{cfu} / \mathrm{ml}$. Immediately after infiltration leaf discs were taken for the d0 samples (white bars) to check for equal infiltration. Three days post infiltration leaf discs were harvested for $\mathrm{d} 3$ samples (black bars). d0 samples represent biological duplicates, whereas d3 samples were taken in triplicates. The error bars show the mean of replicates \pm STDEV. Asterisks indicate statistical significance of the mutants compared to Col-0 (*** $=p \leq$ $0.001, * *=p \leq 0.01, *=p \leq 0.05, n s=p>0.05$ ). P-values were calculated using the unpaired student's t-test. Experiment $A$ was performed twice with similar results; experiments $B$ and $C$ were conducted once. 


\subsection{CLR1 phosphorylation studies}

The putative receptor-like cytoplasmic kinase (RLCK) CLR1 was identified in a yeast twohybrid screen due to its interaction with the CERK1 intracellular kinase domain (see section 3.1). The association of RLCKs with receptor-like kinases (RLKs) is an emerging common theme in plants and RLCKs have been reported to play important roles in signalling cascades downstream of numerous RLKs (Macho and Zipfel, 2014). In several cases transphosphorylation events between the kinase domains have been demonstrated and constitute an indispensable mechanism for intracellular signal transduction (Macho and Zipfel, 2014).

\subsubsection{CERK1 phosphorylates CLR1 in vitro}

To investigate whether CLR1 is an active kinase and to characterize transphosphorylation events between CLR1 and CERK1 in vitro phosphorylation assays were performed. For this, the intracellular kinase domains of wild type and enzymatically inactive CERK1, as well as the putative kinase domain of CLR1 were heterologously produced in E.coli and purified via their respective added C-terminal tag. Expression of the active CERK1 intracellular kinase domain fused to a C-terminal 6xHis-tag (CERK1-His) was perfomed as described previously (GimenezIbanez et al., 2009a). Also, the loss-of-function (kinase dead) version of CERK1-His was expressed as has been described before (cerk1-LOF-His; Petutschnig et al., 2010). Since both His-tagged proteins had already been described previously and their activity was shown, the respective constructs were included in this study. CERK1-His and cerk1-LOF-His were purified via nickel magnetic beads. For CLR1, the coding sequence after the predicted myristoylation site (base pairs 144-1371, amino acids $48-456$ based on TAIR10) was fused C-terminally to a glutathione-S-transferase (GST)-tag (GST-CLR1; Erwig, 2012). The resulting fusion protein was expressed in E. coli and purified via its GST-tag. GST alone served as a control protein. In SDS-PAGE, all proteins were detected at their calculated masses (42 kDa for CERK1-His, 71 kDa for GST-CLR1, 27 kDa for GST-tag alone; Figure 15). 


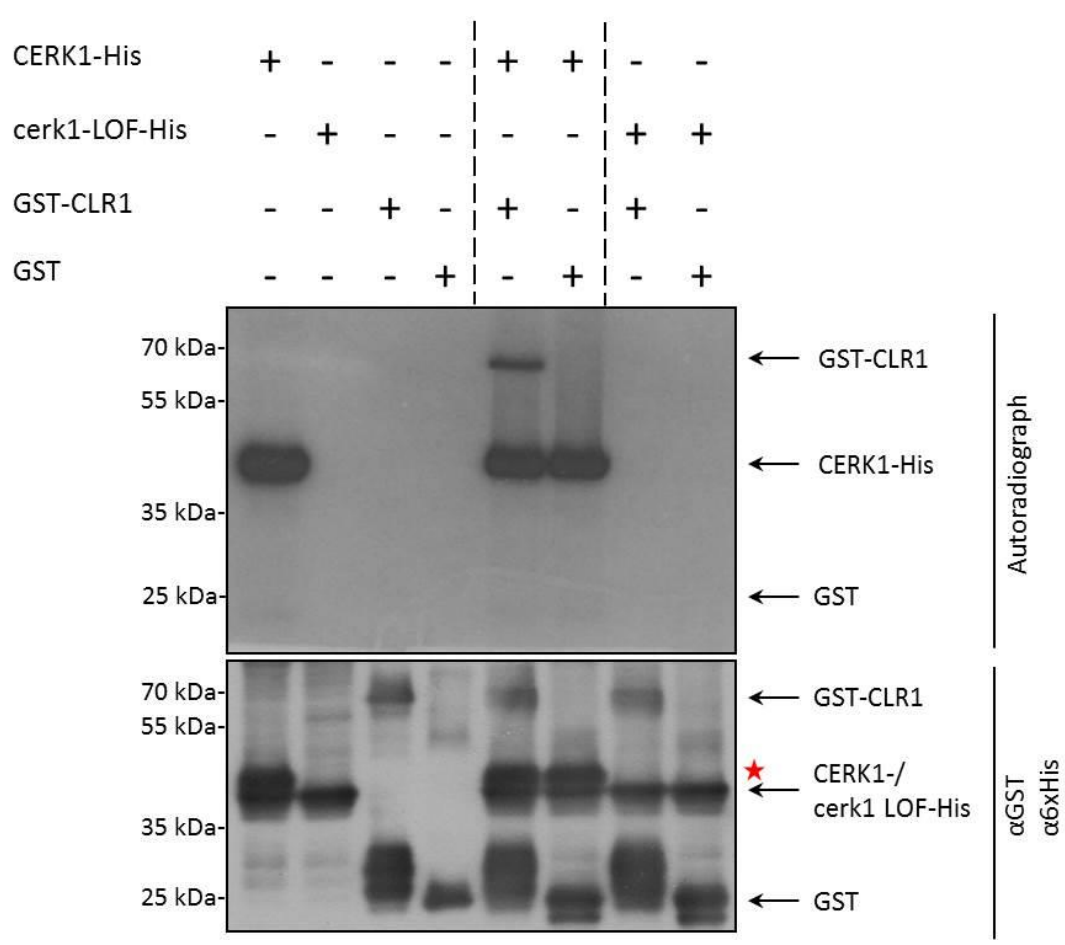

Figure 15. CLR1 is enzymatically inactive, but is transphosphorylated by CERK1 kinase domain in vitro. CLR1 was C-terminally fused to a GST-tag, whereas CERK1 and its kinase dead variant cerk1-LOF were $\mathrm{N}$-terminally fused to a 6xHis-tag. Fusion proteins were heterologously expressed and purified from $E$. coli before being used in an in vitro phosphorylation assay in the presence of [ $\left.\gamma^{32}-\mathrm{P}\right]-A T P$. Upper panel: autoradiograph after SDS-PAGE on $8 \%$ gel. Lower panel: immunoblot with $\alpha \mathrm{GST}$ and $\alpha 6 \mathrm{xHis}$ antibodies of parallel conducted phosphorylation reactions lacking [ $\gamma 32$-P]-ATP. The red star indicates autophosphorylated CERK1. The experiment was repeated three times with similar results.

In in vitro phosphorylation reactions the proteins to be tested were incubated with radioactively labelled $\left[\gamma^{32}-\mathrm{P}\right]-\mathrm{ATP}$. Enzymatically active kinases transfer the radioactive phosphate group to their substrates, facilitating the detection in autoradiographs. First, the intracellular domains of CERK1, cerk1-LOF and CLR1 were tested on their own for autophosphorylation activity (Figure 15, lanes 1-3).

Previous reports showed that the CERK1 kinase domain is active and autophosphorylates in vitro, while the loss-of-function version does not (Petutschnig et al., 2010). These findings were confirmed in this in vitro kinase assay (Figure 15). In the autoradiograph a clear signal for CERK1-His could be detected, but not for cerk1-LOF-His. Also, CERK1-His appeared as a double band in the immunoblot, while cerk1-LOF-His was visible only as a single band. The slower mobility band of CERK1-His likely represents the autophosphorylated form (Figure 15, red star). In agreement with the lacking kinase subdomains identified in the CLR1 amino acid sequence, we were not able to detect any autophosphorylation activity for GST-CLR1. However, it is conceivable that CLR1 may represent a substrate for other active kinases and 
thus this idea was tested in transphosphorylation assays. To do so, GST-CLR1 was incubated either with the His-tagged wild type intracellular domain of CERK1 or the kinase dead variant. Both CERK1 variants were also incubated with only the GST-tag as a negative control (Figure 15, lanes 5-8). In the transphosphorylation assay with CERK1-His, autophosphorylation of CERK1-His is represented by a band at about $42 \mathrm{kDa}$. In addition a band of about $70 \mathrm{kDa}$ corresponding to the GST-CLR1 fusion protein was detected in the same lane. This signal is absent in the transphosphorylation reaction with cerk1-LOF-His

(Figure 15, lane seven), demonstrating CERK1-dependent phosphorylation of CLR1. Any unspecific transphosphorylation of the GST-tag can be excluded since incubation of the GSTtag with CERK1-His showed no signal in the autoradiograph (Figure 15, lane 6).

In summary, in vitro phosphorylation assays confirmed that CLR1 lacks kinase activity and demonstrated that CLR1 is a direct phosphorylation substrate of CERK1 in vitro.

\subsubsection{Chitin-induced and CERK1-dependent phosphorylation of CLR1 in planta}

In order to investigate whether the CERK1-dependent phosphorylation of CLR1 occurs in planta, stably transformed Arabidopsis lines were generated expressing epitope-tagged CLR1. For this, the genomic CLR1 sequence including $1000 \mathrm{bp}$ upstream of the annotated start codon (coding for $M_{1}$ ) was fused to either a C-terminal enhanced cyan fluorescent protein (eCFP)-tag or green fluorescent protein (GFP)-tag. These fusion constructs were stably transformed into Arabidopsis Col-0 and the knockout mutant cerk1-2. Transformants were screened for expression of the transgenic fusion proteins by Western blotting (data not shown), because fluorescence signals were too low for screening by confocal laser scanning microscopy (see below). Stable transgenic lines expressing the $p C L R 1:: C L R 1-e C F P$ construct in Col-0 or cerk1-2 were used for the experiments described below. CERK1 is phosphorylated upon chitin treatment of plants, which is visible as an upward band shift in Western blots (Petutschnig et al., 2010). Thus, the in planta phosphorylation of CLR1 was investigated using the same method. To do so, three independent transgenic lines expressing $p C L R 1:: C L R 1-$ eCFP in Col-0 or cerk1-2 were infiltrated with $100 \mu \mathrm{g} / \mathrm{ml}$ polymeric chitin to induce CERK1 phosphorylation. Col-0 and cerk1-2 were used as controls (Figure 16). 

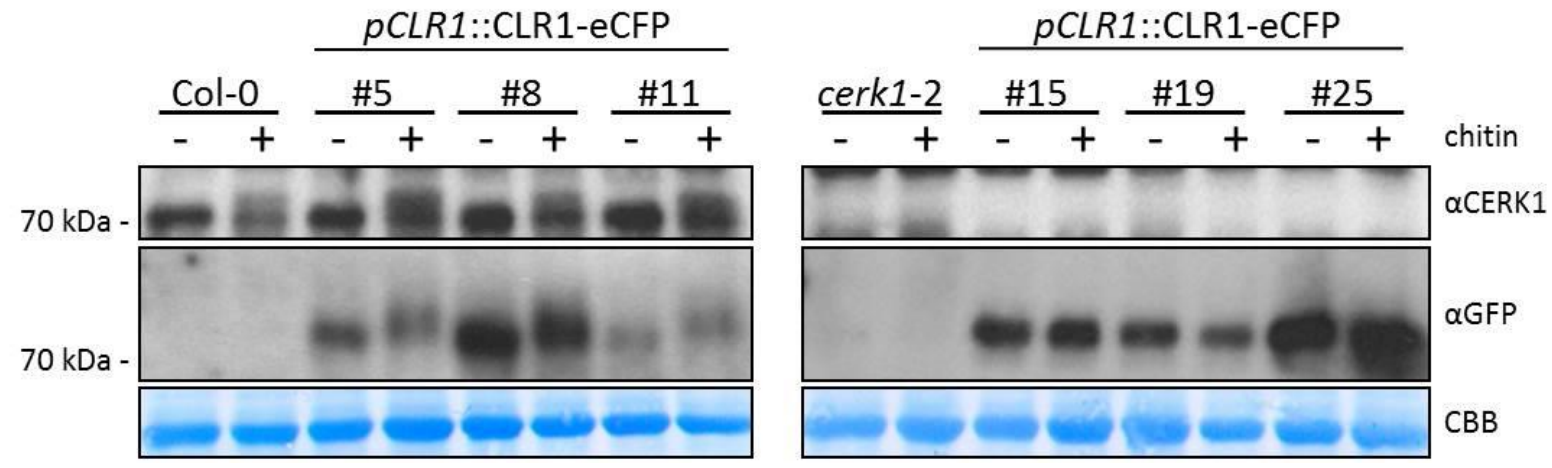

Figure 16. CERK1 and $p C L R 1:: C L R 1-e C F P$ show chitin-induced mobility shift in planta. pCLR1::CLR1-eCFP was stably expressed either in the Col-0 background (left section) or in the cerk1-2 background (right section). Shoots of two-week-old Arabidopsis seedlings were vacuum-infiltrated with $100 \mu \mathrm{g} / \mathrm{ml}$ polymeric chitin and incubated for $\mathbf{3 0} \mathrm{min}$. Western blots of total protein extracts developed with $\alpha$ CERK1 and $\alpha$ GFP antibodies are shown. The bottom panel depicts the Coomassie Brillant Blue (CBB)-stained membrane used as loading control. The experiment was repeated three times with similar results.

Western blots were performed with total protein extracts and probed either with aCERK1 or aGFP antibodies to detect CERK1 and CLR1-eCFP, respectively. The chitin-induced CERK1 band shift could readily be observed in the three transgenic $p C L R 1:: C L R 1-e C F P$ expressing Col-0 lines (\#5, \#8, \#11, Figure 16). As expected, the transgenic plants expressing pCLR1::CLR1-eCFP in the cerk1-2 mutant background did not contain any CERK1 protein. The blot section probed with aGFP shows that $p C L R 1:: C L R 1-e C F P$ is present in both, Col-0 and cerk1-2, as a band of 79,2 kDa. Notably, the $p C L R 1:: C L R 1-e C F P$ fusion protein shows a band shift similar to the CERK1 protein after chitin treatment. This shift is not present in the cerk12 background, indicating that it is not only chitin-induced, but also CERK1-dependent. Since the chitin-induced CERK1 band shift is caused by phosphorylation (Petutschnig et al., 2010) and CLR1 is phosphorylated by CERK1 in vitro (Figure 15), it is highly likely that the chitininduced band shift of CLR1 is caused by phosphorylation as well. However, to rule out that the band shift of CLR1 is due to other protein modifications such as ubiquitination, a $\lambda$ protein phosphatase ( $\lambda$-PPase) assay was performed. For this, $p C L R 1:: C L R 1$-eCFP expressing transgenic Col-0 plants were treated with chitin to induce the chitin-dependent band shift or water as a control. Subsequently, CLR1-eCFP was purified from leaf total protein extracts with GFP-binding protein (GBP) coupled to magnetic beads. An aliquot of the purified protein was directly mixed with sample buffer and frozen away. The remaining two aliquots were incubated in $\lambda$-PPase buffer with or without the enzyme. After the $\lambda$-PPase treatment, proteins were analysed by Western blots and probed with aGFP antibody (Figure 17). 


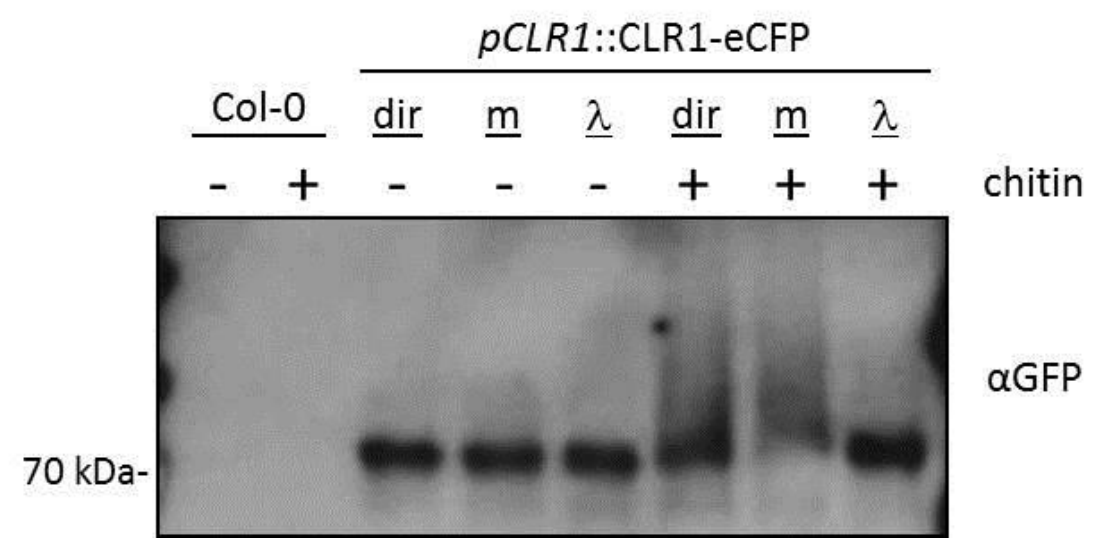

Figure 17. $\lambda$-PPase assay confirms in vivo phosphorylation of $p C L R 1:$ :CLR1-eCFP. Leaves of five-week-old Arabidopsis plants were vacuum-infiltrated with either $\mathrm{H}_{2} \mathrm{O}(-)$ or $100 \mu \mathrm{g} / \mathrm{ml}$ polymeric chitin $(+)$ and incubated for $30 \mathrm{~min}$. CLR1-eCFP was purified from total protein extracts using magnetic GBP beads. Samples were then either directly boiled with SDS buffer (dir), or incubated for $60 \mathrm{~min}$ at $30^{\circ} \mathrm{C}$ with $\lambda$-PPase $(\lambda)$ or mock-incubated without the enzyme $(\mathrm{m})$. A Western blot with aGFP detecting CLR1-eCFP is shown. The experiment was repeated three times with similar results.

A band shift for $p C L R 1:: C L R 1-e C F P$ was only visible in chitin-treated samples (Figure 17). This shift was completely abolished after $\lambda$-PPase treatment. In the control-incubated samples without $\lambda$-PPase the band shift was not affected, demonstrating that loss of the shift is due to dephosphorylation by the $\lambda$-PPase. Thus, the $\lambda$-PPase assay confirms in planta phosphorylation of CLR1.

\subsubsection{In planta phosphorylation of CLR1 is specifically induced by chitin}

Additionally to its function in chitin perception and signalling, CERK1 was reported to be involved in the perception of and immunity against bacterial pathogens (Gimenez-lbanez et al., 2009b; Willmann et al., 2011). clr1 mutants likely also show alterations in immunity towards bacterial pathogens (Figure 14), which raises the question whether CLR1 is involved in signal transduction of bacterial MAMPs. Since CLR1 is phosphorylated upon chitin treatment, several bacterial MAMPs were tested for their ability to induce CLR1 phosphorylation.

First, stably transformed transgenic plants expressing $p C L R 1:: C L R 1-e C F P$ were vacuuminfiltrated with the bacterial peptide MAMPs flg22 and elf18, as well as chitin. As a control for CERK1 phosphorylation the wild type Col-0 was subjected to the same treatments. The upper panel in Figure 18 shows that CERK1 shifted specifically after chitin treatment in the 
wild type as well as in the tested stable transgenic $p C L R 1:$ CLR1-eCFP plants. Treatment with neither one of the two bacterial peptide MAMPs flg22 and elf18, led to a band shift of CERK1. Similar to CERK1, CLR1 also only showed a band shift in the chitin-treated samples.

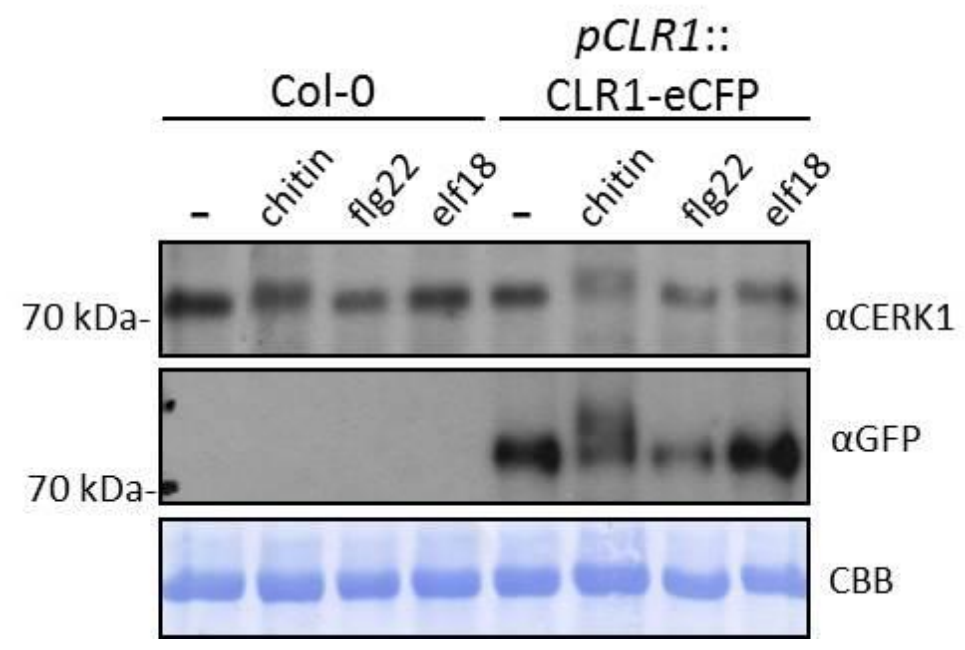

Figure 18. Chitin-specific phosphorylation of CLR1. Leaves of four-week-old Arabidopsis Col-0 and pCLR1::CLR-eCFP expressing Col-0 plants were vacuum-infiltrated with $100 \mu \mathrm{g} / \mathrm{ml}$ polymeric chitin, $100 \mathrm{nM}$ flg22, $100 \mathrm{nM}$ elf18 or with $\mathrm{H}_{2} \mathrm{O}(-)$ and incubated for $30 \mathrm{~min}$. Total protein extracts were analysed by Western blotting with $\alpha$ CERK1 or $\alpha$ GFP antibodies. Equal loading was monitored by CBB staining of the membranes. The experiment was repeated twice with similar results.

In an additional assay also chitin heptamer (7mer) and the bacterial carbohydrate MAMP peptidoglycan (PGN) were tested for their ability to induce phosphorylation of CLR1 (Figure 19). Peptidoglycan is a particularly interesting MAMP to test because it is structurally related to chitin and has been reported to be perceived via CERK1 (Willmann et al., 2011). For this experiment, transgenic lines expressing $p C L R 1:: C L R 1-G F P$ in Col-0 or cerk1-2 background were used. All treatments were performed in parallel for the transgenic lines in the two backgrounds. 
A $\quad \underline{p C L R 1:: C L R 1-G F P \text { in Col-0 }}$

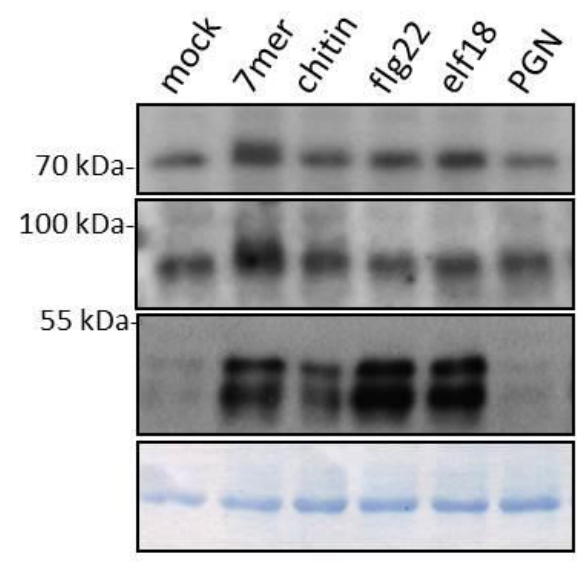

$\alpha$ CERK1

$\alpha \mathrm{GFP}$

apMAPKs

CBB
B
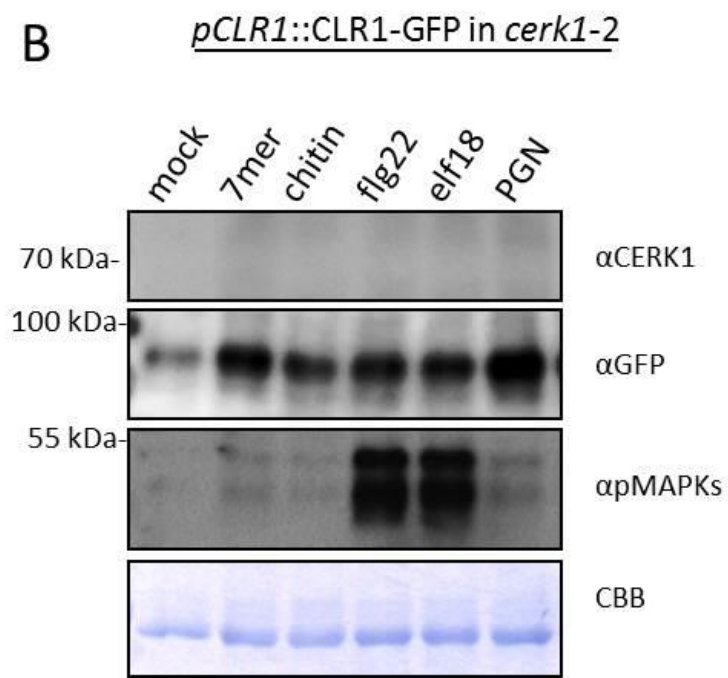

Figure 19. Chitin- and chitin heptamer (7mer)-specific phosphorylation of CLR1. Leaves of four-week-old Arabidopsis plants were vacuum-infiltrated with $100 \mu \mathrm{g} / \mathrm{ml}$ chitin heptamer, $100 \mu \mathrm{g} / \mathrm{ml}$ polymeric chitin, $100 \mathrm{nM}$ flg22, $100 \mathrm{nM}$ elf18, $100 \mu \mathrm{g} / \mathrm{ml}$ peptidoglycan (PGN) or with $\mathrm{H}_{2} \mathrm{O}(-)$ and incubated for $30 \mathrm{~min}$. Total protein extracts were analysed by Western blotting with aCERK1, $\alpha$ GFP or apMAPKs antibodies. Equal loading was monitored by CBB staining of the membranes. CERK1 has a molecular weight of $67.3 \mathrm{kDa}$. MPK3 and MPK6 appear at a molecular weight of $43 \mathrm{kDa}$ and $46 \mathrm{kDa}$, respectively. The experiment was conducted once.

Apart from polymeric chitin, only chitin heptamer (7mer) was able to induce phosphorylation of CERK1 and CLR1 (Figure 19). None of the tested bacterial MAMPs had an effect on phosphorylation of either CERK1 or CLR1.

In addition to the phosphorylation of CERK1 and CLR1, the ability of the various MAMPs to activate MAPKs in the different transgenic lines was analysed. This was done by Western blotting with an antibody recognizing phosphorylated and thus active MAPKs. The upper band corresponds to MPK6 (46 kDa) and the lower one to MPK3 (43 kDa). As expected, chitin, chitin heptamer, elf18 and flg22 induced the activation of MAPKs in the lines expressing $p C L R 1:: C L R 1-G F P$ in the Col-0 wild type background. In the cerk1-2 background chitin and 7mer treatment had no effect on the MAPKs, while flg22 and elf18 as expected induced activation of the depicted MAPKs. Peptidoglycan yielded the only unexpected result, failing to activate MAPKs in either background. 


\subsection{Analysis of two possible CLR1 start codons}

As described in chapter 3.1, CLR1 contains a putative myristoylation site 23 amino acids Cterminal of the protein start annotated by TAIR10. Since many RLCKs contain N-terminal myristoylation motifs (Lin et al., 2013), CLR1 translation might begin at an alternative later start codon that codes for the methionine associated with the myristoylation motif $\left(\mathrm{M}_{2}\right)$ and not the one predicted by TAIR10 $\left(\mathrm{M}_{1}\right)$ (Figure 20).

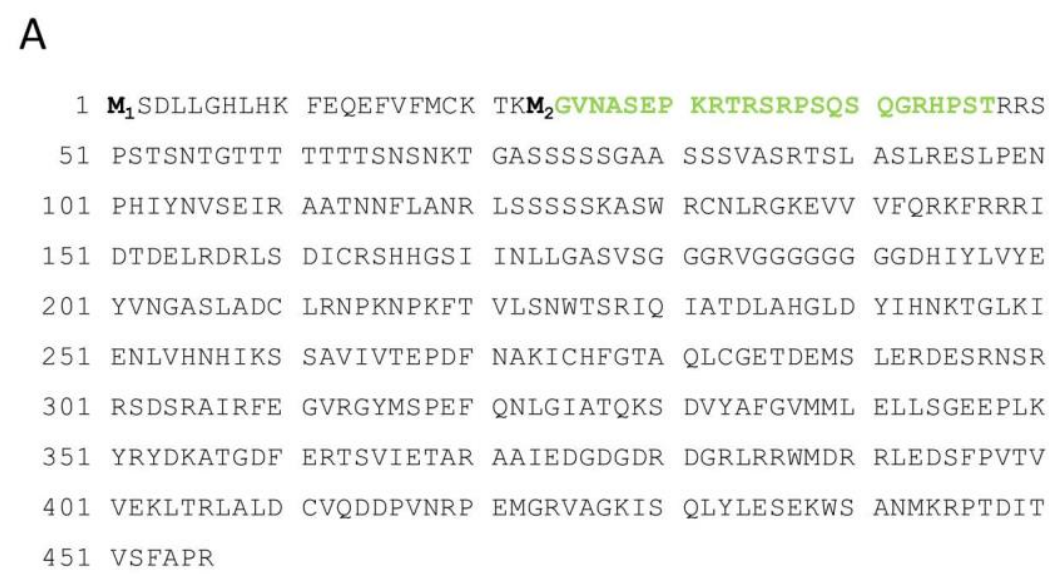

B

a)

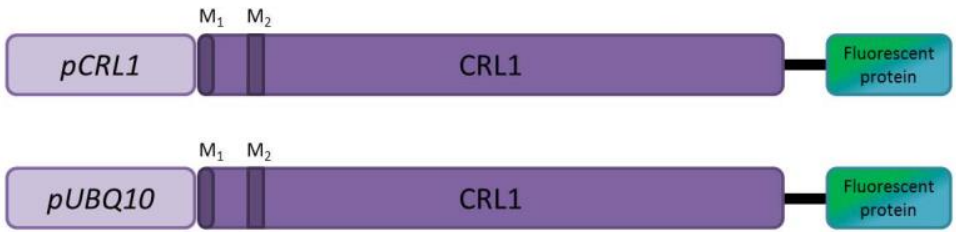

c)

pUBQ10 CRL1

Figure 20. Fusion constructs for identification of the CLR1 start codon. (A) The 456 amino acids of CLR1. Indicated in bold are the originally annotated protein start $\left(M_{1}\right)$ and methionine $\left(M_{2}\right)$ associated with the putative myristoylation motif (bold green). (B) The structure of the three different CLR1 fluorescent proteinfusion constructs generated and analysed in this work. a) Genomic CIR1 sequence with 1000 bp stretch upstream of $M_{1}$ including the endogenous promoter region. b) Full-length CLR1 expressed under the Ubiquitin10 promoter. c) CLR1 starting at the $\mathrm{M}_{2}$ expressed under Ubiquitin10 promoter.

Starting at $\mathrm{M}_{1}$ the calculated molecular mass of CLR1 would be $50.5 \mathrm{kDa}$, whereas the CLR1 protein starting at $\mathrm{M}_{2}$ would be only $47.9 \mathrm{kDa}$. To test which of these variants reflects the true CLR1 protein in planta, three types of CLR1 constructs were used that differ at the start codon but all have the same C-terminal fluorescent protein tag: a) The endogenous promoter constructs already introduced above contain the genomic CLR1 sequence including 
a $1000 \mathrm{bp}$ stretch upstream of the annotated methionine $\left(\mathrm{M}_{1}\right)$. b) The genomic CLR1 sequence starting at the first methionine $\left(M_{1}\right)$ fused to the Ubiquitin10 promoter sequence. c) The genomic CLR1 sequence starting at the second methionine $\left(M_{2}\right)$ fused to the Ubiquitin 10 promoter. The purpose of the overexpression constructs ( $b$ and $c$ ) was to compare the size of the respective fusion proteins to the protein expressed from construct (a). Two sets of these three fusion constructs were generated in two different vector systems with either an eCFP- or GFP-tag.

The generated eCFP-fusion constructs were transiently expressed in Nicotiana benthamiana to analyse the molecular masses of the resulting proteins by SDS-PAGE and Western blotting (Figure $21 \mathrm{~A})$. 

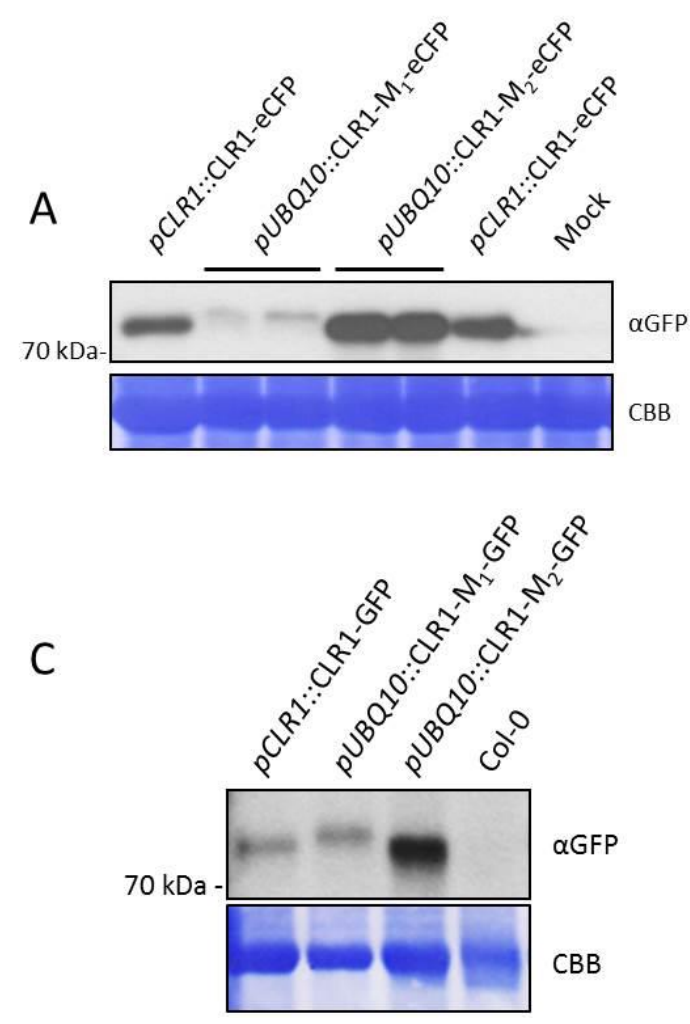
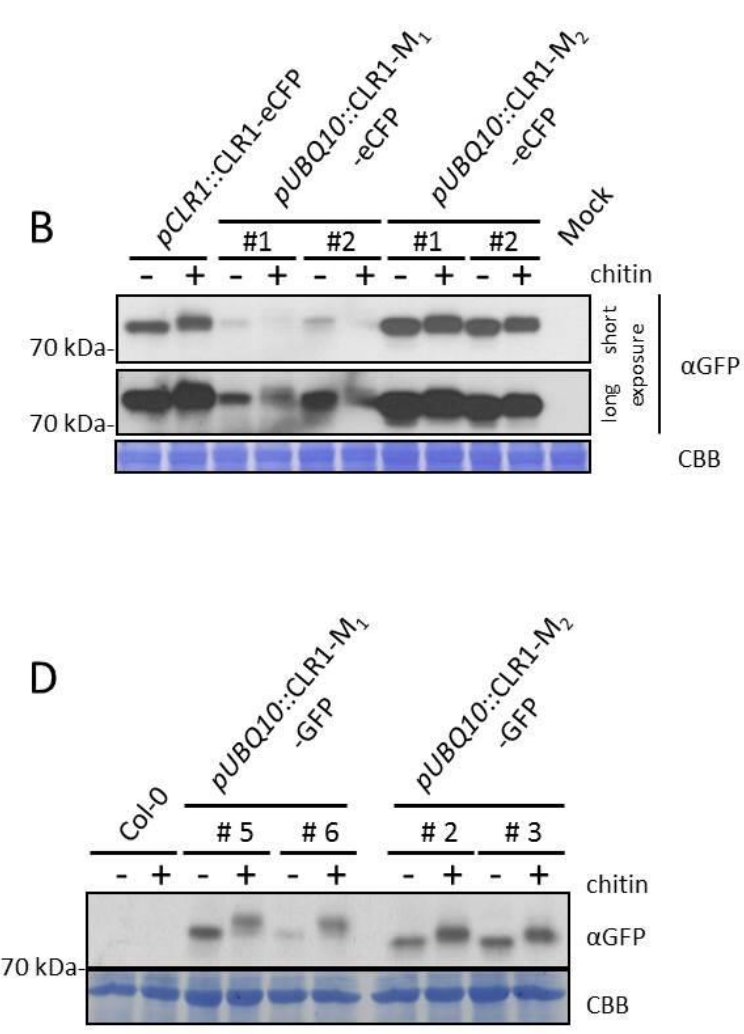

Figure 21. Translation of CLR1 does not start at methionine predicted by TAIR10. A) The indicated CLR1 fusion constructs were transiently expressed in six-week-old $N$. benthamiana plants by syringe-infiltration and analysed 3 dpi. Samples infiltrated with the empty Agrobacterium tumefaciens GV3101 pMP90RK strain were included as a negative control (mock). pUBQ10::CLR1-M -eCFP has an expected molecular mass of 79,2 kDa and $p U B Q 10:: C L R 1-M_{2}-$ eCFP a molecular mass of $76.6 \mathrm{kDa}$. Western blotting with an $\alpha \mathrm{GFP}$ antibody demonstrated that $p U B Q 10:: C L R 1-M_{1}$-eCFP has a higher molecular mass than $p C L R 1:: C L R 1-e C F P$. CBB staining was used to monitor equal loading. B) CLR1 fusion constructs were transiently expressed in $\mathbf{N}$. benthamiana as described in A. Transformed leaves were vacuum-infiltrated with $100 \mu \mathrm{g} / \mathrm{ml}$ polymeric chitin or water and incubated for $30 \mathrm{~min}$. Samples infiltrated with the empty A. tumefaciens GV3101 pMP90RK strain were included as a negative control (mock). Western blotting with a $\alpha$ GFP antibody demonstrated that

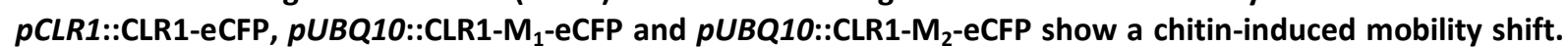
C) Total protein extracts of four-week-old Arabidopsis Col-0 plants stably expressing the indicated CLR1 fusion constructs were analysed via Western blotting. pUBQ10::CLR1-M - GFP has an expected molecular mass of 81.1 kDa and pUBQ10::CLR1-M - GFP a molecular mass of $78.3 \mathrm{kDa}$. Probing with an $\alpha \mathrm{GFP}$ antibody demonstrated that $p U B Q 10:: C L R 1-M_{1}-$ GFP has a higher molecular mass than $p C L R 1:: C L R 1-G F P$. CBB staining was used to monitor equal loading. D) Chitin-induced band shift of $p U B Q 10: \mathrm{CLR}_{1}-\mathrm{M}_{1}-\mathrm{GFP}$ and pUBQ10::CLR-M - -GFP stably expressed in Arabidopsis Col-0 plants. Leaves of four-week-old plants were vacuum-infiltrated with either $100 \mu \mathrm{g} / \mathrm{ml}$ polymeric chitin (+) or with $\mathrm{H}_{2} \mathrm{O}(-)$ and incubated for $30 \mathrm{~min}$. Total protein extracts were loaded onto SDS-PAGE. Western blotting using a $\alpha$ GFP antibody showed that pUBQ10::CLR1-M - -GFP and $p U B Q 10:: C L R 1-M_{2}$-GFP exhibit a chitin-induced mobility shift. Col-0 was used as negative control. Equal loading was monitored by CBB staining.

The protein expressed from $p U B Q 10:: C L R 1-M_{2}-e C F P$ exhibits the same apparent molecular mass as the protein expressed from the endogenous promoter $p C L R 1:: C L R 1-e C F P$ construct. Besides the fact that the intensities of the bands corresponding to the $p U B Q 10:: C R_{1}-M_{1}-$ eCFP protein were significantly weaker than those of the other samples, the bands showed a 
higher molecular mass as well. This finding suggests that the protein translation starts at $M_{2}$ and not at the initially annotated $M_{1}$ (Figure $21 \mathrm{~A}$ ).

To test for presence of the chitin-induced band shift in CLR1 fusion proteins of both lengths, $N$. benthamiana leaves were vacuum-infiltrated with $100 \mu \mathrm{g} / \mathrm{ml}$ polymeric chitin three days after transformation with the eCFP-fusion constructs. Chitin treatment of $N$. benthamiana leaves also led to an upwards shift of bands corresponding to $p C L R 1:$ CLR1-eCFP proteins suggesting that NbCERK1 can interact with AtCLR1 (Figure $21 \mathrm{~B}$ ). Interestingly, proteins expressed from all three constructs ( $p C L R 1:: C L R 1-e C F P, \quad p U B Q 10:: C L R 1-M_{1}$-eCFP, pUBQ10::CLR1-M2-eCFP) showed the chitin-induced shift.

In order to investigate if the results obtained in $N$. benthamiana can also be observed in Arabidopsis, Col-0 plants were stably transformed with pCLR1::CLR1-GFP, pUBQ10::CLR1-M $1^{-}$ GFP and $p U B Q 10:: C L R 1-M_{2}-G F P$. Transformants that expressed the CLR1 fusion proteins were selected and then analysed by SDS-PAGE and Western blotting (Figure $21 \mathrm{C}$ and D). Similar to the results obtained with transient expression in $N$. benthamiana, the shorter pUBQ10::CLR1-M2-GFP fusion protein exhibits the same molecular mass as the protein derived from the endogenous promoter pCLR1::CLR1-GFP construct, while pUBQ10::CLR1-M 1 -GFP migrates at a higher molecular weight. This provides additional evidence that the actual CLR1 protein expressed in wild type Arabidopsis starts at the second methionine $\left(\mathrm{M}_{2}\right)$ associated with the myristoylation motif. To test if both, CLR1 proteins (starting at $\mathrm{M}_{1}$ and $\mathrm{M}_{2}$ ) can be phosphorylated upon chitin perception in Arabidopsis two independent lines per construct were infiltrated with chitin and the samples were analysed by Western blotting (Figure $21 \mathrm{D}$ ). Interestingly, both variants of the CLR1 protein showed the chitin-induced shift. This indicates that the signal transduction from CERK1 to CLR1 is similar in N. benthamiana and Arabidopsis. Since also the longer variant of the CLR1 fusion protein showed the band shift, it is unlikely that myristoylation is important for proper chitin-induced phosphorylation of CLR1.

Furthermore the results suggest that if myristoylation does occur it is probably not required for CLR1 interaction with CERK1. 


\subsection{CLR1 subcellular localization}

\subsubsection{CLR1 is a soluble protein but membrane-associated pools exist in Arabidopsis cells}

As shown in Figure 4 the amino acid sequence of CLR1 contains a putative myristoylation motif. Analyses of different promoter-gene fusions (see above) suggested that this myristoylation motif is located at the very $\mathrm{N}$-terminus of the protein. Thus, myristoylation of CLR1 might take place and might be involved in anchoring CLR1 to membranes. To address the question whether CLR1 is soluble or membrane-associated, microsomal fractionation experiments were performed. For this, transgenic plants stably expressing $p C L R 1:$ CLR1-eCFP in the Col-0 or cerk1-2 background were used. After vacuum-infiltrating the transgenic plants and corresponding controls with $100 \mu \mathrm{g} / \mathrm{ml}$ polymeric chitin, extracts enriched for soluble proteins (S) and membrane-bound proteins (MP) were prepared. Figure 22 A shows the immunoblot results for $p C L R 1:: C L R 1-e C F P$ expressing Col-0 plants and the Col-0 wild type control, whereas Figure $22 \mathrm{~B}$ shows the results for $p C L R 1:: C L R 1-e C F P$ expressed in the cerk1-2 background with the corresponding cerk1-2 control.
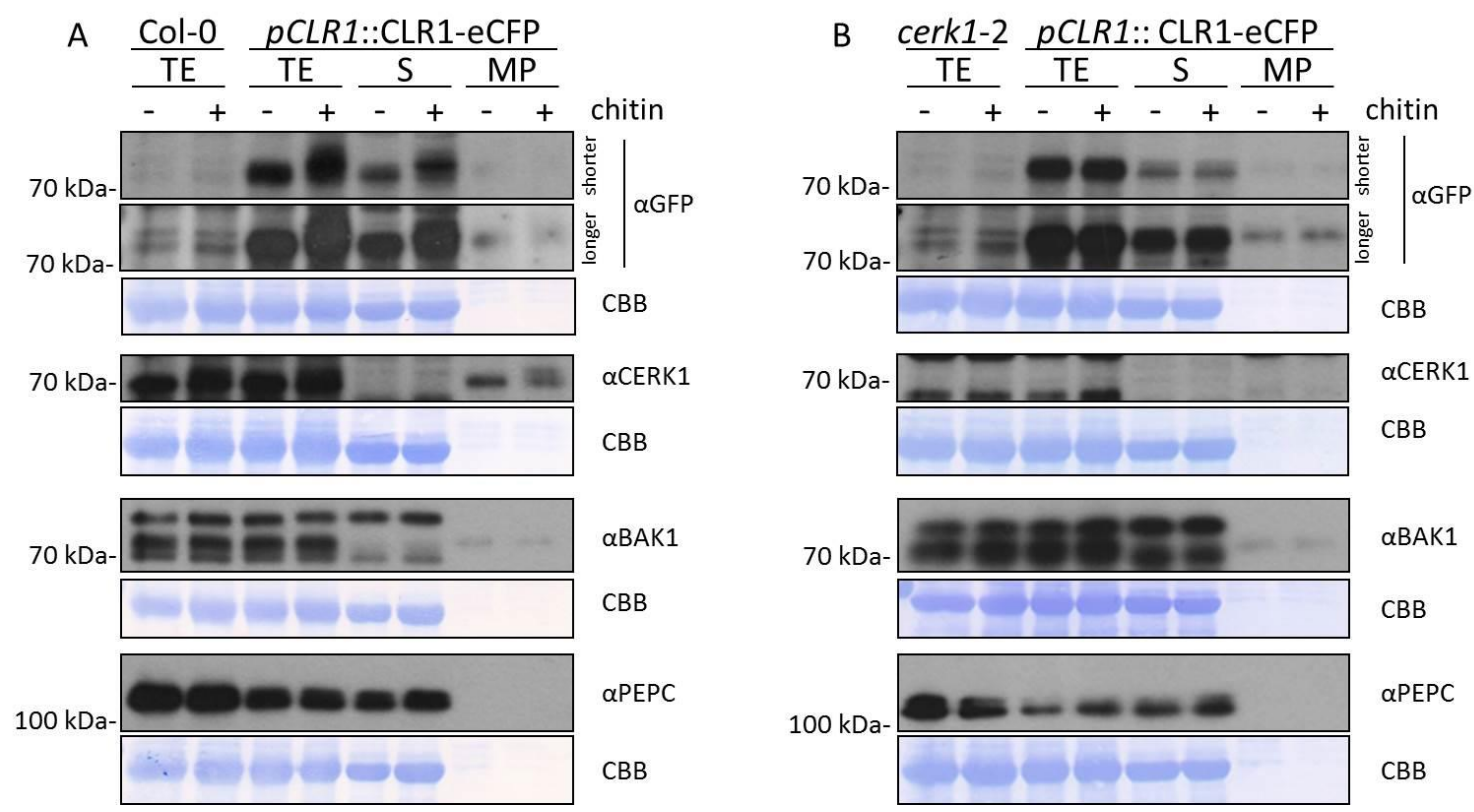

Figure 22. Microsomal preparations reveal that CLR1-eCFP is mainly a soluble protein in Arabidopsis cell extracts, but a smaller membrane-associated pool likely exists. Leaves of transgenic plants stably expressing pCLR1::CLR1-eCFP in Col-0 (A) and cerk1-2 (B) were vacuum-infiltrated and incubated for 30 min with $100 \mu \mathrm{g} / \mathrm{ml}$ polymeric chitin (+). Mock samples were infiltrated in the same way with $\mathrm{H}_{2} \mathrm{O}(-)$. Col-0 and cerk1-2 plants were included as controls. Protein extracts enriched for membrane-bound proteins (MP) and soluble proteins $(S)$ were prepared and analysed by Western blotting together with total protein extracts (TE). CLR1-eCFP (79.2 kDa) was detected with $\alpha$ GFP antibody. Cross contaminations between the fractions were monitored by using specific antibodies for the plasma membrane proteins CERK1 (67.3 kDa) and BAK1 $(73.7 \mathrm{kDa})$ as well as the cytoplasmic protein PEPC (110.3 kDa). Equal loading was monitored by CBB staining. Experiment was performed twice with similar results. 
In the Col-0, as well as in the cerk1-2 background CLR1-eCFP was present in both, the soluble and the membrane-enriched protein fractions. However, the majority of CLR1-eCFP was detected in the soluble protein preparation. Antibodies against the two plasma membrane proteins CERK1 and BRI1-ASSOCIATED RECEPTOR KINASE1 (BAK1) and against the cytoplasmic protein PHOSPHOENOLPYRUVATE CARBOXYLASE (PEPC) were used to confirm the specificity of the S and MP fractions. As expected, full-length CERK1 and BAK1 were detected in the membrane, but not the soluble fraction, whereas PEPC was present in soluble preparation but not the membrane-enriched extract.

As already demonstrated earlier, CLR1 is phosphorylated upon chitin treatment in the Col-0 background, whereas this chitin-induced phosphorylation is not present in the pCLR1::CLR1-eCFP expressing cerk1-2 plants. Interestingly, soluble and membrane-bound subpools of $p C L R 1:: C L R 1-e C F P$ in Col-0 show the CERK1-dependent chitin-induced shift. In summary, the results show that CLR1 in Arabidopsis cell extracts is mainly soluble, but a small membrane- or vesicle-associated pool exists and both subpopulations are phosphorylated upon chitin perception.

\subsubsection{Localization studies with CLR1 fusion proteins transiently expressed in $N$. benthamiana and stably expressed in A. thaliana}

CLR1 is phosphorylated in a chitin- and CERK1-dependent manner in vivo (section 3.3.1). Microsomal preparations of plants expressing $p C L R 1:: C L R 1-e C F P$ from the endogenous promoter revealed that the majority of the protein is found in the soluble protein fraction, whereas a small portion also localized to the microsomal fraction (Figure 22). To get more insight into the in planta subcellular localization of CLR1, $p C L R 1:: C L R 1-G F P$ was expressed transiently in $N$. benthamiana as well as stably in $A$. thaliana and analysed by confocal laser scanning microscopy (CLSM). To assess the potential effect of myristoylation on subcellular localization, $p U B Q 10:: C L R 1-M_{1}-G F P$ and $p U B Q 10:: C L R 1-M_{2}-G F P$ (compare section 3.4) were also transformed and included in the subsequent analyses. Figure 23 shows the localization of the different CLR1 fusion proteins transiently expressed in $N$. benthamiana by Agrobacterium-mediated transformation. As positive control free GFP was expressed and as a negative control, leaves infiltrated with the empty Agrobacterium strain (GV3101 pMP90RK) were used. 


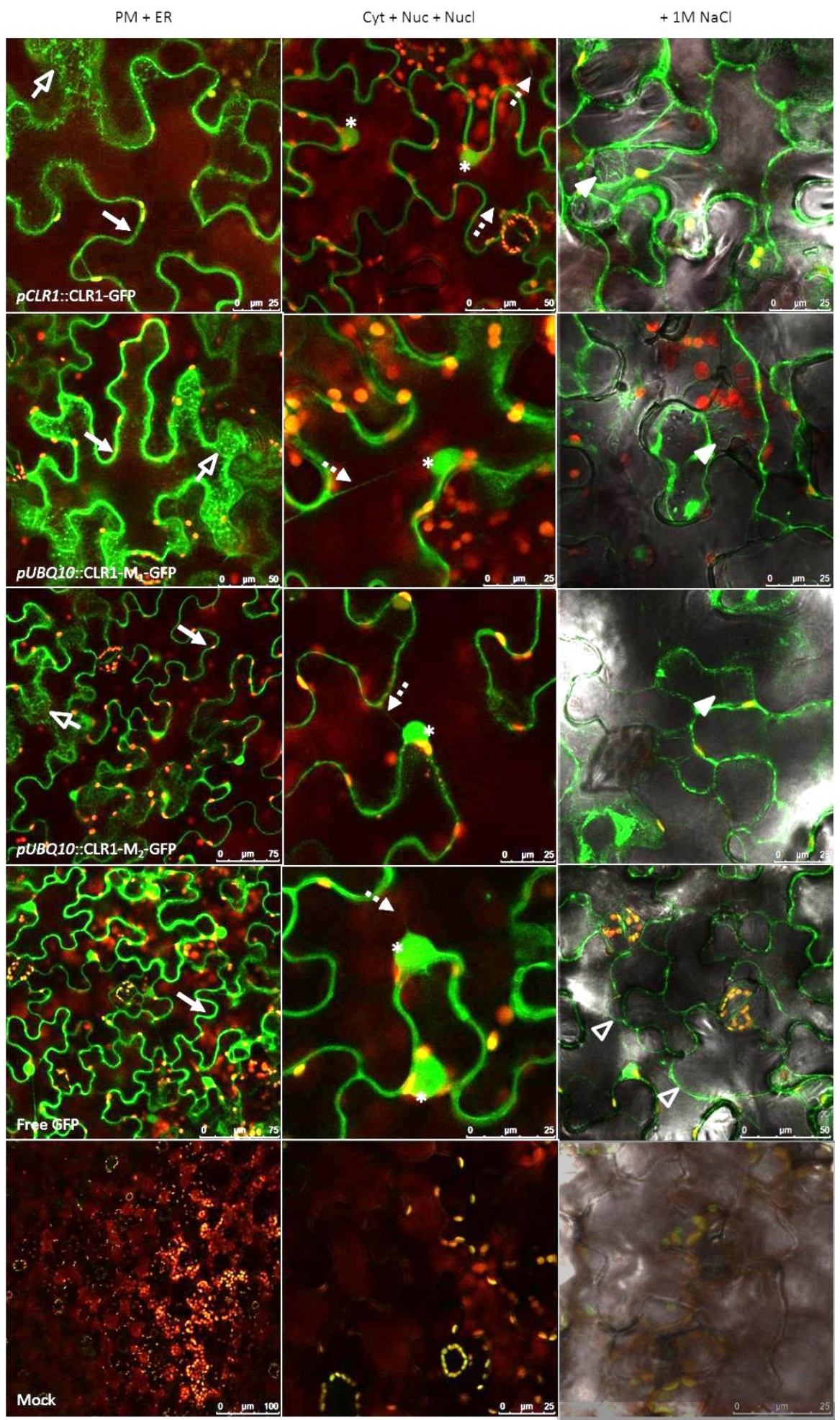

Figure 23. Subcellular localization of CLR1-GFP fusion proteins transiently expressed in $\mathbf{N}$. benthamiana. The genomic $p C L R 1:: C L R 1-G F P$ construct, as wells as $p U B Q 10:: C L R 1-M_{1}-G F P$ and $p U B Q 10:: C L R 1-M_{2}-G F P$ were transformed into $N$. benthamiana by Agrobacterium-mediated transformation. Agrobacteria containing a vector for expression of free GFP were used as positive control. The empty bacteria strain GV3101 pMP90RK was used as negative control (mock). Pictures were taken 3 dpi using the Leica TCS SP5 CLSM. Pictures show overlays of GFP fluorescence in green and chloroplast autofluorescence in red. The plasmolysis images also contain the bright field channel. First column: Empty arrows indicate localization at a reticulate structure which is likely the endoplasmic reticulum (ER), arrows indicate localization at the cell boundary. Second column: Striped arrows indicate cytoplasmic strands, asterisks mark the nuclei. Third column: Plasmolysis, full arrow heads indicate Hechtian strands, empty arrow heads mark plasmolysis events without visible Hechtian strands. Size markers are given in $\mu \mathrm{m}$. 
Confocal laser scanning microscopy (CLSM) revealed that the three tested CLR1 fusion proteins (expressed from the $p C L R 1:: C L R 1-G F P$, $p U B Q 10:: C L R 1-M_{1}-G F P$ and pUBQ10::CLR1-M - GFP constructs) all showed a very similar subcellular localization pattern. CLR1-GFP signal can be observed at the cell periphery, but CLR1-GFP is also present in the cytoplasm, indicated by fluorescence signal in cytoplasmic strands (Figure 23, striped arrows). All three CLR1 fusion proteins were also found in a reticulate structure which likely represents the endoplasmic reticulum (ER) (empty arrows, first column) and in nuclei (asterisk) as well as nucleoli. The free GFP control was used to distinguish the true CLR1 subcellular localization from that of possibly unspecific signal due to free GFP. The free GFP control is found at the cell boundary, in the cytoplasmic strands and nuclei, but not in the nucleoli or ER. To investigate if the signal at the cell periphery corresponds to the plasma membrane, plasmolysis experiments with $1 \mathrm{M} \mathrm{NaCl}$ were performed (Figure 23, third column). With both CLR1-GFP and free GFP the fluorescence signal detached from the cell wall, but while CLR1-GFP was clearly present in Hechtian strands, no fluorescence signal associated with Hechtian strands was visible with free GFP. These findings indicate plasma membrane localization of CLR1-GFP.

Next, the subcellular localization of fusion proteins expressed from the $p C L R 1:: C L R 1-G F P$, pUBQ10::CLR1-M1-GFP and pUBQ10::CLR1-M2-GFP constructs was analysed in stably transformed Arabidopsis plants by CLSM. In comparison to the expression in N. benthamiana, CLR1-GFP signals in the stable transgenic Arabidopsis plants were much weaker (Figure 24). 


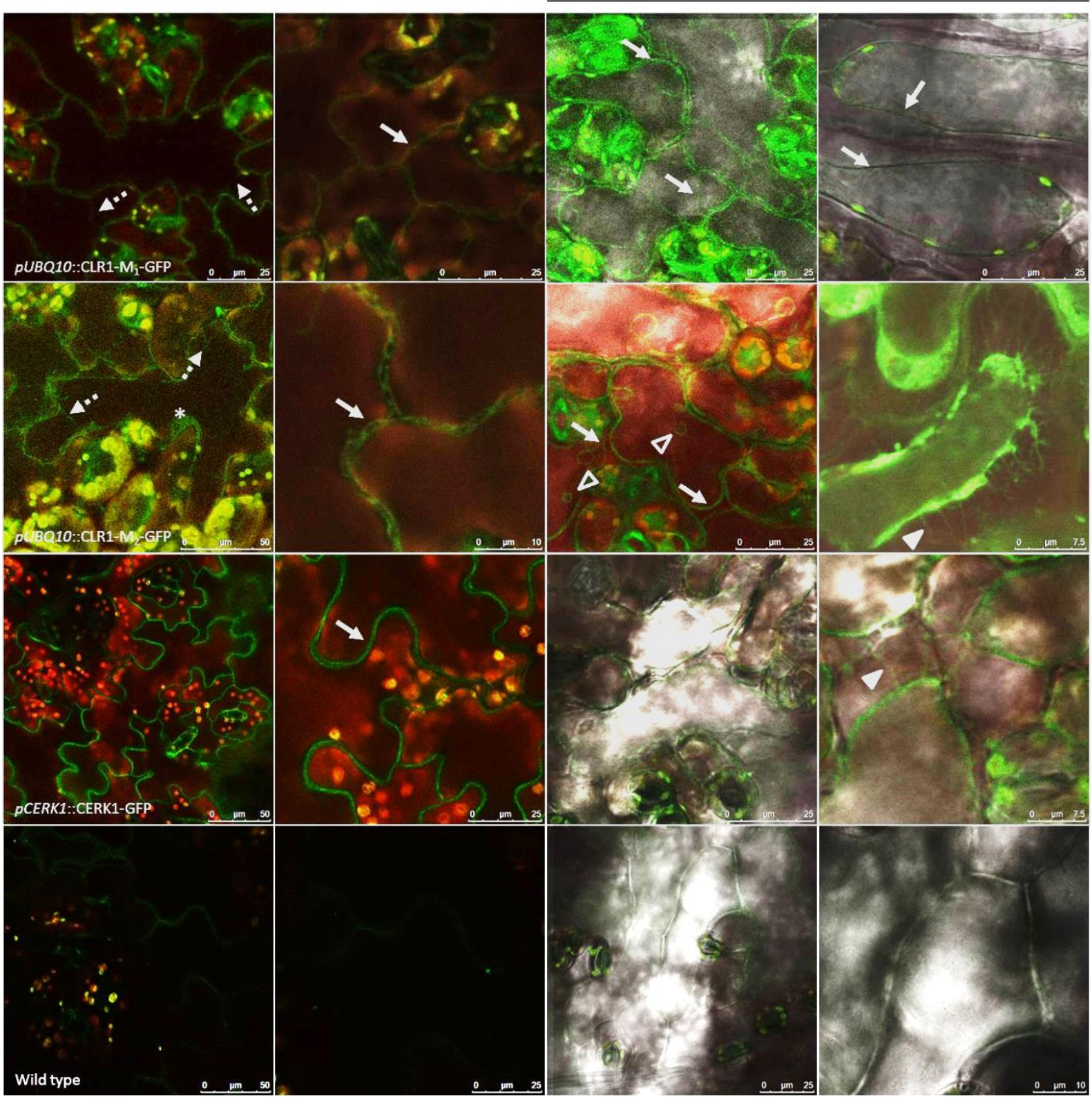

Figure 24. Subcellular localization of $\mathrm{CLR}_{1}-\mathrm{M} 1-\mathrm{GFP}$ and $\mathrm{CLR1}-\mathrm{M}_{2}-\mathrm{GFP}$ stably expressed from the Ubiquitin10 promoter in Arabidopsis thaliana Col-0. Col-0 expressing PCERK1::CERK1-GFP was used as positive control, whereas untransformed wild type Col-0 plants were used as negative control. Pictures were taken using the Leica TCS SP5 CLSM. Pictures in the first and second column represent overlays of GFP fluorescence shown in green and chloroplast autofluorescence shown in red. The overlays in the third and fourth columns also contain the bright field image. First column: Striped arrow heads indicate cytoplasmic strands (cyt). Asterisks mark nuclei (nuc). Second column: Arrows indicate the cell periphery. Third and fourth column depict the subcellular localization upon $1 \mathrm{M} \mathrm{NaCl}$ treatment leading to plasmolysis. Third column: Arrows indicate the plasmolysed plasma membrane and empty arrow heads mark circular invaginations. Fourth column: Arrows show plasma membrane detachment from the cell wall and arrow heads mark Hechtian strands. Size markers are given in $\mu \mathrm{m}$.

With $p C L R 1:: C L R 1-G F P$ no specific signal could be detected at all and thus this construct could not be included in the CLSM analysis. For the two CLR1 constructs driven by the Ubiquitin10 promoter fluorescence could be detected in the cell periphery (Figure 24). Both 
fusion proteins are also present in the cytoplasm, indicated by fluorescence localized to cytoplasmic strands. $p U B Q 10:: C L R 1-M_{2}$-GFP but not $p U B Q 10:: C L R 1-M_{1}-G F P$ was also visible in nuclei (Figure 24, asterisk). After treatment with $1 \mathrm{M} \mathrm{NaCl}$ to induce plasmolysis, pUBQ10::CLR1-M - GFP showed Hechtian strands but $p U B Q 10:: C L R 1-M_{1}-G F P$ did not. Another difference between the two Ubiquitin10 promoter-driven CLR1 constructs was the formation of circular structures within the cell after $\mathrm{NaCl}$ treatment of pUBQ10::CLR1-M2-GFP (Figure 24, empty arrow heads). Since fluorescence of free GFP would have been too strong, pCERK1::CERK1-GFP was used as a control. As expected, pCERK1::CERK1-GFP localized to the cell periphery and also shows a fluorescence signal in the Hechtian strands after $\mathrm{NaCl}$ treatment.

Taken together, these results indicate that the native expression levels of the pCLR1::CLR1-GFP fusion protein were too low to be detected by CLSM in the present experimental setup. However, both CLR1-GFP fusion proteins driven by the Ubiquitin10 promoter were stably expressed in Arabidopsis to expression levels detectable by CLSM. The expression levels of $p U B Q 10:: C L R 1-M_{2}-G F P$ seemed to be higher than those of pUBQ10::CLR1-M 1 -GFP. The fact that CLR1-M - GFP but not CLR1-M 1 -GFP could be observed in nuclei and Hechtian strands, might be explained by the different fluorescence intensities of the fusion proteins.

\subsubsection{Expression of 6-glucuronidase under the native CLR1 promoter reveals expression of CLR1 in hydathodes and stipules}

Based on the results observed by CLSM for the CLR1 subcellular localization (see section 3.5.2) and data obtained from the Arabidopsis eFP Browser (http://bar.utoronto.ca; Winter et al., 2007) the activity of the CLR1 promoter in leaves appears to be very weak. To investigate if expression of CLR1 might be higher in other organs, promoter fusions with $\beta$ glucuronidase (GUS) were generated. The $1000 \mathrm{bp}$ sequence upstream of the annotated start codon of CLR1 was fused to the gusA reporter gene encoding the GUS enzyme to assess the spatial expression pattern of CLR1. The construct was transformed into Col-0 plants and GUS activity was detected by infiltration of the colourless substrate 5-bromo-4-chloro-3indolyl glucuronide (X-Gluc), which is turned into an intensely blue product by the GUS enzyme (Jefferson et al., 1987). Thus, tissues with strong CLR1 promoter activity will show a 
bright blue staining (Figure 25). At least ten independent transgenic Col-0 plants expressing pCLR1::GUS were analysed showing similar results.
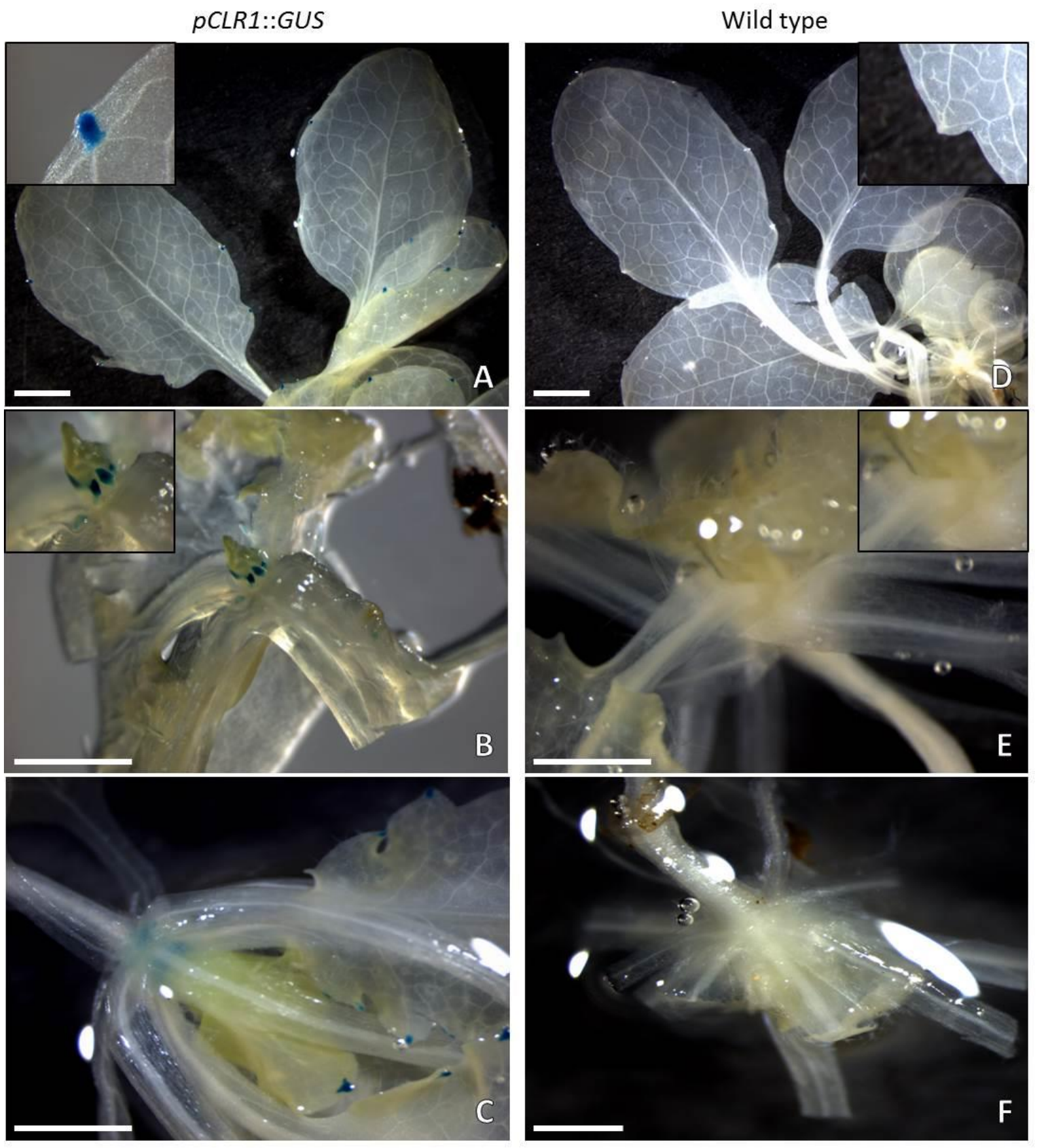

Figure 25. Histochemical staining of Arabidopsis plants expressing $p C L R 1:: G U S$ fusions reveals strong CLR1 promoter activity in hydathodes and stipules. 3-week-old seedlings were analysed. The respective untransformed wild type plants were used as negative control. The histochemical analysis of transgenic pCLR1::GUS plants is depicted in A-C, the wild type in D-F. Scale bars represent $0.5 \mathrm{~mm}$. At least ten independent $p C L R 1:: G U S$ expressing Col-0 lines were analysed giving similar results.

In contrast to the untransformed wild type controls, transgenic plants expressing the pCLR1::GUS construct showed blue staining which was restricted to the hydathodes 
(Figure $25 \mathrm{~A}$ ) and the stipules (Figure $25 \mathrm{~B}$ ). Hydathodes are stomata-like openings at the leaf margins, which secrete water from the xylem vessels in a process called guttation. Since hydathodes are constitutively active openings, they represent ideal entries for pathogen infection (Melotto et al., 2008). Stipules are small tissue outgrowths at the base of leaves and their function is not yet clarified. In both tissues high free auxin concentrations were determined during early leaf development (Aloni et al., 2003).

Since GUS staining experiments revealed strong activity of the CLR1 promoter in hydathodes, Arabidopsis plants expressing $p C L R 1:: C L R 1-G F P$ were analysed for accumulation of the CLR1GFP protein in hydathodes using CLSM (Figure 26). This was done to test whether enhanced CLR1 promoter activity also correlates with enhanced abundance of the CLR1-GFP fusion protein in hydathodes.

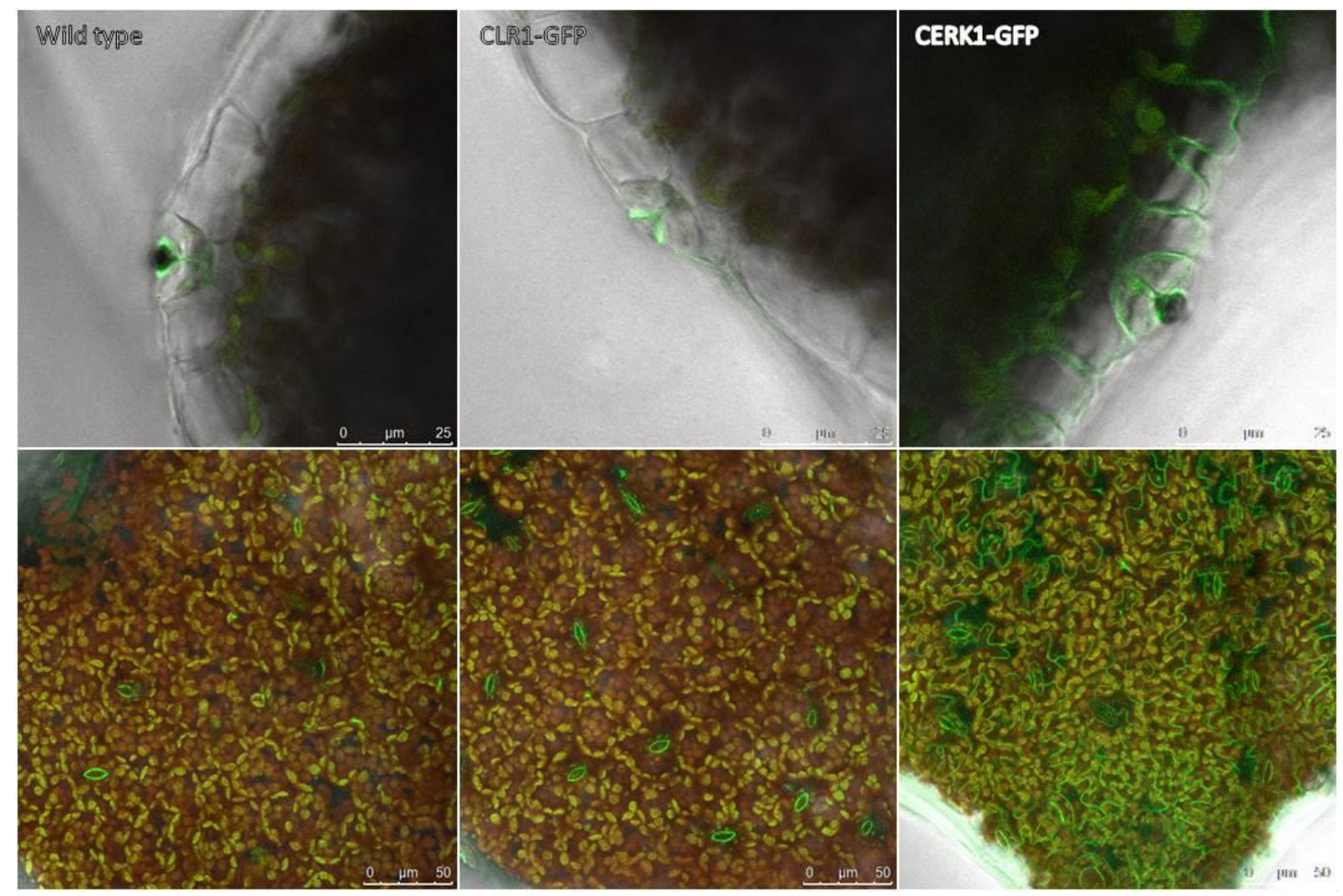

Figure 26. Analysis of $p$ CLR1::CLR1-GFP accumulation in hydathodes using confocal laser scanning microscopy. pCLR1::CLR1-GFP was stably expressed in the Arabidopsis Col-0 background. Plants expressing pCERK1::CERK1-GFP were used as positive control, whereas wild type plants were used as negative control. Pictures were taken using the Leica TCS SP5 CLSM. GFP fluorescence is shown in green, chloroplast autofluorescence is shown in red. Pictures represent overlays of the two channels and the bright field image. Size markers are given in $\mu \mathrm{m}$. 
As mentioned before, no GFP signal could be detected for the $p C L R 1:$ CLR1-GFP fusion protein in the leaf blade because of the low activity of the native CLR1 promoter. Also, no accumulation of $p C L R 1:: C L R 1-G F P$ at hydathodes could be observed. $p C E R K 1:: C E R K 1-G F P$ plants served as positive control and as expected a fluorescence signal could be detected at the plasma membrane of epidermis as well as hydathode cells.

Whether $p C L R 1:: C L R 1-G F P$ accumulates at hydathodes may be analysed by Western blotting in the future. In contrast to confocal microscopy, $p C L R 1:$ CLR1-GFP can be detected in Western blots. Thus this method may be more suited for hydathode analysis. Whether CLR1 plays a role in hydathode immunity remains to be determined by appropriate infection assays. 


\section{Discussion}

In order to mount an effective immune response towards different potential pathogens, plants depend on the presence and activity of PRRs. Recognition of a ligand by the corresponding PRR is a crucial step in activating downstream immune responses involved in restricting pathogen proliferation (Jones and Dangl, 2006). For proper activation of PRRs, complex formation with co-receptors is an important mechanism (Monaghan and Zipfel, 2012). Also, receptor-like cytoplasmic kinases have emerged as important interactors, phosphorylation targets and signal transducers of PRRs (Lin et al., 2013). This study focused on characterization of a novel putative complex partner involved in CERK1-dependent chitin signalling, namely the receptor-like cytoplasmic kinase CLR1.

\subsection{The putative inactive kinase CLR1 resembles the kinase domains of LysM-RLKs}

In the yeast-two hybrid assay performed for this work the receptor-like cytoplasmic kinase CLR1 was identified as an interactor of the CERK1 intracellular domain. CLR1 consists of a serine/ threonine protein kinase domain and a relatively short $\mathrm{N}$-terminal sequence of unknown function. Typical for a RLCK, CLR1 does not contain an extracellular nor transmembrane domain and phylogenetic analyses assigned it to the RLCK subfamily XII (Shiu and Bleecker, 2003). Interestingly, CLR1 did not only interact with the CERK1 kinase domain, it also showed considerable homology to the amino acid sequence of the latter. CLR1 also shares high sequence homology to the kinase domains of other LysM-RLKs described in Arabidopsis (Figure 4). Despite the similarity to LysM-RLKs (I-XII, Figure 4), amino acids important for kinase activity (Hanks et al., 1988) are altered in the kinase subdomains of CLR1. Especially the lack of conserved motifs and amino acids in subdomains I-V which are essential for ATP binding (Hanks and Hunter, 1995) led to the hypothesis that CLR1 has no kinase activity. For example, CLR1 does not contain a highly conserved lysine (K) residue in the VAIK motif of subdomain II which interacts with the phosphate of ATP. Mutation of the lysine renders kinases inactive, which has been shown for RLKs like the LRRRLK ERECTA (Shpak et al., 2003), BAK1, BRI1 (Li et al., 2002) and CERK1 (Petutschnig et al., 2010). The conserved aspartates (D) in the HRD motif in subdomain VIb and the DFG motif in in subdomain VII are also mutated in the CLR1 sequence. Since the three preceding motives were shown to be essential for proper ATP binding and catalytic activity of the kinase (Eyers 
and Murphy, 2013), CLR1 probably is an inactive kinase. The amino acid sequence of CLR1 shows an insertion of several amino acids in the stretch between subdomain VII and VIII also known as the activation loop. The activation loop is required for switching on and off the kinase activity (Taylor and Radzio-Andzelm, 1994). Alterations in this motif in CLR1 additionally supported the hypothesis that CLR1 constitutes an inactive kinase. Later, it could be shown in an in vitro phosphorylation assay (3.3.1) that CLR1 indeed displays no kinase activity.

In Arabidopsis, $13 \%$ of all kinases and $20 \%$ of RLKs were predicted to be catalytically inactive due to alterations in the amino acid sequences of the mentioned conserved motives (Castells and Casacuberta, 2007). In plants, several atypical kinases which lack conserved amino acids necessary for the catalytic activity were described to contribute to signalling processes. These atypical kinases are also known as pseudokinases (Eyers and Murphy, 2013). Since these inactive kinases were shown to be impaired in relaying phosphoryl transfer required for phosphorylation processes, alternative signalling mechanisms are required.

NFR5 and LYK5, two LysM-RLKs in Lotus japonicus and Arabidopsis, involved in Nod-factor signalling and plant immunity, respectively, where suggested to lack kinase activity due to structural alterations (Madsen et al., 2003; Cao et al., 2014). The LYK5 kinase domain showed no kinase activity in in vitro kinase assays. Interestingly, a LYK5 mutant lacking the kinase domain was not able to complement the lyk5-2 mutant phenotype, whereas a LYK5 mutant disrupted in ATP binding did. Although the kinase activity of LYK5 is not important for immune signalling, the presence of the kinase domain seems to be important for proper signalling. Co-immunoprecipitation experiments with the putative complex partner CERK1 also showed that the LYK5 kinase domain is essential for association of the two proteins (Cao et al., 2014). These findings indicate a role for LYK5 in mediating protein-protein interactions.

Besides atypical and pseudokinases, also non-arginine-aspartate (RD) kinases lack conserved amino acids involved in kinase activity. In contrast to RD kinases, non-RD kinases lack the conserved motif consisting of an arginine (R) and a preceding aspartate (D) in the kinase subdomain VIb important for phosphorylation of the activation loop. Most of the characterized RLKs involved in perceiving MAMPs were shown to belong to the class of non- 
RD kinases, whereas CERK1, BRI1, the co-receptor BAK1 and kinases involved in DAMP perception belong to the class of RD kinases (Brutus et al., 2010). Interestingly, the presence or the lack of the RD motif seems to determine the activation mechanisms of the respective kinase. RD kinases were shown to depend on autophosphorylation of the activation loop, whereas non-RD kinases could be constitutively active (Nolen et al., 2001) or activated by mechanisms independent of the autophosphorylation (Nolen et al., 2004). This assumption was also supported by Schwessinger et al. (2011), who showed that the RD-kinases BRI1 and BAK1 had strong auto- and transphosphorylation ability in vitro, whereas the non-RD kinases FLS2 and EFR had only weak to no phosphorylation activity at all.

One mechanism executed by non-RD kinases for activation is the release of a C-terminal autoinhibitory domain (AID). This mechanisms is well-described for animal proteins as for example giant protein kinases (Kobe et al., 1996), muscle myosin light chain kinases (MLCKs) (Yano et al., 1993) and calmodulin (CaM)- dependent protein kinases (CaMK) (Goldberg et al., 1996). But also in plants autoinhibition represents a common mechanism. As shown for the Arabidopsis CALCIUM-DEPENDENT PROTEIN KINASE (CDPK)- SNF1-RELATED PROTEIN KINASES (SnRK) superfamily (Hrabak et al., 2003; Gleason et al., 2006), including SALT OVERLY SENSITIVE2 (SOS2) protein kinase which was suggested to be autoinhibited by a domain required for binding of its signalling partner SOS3 (Guo et al., 2001). For the vertebrate giant muscle protein non-RD kinase titin it was shown that besides regulation through an autoinhibitory $\mathrm{Ca}^{2+} / \mathrm{CaM}$-binding domain, also the phosphorylation of an inhibitory tyrosine residue in the $\mathrm{P}+1$ loop of the kinase domain is important for activation of the protein (Mayans et al., 1998).

For animal and plant non-RD kinases, like INTERLEUKIN-1 RECEPTOR-ASSOCIATED KINASE1 (IRAK1, Knop and Martin, 1999) and XA21 (Andaya and Ronald, 2003), respectively, it was shown that kinase activity was dispensable for at least some of the downstream responses, indicating similar to the above mentioned LYK5 a scaffolding function of some kinase domains. Although the two non-RD kinases FLS2 and EFR only showed a weak kinase activity, their catalytic activity is necessary for proper signalling, contradicting the sole scaffolding function. Interestingly, heterodimerization with the co-receptor BAK1 was independent of a functional kinase domain (Schwessinger et al., 2011). 
Lack of the conserved RD motif, assigning CLR1 to the class of non-RD kinases, and subsequent impairment in autophosphorylation activity, additionally supports the predicted enzymatic inactivity of CLR1. Recently, the two pseudokinases RESISTANCE RELATED KINASE1 (RKS1) and HOPZ-ETI-DEFICIENT1 (ZED1) have been described to play a role in Arabidopsis immunity (Roux et al., 2014). Similar to CLR1, both kinases are classified to the RLCK XII subfamily (Shiu and Bleecker, 2003). Similar to CLR1 they lack the conserved aspartate (D) of the RD motif and are therefore non-RD kinases. Interestingly, the RLCK XII subfamily contains an over-average amount of pseudokinases compared to other RLCK subfamilies (Lehti-Shiu and Shiu, 2012; Roux et al., 2014). Although both pseudokinases are involved in Arabidopsis immunity, RKS1 was shown to confer broad spectrum resistance to Xanthomonas campestris (Huard-Chauveau et al., 2013) and ZED1 is involved in mediating ETI upon recognition of the Pseudomonas syringae type III effector HopZ1a (Lewis et al., 2013), no kinase activity could be detected for either of the kinases. RKS1 and ZED1 cluster in a gene locus together with six additional ZED1-RELATED KINASES (ZRKs), amongst which is also the active kinase ZRK10. Similar to the Pto kinases in tomato, which were also shown to be present in a cluster and to transphosphorylate (Gutierrez et al., 2010; Ntoukakis et al., 2013), also RKS1 and ZED1 could be transphosphorylated through other active ZRK proteins as for example ZRK10 in a putative complex.

Subsequently, although CLR1 represents an atypical kinase it could still be involved in mediating protein-protein interactions or function as substrate for other active kinases. At least for CERK1, it could be shown in this study that it not only associates with but also phosphorylates CLR1.

\subsection{CLR1 is a potentially myristoylated protein}

\subsubsection{CLR1 contains a myristoylation motif}

Besides the homology to LysM-RLK kinase domains the amino acid sequence of CLR1 revealed some additional features which could be important for its function. Using the PlantsP online prediction tool (http://plantsp.genomics.purdue.edu/myrist.html; Podell and Gribskov, 2004) an internal N-myristoylation motif was identified 23 amino acids C-terminal of the $\mathrm{N}$-terminus. $\mathrm{N}$-myristoylation usually is a co-translational protein modification 
involving the attachment of a myristic acid residue to the glycine residue at position two of a nascent polypeptide chain (Johnson et al., 1994). Over 300 Arabidopsis proteins have been predicted to by myristoylated (Podell and Gribskov, 2004). N-myristoylation was shown to be involved in biological processes like development and signal transduction (Zha, 2000; Thompson and Okuyama, 2000; Podell and Gribskov, 2004). Most commonly Nmyristoylation was shown to facilitate membrane association of the corresponding proteins. For several protein kinases of different families including RLCKs (Burr et al., 2011; Ranf et al., 2014), calcium-dependent protein kinases (CDPKs, Mehlmer et al., 2010; Lu and Hrabak, 2013) and small GTPases (Boisson et al., 2003) the necessity of N-myristoylation for membrane association was shown. G2A mutations leading to disruption of the $\mathrm{N}$ myristoylation motif led to loss of membrane association in various proteins like BIK1, PBL1, CPK5 and CAST AWAY (Burr et al., 2011; Ranf et al., 2014; Lu and Hrabak, 2013). Ranf and colleagues (2014) showed that for flg22-dependent phosphorylation of BIK1 and PBL1 Nmyristoylation of the two kinases is essential, suggesting that the correct subcellular localization of RLCKs is important for proper phosphotransfer. However, the mutant forms of the two RLCKs, BIK1 ${ }^{\mathrm{G} 2 \mathrm{~A}}$ and $\mathrm{PBL1}{ }^{\mathrm{G} 2 \mathrm{~A}}$, still exhibited autophosphorylation ability in vitro. Intriguingly, PBL1 ${ }^{\mathrm{G} 2 \mathrm{~A}}$ was not able to complement the pb/1 mutant concerning MAMPinduced immune responses implying the importance of $\mathrm{N}$-myristoylation not only for membrane-association but also for proper function of the RLCK (Ranf et al., 2014).

$\mathrm{N}$-Myristoylation is also important for protein-protein interactions. Not only does the hydrophobic myristate chain lead to membrane association and subsequent association with other membrane-bound proteins, but the hydrophobic moiety itself was reported to be able to interact with hydrophobic regions of other proteins (Thompson and Okuyama, 2000).

Although $\mathrm{N}$-myristoylation is an irreversible modification, the subsequent membrane association was shown to be reversible by a mechanism named 'myristoyl switch' (Zozulya and Stryer, 1992). In animals, the myristoylated $\mathrm{Ca}^{2+}$-binding protein Recoverin, serves as $\mathrm{Ca}^{2+}$ sensor involved in phototransduction in retinal rod cells (Baldwin and Ames, 1998). Under low $\mathrm{Ca}^{2+}$ conditions the $\mathrm{N}$-terminal myristoyl group is secluded in a hydrophobic pocket of the protein. Upon $\mathrm{Ca}^{2+}$-binding the myristoyl moiety is released in a liganddependent manner to establish membrane binding (Baldwin and Ames, 1998; Ames et al., 2000). Although for several plant proteins of the CDPK-SnRK subfamily a possible regulation 
via the myristoyl switch was predicted (Ishitani et al., 2000; Martín and Busconi, 2000; Batistič et al., 2008), so far, no evidence for plant proteins using this mechanism has been reported.

The predicted myristoylation motif in CLR1 is located behind an internal methionine $\left(M_{2}\right) 23$ amino acids C-terminal of the predicted protein start at methionine $\left(M_{1}\right)$. This raised the question how and if CLR1 can be myristoylated. One possibility for CLR1 to get myristoylated could be by post-translational $\mathrm{N}$-myristoylation. Here, a mature protein is enzymatically cleaved by caspases in order to expose a previously internal glycine residue for subsequent $\mathrm{N}$-myristoylation (Zha, 2000). This mechanism was shown to play an important role during apoptosis for several eukaryotic proteins (Zha, 2000; Vilas et al., 2006; Tilleman et al., 2012). So far, post-translational N-myristoylation was only shown to occur during apoptosis in animal cells. Hence, it is unlikely to apply for CLR1. Also, the fact that the fusion protein expressed from $p U B Q 10:: C L R 1-M_{1}-$ GFP showed a higher molecular mass compared to the proteins expressed from $p C L R 1:: C L R 1-G F P$ and $p U B Q 10:: C L R 1-M_{2}-G F P$ (see section 3.4) indicates that the proteins were not post-translationally cleaved ahead of the annotated internal methionine $M_{2}$. Therefore, it seems more likely that the CLR1 sequence was not annotated correctly and the actual protein start is represented by the current internal $M_{2}$. Podell and Gribskov (2004) have already suggested that some predicted internal myristoylation sites could be the results of gene annotation errors, since post-translational $\mathrm{N}$-myristoylation is rather unusual.

\subsubsection{CLR1 does not start at the annotated start codon}

To analyse whether the start codon annotated by TAIR10 (coding for $M_{1}$ ) or the ATG associated with the myristoylation motif (coding for $M_{2}$ ) is the in vivo start of the CLR1 protein, three different CLR1-fluoresence protein (FP) fusion constructs were generated: 1) pCLR1::CLR1-FP, 2) pUBQ10::CLR1-M 1 -FP and 3) pUBQ10::CLR1-M $-\mathrm{FP}$. Transient expression of the three fusion proteins in $N$. benthamiana, as well as stable expression in A. thaliana revealed that the molecular mass of the CLR1-FP fusion protein expressed from pUBQ10::CLR1-M2-FP resembled the molecular mass of the CLR1-FP protein expressed under the native promoter ( $p C L R 1:: C L R 1-F P)$. In contrast, the CLR1-FP fusion protein expressed from $p U B Q 10:: C L R 1-M_{1}-F P$ showed a higher apparent molecular mass. These results suggest 
that indeed the CLR1 sequence is not predicted correctly in the current Arabidopsis genome annotation (TAIR10, https://www.arabidopsis.org) and that the endogenous CLR1 protein seems to start at the start codon coding for $\mathrm{M}_{2}$. Results from the analysis of clr1 T-DNA insertion lines are in agreement with this finding. Chitin-induced gene expression is reduced in the two lines clr1-3 and clr1-4, which disrupt the kinase domain of CLR1 (3.2.4 and 3.2.5). However, clr1-1, the T-DNA mutant with insertion located between the two possible start codons, showed only a weak reduction of chitin-induced gene expression compared to the wild type Col-0, indicating that it is probably not a knockout line (see 4.4 and 4.5).

The fact that CLR1 does not start at the annotated start codon means that it could undergo co-translational N-myristoylation, which is a much more common mechanism than posttranslational $\mathrm{N}$-myristoylation. Consequently, the finding that CLR1 is a shorter protein than predicted makes it more likely to be indeed myristoylated. Interestingly, N-myristoylation of CLR1 seemed not important for phosphorylation by CERK1 since both fusion proteins, pUBQ10::CLR1-M1-GFP and $p U B Q 10:: C L R 1-M_{2}-G F P$, showed the chitin-induced mobility shift (Figure 21). In contrast to the flg22-induced phosphorylation of BIK1 and PBL1 which was shown to depend on N-myristoylation of the RLCKs (Ranf et al., 2014).

For most of the described $\mathrm{N}$-myristoylated proteins, the lipid modification is essential for membrane association of the corresponding protein, as it was shown for several RLCKs like CASTAWAY (Burr et al., 2011). Although CLR1 is suggested to be membrane-associated due to $\mathrm{N}$-myristoylation, the majority of the protein seems to be cytoplasmic in microsomal preparations with only a small quantity of the protein associated with membranes (Figure 22). This finding could be due to disruption of the N-myristoylation of CLR1 during the extraction method, since also subcellular localization studies with fluorescence-tagged CLR1 indicate plasma membrane-association of the protein. Several myristoylated proteins were shown to be not membrane-associated but located to the cytoplasm or as described before showed reversible membrane-association due to 'myristoyl switches' (Towler et al., 1988; Ames et al., 2000). Interestingly, it was shown that $\mathrm{N}$-myristoylation alone is not sufficient for efficient anchoring of proteins to membranes, thus myristoylated proteins need a second membrane binding signal (Resh, 1999). This second signal could be a polybasic domain for electrostatic interaction with membrane bilayers (Sigal et al., 1994; Zhou et al., 1994) or an additional lipid modification as for example palmitoylation (Galbiati et al., 1996; Wolven et 
al., 1997). Palmitoylation represents a post-translational reversible protein modification where a 16-C saturated fatty acid (palmitate) is attached to a cysteine residue (Linder, 2001). Additionally, also the interaction with another membrane-bound protein can enhance the membrane-association of a myristoylated protein. So far, less is known about a second membrane-binding signal in myristoylated proteins, although Hemsley and colleagues (2013) suggested that more than 600 Arabidopsis proteins are subject to S-acetylation due to thioester linkages. One plant protein which requires both, N-myristoylation and palmitoylation for efficient membrane-binding is the rice CALCIUM-DEPENDENT PROTEIN KINASE (CDPK, Martín and Busconi, 2000). Also the Arabidopsis RLCK II family protein SHORT SUSPENSOR (SSP) involved in embryonic patterning depends of $\mathrm{N}$-myristoylation and palmitoylation for membrane-binding and probably also for proper function (Bayer et al., 2009). For other membrane-localized proteins like the pepper PIK1 (Kim and Hwang, 2011) and Arabidopsis CPK32 (Choi et al., 2005), only the presence of putative N-myristoylation and palmitoylation sites was reported.

Since the CLR1 amino acid sequence contains no cysteine residues adjacent to the myristoylated glycine, it is unlikely that CLR1 is subject to $\mathrm{N}$-terminal palmitoylation. However, CLR1 possesses several residues of the basic amino acids lysine (K) and arginine (R) in its $\mathrm{N}$-terminal domain, indicating a possible additional membrane-association through this domain. The interaction with the CERK1 kinase domain seems not required for efficient membrane association of CLR1, since no difference in localization could be observed for CLR1 fusion proteins expressed in Col-0 or cerk1-2 background (data not shown). Whether, CLR1 associates with other membrane proteins involved in chitin signalling like LYK4 and LYK5 remains speculative. Transgenic lyk4 and lyk5 plants expressing $p C L R 1:: C L R 1-G F P$ could be used to analyse the subcellular localization of CLR1 and whether loss of the two proteins alters the observed plasma membrane-association of CLR1.

Interestingly, CLR1 also harbours a predicted uncommon NLS in form of a glycine-rich loop integrated between kinase subdomains IV and V (Figure 4) suggesting a possible nuclear localization and DNA-binding capacity of CLR1 (Cokol et al., 2000). Together with the Nmyristoylation motif involved in membrane-association of proteins, this could indicate that CLR1 has the ability to change its subcellular localization. This translocation could be mediated by a 'myristoyl switch' or due to a differential subcellular localization of 
myristoylated and non-myristoylated CLR1. The animal neuron-specific activators p35 and p39 which activate the CYCLIN-DEPENDENT KINASE5 (CDK5) were shown to be plasma membrane-localized when myristoylated. Mutating the myristoylation motif led to nuclear accumulation of the two proteins (Asada et al., 2008). To analyse whether myristoylation of CLR1 is important for the observed PM-localization, the putative $\mathrm{N}$-myristoylated glycine residue of the existing CLR1 fusion constructs should be mutated to an alanine as described for other myristoylated proteins like SOS3 (Ishitani et al., 2000), PBL1 and BIK1 (Ranf et al., 2014). The mutant fusion proteins could then be further analysed concerning their subcellular localization via CLSM and microsomal fractionations. Similar results could be obtained by treating transgenic Col-0 plants expressing $p C L R 1:: C L R 1-G F P$ with 2hydroxymyristic acid (HMA), the competitive inhibitor of the $\mathrm{N}$-myristoyltransferase, the enzyme catalysing myristoylation (Ishitani et al., 2000). If CLR1 subcellular localization depends on proper $\mathrm{N}$-myristoylation, mutating the myristoylation site or inhibition of myristoylation itself should alter its localization.

\subsection{The kinase inactive CLR1 is a direct downstream phosphorylation target of CERK1}

The RLCK CLR1 was identified as an interactor of the CERK1 kinase domain in a yeast twohybrid screen. Since RLCKs are known as downstream interactors and phosphorylation targets of RLKs (Lin et al., 2013), it seemed likely that CLR1 is a substrate of CERK1. Welldescribed examples for RLK/RLCK signalling partners in plants are CERK1 and PBL27 (Shinya et al., 2014), BAK1 and BIK1 (Nam and Li, 2002; Li et al., 2002), and OsCERK1 and OsRLCK185 (Yamaguchi et al., 2013). This hypothesis was confirmed in an in vitro phosphorylation assay using heterologously expressed fusion proteins (3.3.1). As expected, based on the analysis of CLR1 kinase subdomains, GST-CLR1 did not show kinase activity. However, it was phosphorylated by the CERK1 intracellular domain (CERK1-His). CERK1-His did not transphosphorylate the GST-tag on its own, confirming that the transphosphorylation was CLR1-specific.

The kinase assays that demonstrated direct phosphorylation of CLR1 by CERK1 were performed in vitro using heterologous proteins produced in E. coli. The next step was then to 
confirm that phosphorylation of CLR1 by CERK1 also occurs in planta. Stable transgenic Arabidopsis plants expressing $p C L R 1:: C L R 1-e C F P$ were analysed with respect to CERK1induced CLR1 phosphorylation. Western blot experiments showed that CLR1 shows a chitininduced band shift that requires the presence of CERK1. A similar mobility shift could be seen for CERK1 itself upon chitin treatment and was found to be caused by phosphorylation (Petutschnig et al., 2010). For other RLCKs like PBL27 (Shinya et al., 2014), BIK1 and PBL1 (Zhang et al., 2010) this MAMP-induced mobility shift was also demonstrated. LYK5, a LysMRLK that is phosphorylated by CERK1 after chitin treatment also displays such a band shift (Erwig et al., in preparation). A $\lambda$-PPase assay confirmed that the chitin-induced mobility shift of CLR1 is indeed due to phosphorylation. These findings suggest that CLR1 is a substrate of CERK1 in planta (Figure 16 and Figure 17). Treatment with other bacterial MAMPs showed that CLR1 phosphorylation is specific to polymeric chitin and chitin heptamer (7mer), as none of the tested bacterial MAMPs were able to induce the mobility shift (Figure 18 and Figure 19). Similar to PBL27 (Shinya et al., 2014), CLR1 seems to be specifically involved in chitin-induced downstream signalling events mediated by CERK1. However, not all chitininduced downstream immune responses were affected in clr1 mutants and those which were influenced were not abolished completely. This suggests that CLR1 functions downstream of CERK1 together with an additional signalling component, as for example another RLCK like PBL27. It has also been shown for other RLCKs like BIK1, PBS1 and several PBL proteins (Zhang et al., 2010; Liu et al., 2013) to function in the same signalling pathway, but also regulating different specific defence responses.

\subsection{CLR1 in CERK1-dependent chitin-signalling}

Upon perception of MAMPs by PRRs and transduction of the signal via RLCKs downstream defence responses are activated that result in PTI (Monaghan and Zipfel, 2012). The RLCK CLR1 analysed in this study functions downstream of CERK1 in chitin signalling since CERK1 phosphorylates CLR1 upon chitin treatment, but chitin-induced CERK1 phosphorylation was not altered in the tested clr1 mutants. However, early downstream defence responses like the production of ROS (Apel and Hirt, 2004) and activation of MAPKs (Tena et al., 2001) involved in signalling cascades seemed to be affected in clr1 mutants upon chitin treatment. All three tested clr1 mutant alleles showed a reduced sensitivity to chitin in ROS-burst assays 
(Figure 7). Interestingly, a reduction of chitin-induced MAPK activation could be detected for clr1-4, but not the other two T-DNA lines cIr1-1 and clr1-3. To assess the effect of CLR1 loss on chitin-induced gene expression, qRT-PCR experiments were performed with defencerelated WRKY genes (Wan et al., 2004) upon treatment with increasing chitin concentrations. All three cIr1 mutant alleles showed reduced expression for WRKY3O and WRKY53 compared to Col-0, with clr1-3 and clr1-4 exhibiting a more severe reduction in comparison to clr1-1. The differences between the T-DNA lines are likely due to the position of the T-DNA insertion and the differences between the assay types may reflect their sensitivity. As mentioned before, the T-DNA insertion of clr1-1 is located upstream of the newly described start codon coding for $M_{2}$, thus clr1-1 is likely a knockdown rather than a knockout mutant. c/r1-3 and c/r1-4 both carry T-DNA insertions within the kinase domain of CLR1, but clr1-4 is located further upstream, possibly making it a stronger allele. ROS-burst assays require a high concentration of chitin for a reliable read out, thus even weak alleles of CLR1 might show a reduced ROS response. MAPK activation and gene expression are more sensitive, and thus might make differences between the alleles visible. It cannot be ruled out that the requirements for MAPK activation and gene expression differ. A truncated protein in clr1-3 might be able to mediate MAPK activation, but not chitin-induced gene expression. In contrast to the expression of WRKY3O and WRKY53, the expression levels of WRKY33 were not obviously altered in the $c / r 1$ mutants compared to the wild type. Sole treatment with the lower chitin concentrations led to a significant reduction of expression in all three clr1 T-DNA mutants. This indicates that different subsets of genes may be more, and others less affected by loss of CLR1. The reduced responsiveness of the T-DNA mutants to chitin was even clearer when treated with chitin heptamer (7mer). Here, all mutant lines showed a significant reduction in the expression of the tested WRKY genes.

To test whether the clr1 T-DNA lines were also impaired in expression of specifically chitinresponsive genes, additionally to the general MAMP-induced WRKY genes, two putative new marker genes were tested. Although the induction of both genes, At3g43250 and At4g16820, upon chitin treatment could be confirmed, no significant alterations in expression could be detected for the $c / r 1$ mutants upon chitin or 7 mer treatment compared to Col-0. The different biological replicates showed a high variation in the expression levels, probably due to the generally low expression of At3g43250 and At4g16820 in planta. Therefore the two putative marker genes were not used in further experiments. 
Taken together, the obtained results indicate an involvement of CLR1 in chitin-signalling. The phenotypes of clr1 mutants are less severe than the phenotype of the CERK1 knockout mutant, cerk1-2 (Miya et al., 2007). This suggests that CLR1 contributes to full chitin signalling, but is not essential for it. Since CLR1 is a single copy gene in Arabidopsis, functional redundancy seems unlikely. Also, the two LysM-RLKs LYK4 and LYK5 which were shown to be involved in chitin signalling showed intermediate mutant phenotypes between the wild type and the cerk1-2 knockout mutant (Wan et al., 2012; Cao et al., 2014).

Furthermore, different clr1 alleles were impaired to different degrees and not all early chitin-induced defence responses were affected equally. A similar situation has been described for the RLCK PBL27, which was shown to selectively regulate chitin-induced defence responses (Shinya et al., 2014). Although MAPK activation, callose deposition and defence-gene expression were impaired in pb/27 mutants, the ROS production was not altered. Similar to the different tested clr1 alleles, also the localisation of the T-DNA in the PBL27 sequence had an effect on the impact of the observed phenotypes (Shinya et al., 2014).

To gain further information about the function of CLR1, further CERK1-dependent chitininduced defence responses should be checked in clr1 mutants, as for example the callose deposition and $\mathrm{Ca}^{2+}$ levels.

\subsection{CLR1 in CERK1-mediated immunity}

Consistent with the rather subtle chitin signalling phenotypes of clr1 mutants, no significant impairment in immunity against fungal pathogens was observed for these mutants. In contrast to CERK1, which has been shown to be involved in the resistance against the incompatible fungus A. brassicicola (Miya et al., 2007) as well as different Pseudomonas syringae pv. tomato (Pst) DC3000 strains (Gimenez-lbanez et al., 2009a; Gimenez-lbanez et al., 2009b). Also PBL27, the RLCK that functions downstream of CERK1, was demonstrated to play a role in resistance against A. brassicicola and non-pathogenic Pst DC3000 (Shinya et al., 2014). The impaired resistance against fungal pathogens that has been described for cerk1-2 could not be observed in this study. This generally indicates that the contribution of chitin 
signalling to immunity against fungal pathogens is subtle in Arabidopsis and probably many other factors from fungal pathogens are recognized as well.

For CERK1, PBL27 and OsRLCK185, a contribution to resistance against bacterial pathogens was proposed (Gimenez-lbanez et al., 2009b; Yamaguchi et al., 2013; Shinya et al., 2014). To test if this is also the case with CLR1, inoculation experiments with Pst were performed. Infections with the virulent Pst DC3000 (-) and the non-virulent Pst DC3000 ( $\mathrm{hrcC}$ ) showed no significant alterations in resistance in the clr1 mutants compared to Col-0 (Figure 14). This is probably due to the fact that subtle phenotypes in the $c / r 1$ mutants were suppressed due to the strong virulence of Pst DC3000, whereas the non-virulent Pst DC3000 ( $\mathrm{hrCC}$ ) is hardly able to proliferate efficiently on Arabidopsis. Also the significantly more susceptible phenotype for cerk1 mutants (Gimenez-Ibanez et al., 2009a; Shinya et al., 2014) could not be reproduced under our conditions. Interestingly, infection with the weakly virulent Pst DC3000 ( $\triangle$ avrPto/ $\triangle$ avrPtoB) strain showed a significant increase of bacterial proliferation in clr1-3 similar to cerk1-2. Also, the other clr1 alleles showed a trend for increased susceptibility to Pst DC3000 ( $\triangle$ avrPto/ $\triangle$ avrPtoB) although the results were not significant (Figure 14). Intriguingly, neither flg22 nor PGN induce phosphorylation of CLR1 in Western blot experiments, indicating that CLR1 could be involved in perception of an additional, yet unknown bacterial MAMP.

Stable expression of the CLR1 promoter-GUS fusion gene ( $p C L R 1:: G U S)$ in Arabidopsis indicated an enhanced CLR1 promoter activity in hydathodes. Hydathodes represent specialised secretory structures involved in guttation. Guttation is a well-described process where due to low transpiration activity and high soil moisture, water pressure increases in the roots and can be released through the constitutively open hydathodes. The exposed guttation droplets can be contaminated by bacteria, which together with drawn back liquid can easily enter the leaves vascular tissue through the hydathode cavity. Since hydathodes are constitutively open they lack a structural barrier against pathogen infection (Taiz and Zeiger, 2007). Pathogens like Xanthomonas campestris pv. campestris (Xcc) and other closely related crucifer-infecting pathovars have been shown to enter their hosts mainly through hydathodes and stomata (Cook et al., 1952; Bretschneider et al., 1989; Hugouvieux et al., 1998). Genes of several defence-related components as for example the LysM-CONTAINING RECEPTOR-LIKE KINASE4 (LYK4, Wan et al., 2012), the PAMP-induced secreted peptides PIP1 
and PIP2 (Hou et al., 2014) and chitinases (Gerhardt et al., 2004) have been shown to be highly expressed in hydathodes possibly performing a role in hydathode-specific immunity.

Taken together we could show that the contribution of CLR1 in resistance against fungal and bacterial pathogens is rather low. One explanation could be that CLR1 is mainly involved in resistance against pathogens entering via hydathodes due to the enhanced CLR1 promoter activity in this tissue. By vacuum-infiltrating the bacteria into the leaves as performed in this study, entry of the pathogen through hydathodes is circumvented. Thus, infection assays using pathogens like Xanthomonas which enter via hydathodes or techniques which promote pathogen entry via hydathodes could give more insights into this issue.

\subsection{Possible roles of CLR1 in CERK1-dependent PTI or ETI}

So far, CLR1 seems to play a role in CERK1-mediated chitin signalling by modulating downstream immune responses and signalling events. The production of ROS, as well as the expression of defence-related genes was altered in clr1 T-DNA insertion mutants as shown in this study. A selective regulation of downstream CERK1-triggered defence responses was previously also shown for the RLCK PBL27 (Shinya et al., 2014). CLR1 and PBL27 could act in concert for full chitin-signalling. It is a common theme that different PRRs share downstream RLCKs, but also vice versa, that several RLCKs function downstream of the same PRR (Lin et al., 2013). Interestingly, especially RLCKs of the subfamilies VII and XII seem to play an important role in the signal transduction. BIK1, PBS1 and PBL proteins of the RLCK subfamily VII transmit flg22 signals downstream of the FLS2 complex (Lu et al., 2010; Zhang et al., 2010). Similarly, the subfamily VII RLCK CDG1 mediates BL signals perceived by BRI1 (Kim et al., 2011). BSK1 (and its homologs) belongs to the subfamily XII and was identified as a regulator of BRI1-mediated BL responses (Tang et al., 2008). Similar to the LRR-RLK BAK1, it was later shown to also be involved in PTI signalling mediated by FLS2 (Shi et al., 2013a; Shi et al., 2013b). Thus in both, flg22 and BL signalling, subfamily VII and XII RLCKs act downstream of the receptor complexes.

While BIK1 does play some role in CERK1-mediated chitin signalling (Zhang et al., 2010), the main VII RLCK downstream of CERK1 appears to be PBL27 (Shinya et al., 2014). CLR1 as a 
member of the RLCK subfamily XII could contribute to CERK1-dependent chitin signalling similar to the BSK family in flg22 and BL signalling.

Potentially, CLR1 could also function as an effector target involved in triggering ETI as it was proposed for PBS1 (Zhang et al., 2010). PBS1 was shown to be guarded by the CC-NB-LRR R protein RESISTANCE TO PSEUDOMONAS SYRINGAE5 (RPS5). The bacterial effector AvrPphB interacts with PBS1 and other members of the PBL family and proteolytically cleaves them to supress PTI. Alterations of PBS1 are then sensed by RPS5 which subsequently induces ETI responses (Shao et al., 2003; Ade et al., 2007; Lin et al., 2013). Components involved in PTI, including several PRRs, have already previously been described to constitute effector targets (Fu et al., 2007; J Zhang et al., 2007; Xiang et al., 2008; Göhre et al., 2008; Zhou and Chai, 2008; Gimenez-Ibanez et al., 2009a). Based on its significant homology to the kinase domains of LysM-RLKs, CLR1 could also constitute an effector target mimic functioning as decoy (van der Hoorn and Kamoun, 2008). One example for this is the tomato RLCK Pto which directly interacts with the effectors AvrPto and AvrPtoB and is also required for AvrPto- and AvrPtoB-triggered ETI. Pto is guarded by the R protein Prf with which it forms a complex involved in effector recognition (Mucyn et al., 2006). AvrPto functions as kinase inhibitor and was shown to block the activity of FLS2 and EFR promoting pathogen virulence (Xing et al., 2007; Xiang et al., 2008). AvrPtoB is a E3 ubiquitin ligase which targets different host components involved in PTI, as for example FLS2 (Göhre et al., 2008) and CERK1 (Gimenez-Ibanez et al., 2009a), but also the tomato R protein Fen involved in the initiation of HR (Rosebrock et al., 2007). No function in PTI could be attributed to Pto to date (Oh and Martin, 2011) and the fact that AvrPto promotes bacterial virulence also in plants lacking Pto (Chang et al., 2000), has led to a model where Pto only functions as an effector decoy, whereas the actual effector targets are FLS2, CERK1 and other Ser/Thr kinases (Xiang et al., 2008; Zipfel and Rathjen, 2008; Gimenez-Ibanez et al., 2009a). Because of the relatively mild phenotype of clr1 mutants it is tempting to speculate that CLR1 might be a decoy for CERK1 or other LysM-RLKs. Investigation of AvrPtoB-mediated degradation of CERK1 (GimenezIbanez et al., 2009a) in a clr1 knockout background could shed light on this in the future. 


\subsection{Conclusion}

Overall, CLR1 is a receptor-like cytoplasmic kinase, which resembles high homology to the kinase domain of other LysM-RLKs present in Arabidopsis. Presumably, the annotated sequence of CLR1 on TAIR10 is wrong and the actual gene starts further downstream exhibiting an N-terminal myristoylation motif. Whether this lipid modification involved in membrane association of proteins is important for CLR1 function and subcellular localization is not yet clear, since CLR1 fusion proteins with and without exposing the N-terminal myristoylation motif are phosphorylated by CERK1, respectively. CLR1 seems to play a minor role in chitin signalling, due to subtle phenotypes in chitin-induced ROS production and defence gene expression. Interestingly, cIr1 T-DNA mutants show an enhanced susceptibility against the weakly virulent Pst DC3000 (avrPto/ avrPtoB), although treatment with bacterial MAMPs flg22 and PGN had no influence on CLR1 phosphorylation. Together with the enhanced CLR1 promoter expression in hydathodes, these results could indicate an additional role besides involvement in chitin signalling for CLR1 in immunity against bacterial pathogens entering through hydathodes.

\subsection{Outlook}

This study showed that the CLR1 sequence on TAIR10 is the result of an annotation error and the actual sequence starts further $\mathrm{C}$-terminal exposing a putative $\mathrm{N}$-myristoylation motif. So far, it seems as if the myristoylation motif has no influence on the phosphorylation of CLR1, since CLR1 fusion proteins with different $\mathrm{N}$-termini were all phosphorylated in a CERK1dependent manner. Additionally, these fusion proteins also showed a similar subcellular localization. To analyse whether CLR1 is actually an N-myristoylation substrate, in vitro translation assays with radiolabelled myristic acid should be performed. As controls, CLR1 constructs with a G2A mutation should be generated and included in the mentioned assay. Also, the already performed experiments should be repeated with the mutant $C L R 1^{\text {G2A }}$ fusion proteins to assess the importance of the $\mathrm{N}$-myristoylation for CLR1 function and subcellular localization.

CLR1 seems to play a role in CERK1-mediated chitin signalling based on reduced ROS production and expression of defence-related genes in clr1 T-DNA mutants. These 
phenotypes could be further affirmed by additional assays as for example analysing the MAMP-induced callose deposition in c/r1 T-DNA mutants and measuring the $\mathrm{Ca}^{2+}$ response upon MAMP-perception in clr1 T-DNA mutants crossed with stable transgenic plants expressing the $\mathrm{Ca}^{2+}$-binding protein Aequorin.

clr1 mutants showed no obvious phenotype upon infection with fungal pathogens and also the infection with bacterial pathogens only induced a subtle phenotype. Interestingly, stable transgenic Arabidopsis plants expressing $p C L R 1:: G U S$ revealed an enhanced CLR1 promotor activity in hydathodes. Pathogen assays using for example $X c c$ strains should be performed to analyse an involvement of CLR1 in hydathode-mediated immunity. Additionally, infection methods restricting pathogen entry to the hydathodes as for example soaking leaf rims in bacterial solution could also help analysing CLR1 contribution to plant immunity.

So far CLR1 seems to be a phosphorylation target of CERK1 due to results from experiments like the yeast two-hybrid analysis and in vitro and in vivo phosphorylation assays. Next, it would be interesting to analyse whether CLR1 also associates with other RLKs involved in chitin-signalling like LYK4 and LYK5. For this, stable transgenic lyk4 and lyk5 plants expressing CLR1 fusion proteins should be generated and analysed in similar experiments as described in this study. Moreover, interactions between CLR1 and the other LysM-RLKS could be confirmed in planta by using the bimolecular fluorescence complementation (BiFC).

Due to its homology to the kinase domain of Arabidopsis LysM-RLKs and the rather subtle phenotypes in chitin signalling and plant immunity, CLR1 could potentially be an effector target functioning as decoy. To test this, CLR1 could be used in a yeast two-hybrid screen using a pathogen effector cDNA library to check for interaction with pathogen effectors. 


\section{References}

Ade J, DeYoung BJ, Golstein C, Innes RW. 2007. Indirect activation of a plant nucleotide binding site-leucine-rich repeat protein by a bacterial protease. Proceedings of the National Academy of Sciences of the United States of America 104: 2531-2536.

Alfano JR, Collmer A. 1997. The type III (Hrp) secretion pathway of plant pathogenic bacteria: trafficking harpins, Avr proteins, and death. Journal of Bacteriology 179: 56555662.

Aloni R, Schwalm K, Langhans M, Ullrich Cl. 2003. Gradual shifts in sites of free-auxin production during leaf-primordium development and their role in vascular differentiation and leaf morphogenesis in Arabidopsis. Planta 216: 841-853.

Alonso JM, Stepanova AN, Leisse TJ, Kim CJ, Chen H, Shinn P, Stevenson DK, Zimmerman J, Barajas P, Cheuk R, Gadrinab C, Heller C, Jeske A, Koesema E, Meyers CC, Parker H, Prednis L, Ansari Y, Choy N, Deen H, Geralt M, Hazari N, Hom E, Karnes M, Mulholland C, Ndubaku R, Schmidt I, Guzman P, Aguilar-Henonin L, Schmid M, Weigel D, Carter DE, Marchand T, Risseeuw E, Brogden D, Zeko A, Crosby WL, Berry CC, Ecker JR. 2003. Genome-wide insertional mutagenesis of Arabidopsis thaliana. Science (New York, N.Y.) 301: 653-657.

Altschul SF, Madden TL, Schäffer AA, Zhang J, Zhang Z, Miller W, Lipman DJ. 1997. Gapped BLAST and PSI-BLAST: a new generation of protein database search programs. Nucl. Acids Res. 25: 3389-3402.

Ames JB, Ikura M, Stryer L. 2000. Molecular structure of membrane-targeting calcium sensors in vision: Recoverin and guanylate cyclase-activating protein 2. In: Palczewski K, ed. Vertebrate phototransduction and the visual cycle. San Diego: Acad. Press, 121-132.

Amor BB, Shaw SL, Oldroyd GED, Maillet F, Penmetsa RV, Cook D, Long SR, Dénarié J, Gough C. 2003. The NFP locus of Medicago truncatula controls an early step of Nod factor signal transduction upstream of a rapid calcium flux and root hair deformation. The Plant Journal 34: 495-506.

Andaya CB, Ronald PC. 2003. A catalytically impaired mutant of the rice Xa21 receptor kinase confers partial resistance to Xanthomonas oryzae pv oryzae. Physiological and Molecular Plant Pathology 62: 203-208.

Antolín-Llovera M, Ried MK, Parniske M. 2014. Cleavage of the SYMBIOSIS RECEPTOR-LIKE KINASE ectodomain promotes complex formation with Nod factor receptor 5 . Current biology CB 24: 422-427.

Ao Y, Li Z, Feng D, Xiong F, Liu J, Li J, Wang M, Wang J, Liu B, Wang H. 2014. OsCERK1 and OsRLCK176 play important roles in peptidoglycan and chitin signaling in rice innate immunity. The Plant journal for cell and molecular biology 80: 1072-1084.

Apel K, Hirt H. 2004. Reactive oxygen species: metabolism, oxidative stress, and signal transduction. Annual review of plant biology 55: 373-399.

Ardourel M, Demont N, Debellé F, Maillet F, Billy Fd, Promé JC, Dénarié J, Truchet G. 1994. Rhizobium meliloti lipooligosaccharide nodulation factors: different structural 
requirements for bacterial entry into target root hair cells and induction of plant symbiotic developmental responses. Plant Cell 6: 1357-1374.

Arrighi J, Barre A, Amor BB, Bersoult A, Soriano LC, Mirabella R, Carvalho-Niebel Fd, Journet $E$, Ghérardi $M$, Huguet $T$, Geurts R, Dénarié J, Rougé $P$, Gough $C$. 2006. The Medicago truncatula Lysine Motif-Receptor-Like Kinase Gene Family Includes NFP and New Nodule-Expressed Genes. Plant Physiol. 142: 265-279.

Asada A, Yamamoto N, Gohda M, Saito T, Hayashi N, Hisanaga S. 2008. Myristoylation of p39 and p35 is a determinant of cytoplasmic or nuclear localization of active cyclindependent kinase 5 complexes. Journal of neurochemistry 106: 1325-1336.

Ausubel FM. 2005. Are innate immune signaling pathways in plants and animals conserved? Nature immunology 6: 973-979.

Badel JL, Nomura K, Bandyopadhyay S, Shimizu R, Collmer A, He SY. 2003. Pseudomonas syringae pv. tomato DC3000 HopPtoM (CEL ORF3) is important for lesion formation but not growth in tomato and is secreted and translocated by the Hrp type III secretion system in a chaperone-dependent manner. Molecular microbiology 49: 1239-1251.

Baldwin AN, Ames JB. 1998. Core mutations that promote the calcium-induced allosteric transition of bovine recoverin. Biochemistry 37: 17408-17419.

Bartsch M, Gobbato E, Bednarek P, Debey S, Schultze JL, Bautor J, Parker JE. 2006. Salicylic Acid-Independent ENHANCED DISEASE SUSCEPTIBILITY1 Signaling in Arabidopsis Immunity and Cell Death Is Regulated by the Monooxygenase FMO1 and the Nudix Hydrolase NUDT7. Plant Cell 18: 1038-1051.

Bateman A, Bycroft M. 2000. The structure of a LysM domain from E. coli membrane-bound Iytic murein transglycosylase D (MltD). Journal of molecular biology 299: 1113-1119.

Batistič O, Sorek N, Schültke S, Yalovsky S, Kudla J. 2008. Dual Fatty Acyl Modification Determines the Localization and Plasma Membrane Targeting of CBL/CIPK Ca2+ Signaling Complexes in Arabidopsis. Plant Cell 20: 1346-1362.

Bayer M, Nawy T, Giglione C, Galli M, Meinnel T, Lukowitz W. 2009. Paternal Control of Embryonic Patterning in Arabidopsis thaliana. Science 323: 1485-1488.

Boisson B, Giglione C, Meinnel T. 2003. Unexpected protein families including cell defense components feature in the $\mathrm{N}$-myristoylome of a higher eukaryote. The Journal of biological chemistry 278: 43418-43429.

Boller T. 1995. Chemoperception of Microbial Signals in Plant Cells. Annu. Rev. Plant. Physiol. Plant. Mol. Biol. 46: 189-214.

Boller T, Felix G. 2009. A renaissance of elicitors: perception of microbe-associated molecular patterns and danger signals by pattern-recognition receptors. Annual review of plant biology 60: 379-406.

Boller T, Flury P. 2012. Peptides as Danger Signals: MAMPs and DAMPs. In: Irving H, Gehring C, eds. Plant Signaling Peptides. Berlin Heidelberg: Springer Berlin Heidelberg, 163-181.

Boller T, He SY. 2009. Innate immunity in plants: an arms race between pattern recognition receptors in plants and effectors in microbial pathogens. Science (New York, N.Y.) 324: 742-744. 
Bolton MD, van Esse HP, Vossen JH, Jonge R de, STERGIOPOULOS I, Stulemeijer, Iris J. E., Van Den Berg, Grardy C. M., Borrás-Hidalgo O, Dekker HL, Koster CG de, de Wit, PIERRE J. G. M., Joosten, Matthieu H. A. J., Thomma, Bart P. H. J. 2008. The novel Cladosporium fulvum lysin motif effector Ecp6 is a virulence factor with orthologues in other fungal species. Molecular microbiology 69: 119-136.

Bowling SA, Guo A, Cao H, Gordon AS, Klessig DF, Dong X. 1994. A mutation in Arabidopsis that leads to constitutive expression of systemic acquired resistance. Plant Cell 6: 18451857.

Brachmann CB, Davies A, Cost GJ, Caputo E, Li J, Hieter P, Boeke JD. 1998. Designer deletion strains derived from Saccharomyces cerevisiae S288C: a useful set of strains and plasmids for PCR-mediated gene disruption and other applications. Yeast (Chichester, England) 14: 115-132.

Bradford MM. 1976. A rapid and sensitive method for the quantitation of microgram quantities of protein utilizing the principle of protein-dye binding. Analytical Biochemistry 72: 248-254.

Bretschneider KE, Gonella MP, Robeson DJ. 1989. A comparative light and electron microscopical study of compatible and incompatible interactions between Xanthomonas campestris pv. campestris and cabbage (Brassica oleracea). Physiological and Molecular Plant Pathology 34: 285-297.

Broghammer A, Krusell L, Blaise M, Sauer J, Sullivan JT, Maolanon N, Vinther M, Lorentzen A, Madsen EB, Jensen KJ, Roepstorff P, Thirup S, Ronson CW, Thygesen MB, Stougaard J. 2012. Legume receptors perceive the rhizobial lipochitin oligosaccharide signal molecules by direct binding. PNAS 109: 13859-13864.

Brutus A, Sicilia F, Macone A, Cervone F, Lorenzo G de. 2010. A domain swap approach reveals a role of the plant wall-associated kinase 1 (WAK1) as a receptor of oligogalacturonides. PNAS 107: 9452-9457.

Buell CR, Joardar V, Lindeberg M, Selengut J, Paulsen IT, Gwinn ML, Dodson RJ, Deboy RT, Durkin AS, Kolonay JF, Madupu R, Daugherty S, Brinkac L, Beanan MJ, Haft DH, Nelson WC, Davidsen T, Zafar N, Zhou L, Liu J, Yuan Q, Khouri H, Fedorova N, Tran B, Russell D, Berry $K$, Utterback $T$, van Aken SE, Feldblyum TV, D'Ascenzo M, Deng W, Ramos AR, Alfano JR, Cartinhour S, Chatterjee AK, Delaney TP, Lazarowitz SG, Martin GB, Schneider DJ, Tang X, Bender CL, White O, Fraser CM, Collmer A. 2003. The complete genome sequence of the Arabidopsis and tomato pathogen Pseudomonas syringae pv. tomato DC3000. Proceedings of the National Academy of Sciences of the United States of America 100: 10181-10186.

Buist G, Steen A, Kok J, Kuipers OP. 2008. LysM, a widely distributed protein motif for binding to (peptido)glycans. Molecular microbiology 68: 838-847.

Burr CA, Leslie ME, Orlowski SK, Chen I, Wright CE, Daniels MJ, Liljegren SJ. 2011. CAST AWAY, a membrane-associated receptor-like kinase, inhibits organ abscission in Arabidopsis. Plant Physiol. 156: 1837-1850. 
Cao H, Bowling SA, Gordon AS, Dong X. 1994. Characterization of an Arabidopsis Mutant That Is Nonresponsive to Inducers of Systemic Acquired Resistance. Plant Cell 6: 15831592.

Cao Y, Liang Y, Tanaka K, Nguyen CT, Jedrzejczak RP, Joachimiak A, Stacey G. 2014. The kinase LYK5 is a major chitin receptor in Arabidopsis and forms a chitin-induced complex with related kinase CERK1. eLife 3.

Castells E, Casacuberta JM. 2007. Signalling through kinase-defective domains: the prevalence of atypical receptor-like kinases in plants. Journal of experimental botany 58: 3503-3511.

Chang JH, Rathjen JP, Bernal AJ, Staskawicz BJ, Michelmore RW. 2000. avrPto enhances growth and necrosis caused by Pseudomonas syringae pv.tomato in tomato lines lacking either Pto or Prf. Molecular plant-microbe interactions MPMI 13: 568-571.

Chinchilla D. 2007. A flagellin-induced complex of the receptor FLS2 and BAK1 initiates plant defence. Nature 448: 497-500.

Chinchilla D, Bauer Z, Regenass M, Boller T, Felix G. 2006. The Arabidopsis Receptor Kinase FLS2 Binds flg22 and Determines the Specificity of Flagellin Perception. Plant Cell 18: 465-476.

Chisholm ST, Coaker G, Day B, Staskawicz BJ. 2006. Host-microbe interactions: shaping the evolution of the plant immune response. Cell 124: 803-814.

Choi H, Park H, Park JH, Kim S, Im M, Seo H, Kim Y, Hwang I, Kim SY. 2005. Arabidopsis Calcium-Dependent Protein Kinase AtCPK32 Interacts with ABF4, a Transcriptional Regulator of Abscisic Acid-Responsive Gene Expression, and Modulates Its Activity. Plant Physiol. 139: 1750-1761.

Clark SE, Running MP, Meyerowitz EM. 1993. CLAVATA1, a regulator of meristem and flower development in Arabidopsis. Development 119: 397-418.

Clough SJ, Bent AF. 1998. Floral dip: a simplified method forAgrobacterium-mediated transformation ofArabidopsis thaliana. The Plant Journal 16: 735-743.

Cokol M, Nair R, Rost B. 2000. Finding nuclear localization signals. EMBO Rep. 1: 411-415.

Cook AA, Walker JC, Larson RH. 1952. Studies on the disease cycle of black rot of crucifers. Phytopathology: 162-167.

Dangl JL, Horvath DM, Staskawicz BJ. 2013. Pivoting the plant immune system from dissection to deployment. Science (New York, N.Y.) 341: 746-751.

Dangl JL, Jones JD. 2001. Plant pathogens and integrated defence responses to infection. Nature 411: 826-833.

de Wit, P J G M. 2007. How plants recognize pathogens and defend themselves. Cellular and molecular life sciences CMLS 64: 2726-2732.

de Wit, PIERRE J. G. M., MEHRABI R, VAN DEN BURG, HARROLD A., STERGIOPOULOS I. 2009. Fungal effector proteins: past, present and future. Molecular plant pathology 10: 735-747.

Deng WL, Preston G, Collmer A, Chang CJ, Huang HC. 1998. Characterization of the hrpC and hrpRS operons of Pseudomonas syringae pathovars syringae, tomato, and glycinea and 
analysis of the ability of hrpF, hrpG, hrcC, hrpT, and hrpV mutants to elicit the hypersensitive response and disease in plants. Journal of Bacteriology 180: 4523-4531.

Dodds PN, Lawrence GJ, Catanzariti A, Teh T, Wang CA, Ayliffe MA, Kobe B, Ellis JG. 2006. Direct protein interaction underlies gene-for-gene specificity and coevolution of the flax resistance genes and flax rust avirulence genes. Proceedings of the National Academy of Sciences of the United States of America 103: 8888-8893.

Dodds PN, Rathjen JP. 2010. Plant immunity: towards an integrated view of plant-pathogen interactions. Nature reviews. Genetics 11: 539-548.

Dou D, Kale SD, Wang X, Jiang RHY, Bruce NA, Arredondo FD, Zhang X, Tyler BM. 2008. RXLR-mediated entry of Phytophthora sojae effector Avr1b into soybean cells does not require pathogen-encoded machinery. The Plant cell 20: 1930-1947.

Durrant WE, Dong X. 2004. Systemic acquired resistance. Annual review of phytopathology 42: 185-209.

Erwig J. 2012. The Function of Arabidopsis LysM-RLK3, LysM-RLK4 and LYM2 in Chitin Signaling and other CERK1-mediated Processes. Master Thesis.

Eyers PA, Murphy JM. 2013. Dawn of the dead: protein pseudokinases signal new adventures in cell biology. Biochemical Society transactions 41: 969-974.

Faulkner C, Petutschnig E, Benitez-Alfonso Y, Beck M, Robatzek S, Lipka V, Maule AJ. 2013. LYM2-dependent chitin perception limits molecular flux via plasmodesmata. Proceedings of the National Academy of Sciences of the United States of America 110: 9166-9170.

Felix G, Duran JD, Volko S, Boller T. 1999. Plants have a sensitive perception system for the most conserved domain of bacterial flagellin. The Plant Journal 18: 265-276.

Feng F, Yang F, Rong W, Wu X, Zhang J, Chen S, He C, Zhou J. 2012. A Xanthomonas uridine 5'-monophosphate transferase inhibits plant immune kinases. Nature 485: 114.

Feys BJ, Wiermer M, Bhat RA, Moisan LJ, Medina-Escobar N, Neu C, Cabral A, Parker JE. 2005. Arabidopsis SENESCENCE-ASSOCIATED GENE101 stabilizes and signals within an ENHANCED DISEASE SUSCEPTIBILITY1 complex in plant innate immunity. Plant Cell 17: 2601-2613.

Frye CA, Innes RW. 1998. An Arabidopsis Mutant with Enhanced Resistance to Powdery Mildew. THE PLANT CELL ONLINE 10: 947-956.

Fu ZQ, Guo M, Jeong B, Tian F, Elthon TE, Cerny RL, Staiger D, Alfano JR. 2007. A type III effector ADP-ribosylates RNA-binding proteins and quells plant immunity. Nature 447: 284-288.

Galbiati F, Guzzi F, Magee Al, Milligan G, Parenti M. 1996. Chemical inhibition of myristoylation of the G-protein Gi1 alpha by 2-hydroxymyristate does not interfere with its palmitoylation or membrane association. Evidence that palmitoylation, but not myristoylation, regulates membrane attachment. Biochemical Journal 313: 717-720.

Galletti R, Ferrari S, Lorenzo G de. 2011. Arabidopsis MPK3 and MPK6 play different roles in basal and oligogalacturonide- or flagellin-induced resistance against Botrytis cinerea. Plant Physiol. 157: 804-814.

Gampala SS, Kim T, He J, Tang W, Deng Z, Bai M, Guan S, Lalonde S, Sun Y, Gendron JM, Chen H, Shibagaki N, Ferl RJ, Ehrhardt D, Chong K, Burlingame AL, Wang Z. 2007. An 
Essential Role for 14-3-3 Proteins in Brassinosteroid Signal Transduction in Arabidopsis. Developmental Cell 13: 177-189.

Gay NJ, Gangloff M. 2007. Structure and function of Toll receptors and their ligands. Annual review of biochemistry 76: 141-165.

Gerhardt, Liliane B. de A., Magioli C, Perez AB, Margis R, Sachetto-Martins G, MargisPinheiro M. 2004. AtchitIV gene expression is stimulated under abiotic stresses and is spatially and temporally regulated during embryo development. Genet. Mol. Biol. 27: 118-123.

Gimenez-Ibanez S, Hann DR, Ntoukakis V, Petutschnig E, Lipka V, Rathjen JP. 2009a. AvrPtoB targets the LysM receptor kinase CERK1 to promote bacterial virulence on plants. Current biology CB 19: 423-429.

Gimenez-Ibanez S, Ntoukakis V, Rathjen JP. 2009b. The LysM receptor kinase CERK1 mediates bacterial perception in Arabidopsis. Plant Signal Behav 4: 539-541.

Gleason C, Chaudhuri S, Yang T, Muñoz A, Poovaiah BW, Oldroyd GED. 2006. Nodulation independent of rhizobia induced by a calcium-activated kinase lacking autoinhibition. Nature 441: 1149.

Göhre V, Spallek T, Häweker H, Mersmann S, Mentzel T, Boller T, Torres M de, Mansfield JW, Robatzek S. 2008. Plant pattern-recognition receptor FLS2 is directed for degradation by the bacterial ubiquitin ligase AvrPtoB. Current biology CB 18: 1824-1832.

Goldberg J, Nairn AC, Kuriyan J. 1996. Structural Basis for the Autoinhibition of Calcium/Calmodulin-Dependent Protein Kinase I. Cell 84: 875-887.

Gómez-Gómez L, Boller T. 2000. FLS2. Molecular cell 5: 1003-1011.

Govrin EM, Levine A. 2000. The hypersensitive response facilitates plant infection by the necrotrophic pathogen Botrytis cinerea. Current Biology 10: 751-757.

Grefen C, Donald N, Hashimoto K, Kudla J, Schumacher K, Blatt MR. 2010. A ubiquitin-10 promoter-based vector set for fluorescent protein tagging facilitates temporal stability and native protein distribution in transient and stable expression studies. The Plant Journal 64: 355-365.

Guo Y, Halfter U, Ishitani M, Zhu J. 2001. Molecular Characterization of Functional Domains in the Protein Kinase SOS2 That Is Required for Plant Salt Tolerance. Plant Cell 13: 13831400.

Gust AA, Biswas R, Lenz HD, Rauhut T, Ranf S, Kemmerling B, Götz F, Glawischnig E, Lee J, Felix G, Nürnberger T. 2007. Bacteria-derived Peptidoglycans Constitute Pathogenassociated Molecular Patterns Triggering Innate Immunity in Arabidopsis. J. Biol. Chem. 282: 32338-32348.

Gutierrez JR, Balmuth AL, Ntoukakis V, Mucyn TS, Gimenez-lbanez S, Jones AME, Rathjen JP. 2010. Prf immune complexes of tomato are oligomeric and contain multiple Pto-like kinases that diversify effector recognition. The Plant Journal 61: 507-518.

Guy E, Lautier M, Chabannes M, Roux B, Lauber E, Arlat M, Noël LD. 2013. xopAC -triggered Immunity against Xanthomonas Depends on Arabidopsis Receptor-Like Cytoplasmic Kinase Genes PBL2 and RIPK. PLOS ONE 8: e73469. 
Han L, Li G, Yang K, Mao G, Wang R, Liu Y, Zhang S. 2010. Mitogen-activated protein kinase 3 and 6 regulate Botrytis cinerea-induced ethylene production in Arabidopsis. The Plant journal for cell and molecular biology 64: 114-127.

Han S, Lee S, Ronald PC. 2011. Secretion, modification, and regulation of Ax21. Current opinion in microbiology 14: 62-67.

Hanks S, Quinn A, Hunter T. 1988. The protein kinase family: Conserved features and deduced phylogeny of the catalytic domains. Science 241: 42-52.

Hanks SK, Hunter T. 1995. Protein kinases 6. The eukaryotic protein kinase superfamily: kinase (catalytic) domain structure and classification. FASEB J 9: 576-596.

Hann DR, Rathjen JP. 2007. Early events in the pathogenicity of Pseudomonas syringae on Nicotiana benthamiana. The Plant journal for cell and molecular biology 49: 607-618.

Hayafune M, Berisio R, Marchetti R, Silipo A, Kayama M, Desaki Y, Arima S, Squeglia F, Ruggiero A, Tokuyasu K, Molinaro A, Kaku H, Shibuya N. 2014. Chitin-induced activation of immune signaling by the rice receptor CEBiP relies on a unique sandwich-type dimerization. Proceedings of the National Academy of Sciences of the United States of America 111: E404-13.

He JX. 2002. The GSK3-like kinase BIN2 phosphorylates and destabilizes BZR1, a positive regulator of the brassinosteroid signaling pathway in Arabidopsis. Proc. Natl Acad. Sci. USA 99: 10185-10190.

He K, Gou X, Yuan T, Lin H, Asami T, Yoshida S, Russell SD, Li J. 2007. BAK1 and BKK1 regulate brassinosteroid-dependent growth and brassinosteroid-independent cell-death pathways. Current biology CB 17: 1109-1115.

Heath MC. 2000. Nonhost resistance and nonspecific plant defenses. Current opinion in plant biology 3: 315-319.

Heese A, Hann DR, Gimenez-Ibanez S, Jones AME, He K, Li J, Schroeder JI, Peck SC, Rathjen JP. 2007. The receptor-like kinase SERK3/BAK1 is a central regulator of innate immunity in plants. Proceedings of the National Academy of Sciences of the United States of America 104: 12217-12222.

Heintzen C, Melzer S, Fischer R, Kappeler S, Apel K, Staiger D. 1994. A light- and temperature-entrained circadian clock controls expression of transcripts encoding nuclear proteins with homology to RNA-binding proteins in meristematic tissue. The Plant journal for cell and molecular biology 5: 799-813.

Heintzen C, Nater M, Apel K, Staiger D. 1997. AtGRP7, a nuclear RNA-binding protein as a component of a circadian-regulated negative feedback loop in Arabidopsis thaliana. Proceedings of the National Academy of Sciences of the United States of America 94: 8515-8520.

Hellens R, Edwards EA, Leyland N, Bean S, Mullineaux P. 2000. pGreen: a versatile and flexible binary $\mathrm{Ti}$ vector for Agrobacterium-mediated plant transformation: Plant Molecular Biology. Plant Mol Biol 42: 819-832.

Hemsley PA, Weimar T, Lilley KS, Dupree P, Grierson CS. 2013. A proteomic approach identifies many novel palmitoylated proteins in Arabidopsis. New Phytologist 197: 805814. 
Hoorn, Renier A. L. van der, Kamoun S. 2008. From Guard to Decoy: A New Model for Perception of Plant Pathogen Effectors. Plant Cell 20: 2009-2017.

Hou S, Wang X, Chen D, Yang X, Wang M, Turrà D, Di Pietro A, Zhang W. 2014. The secreted peptide PIP1 amplifies immunity through receptor-like kinase 7. PLoS pathogens 10: e1004331.

Hrabak EM, Chan CWM, Gribskov M, Harper JF, Choi JH, Halford N, Kudla J, Luan S, Nimmo HG, Sussman MR, Thomas M, Walker-Simmons K, Zhu J, Harmon AC. 2003. The Arabidopsis CDPK-SnRK Superfamily of Protein Kinases. Plant Physiol. 132: 666-680.

Huard-Chauveau C, Perchepied L, Debieu M, Rivas S, Kroj T, Kars I, Bergelson J, Roux F, Roby D. 2013. An Atypical Kinase under Balancing Selection Confers Broad-Spectrum Disease Resistance in Arabidopsis. PLOS Genet 9: e1003766.

Huffaker A, Dafoe NJ, Schmelz EA. 2011. ZmPep1, an ortholog of Arabidopsis elicitor peptide 1 , regulates maize innate immunity and enhances disease resistance. Plant physiology 155: $1325-1338$.

Huffaker A, Pearce G, Ryan CA. 2006. An endogenous peptide signal in Arabidopsis activates components of the innate immune response. Proceedings of the National Academy of Sciences of the United States of America 103: 10098-10103.

Huffaker A, Ryan CA. 2007. Endogenous peptide defense signals in Arabidopsis differentially amplify signaling for the innate immune response. Proceedings of the National Academy of Sciences of the United States of America 104: 10732-10736.

Hugouvieux V, Barber CE, Daniels MJ. 1998. Entry of Xanthomonas campestris pv. campestris into hydathodes of Arabidopsis thaliana leaves: a system for studying early infection events in bacterial pathogenesis. Molecular plant-microbe interactions MPMI 11: 537-543.

lizasa E, Mitsutomi M, Nagano Y. 2010. Direct binding of a plant LysM receptor-like kinase, LysM RLK1/CERK1, to chitin in vitro. The Journal of biological chemistry 285: 2996-3004.

Ishitani M, Liu J, Halfter U, Kim C, Shi W, Zhu J. 2000. SOS3 Function in Plant Salt Tolerance Requires N-Myristoylation and Calcium Binding. Plant Cell 12: 1667-1677.

Jefferson RA, Kavanagh TA, Bevan MW. 1987. GUS fusions: beta-glucuronidase as a sensitive and versatile gene fusion marker in higher plants. The EMBO journal 6: 39013907.

Jeong S, Trotochaud AE, Clark SE. 1999. The Arabidopsis CLAVATA2 Gene Encodes a Receptor-like Protein Required for the Stability of the CLAVATA1 Receptor-like Kinase. Plant Cell 11: 1925-1933.

Jia Y, McAdams SA, Bryan GT, Hershey HP, Valent B. 2000. Direct interaction of resistance gene and avirulence gene products confers rice blast resistance. The EMBO journal 19: 4004-4014.

Jin Q, Thilmony R, Zwiesler-Vollick J, He S. 2003. Type III protein secretion in Pseudomonas syringae. Microbes and Infection 5: 301-310.

Johnson DR, Bhatnagar RS, Knoll U, Gordon JI. 1994. Genetic and biochemical studies of protein N-myristoylation. Annual review of biochemistry 63: 869-914.

Jones, Jonathan D G, Dangl JL. 2006. The plant immune system. Nature 444: 323-329. 
Jonge $\mathbf{R}$ de, Thomma, Bart P H J. 2009. Fungal LysM effectors: extinguishers of host immunity? Trends in microbiology 17: 151-157.

Kadota Y, Sklenar J, Derbyshire P, Stransfeld L, Asai S, Ntoukakis V, Jones JDG, Shirasu K, Menke F, Jones A, Zipfel C. 2014. Direct Regulation of the NADPH Oxidase RBOHD by the PRR-Associated Kinase BIK1 during Plant Immunity. Molecular cell 54: 43-55.

Kaku H, Nishizawa Y, Ishii-Minami N, Akimoto-Tomiyama C, Dohmae N, Takio K, Minami E, Shibuya N. 2006. Plant cells recognize chitin fragments for defense signaling through a plasma membrane receptor. Proceedings of the National Academy of Sciences of the United States of America 103: 11086-11091.

Kale SD, Tyler BM. 2011. Entry of oomycete and fungal effectors into plant and animal host cells. Cellular microbiology 13: 1839-1848.

Karlova R, Boeren S, Russinova E, Aker J, Vervoort J, Vries Sd. 2006. The Arabidopsis SOMATIC EMBRYOGENESIS RECEPTOR-LIKE KINASE1 Protein Complex Includes BRASSINOSTEROID-INSENSITIVE1. Plant Cell 18: 626-638.

Kearse M, Moir R, Wilson A, Stones-Havas S, Cheung M, Sturrock S, Buxton S, Cooper A, Markowitz S, Duran C, Thierer T, Ashton B, Meintjes P, Drummond A. 2012. Geneious Basic: An integrated and extendable desktop software platform for the organization and analysis of sequence data. Bioinformatics 28: 1647-1649.

Kemmerling B, Schwedt A, Rodriguez P, Mazzotta S, Frank M, Qamar SA, Mengiste T, Betsuyaku S, Parker JE, Müssig C, Thomma, Bart P H J, Albrecht C, Vries SC de, Hirt H, Nürnberger T. 2007. The BRI1-associated kinase 1, BAK1, has a brassinolide-independent role in plant cell-death control. Current biology CB 17: 1116-1122.

Kim DS, Hwang BK. 2011. The pepper receptor-like cytoplasmic protein kinase CaPIK1 is involved in plant signaling of defense and cell-death responses. The Plant journal for cell and molecular biology 66: 642-655.

Kim T, Guan S, Burlingame AL, Wang Z. 2011. The CDG1 kinase mediates brassinosteroid signal transduction from BRI1 receptor kinase to BSU1 phosphatase and GSK3-like kinase BIN2. Molecular cell 43: 561-571.

Kim T, Guan S, Sun Y, Deng Z, Tang W, Shang J, Sun Y, Burlingame AL, Wang Z. 2009. Brassinosteroid signal transduction from cell-surface receptor kinases to nuclear transcription factors. Nature cell biology 11: 1254-1260.

Kleinboelting N, Huep G, Kloetgen A, Viehoever P, Weisshaar B. 2012. GABI-Kat SimpleSearch: new features of the Arabidopsis thaliana T-DNA mutant database. Nucleic acids research 40: D1211-5.

Knop J, Martin MU. 1999. Effects of IL-1 receptor-associated kinase (IRAK) expression on IL-1 signaling are independent of its kinase activity. FEBS Letters 448: 81-85.

Kobe B, Heierhorst J, Feil SC, Parker MW, Benian GM, Weiss KR, Kemp BE. 1996. Giant protein kinases: domain interactions and structural basis of autoregulation. The EMBO journal 15: 6810-6821.

Koncz C, Schell J. 1986. The promoter of TL-DNA gene 5 controls the tissue-specific expression of chimaeric genes carried by a novel type of Agrobacterium binary vector: Molecular and General Genetics MGG. Molec Gen Genet 204: 383-396. 
Kouzai Y, Mochizuki S, Nakajima K, Desaki Y, Hayafune M, Miyazaki H, Yokotani N, Ozawa K, Minami E, Kaku H, Shibuya N, Nishizawa Y. 2014. Targeted gene disruption of OSCERK1 reveals its indispensable role in chitin perception and involvement in the peptidoglycan response and immunity in rice. Molecular plant-microbe interactions MPMI 27: 975-982.

Krol E, Mentzel T, Chinchilla D, Boller T, Felix G, Kemmerling B, Postel S, Arents M, Jeworutzki E, Al-Rasheid KAS, Becker D, Hedrich R. 2010. Perception of the Arabidopsis danger signal peptide 1 involves the pattern recognition receptor AtPEPR 1 and its close homologue AtPEPR2. The Journal of biological chemistry 285: 13471-13479.

Kunze G, Zipfel C, Robatzek S, Niehaus K, Boller T, Felix G. 2004. The N Terminus of Bacterial Elongation Factor Tu Elicits Innate Immunity in Arabidopsis Plants. Plant Cell 16: 34963507.

Laluk K, Luo H, Chai M, Dhawan R, Lai Z, Mengiste T. 2011. Biochemical and Genetic Requirements for Function of the Immune Response Regulator BOTRYTIS-INDUCED KINASE1 in Plant Growth, Ethylene Signaling, and PAMP-Triggered Immunity in Arabidopsis. Plant Cell 23: 2831-2849.

Lamesch P, Berardini TZ, Li D, Swarbreck D, Wilks C, Sasidharan R, Muller R, Dreher K, Alexander DL, Garcia-Hernandez M, Karthikeyan AS, Lee CH, Nelson WD, Ploetz L, Singh S, Wensel A, Huala E. 2012. The Arabidopsis Information Resource (TAIR): improved gene annotation and new tools. Nucl. Acids Res. 40: D1202-D1210.

Lehti-Shiu MD, Shiu S. 2012. Diversity, classification and function of the plant protein kinase superfamily. Philosophical Transactions of the Royal Society of London B: Biological Sciences 367: 2619-2639.

Lewis JD, Lee AH, Hassan JA, Wan J, Hurley B, Jhingree JR, Wang PW, Lo T, Youn J, Guttman DS, Desveaux D. 2013. The Arabidopsis ZED1 pseudokinase is required for ZAR1mediated immunity induced by the Pseudomonas syringae type III effector HopZ1a. PNAS 110: $18722-18727$.

Li J, Nam KH. 2002. Regulation of Brassinosteroid Signaling by a GSK3/SHAGGY-Like Kinase. Science 295: 1299-1301.

Li J, Wen J, Lease KA, Doke JT, Tax FE, Walker JC. 2002. BAK1, an Arabidopsis LRR Receptorlike Protein Kinase, Interacts with BRI1 and Modulates Brassinosteroid Signaling. Cell 110: 213-222.

Li X, Clarke JD, Zhang Y, Dong X. 2001. Activation of an EDS1-mediated R-gene pathway in the snc1 mutant leads to constitutive, NPR1-independent pathogen resistance. Mol. Plant Microbe Interact. 14: 1131-1139.

Li X, Lin H, Zhang W, Zou Y, Zhang J, Tang X, Zhou J. 2005. Flagellin induces innate immunity in nonhost interactions that is suppressed by Pseudomonas syringae effectors. Proceedings of the National Academy of Sciences of the United States of America 102: 12990-12995.

Libault M, Wan J, Czechowski T, Udvardi M, Stacey G. 2007. Identification of 118 Arabidopsis transcription factor and 30 ubiquitin-ligase genes responding to chitin, a plant-defense elicitor. Molecular plant-microbe interactions MPMI 20: 900-911. 
Limpens E, Franken C, Smit P, Willemse J, Bisseling T, Geurts R. 2003. LysM Domain Receptor Kinases Regulating Rhizobial Nod Factor-Induced Infection. Science 302: 630633.

Lin N, Martin GB. 2005. An avrPto/avrPtoB mutant of Pseudomonas syringae pv. tomato DC3000 does not elicit Pto-mediated resistance and is less virulent on tomato. Molecular plant-microbe interactions MPMI 18: 43-51.

Lin W, Ma X, Shan L, He P. 2013. Big roles of small kinases: the complex functions of receptor-like cytoplasmic kinases in plant immunity and development. Journal of integrative plant biology 55: 1188-1197.

Linder ME. 2001. 8 Reversible modification of proteins with thioester-linked fatty acids. In: Tamanoi F, Sigman DS, eds. Protein lipidation. San Diego, Calif.: Acad. Press, 215-240.

Lindgren PB. 1997. The role of hrp genes during plant-bacterial interactions. Annual review of phytopathology 35: 129-152.

Lipka V, Dittgen J, Bednarek P, Bhat R, Wiermer M, Stein M, Landtag J, Brandt W, RosahI S, Scheel D, Llorente F, Molina A, Parker J, Somerville S, Schulze-Lefert P. 2005. Pre- and postinvasion defenses both contribute to nonhost resistance in Arabidopsis. Science 310: 1180-1183.

Liu B, Li J, Ao Y, Qu J, Li Z, Su J, Zhang Y, Liu J, Feng D, Qi K, He Y, Wang J, Wang H. 2012. Lysin motif-containing proteins LYP4 and LYP6 play dual roles in peptidoglycan and chitin perception in rice innate immunity. The Plant cell 24: 3406-3419.

Liu T, Liu Z, Song C, Hu Y, Han Z, She J, Fan F, Wang J, Jin C, Chang J, Zhou J, Chai J. 2012. Chitin-induced dimerization activates a plant immune receptor. Science (New York, N.Y.) 336: 1160-1164.

Liu Z, Wu Y, Yang F, Zhang Y, Chen S, Xie Q, Tian X, Zhou J. 2013. BIK1 interacts with PEPRs to mediate ethylene-induced immunity. Proceedings of the National Academy of Sciences of the United States of America 110: 6205-6210.

Lu D, Wu S, Gao X, Zhang Y, Shan L, He P. 2010. A receptor-like cytoplasmic kinase, BIK1, associates with a flagellin receptor complex to initiate plant innate immunity. Proceedings of the National Academy of Sciences of the United States of America 107: 496-501.

Lu SX, Hrabak EM. 2013. The myristoylated amino-terminus of an Arabidopsis calciumdependent protein kinase mediates plasma membrane localization. Plant molecular biology 82: 267-278.

Macho AP, Zipfel C. 2014. Plant PRRs and the activation of innate immune signaling. Molecular cell 54: 263-272.

Mackey D, Belkhadir Y, Alonso JM, Ecker JR, Dangl JL. 2003. Arabidopsis RIN4 Is a Target of the Type III Virulence Effector AvrRpt2 and Modulates RPS2-Mediated Resistance. Cell 112: 379-389.

Madsen EB, Antolín-Llovera M, Grossmann C, Ye J, Vieweg S, Broghammer A, Krusell L, Radutoiu S, Jensen ON, Stougaard J, Parniske M. 2011. Autophosphorylation is essential for the in vivo function of the Lotus japonicus Nod factor receptor 1 and receptor- 
mediated signalling in cooperation with Nod factor receptor 5. The Plant journal for cell and molecular biology 65: 404-417.

Madsen EB, Madsen LH, Radutoiu S, Olbryt M, Rakwalska M, Szczyglowski K, Sato S, Kaneko T, Tabata S, Sandal N, Stougaard J. 2003. A receptor kinase gene of the LysM type is involved in legume perception of rhizobial signals. Nature 425: 637-640.

Mao G, Meng X, Liu Y, Zheng Z, Chen Z, Zhang S. 2011. Phosphorylation of a WRKY Transcription Factor by Two Pathogen-Responsive MAPKs Drives Phytoalexin Biosynthesis in Arabidopsis. Plant Cell 23: 1639-1653.

Marc Libault, Jinrong Wan, Tomasz Czechowski, Michael Udvardi, and Gary Stacey. Identification of 118 Arabidopsis Transcription Factor and 30 Ubiquitin-Ligase Genes Responding to Chitin, a Plant-Defense Elicitor, in press.

Marchler-Bauer A, Derbyshire MK, Gonzales NR, Lu S, Chitsaz F, Geer LY, Geer RC, He J, Gwadz M, Hurwitz DI, Lanczycki CJ, Lu F, Marchler GH, Song JS, Thanki N, Wang Z, Yamashita RA, Zhang D, Zheng C, Bryant SH. 2015. CDD: NCBI's conserved domain database. Nucleic acids research 43: D222-6.

Martin DDO, Beauchamp E, Berthiaume LG. 2011. Post-translational myristoylation: Fat matters in cellular life and death. Biochimie 93: 18-31.

Martín ML, Busconi L. 2000. Membrane localization of a rice calcium-dependent protein kinase (CDPK) is mediated by myristoylation and palmitoylation. The Plant Journal 24: 429-435.

Mayans O, Ven, Peter F. M. van der, Wilm M, Mues A, Young P, Fürst DO, Wilmanns $M$, Gautel M. 1998. Structural basis for activation of the titin kinase domain during myofibrillogenesis. Nature 395: 863.

Mazzotta S, Kemmerling B. 2011. PATTERN RECOGNITION IN PLANT INNATE IMMUNITY. Journal of Plant Pathology 93: 7-17.

Mehlmer N, Wurzinger B, Stael S, Hofmann-Rodrigues D, Csaszar E, Pfister B, Bayer R, Teige M. 2010. The $\mathrm{Ca}(2+)$-dependent protein kinase CPK3 is required for MAPKindependent salt-stress acclimation in Arabidopsis. The Plant journal for cell and molecular biology 63: 484-498.

Melotto M, Underwood W, He SY. 2008. Role of Stomata in Plant Innate Immunity and Foliar Bacterial Diseases. Annual review of phytopathology 46: 101-122.

Mészáros T, Helfer A, Hatzimasoura E, Magyar Z, Serazetdinova L, Rios G, Bardóczy V, Teige M, Koncz C, Peck S, Bögre L. 2006. The Arabidopsis MAP kinase kinase MKK1 participates in defence responses to the bacterial elicitor flagellin. The Plant Journal 48: 485-498.

Miles GP, Samuel MA, Zhang Y, Ellis BE. 2005. RNA interference-based (RNAi) suppression of AtMPK6, an Arabidopsis mitogen-activated protein kinase, results in hypersensitivity to ozone and misregulation of AtMPK3. Environmental Pollution 138: 230-237.

Mita S de, Streng A, Bisseling T, Geurts R. 2014. Evolution of a symbiotic receptor through gene duplications in the legume-rhizobium mutualism. The New phytologist 201: 961972.

Miya et al., 2007. CERK1, a LysM receptor kinase, is essential for chitin elicitor signaling in Arabidopsis, in press. 
Miya A, Albert P, Shinya T, Desaki Y, Ichimura K, Shirasu K, Narusaka Y, Kawakami N, Kaku H, Shibuya N. 2007. CERK1, a LysM receptor kinase, is essential for chitin elicitor signaling in Arabidopsis. Proceedings of the National Academy of Sciences of the United States of America 104: 19613-19618.

Miyata K, Kozaki T, Kouzai Y, Ozawa K, Ishii K, Asamizu E, Okabe Y, Umehara Y, Miyamoto A, Kobae Y, Akiyama K, Kaku H, Nishizawa Y, Shibuya N, Nakagawa T. 2014. The bifunctional plant receptor, OSCERK1, regulates both chitin-triggered immunity and arbuscular mycorrhizal symbiosis in rice. Plant \& cell physiology 55: 1864-1872.

Monaghan J, Matschi S, Shorinola O, Rovenich H, Matei A, Segonzac C, Malinovsky FG, Rathjen JP, MacLean D, Romeis T, Zipfel C. 2014. The calcium-dependent protein kinase CPK28 buffers plant immunity and regulates BIK1 turnover. Cell host \& microbe 16: 605615.

Monaghan J, Zipfel C. 2012. Plant pattern recognition receptor complexes at the plasma membrane. Current opinion in plant biology 15: 349-357.

Mucyn TS, Clemente A, Andriotis VME, Balmuth AL, Oldroyd GED, Staskawicz BJ, Rathjen JP. 2006. The Tomato NBARC-LRR Protein Prf Interacts with Pto Kinase in Vivo to Regulate Specific Plant Immunity. Plant Cell 18: 2792-2806.

Mulder L, Lefebvre B, Cullimore J, Imberty A. 2006. LysM domains of Medicago truncatula NFP protein involved in Nod factor perception. Glycosylation state, molecular modeling and docking of chitooligosaccharides and Nod factors. Glycobiology 16: 801-809.

Muthamilarasan M, Prasad M. 2013. Plant innate immunity: An updated insight into defense mechanism: Journal of Biosciences. J Biosci 38: 433-449.

Muto H, Yabe N, Asami T, Hasunuma K, Yamamoto KT. 2004. Overexpression of Constitutive Differential Growth 1 Gene, Which Encodes a RLCKVII-Subfamily Protein Kinase, Causes Abnormal Differential and Elongation Growth after Organ Differentiation in Arabidopsis. Plant Physiol. 136: 3124-3133.

Muzzarelli RAA. 1977. Chitin. Oxford: Pergamon Pr.

Nakagawa T, Kaku H, Shimoda Y, Sugiyama A, Shimamura M, Takanashi K, Yazaki K, Aoki T, Shibuya N, Kouchi H. 2011. From defense to symbiosis: limited alterations in the kinase domain of LysM receptor-like kinases are crucial for evolution of legume-Rhizobium symbiosis. The Plant journal for cell and molecular biology 65: 169-180.

Nakamura S, Mano S, Tanaka Y, Ohnishi M, Nakamori C, Araki M, Niwa T, Nishimura M, Kaminaka H, Nakagawa T, Sato Y, Ishiguro S. 2010. Gateway binary vectors with the bialaphos resistance gene, bar, as a selection marker for plant transformation. Bioscience, biotechnology, and biochemistry 74: 1315-1319.

Nam KH, Li J. 2002. BRI1/BAK1, a Receptor Kinase Pair Mediating Brassinosteroid Signaling. Cell 110: 203-212.

Narusaka Y, Shinya T, Narusaka M, Motoyama N, Shimada H, Murakami K, Shibuya N. 2013. Presence of LYM2 dependent but CERK1 independent disease resistance in Arabidopsis. Plant signaling \& behavior 8.

Navarro L, Jay F, Nomura K, He SY, Voinnet O. 2008. Suppression of the microRNA pathway by bacterial effector proteins. Science (New York, N.Y.) 321: 964-967. 
Navarro L, Zipfel C, Rowland O, Keller I, Robatzek S, Boller T, Jones JDG. 2004. The Transcriptional Innate Immune Response to flg22. Interplay and Overlap with Avr GeneDependent Defense Responses and Bacterial Pathogenesis. Plant Physiol. 135: 11131128.

Nolen B, Taylor S, Ghosh G. 2004. Regulation of Protein Kinases. Molecular cell 15: 661-675.

Nolen B, Yun CY, Wong CF, McCammon JA, Fu X, Ghosh G. 2001. The structure of Sky1p reveals a novel mechanism for constitutive activity. Nature Structural \& Molecular Biology 8: 176.

Ntoukakis V, Balmuth AL, Mucyn TS, Gutierrez JR, Jones AME, Rathjen JP. 2013. The Tomato Prf Complex Is a Molecular Trap for Bacterial Effectors Based on Pto Transphosphorylation. PLOS Pathog 9: e1003123.

Nühse TS, Bottrill AR, Jones AME, Peck SC. 2007. Quantitative phosphoproteomic analysis of plasma membrane proteins reveals regulatory mechanisms of plant innate immune responses. The Plant Journal 51: 931-940.

Nürnberger T, Brunner F, Kemmerling B, Piater L. 2004. Innate immunity in plants and animals: Striking similarities and obvious differences. Immunol Rev 198: 249-266.

Nürnberger T, Lipka V. 2005. Non-host resistance in plants: new insights into an old phenomenon. Molecular plant pathology 6: 335-345.

O'Connell RJ, Panstruga R. 2006. Tête à tête inside a plant cell: establishing compatibility between plants and biotrophic fungi and oomycetes. New Phytologist 171: 699-718.

Oh C, Martin GB. 2011. Effector-triggered immunity mediated by the Pto kinase. Trends in plant science 16: 132-140.

Oldroyd GED, Downie JA. 2008. Coordinating nodule morphogenesis with rhizobial infection in legumes. Annual review of plant biology 59: 519-546.

Panstruga R, Dodds PN. 2009. Terrific protein traffic: the mystery of effector protein delivery by filamentous plant pathogens. Science (New York, N.Y.) 324: 748-750.

Park C, Chen S, Shirsekar G, Zhou B, Khang CH, Songkumarn P, Afzal AJ, Ning Y, Wang R, Bellizzi M, Valent B, Wang G. 2012. The Magnaporthe oryzae Effector AvrPiz-t Targets the RING E3 Ubiquitin Ligase APIP6 to Suppress Pathogen-Associated Molecular PatternTriggered Immunity in Rice. Plant Cell 24: 4748-4762.

Peñaloza-Vázquez A, Preston GM, Collmer A, Bender CL. 2000. Regulatory interactions between the Hrp type III protein secretion system and coronatine biosynthesis in Pseudomonas syringae pv. tomato DC3000. Microbiology 146: 2447-2456.

Petutschnig EK, Jones, Alexandra M E, Serazetdinova L, Lipka U, Lipka V. 2010. The lysin motif receptor-like kinase (LysM-RLK) CERK1 is a major chitin-binding protein in Arabidopsis thaliana and subject to chitin-induced phosphorylation. The Journal of biological chemistry 285: 28902-28911.

Pfund C, Tans-Kersten J, Dunning FM, Alonso JM, Ecker JR, Allen C, Bent AF. 2004. Flagellin is not a major defense elicitor in Ralstonia solanacearum cells or extracts applied to Arabidopsis thaliana. Molecular plant-microbe interactions MPMI 17: 696-706.

Podell S, Gribskov M. 2004. Predicting N-terminal myristoylation sites in plant proteins. BMC Genomics 5: 37. 
Postel S, Küfner I, Beuter C, Mazzotta S, Schwedt A, Borlotti A, Halter T, Kemmerling B, Nürnberger T. 2010. The multifunctional leucine-rich repeat receptor kinase BAK1 is implicated in Arabidopsis development and immunity. European journal of cell biology 89: 169-174.

Qi Z, Verma R, Gehring C, Yamaguchi Y, Zhao Y, Ryan CA, Berkowitz GA. 2010. Ca2+ signaling by plant Arabidopsis thaliana Pep peptides depends on AtPepR1, a receptor with guanylyl cyclase activity, and cGMP-activated Ca2+ channels. PNAS 107: 2119321198.

Radutoiu S, Madsen LH, Madsen EB, Felle HH, Umehara Y, Grønlund M, Sato S, Nakamura Y, Tabata S, Sandal N, Stougaard J. 2003. Plant recognition of symbiotic bacteria requires two LysM receptor-like kinases. Nature 425: 585-592.

Ramonell K, Berrocal-Lobo M, Koh S, Wan J, Edwards H, Stacey G, Somerville S. 2005. Lossof-function mutations in chitin responsive genes show increased susceptibility to the powdery mildew pathogen Erysiphe cichoracearum. Plant physiology 138: 1027-1036.

Ranf S, Eschen-Lippold L, Fröhlich K, Westphal L, Scheel D, Lee J. 2014. Microbe-associated molecular pattern-induced calcium signaling requires the receptor-like cytoplasmic kinases, PBL1 and BIK1. BMC plant biology 14: 374.

Resh MD. 1999. Fatty acylation of proteins: new insights into membrane targeting of myristoylated and palmitoylated proteins. Biochimica et Biophysica Acta (BBA) Molecular Cell Research 1451: 1-16.

Rey T, Nars A, Bonhomme M, Bottin A, Huguet S, Balzergue S, Jardinaud M, Bono J, Cullimore J, Dumas B, Gough C, Jacquet C. 2013. NFP, a LysM protein controlling Nod factor perception, also intervenes in Medicago truncatula resistance to pathogens. New Phytologist 198: 875-886.

Riely BK, Ané J, Penmetsa RV, Cook DR. 2004. Genetic and genomic analysis in model legumes bring Nod-factor signaling to center stage. Current opinion in plant biology 7: 408-413.

Rose, Jocelyn K. C., Ham K, Darvill AG, Albersheim P. 2002. Molecular Cloning and Characterization of Glucanase Inhibitor Proteins Coevolution of a Counterdefense Mechanism by Plant Pathogens. Plant Cell 14: 1329-1345.

Rosebrock TR, Zeng L, Brady JJ, Abramovitch RB, Xiao F, Martin GB. 2007. A bacterial E3 ubiquitin ligase targets a host protein kinase to disrupt plant immunity. Nature 448: 370.

Roux F, Noël L, Rivas S, Roby D. 2014. ZRK atypical kinases: emerging signaling components of plant immunity. The New phytologist 203: 713-716.

Roux M, Schwessinger B, Albrecht C, Chinchilla D, Jones A, Holton N, Malinovsky FG, Tör M, Vries Sd, Zipfel C. The Arabidopsis Leucine-Rich Repeat Receptor-Like Kinases BAK1/SERK3 and BKK1/SERK4 Are Required for Innate Immunity to Hemibiotrophic and Biotrophic Pathogens. Plant Cell 23: 2440-2455.

Roux M, Schwessinger B, Albrecht C, Chinchilla D, Jones A, Holton N, Malinovsky FG, Tör M, Vries Sd, Zipfel C. 2011. The Arabidopsis Leucine-Rich Repeat Receptor-Like Kinases BAK1/SERK3 and BKK1/SERK4 Are Required for Innate Immunity to Hemibiotrophic and Biotrophic Pathogens. Plant Cell 23: 2440-2455. 
Ruduś I, Terai H, Shimizu T, Kojima H, Hattori K, Nishimori Y, Tsukagoshi H, Kamiya Y, Seo M, Nakamura K, Kępczyński J, Ishiguro S. 2014. Wound-induced expression of DEFECTIVE IN ANTHER DEHISCENCE1 and DAD1-like lipase genes is mediated by both CORONATINE INSENSITIVE1-dependent and independent pathways in Arabidopsis thaliana: Plant Cell Reports. Plant Cell Rep 33: 849-860.

Schornack S, van Damme M, Bozkurt TO, Cano LM, Smoker M, Thines M, Gaulin E, Kamoun S, Huitema E. 2010. Ancient class of translocated oomycete effectors targets the host nucleus. PNAS 107: 17421-17426.

Schulze B, Mentzel T, Jehle AK, Mueller K, Beeler S, Boller T, Felix G, Chinchilla D. 2010. Rapid heteromerization and phosphorylation of ligand-activated plant transmembrane receptors and their associated kinase BAK1. The Journal of biological chemistry 285: 9444-9451.

Schwessinger B, Roux M, Kadota Y, Ntoukakis V, Sklenar J, Jones A, Zipfel C. 2011. Phosphorylation-dependent differential regulation of plant growth, cell death, and innate immunity by the regulatory receptor-like kinase BAK1. PLoS genetics 7: e1002046.

Shan L, He P, Li J, Heese A, Peck SC, Nürnberger T, Martin GB, Sheen J. 2008. Bacterial effectors target the common signaling partner BAK1 to disrupt multiple MAMP receptorsignaling complexes and impede plant immunity. Cell host \& microbe 4: 17-27.

Shao F, Golstein C, Ade J, Stoutemyer M, Dixon JE, Innes RW. 2003. Cleavage of Arabidopsis PBS1 by a bacterial type III effector. Science (New York, N.Y.) 301: 1230-1233.

Shi H, Shen Q, Qi Y, Yan H, Nie H, Chen Y, Zhao T, Katagiri F, Tang D. 2013a. BR-SIGNALING KINASE1 Physically Associates with FLAGELLIN SENSING2 and Regulates Plant Innate Immunity in Arabidopsis. Plant Cell 25: 1143-1157.

Shi H, Yan H, Li J, Tang D. 2013b. BSK1, a receptor-like cytoplasmic kinase, involved in both BR signaling and innate immunity in Arabidopsis. Plant signaling \& behavior 8.

Shimizu T, Nakano T, Takamizawa D, Desaki Y, Ishii-Minami N, Nishizawa Y, Minami E, Okada K, Yamane H, Kaku H, Shibuya N. 2010. Two LysM receptor molecules, CEBiP and OsCERK1, cooperatively regulate chitin elicitor signaling in rice. The Plant journal for cell and molecular biology 64: 204-214.

Shinya T, Motoyama N, Ikeda A, Wada M, Kamiya K, Hayafune M, Kaku H, Shibuya N. 2012. Functional characterization of CEBiP and CERK1 homologs in arabidopsis and rice reveals the presence of different chitin receptor systems in plants. Plant \& cell physiology 53: 1696-1706.

Shinya T, Nakagawa T, Kaku H, Shibuya N. 2015. Chitin-mediated plant-fungal interactions: catching, hiding and handshaking. Current opinion in plant biology 26: 64-71.

Shinya T, Yamaguchi K, Desaki Y, Yamada K, Narisawa T, Kobayashi Y, Maeda K, Suzuki M, Tanimoto T, Takeda J, Nakashima M, Funama R, Narusaka M, Narusaka Y, Kaku H, Kawasaki T, Shibuya N. 2014. Selective regulation of the chitin-induced defense response by the Arabidopsis receptor-like cytoplasmic kinase PBL27. The Plant journal for cell and molecular biology 79: 56-66.

Shiu and Bleecker, 2001. Receptor-like kinases from Arabidopsis form a monophyletic gene family related to animal receptor kinases, in press. 
Shiu S, Karlowski WM, Pan R, Tzeng Y, Mayer, Klaus F. X., Li W. 2004. Comparative Analysis of the Receptor-Like Kinase Family in Arabidopsis and Rice. Plant Cell 16: 1220-1234.

Shiu SH, Bleecker AB. 2001. Receptor-like kinases from Arabidopsis form a monophyletic gene family related to animal receptor kinases. Proc. Natl. Acad. Sci. U.S.A. 98: 1076310768.

Shiu SH, Bleecker AB. 2003. Expansion of the receptor-like kinase/Pelle gene family and receptor-like proteins in Arabidopsis. Plant Physiol. 132: 530-543.

Shpak ED, Lakeman MB, Torii KU. 2003. Dominant-Negative Receptor Uncovers Redundancy in the Arabidopsis ERECTA Leucine-Rich Repeat Receptor-Like Kinase Signaling Pathway That Regulates Organ Shape. Plant Cell 15: 1095-1110.

Sigal CT, Zhou W, Buser CA, McLaughlin S, Resh MD. 1994. Amino-terminal basic residues of Src mediate membrane binding through electrostatic interaction with acidic phospholipids. PNAS 91: 12253-12257.

Siomi H, Dreyfuss G. 1995. A nuclear localization domain in the hnRNP A1 protein. The Journal of Cell Biology 129: 551-560.

Smit P, Limpens E, Geurts R, Fedorova E, Dolgikh E, Gough C, Bisseling T. 2007. Medicago LYK3, an Entry Receptor in Rhizobial Nodulation Factor Signaling. Plant Physiol. 145: 183191.

Song J, Win J, Tian M, Schornack S, Kaschani F, llyas M, Hoorn, Renier A. L. van der, Kamoun S. 2009. Apoplastic effectors secreted by two unrelated eukaryotic plant pathogens target the tomato defense protease Rcr3. PNAS 106: 1654-1659.

Song W, Wang G, Chen L, Kim H, Pi L, Holsten T, Gardner J, Wang B, Zhai W, Zhu L, Fauquet C, Ronald P. 1995. A Receptor Kinase-Like Protein Encoded by the Rice Disease Resistance Gene, Xa21. Science 270: 1804-1806.

Sun W, Dunning FM, Pfund C, Weingarten R, Bent AF. 2006. Within-species flagellin polymorphism in Xanthomonas campestris pv campestris and its impact on elicitation of Arabidopsis FLAGELLIN SENSING2-dependent defenses. The Plant cell 18: 764-779.

Sun Y, Fan X, Cao D, Tang W, He K, Zhu J, He J, Bai M, Zhu S, Oh E, Patil S, Kim T, Ji H, Wong WH, Rhee SY, Wang Z. 2010. Integration of Brassinosteroid Signal Transduction with the Transcription Network for Plant Growth Regulation in Arabidopsis. Developmental Cell 19: 765-777.

Sun Y, Han Z, Tang J, Hu Z, Chai C, Zhou B, Chai J. 2013. Structure reveals that BAK1 as a coreceptor recognizes the BRI1-bound brassinolide. Cell research 23: 1326-1329.

Taiz L, Zeiger E. 2007. Plant physiology: Das Original mit Übersetzungshilfen, 4. ed. Heidelberg: Spektrum Akad. Verl./Springer.

Tang W. 2011. PP2A activates brassinosteroid-responsive gene\&nbsp;expression and plant growth by dephosphorylating\&nbsp;BZR1. Nat. Cell Biol. 13: 124-131.

Tang W, Kim T, Oses-Prieto JA, Sun Y, Deng Z, Zhu S, Wang R, Burlingame AL, Wang Z. 2008. BSKs mediate signal transduction from the receptor kinase BRI1 in Arabidopsis. Science (New York, N.Y.) 321: 557-560.

Taylor SS, Radzio-Andzelm E. 1994. Three protein kinase structures define a common motif. Structure 2: 345-355. 
Tena G, Asai T, Chiu W, Sheen J. 2001. Plant mitogen-activated protein kinase signaling cascades. Current opinion in plant biology 4: 392-400.

Thompson GA, Okuyama H. 2000. Lipid-linked proteins of plants. Progress in Lipid Research 39: 19-39.

Thordal-Christensen H. 2003. Fresh insights into processes of nonhost resistance. Current opinion in plant biology 6: 351-357.

Tilleman L, Henau S de, Pauwels M, Nagy N, Pintelon I, Braeckman BP, Wael K de, van Doorslaer S, Adriaensen D, Timmermans J, Moens L, Dewilde S. 2012. An Nmyristoylated globin with a redox-sensing function that regulates the defecation cycle in Caenorhabditis elegans. PloS one 7: e48768.

Tintor N, Ross A, Kanehara K, Yamada K, Fan L, Kemmerling B, Nürnberger T, Tsuda K, Saijo Y. 2013. Layered pattern receptor signaling via ethylene and endogenous elicitor peptides during Arabidopsis immunity to bacterial infection. PNAS 110: 6211-6216.

Torres MA, Jones JDG, Dangl JL. 2006. Reactive oxygen species signaling in response to pathogens. Plant physiology 141: 373-378.

Torres M de, Mansfield JW, Grabov N, Brown IR, Ammouneh H, Tsiamis G, Forsyth A, Robatzek S, Grant M, Boch J. 2006. Pseudomonas syringae effector AvrPtoB suppresses basal defence in Arabidopsis. The Plant journal for cell and molecular biology 47: 368382.

Towler DA, Gordon JI, Adams SP, Glaser L. 1988. The biology and enzymology of eukaryotic protein acylation. Annual review of biochemistry 57: 69-99.

van Hulten M, Pelser M, van Loon LC, Pieterse CMJ, Ton J. 2006. Costs and benefits of priming for defense in Arabidopsis. Proc. Natl. Acad. Sci. U.S.A. 103: 5602-5607.

Veronese P, Nakagami H, Bluhm B, AbuQamar S, Chen X, Salmeron J, Dietrich RA, Hirt H, Mengiste T. 2006. The Membrane-Anchored BOTRYTIS-INDUCED KINASE1 Plays Distinct Roles in Arabidopsis Resistance to Necrotrophic and Biotrophic Pathogens. Plant Cell 18: 257-273.

Vert G, Chory J. 2006. Downstream nuclear events in brassinosteroid signalling. Nature 441: 96.

Vij S, Giri J, Dansana PK, Kapoor S, Tyagi AK. 2008. The receptor-like cytoplasmic kinase (OsRLCK) gene family in rice: organization, phylogenetic relationship, and expression during development and stress. Molecular plant 1: 732-750.

Vilas GL, Corvi MM, Plummer GJ, Seime AM, Lambkin GR, Berthiaume LG. 2006. Posttranslational myristoylation of caspase-activated p21-activated protein kinase 2 (PAK2) potentiates late apoptotic events. PNAS 103: 6542-6547.

Wan J, Tanaka K, Zhang X, Son GH, Brechenmacher L, Nguyen, Tran Hong Nha, Stacey G. 2012. LYK4, a lysin motif receptor-like kinase, is important for chitin signaling and plant innate immunity in Arabidopsis. Plant physiology 160: 396-406.

Wan J, Zhang S, Stacey G. 2004. Activation of a mitogen-activated protein kinase pathway in Arabidopsis by chitin. Molecular plant pathology 5: 125-135. 
Wan J, Zhang X, Neece D, Ramonell KM, Clough S, Kim S, Stacey MG, Stacey G. 2008. A LysM receptor-like kinase plays a critical role in chitin signaling and fungal resistance in Arabidopsis. The Plant cell 20: 471-481.

Wang G, Roux B, Feng F, Guy E, Li L, Li N, Zhang X, Lautier M, Jardinaud M, Chabannes M, Arlat M, Chen S, He C, Noël LD, Zhou J. 2015. The Decoy Substrate of a Pathogen Effector and a Pseudokinase Specify Pathogen-Induced Modified-Self Recognition and Immunity in Plants. Cell host \& microbe 18: 285-295.

Wang X. 2008. Sequential transphosphorylation of the BRI1/BAK1 receptor kinase complex impacts early events in brassinosteroid signaling. Dev. Cell 15: 220-235.

Wang Z, Nakano T, Gendron J, He J, Chen M, Vafeados D, Yang Y, Fujioka S, Yoshida S, Asami T. 2002. Nuclear-Localized BZR1 Mediates Brassinosteroid-Induced Growth and Feedback Suppression of Brassinosteroid Biosynthesis. Developmental Cell 2: 505-513.

Whisson SC, Boevink PC, Moleleki L, Avrova AO, Morales JG, Gilroy EM, Armstrong MR, Grouffaud S, van West P, Chapman S, Hein I, Toth IK, Pritchard L, Birch, Paul R. J. 2007. A translocation signal for delivery of oomycete effector proteins into host plant cells. Nature 450: 115-118.

Willmann R, Lajunen HM, Erbs G, Newman M, Kolb D, Tsuda K, Katagiri F, Fliegmann J, Bono J, Cullimore JV, Jehle AK, Götz F, Kulik A, Molinaro A, Lipka V, Gust AA, Nürnberger T. 2011. Arabidopsis lysin-motif proteins LYM1 LYM3 CERK1 mediate bacterial peptidoglycan sensing and immunity to bacterial infection. Proceedings of the National Academy of Sciences of the United States of America 108: 19824-19829.

Winter D, Vinegar B, Nahal H, Ammar R, Wilson GV, Provart NJ. 2007. An "Electronic Fluorescent Pictograph" Browser for Exploring and Analyzing Large-Scale Biological Data Sets. PLOS ONE 2: e718.

Wolven A, Okamura H, Rosenblatt Y, Resh MD. 1997. Palmitoylation of p59fyn is reversible and sufficient for plasma membrane association. Molecular Biology of the Cell 8: 11591173.

Xiang T, Zong N, Zou Y, Wu Y, Zhang J, Xing W, Li Y, Tang X, Zhu L, Chai J, Zhou J. 2008. Pseudomonas syringae effector AvrPto blocks innate immunity by targeting receptor kinases. Current biology CB 18: 74-80.

Xing W, Zou Y, Liu Q, Liu J, Luo X, Huang Q, Chen S, Zhu L, Bi R, Hao Q, Wu J, Zhou J, Chai J. 2007. The structural basis for activation of plant immunity by bacterial effector protein AvrPto. Nature 449: 243-247.

Xu R, Blanvillain S, Feng J, Jiang B, Li X, Wei H, Kroj T, Lauber E, Roby D, Chen B, He Y, Lu G, Tang D, Vasse J, Arlat M, Tang J. 2008. AvrACXcc8004, a Type III Effector with a LeucineRich Repeat Domain from Xanthomonas campestris Pathovar campestris Confers Avirulence in Vascular Tissues of Arabidopsis thaliana Ecotype Col-0. J. Bacteriol. 190: 343-355.

Yamaguchi K, Yamada K, Ishikawa K, Yoshimura S, Hayashi N, Uchihashi K, Ishihama N, Kishi-Kaboshi M, Takahashi A, Tsuge S, Ochiai H, Tada Y, Shimamoto K, Yoshioka H, Kawasaki T. 2013. A receptor-like cytoplasmic kinase targeted by a plant pathogen 
effector is directly phosphorylated by the chitin receptor and mediates rice immunity. Cell host \& microbe 13: 347-357.

Yamaguchi Y, Huffaker A, Bryan AC, Tax FE, Ryan CA. 2010. PEPR2 Is a Second Receptor for the Pep1 and Pep2 Peptides and Contributes to Defense Responses in Arabidopsis. Plant Cell 22: 508-522.

Yamaguchi Y, Pearce G, Ryan CA. 2006. The cell surface leucine-rich repeat receptor for AtPep1, an endogenous peptide elicitor in Arabidopsis, is functional in transgenic tobacco cells. Proceedings of the National Academy of Sciences of the United States of America 103: 10104-10109.

Yano K, Araki Y, Hales SJ, Tanaka M, Ikebe M. 1993. Boundary of the autoinhibitory region of smooth muscle myosin light-chain kinase. Biochemistry 32: 12054-12061.

Yin Y, Wang Z, Mora-Garcia S, Li J, Yoshida S, Asami T, Chory J. 2002. BES1 Accumulates in the Nucleus in Response to Brassinosteroids to Regulate Gene Expression and Promote Stem Elongation. Cell 109: 181-191.

Zha J. 2000. Posttranslational N-Myristoylation of BID as a Molecular Switch for Targeting Mitochondria and Apoptosis. Science 290: 1761-1765.

Zhang J, Li W, Xiang T, Liu Z, Laluk K, Ding X, Zou Y, Gao M, Zhang X, Chen S, Mengiste T, Zhang $Y$, Zhou J. 2010. Receptor-like cytoplasmic kinases integrate signaling from multiple plant immune receptors and are targeted by a Pseudomonas syringae effector. Cell host \& microbe 7: 290-301.

Zhang J, Shao F, Li Y, Cui H, Chen L, Li H, Zou Y, Long C, Lan L, Chai J, Chen S, Tang X, Zhou J. 2007. A Pseudomonas syringae effector inactivates MAPKs to suppress PAMP-induced immunity in plants. Cell host \& microbe 1: 175-185.

Zhang X, Wu X, Findley S, Wan J, Libault M, Nguyen HT, Cannon SB, Stacey G. 2007. Molecular Evolution of Lysin Motif-Type Receptor-Like Kinases in Plants. Plant Physiol. 144: 623-636.

Zhao C, Nie H, Shen Q, Zhang S, Lukowitz W, Tang D. 2014. EDR1 Physically Interacts with MKK4/MKK5 and Negatively Regulates a MAP Kinase Cascade to Modulate Plant Innate Immunity. PLOS Genet 10: e1004389.

Zhou J, Chai J. 2008. Plant pathogenic bacterial type III effectors subdue host responses. Current opinion in microbiology 11: 179-185.

Zhou W, Parent $\mathrm{U}$, Wills JW, Resh MD. 1994. Identification of a membrane-binding domain within the amino-terminal region of human immunodeficiency virus type 1 Gag protein which interacts with acidic phospholipids. J. Virol. 68: 2556-2569.

Ziemienowicz A, Haasen D, Staiger D, Merkle T. 2003. Arabidopsis transportin1 is the nuclear import receptor for the circadian clock-regulated RNA-binding protein AtGRP7. Plant Mol Biol 53: 201-212.

Zipfel C. 2008. Pattern-recognition receptors in plant innate immunity. Current opinion in immunology 20: 10-16.

Zipfel C. 2009. Early molecular events in PAMP-triggered immunity. Current opinion in plant biology 12: 414-420. 
Zipfel C, Kunze G, Chinchilla D, Caniard A, Jones JDG, Boller T, Felix G. 2006. Perception of the bacterial PAMP EF-Tu by the receptor EFR restricts Agrobacterium-mediated transformation. Cell 125: 749-760.

Zipfel C, Rathjen JP. 2008. Plant Immunity: AvrPto Targets the Frontline. Current Biology 18: R218-R220.

Zipfel C, Robatzek S, Navarro L, Oakeley EJ, Jones JDG, Felix G, Boller T. 2004. Bacterial disease resistance in Arabidopsis through flagellin perception. Nature 428: 764-767.

Zozulya S, Stryer L. 1992. Calcium-myristoyl protein switch. PNAS 89: 11569-11573. 


\section{Supplemental}
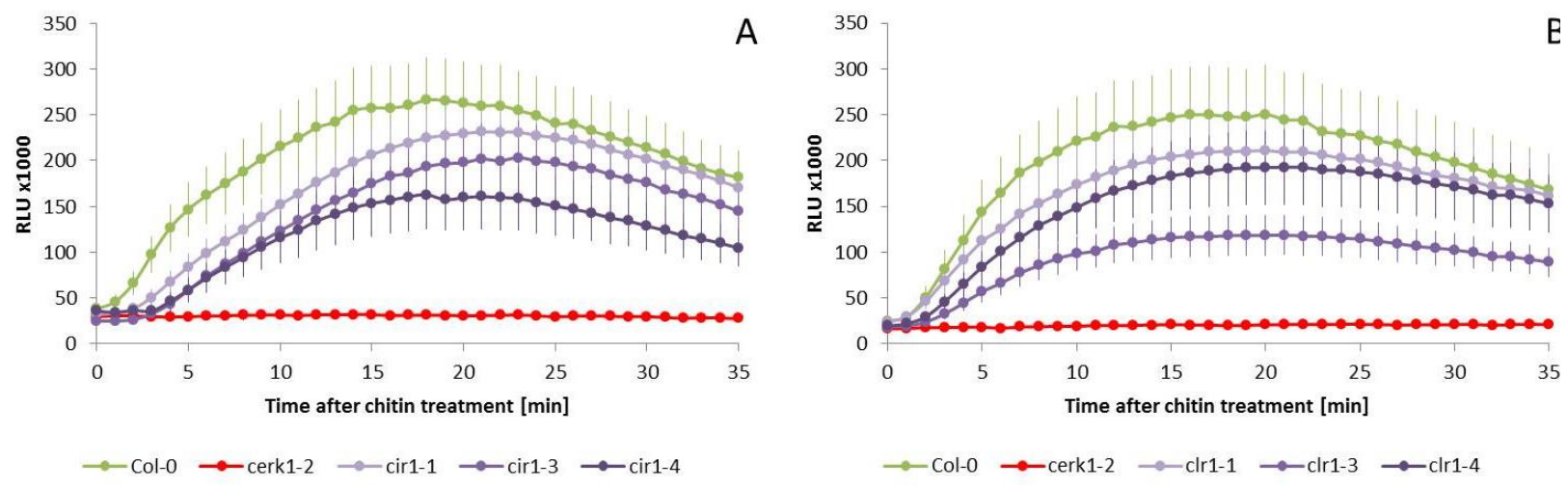

Suppl. Figure 1. clr1 mutants show reduced ROS generation upon chitin treatment. Diagrams depict two independent repetitions of the experiment in Figure 7. Leaf discs of five-week-old Arabidopsis plants were treated with $100 \mu \mathrm{g} / \mathrm{ml}$ polymeric chitin. Relative luminescence units (RLUs) were measured for 35 min after the treatment. The data shown are the means \pm SE of 12 leaf discs per genotype measured for 35 min.

Suppl. Table 1. List of 27 genes induced at least 2.5-fold upon chitooctamer (8mer) and crab shell chitin (CSC) treatment (Ramonell et al., 2005), which were not induced upon flg22 and elf18/ elf26 treatment. The two genes (At4g16820 and At3g43250) used for further qRT-PCR analysis in this work are highlighted in bold. Modified from Ramonell et al., 2005.

\begin{tabular}{|c|c|c|c|c|c|c|c|}
\hline \multirow{2}{*}{ AGI } & \multicolumn{2}{|c|}{ Ramonell et al., $2005^{1}$} & \multirow{2}{*}{$\begin{array}{l}\text { Mészáros et } \\
\text { al., } 2006^{2}\end{array}$} & \multirow{2}{*}{$\begin{array}{l}\text { Zipfel et al., } \\
2004^{3}\end{array}$} & \multirow{2}{*}{$\begin{array}{l}\text { Zipfel et } \\
\text { al., } 2006^{3}\end{array}$} & \multirow{2}{*}{$\begin{array}{l}\text { Navarro et } \\
\text { al., } 2004^{4}\end{array}$} & \multirow{2}{*}{$\begin{array}{l}\text { Tintor et } \\
\text { al., } 2013^{5}\end{array}$} \\
\hline & $8 \mathrm{mer}$ & CSC mix & & & & & \\
\hline At4g16820 & 37,2 & 42,0 & ni & ni & ni & 2,98 & ni \\
\hline At3g53600 & 18,6 & 25,0 & ni & ni & ni & ni & ni \\
\hline At3g43250 & 14,9 & 19,5 & ni & ni & ni & ni & ni \\
\hline At2g45760 & 5,2 & 15,7 & ni & 2 & 1.4 & ni & ni \\
\hline At1g61460 & 6,3 & 8,4 & ni & ni & ni & ni & ni \\
\hline At1g76210 & 4,8 & 9,0 & ni & ni & ni & ni & ni \\
\hline At1g21230 & 5,6 & 8,8 & ni & ni & ni & ni & ni \\
\hline At5g48530 & 4,5 & 6,6 & ni & ni & ni & ni & ni \\
\hline At1g33760 & 7,1 & 6,1 & ni & ni & ni & ni & ni \\
\hline At1g67000 & 4,5 & 5,8 & ni & ni & ni & ni & ni \\
\hline At2g25460 & 6,4 & 7,5 & ni & ni & ni & ni & ni \\
\hline At1g32960 & 6,8 & 8,3 & ni & ni & ni & ni & 1,39 \\
\hline At1g42980 & 5,4 & 5,4 & ni & ni & ni & ni & ni \\
\hline
\end{tabular}




\begin{tabular}{|c|c|c|c|c|c|c|c|}
\hline At2g37810 & 5,1 & 5,1 & ni & ni & ni & ni & ni \\
\hline At3g44860 & 4,1 & 5,5 & ni & ni & ni & ni & 1,45 \\
\hline At5g66620 & 3,0 & 4,6 & ni & ni & ni & ni & ni \\
\hline At1g77910 & 2,6 & 3,7 & ni & ni & ni & ni & ni \\
\hline At2g38590 & 5,5 & 5,6 & ni & ni & ni & ni & ni \\
\hline At5g46510 & 2,9 & 4,0 & ni & ni & ni & ni & ni \\
\hline At5g39100 & 4,5 & 4,5 & ni & 1.2 & 1 & ni & ni \\
\hline At1g51280 & 3,1 & 3,3 & ni & 1.7 & 1.4 & ni & ni \\
\hline At1g73010 & 3,1 & 3,7 & ni & 1.9 & 2.3 & ni & ni \\
\hline At2g28820 & 2,8 & 3,3 & ni & ni & ni & ni & ni \\
\hline At1g64380 & 3,5 & 3,5 & ni & ni & ni & ni & ni \\
\hline At3g48450 & 2,8 & 2,8 & ni & ni & ni & ni & ni \\
\hline At1g17240 & 2,9 & 3,0 & ni & ni & ni & ni & ni \\
\hline At4g29610 & 4,0 & 2,6 & ni & ni & ni & ni & ni \\
\hline
\end{tabular}

ni: not included in the respective data set because PAMP-triggered gene induction was below threshold.

${ }^{1}$ Threshold $=$ Genes $\geq 1$.5-fold induction after normalization.

${ }^{2}$ Threshold = > 3-fold change of expression after normalization using the global scaling method. Expression signals $<\mathbf{5 0}$ were floored to $\mathbf{5 0}$ to eliminate noise and the number of minor significant changes.

${ }^{3}$ Threshold $=$ Raw value $>100$ in one of the experiments. Genes with a p-value cut-off of $<0.003$ between the repetitions were further analysed. Genes with a $p$-value $>0.05$ in all repetitions were discarded from analysis. Data were further filtered using a one-way ANOVA (p-value $<0.05$ ) with a Benjamini and Hochberg false discovery multiple testing correction.

${ }^{4}$ Threshold = Expression level $\geq 10$ (noise level of expression) and p-value cut-off $<0.05$.

${ }^{5}$ Threshold $=$ Genes with $a \geq 2$-fold change in transcript levels (q-value $\leq 0.05$ ) after normalization to the 0 time point. 

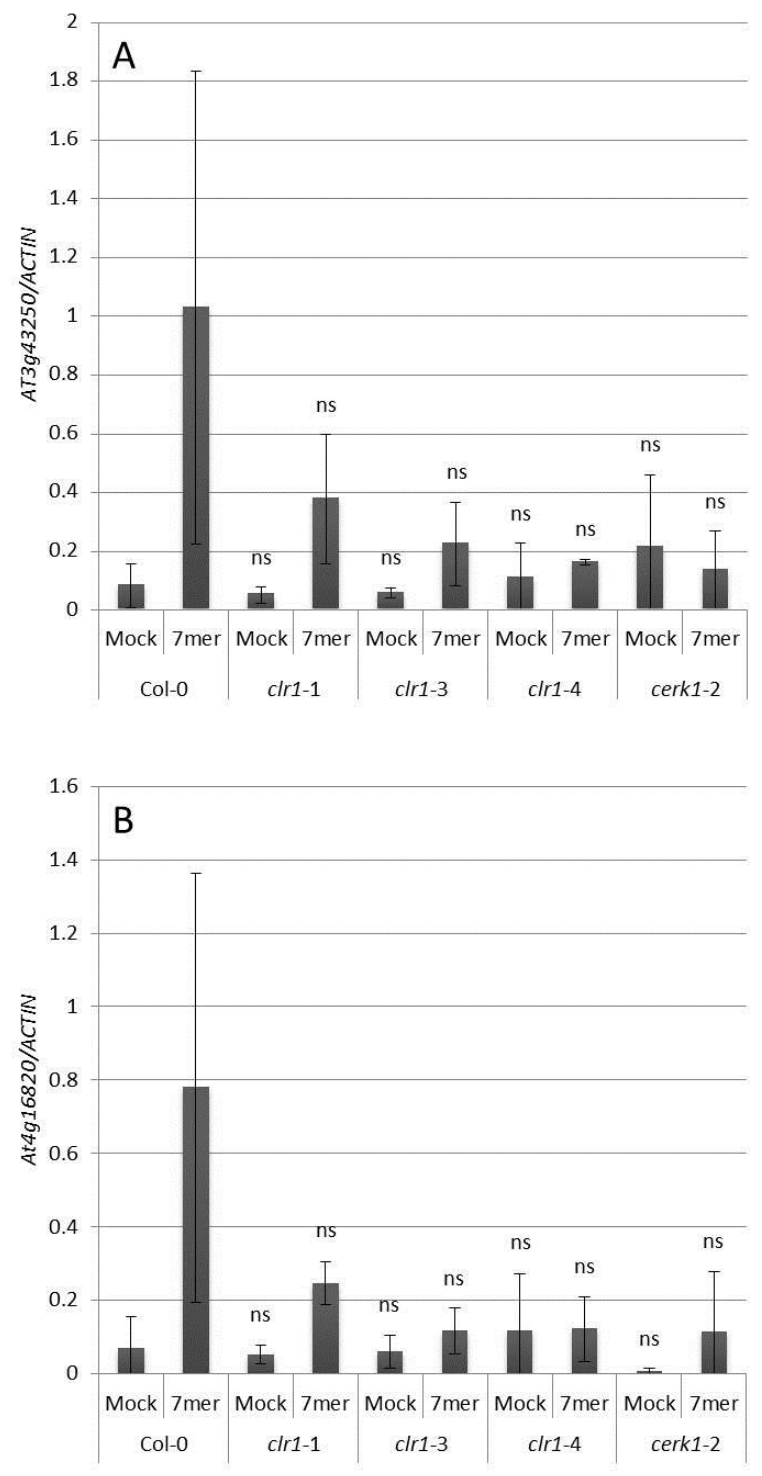

Suppl. Figure 2. Expression levels of the putatively chitin-specific marker genes (At3g43250 and At4g16820) are only weakly induced after treatment with chitin heptamer (7mer). Two-week-old in vitro grown seedlings of the indicated clr1 mutants were treated with $1 \mu \mathrm{M} 7 \mathrm{mer}$ and incubated for $30 \mathrm{~min}$. Col-0 and cerk1-2 were included as positive and negative control, respectively. QRT-PCR of the following genes was performed: (A) At3g43250, (B) At4g16820. ACTIN8 served as a reference gene. The bars represent the mean \pm STDEV of three biological replicates consisting of 4 technical repetitions. The expression levels in the mutants were not statistically different from Col-0 (ns). P-values were calculated using the unpaired student's t-test. 


\section{Danksagung}

Zum Ende meiner Doktorarbeit gibt es noch einige Personen bei denen ich mich für die Begleitung und Unterstützung, obgleich akademisch oder privat, in den letzten Jahren bedanken will.

Zu allererst möchte ich Prof. Dr. Volker Lipka danken, dass er mir dieses interessante und breitgefächerte Thema überlassen hat und mir damit die Möglichkeit gab, meine Arbeit in seiner Abteilung anzufertigen. Seine durch Fachwissen und Begeisterung geprägte Unterstützung, sowie seine konstruktive Kritik wirkten stets motivierend auf mich und trugen damit maßgeblich zum Gelingen dieser Arbeit bei. Durch die von ihm gewährte Freiheit innerhalb meines Projekts förderte er nicht nur, dass ich meinen Grips anstrenge, sondern auch meine Kreativität. Auch für seine Funktion als Erstprüfer und die damit verbundene Begutachtung dieser Arbeit und stets positiven Diskussionen während der jährlichen Fortschrittsberichte möchte ich mich sehr bedanken. Neben seiner professionellen Unterstützung sorgte er auch durch private und außerlaborliche Gespräche und Aktivitäten für ein freundschaftliches und dadurch produktives Klima in der Abteilung.

Ein großes Dankeschön geht auch an Dr. Elena Petutschnig für die Betreuung während der Anfertigung dieser Arbeit, sowohl im Labor als auch am Schreibtisch. Durch ihr fundiertes Wissen und ihre Erfahrung war sie eine große Hilfe bei der Durchführung und Planung dieser Arbeit. Viele anregende Gespräche und wertvolle Ratschläge trugen sehr zur Entwicklung des Projektes bei. Auch möchte ich mich für ihre Geduld, ihren Einsatz und die konstruktive Kritik beim Lesen dieser Arbeit bedanken.

Des Weiteren möchte ich mich bei PD Dr. Thomas Teichmann für die Übernahme des Koreferats bedanken. Bei ihm und bei Prof. Dr. Christiane Gatz möchte ich mich zudem für das Mitwirken in meinem Betreuungsausschuss, die kompetenten Ratschläge und Anregungen, sowie die konstruktiven Diskussionen nach den jährlichen Fortschrittsberichten bedanken.

Bei Prof Dr. Andrea Polle, Prof. Dr. Cynthia Gleason und Prof. Dr. Ivo Feußner bedanke ich mich für die Bereitschaft zusammen mit meinem Betreuungsausschuss meine Prüfungskommission zu bilden.

Großer Dank gebührt auch Sabine Wolfarth, Ludmilla Heck-Hrarti und Katharina Dworak für die uneingeschränkte Hilfe im Labor. Durch ihre warmherzige und zuvorkommende Art waren sie stets eine große Unterstützung. Danke auch, dass ihr des Öfteren leergemachte Lösungen, unaufgeräumte Laborplätze und vergessen Spüldienste, aufgefüllt, aufgeräumt und übernommen habt. Melanie Klenke und Gaby Schauermann möchte ich auch für ihre zuverlässige Hilfe im Laboralltag danken. 
Unseren Gärtnern Feli, Susanne und Herrn Wedemeyer danke ich für das stopfen zahlreicher Erdtöpfe und darüber hinaus auch für alle anderen Arbeiten und Hilfen.

Ein riesiges Dankeschön geht an Charlotte, die seit unserer gemeinsamen „Kellerlaborzeit“ nicht nur eine Kollegin, sondern auch eine sehr gute Freundin geworden ist! Danke, für deine grenzenlose Hilfsbereitschaft, deine Tipps, Tricks und Ratschläge, ein immer offenes Ohr, den einen oder anderen Abend im Labor und das Korrekturlesen dieser Arbeit. Auch bei Karin, Alexandra, Johanna, Michaela und Sabine möchte ich mich herzlich für die gemeinsame Zeit innerhalb und außerhalb des Labors bedanken. Danke, für eure tiefe Freundschaft, die stundenlangen Gespräche, eure Hilfe, eure Ratschläge und einfach dafür, dass ihr immer für mich da wart (in guten wie in schlechten Zeiten ;)). Bei Alexandra möchte ich mich zudem noch für das Lesen meiner Arbeit danken.

Auch bei Christopher und Jan möchte ich mich für die gemeinsame Zeit im Labor und für die wirklich tolle Arbeitsatmosphäre bedanken.

Zusätzlich möchte ich mich auch bei allen aktuellen und ehemaligen Mitgliedern der Abteilung für die freundschaftliche Arbeitsatmosphäre, gemeinsame Gespräche und Aktivitäten, sowie jegliche Unterstützung während meiner Doktorandenzeit bedanken.

Auch bei meinen Freunden außerhalb des Labors möchte ich mich für den Beistand und die gerne angenommene Ablenkung während der letzten Jahre bedanken. Danke, Ronja, Torge, Sandra, Niko, Andrea und Karin.

Nicht zuletzt möchte ich mich von ganzem Herzen bei meiner Familie und Robert bedanken. Ohne die stete Unterstützung meiner Eltern während der letzten Jahre, hätte ich es nie soweit geschafft. Danke, dass ihr immer für mich da seid und an mich, und an das was ich mache glaubt.

Robert, dir danke ich dafür, dass du trotz der teilweise großen Entfernung immer für mich da warst. Danke, dass du so manche überstrapazierten Nerven ausgehalten hast, dass du mich stets aufgemuntert und mir immer Mut zugesprochen hast. 
